\title{
Caracterização de resistência a inseticidas em populações da subfamília Triatominae \\ (Hemiptera:Reduviidae), vetores de Trypanosoma \\ cruzi Chagas, 1909
}

Marcos Takashi Obara

Tese apresentada ao Programa de PósGraduação em Saúde Pública da Faculdade de Saúde Pública da Universidade de São Paulo para obtenção do título de Doutor em Saúde Pública.

Área de Concentração: Epidemiologia

Orientador: Prof. Dr. José M. Soares Barata

São Paulo

2010 
Dedico aos meus pais, Yassutaro e Shigueko Obara, pelo amor e proteção contra o mal. De meu pai, os cuidados pela vida, de minha Mãe, a saudade.

À minha irmã, Daniela Sayuri Obara, pela infância que tivemos.

À minha esposa, Pauliana Q. da Silva, pela ajuda e paciência. Aos meus amigos, pelo amparo e solidariedade. Aos meus mestres, pela doutrina e exemplo de vida. 


\section{AGRADECIMENTOS}

Meus sinceros agradecimentos:

Ao amigo e mestre Prof. Tit. José M. S. Barata, do Departamento de Epidemiologia da Faculdade de Saúde Pública/USP; não só pela confiança, compreensão, paciência, incentivo, como também pelos ensinamentos intelectuais e morais que serão lembrados, continuamente, durante toda minha vida.

Ao Dr. João Aristeu da Rosa, do Departamento de Ciências Biológicas/UNESP pela amizade, confiança e estímulo durante todo este trabalho. Agradeço também pelo auxílio na realização das análises com o Microscópio Eletrônico de Varredura e pela doação de material entomológico utilizado nesta tese. Ainda, estendo meus agradecimentos para o técnico João Molina Gil pela dedicação de mais de vinte anos na manutenção do insetário de Triatominae.

Aos Dr. (s) José Jurberg, Cleber Galvão e José Rodrigues Coura da Fundação do Instituto Oswaldo Cruz/Rio de Janeiro pelo envio de material entomológico, possibilitando, assim, a realização deste trabalho.

À Prof ${ }^{\mathrm{a}}$. Dr ${ }^{\mathrm{a}}$. Maria Anice Mureb Sallum, do Departamento de Epidemiologia da Faculdade de Saúde Pública/USP, pelo aprendizado na manutenção da coleção entomológica da FSP/USP e pelas valiosas considerações, durante a fase de qualificação do pré-projeto.

Ao Prof. Livre Docente Delsio Natal, do Departamento de Epidemiologia da Faculdade de Saúde Pública/USP, pela amizade e incentivo assim como pela minuciosa revisão do manuscrito.

Ao Dr. Eduardo Bracco, da Superintendência de Controle de Endemias/SUCEN/SP, pelas sugestões no projeto que melhoraram os resultados obtidos nesse trabalho.

Ao Dr. Eduardo Zerba e à Dr ${ }^{\mathrm{a}}$. Claudia Vassena do Centro de Investigaciones en Plagas e Insecticidas/CIPEIN, Buenos Aires, Argentina por me receber e disponibilizar as metodologias de ensaios biológicos dose resposta e dose diagnóstica que permitiram a concretização desse trabalho. 
Aos colegas Carmo Pereira, Mardones da Costa Flores Sobrinho, Kátia Maria Leal Braga e Joyce Pereira do Laboratório de Entomologia Médica da CGLAB/SVS/MS pelo auxílio na criação e manutenção do insetário de triatomíneos.

Aos técnicos da Secretaria Estadual de Saúde da Bahia Renato de Freitas Araujo, Itamar Glicério Rocha, Gilberto Alves de Brito, Adélcio Tomas de Oliveira, Euzélio P. Amorim, José Rodrigues dos Santos, Francisco V. Costa e Paulo Henrique Amarante de Carvalho pela captura de material de campo. Também agradeço ao Gerente Estadual do Programa de Controle da Doença de Chagas da Bahia Jorge Matos pelo atendimento à solicitação de envio de material.

À equipe da Secretaria Estadual de Saúde de Goiás composta pela diretora do Laboratório Central de Saúde Pública/LACEN/GO Maria Barbara H. Rodrigues, à chefe da divisão de biologia médica Carmem Helena Ramos e aos técnicos Hedviges F. de Souza, Geraldo Ricardo da Silva, Valdomiro Alves Bezerra, Manuel P. dos Santos, Mário Vieira de Brito, Odeswaldo Ferreira dos Santos, Raul Gonçalves da Silva, Djalma Moreira, João Batista de Melo e Marcelo Santalucia pela aquisição e envio de material entomológico oriundo de diversos municípios desse estado.

Ao Coordenador da Vigilância Ambiental Dr. Oberdan Ferreira Coutinho e a Superintendente de Vigilância em Saúde Maria da Conceição E. Villa da Secretaria Estadual de Saúde do Mato Grosso pela viabilização das capturas de triatomíneos e aos funcionários Aécio de Paula e Shirley R. Ramos pelo envio de amostras vivas.

Aos técnicos da Secretaria Estadual de Saúde do Mato Grosso do Sul Marcos Batista, Aloízio Ferreira dos Santos, Celeste de S. Sarmento, Leonísio Garcia Lopes, João França, Domingos Candido de Araujo, Luiz Gonzaga Silva, e em especial ao entomólogo Paulo Silva de Almeida pela rapidez e agilidade na captura e envio de espécies vivas, procedentes de diversos municípios desse estado.

Aos técnicos da Secretaria Estadual de Saúde de Minas Gerais Geraldo Homero e Milton Soares da Fonseca pela realização de captura de espécies para esse estudo.

Aos técnicos da Secretaria Estadual de Saúde da Paraíba Gilvano Pereira, Anísio Medeiro, Francisco Canindé, Paulo Cesar e Laura Ney pelas capturas e envio de triatomíneos vivos para a realização desse trabalho. 
Aos entomólogos Allan Martins, Silvestre Marques de Moura e Júlio Oswaldo da Secretaria Estadual de Saúde do Paraná pelo envio de amostras triatomínicas.

Aos técnicos da Secretaria Estadual de Saúde de Pernambuco Edson Leite, Francisco de Assis Candido, Joenildo, J. Filho, Maria do Socorro Guedes, Genova Lins, Lourimar Batista Lima e à Diretora do Laboratório Central de Saúde Pública/LACEN/PE Terezinha de Jesus Carvalho pela obtenção e envio de amostras entomológicas para subsidiar a realização desse trabalho.

Ao Prof. Reginaldo Roris Cavalcante e ao técnico Moisés Braulio Rocha, do Núcleo de Entomologia do Piauí (NEPI) da Secretaria Estadual de Saúde do Piauí, pela captura e envio de amostras vivas de triatomíneos para a realização dos testes de monitoramento de resistência.

Aos técnicos da Secretaria Estadual de Saúde do Rio Grande do Norte José Ferreira da Silva, José David, Arlinete S. Medeiros e à Diretora do LACEN/PE Maria Goretti Lins de Queiroz pela obtenção de triatomíneos vivos para a viabilização desse estudo.

À entomóloga Iza Alencar e à Gerente Estadual do Programa de Controle da Doença de Chagas do Estado do Tocantins Anália Gomes da Secretaria Estadual de Saúde do Tocantins pelo envio de material entomológico.

Ao Isaías Neto, da Coordenação de Insumos Estratégicos/SVS/MS, pela solicitação do inseticida deltametrina grau técnico que foi utilizado durante os bioensaios dose resposta e os ensaios de campo.

Ao Vinícius Coelho, da Bayer Indústria Ltda, pelo fornecimento do piretróide deltametrina grau técnico e comercial que possibilitou a realização dos ensaios laboratoriais e de campo.

À Maria de Lourdes G. Macoris, Vanessa Garbeloto e Juliana T. de Deus; da Superintendência de Controle de Endemias/Marília/São Paulo, pelo carinho e valiosas contribuições na análise do coeficiente angular das diferentes populações de campo, imprescindíveis para os resultados da tese.

Ao amigo e Prof. Dr. Rodrigo Gurgel Gonçalves, do Departamento de Medicina Tropical da Universidade de Brasília, pelo apoio nas análises estatísticas fundamentais para a diferenciação das amostras e para a conclusão do trabalho. 
Ao amigo Janduhy Pereira dos Santos, da Coordenação de Vigilância Ambiental da Secretaria de Vigilância em Saúde do Ministério da Saúde, pelo apoio na confecção dos mapas contendo a distribuição geográfica das amostras estudadas.

Aos biólogos, amigos e funcionários, Walter Ceretti Jr. e Paulo R. Urbinatti do Lab. de Triatomíneos e Culicídeos/FSP/USP, pelos importantes ensinamentos e apoio constante durante minha vida.

Às funcionárias Ângela M. P. S. Andrade, Samantha Lemos Turte, Marilene Rosa Silva, Maria Aparecida Mendes, Renilda Shimono e Vânia Santos, da Comissão de Pós Graduação/FSP pela amizade, carinho, prontidão e agilidade, em relação à todas às orientações disponibilizadas, durante o período de realização deste curso.

As funcionárias Rita de Cássia Silva Dias, Palmira Barros, Teodora de Paiva Pinheiro e Elisabete Nassar Ribeiro, da Secretaria do Departamento de Epidemiologia da FSP/USP também pelas sugestões e orientações prestadas durante todo este trabalho.

À funcionária Gisele L. Cano de Oliveira, do Serviço de Comutação da Biblioteca da Faculdade de Saúde Pública/USP, pelo excelente serviço prestado em relação ao envio de diversos artigos e livros que foram fundamentais para a elaboração final dessa tese.

Aos antigos e novos coordenadores: Maria Candida de Souza Dantas, Eduardo Guerra, André Gemal e Mauro Elkhoury - da Coordenação Geral de Laboratórios de Saúde Pública da Secretaria de Vigilância em Saúde do Ministério da Saúde/Brasília - pela liberação para obtenção dos créditos exigidos pelo Programa de Pós-graduação da FSP/USP.

Aos amigos e colegas da Secretaria de Vigilância em Saúde Karina R. J. Cavalcante, Paulo Cesar, Selma L. Suzuki, Soraya Santos, Lúcia Berto, Nelma Faria, Mário Althoff, Mauro Arruda, Roberts Gomes, Karla Neves, Suelene Mamede, Vanessa Porto, Aline Reis, Marli Rocha, Rosa M. Silva, Lúcia Farah, Patrícia Freire, Rosangela Machado, Glauciene Figueredo e Simone Vivaldini pela tolerância e paciência no dia-a-dia.

Especialmente a todos aqueles que nos mais diversos momentos ajudaram direta ou indiretamente na realização e conclusão desta pesquisa. 


\section{RESUMO}

Obara MT. Caracterização de resistência a inseticidas em populações da subfamília Triatominae (Hemiptera: Reduviidae), vetores de Trypanosoma cruzi Chagas, 1909. [tese de doutorado]. São Paulo: Faculdade de Saúde Pública da USP; 2010.

Introdução - A doença de Chagas (DC) ainda é considerada um importante problema de Saúde Pública em vários países da America Latina. Nessas áreas, pelo menos 12 a 14 milhões de pessoas estão infectadas por Trypanosoma cruzi Chagas, 1909 e cerca de 28 milhões encontram-se expostas ao risco de contaminação. Sem vacina e tratamento, o controle da transmissão da DC depende do combate aos insetos vetores com inseticidas residuais. Atualmente, há registros de focos de populações de Triatoma infestans Klug, 1834 resistentes a deltametrina, $\beta$ cipermetrina e $\beta$-ciflutrina, no norte da Argentina e sul da Bolívia. No Brasil, populações de T. sordida Stål, 1859 já foram detectadas com resistência inicial a deltametrina, nos municípios de Bocaiúva e Coração de Jesus, Estado de Minas Gerais. Objetivos - Analisar os níveis de resistência de Panstrongylus megistus Burmeister, 1835; T. brasiliensis Neiva, 1911 e T. sordida ao inseticida deltametrina. Descrever a interação desse composto na cutícula dorsal de ninfas de $1^{\circ}$ estádio. Padronizar bioensaios de campo para estudo de resistência em populações de triatomíneos. Métodos - Nesta tese foram feitos bioensaios dose resposta com colônias de referência, comparando-as com populações de campo procedentes de onze estados endêmicos do Brasil. Complementarmente, a Microscopia Eletrônica de Varredura (MEV) foi utilizada para estudar a cutícula das ninfas de $1^{\circ}$ estádio tratadas com diferentes concentrações de deltametrina. Os bioensaios de campo foram realizados utilizando substratos de barro, tijolo e madeira. Os resultados obtidos dos bioensaios dose resposta foram estimados pela análise de Probitos. As diferenças entre as populações foram estabelecidas por Análise de Variância (ANOVA) e teste de Tukey. Resultados - O nível de resistência a deltametrina de 38 populações de triatomíneos foi avaliado no biênio 2008-2009. Detectou-se pela primeira vez baixo nível de resistência para a população de $P$. megistus do município 
de Serranópolis do Iguaçu/PR. Contudo, devido à ampla distribuição geográfica e às diferenças no comportamento de $P$. megistus, torna-se indispensável aumentar o número de amostras, principalmente da Região Nordeste do país. As populações de T. brasiliensis TbPIOeF $\left(\mathrm{RR}_{50}=1,94\right)$ e TbPIOeS $\left(\mathrm{RR}_{50}=2,17\right)$, do município de Oeiras/PI, apresentaram os maiores valores de $\mathrm{RR}_{50}$. Provavelmente, os valores obtidos sejam em função das aplicações sistemáticas de inseticidas químicos, desde a década de 70. No entanto, observa-se que as pequenas alterações de suscetibilidade a inseticidas, até agora, não contribuíram para a emergência de novos casos da DC. De modo geral, os níveis de resistência de T. brasiliensis encontram-se baixos para os municípios avaliados. A elevada mobilidade espacial de T. brasiliensis pode ser considerada como principal obstáculo para a seleção de indivíduos resistentes. A outra explicação seria a eficiente ação toxicológica dos inseticidas da classe dos piretróides. Os valores de $\mathrm{RR}_{50}$ para as populações de $T$. sordida foram menores que três permitindo classificá-las como suscetíveis a deltametrina. Em MEV a cutícula dorsal de ninfas de $1^{\circ}$ estádio de três espécies estudadas apresenta-se constituída por um conjunto de cavidades intercomunicantes formada por linhas de contorno sinuoso. Essa arquitetura tegumentar, provavelmente favorece a penetração e distribuição de inseticidas. Em P. megistus nota-se a formação de "extrusões solidificadas" aderidas na superfície das suturas intersegmentares. Confirma-se que a aplicação de deltametrina, na concentração de $25 \mathrm{mg}$ i.a. $/ \mathrm{m}^{2}$, nos substratos de barro, tijolo e madeira elimina de modo uniforme (100\%), mesmo as populações que apresentaram as maiores frequências de resistência. Conclusões - Os ensaios conduzidos mostraram que não há necessidade de substituição do inseticida utilizado nas campanhas de controle de vetores da DC no Brasil. Contudo, as alterações temporais de suscetibilidade deverão ser rigorosas e continuamente acompanhadas para orientar adequadamente o planejamento das estratégias de controle. Para isso deverá ser instituída a Rede Nacional de Monitoramento de Resistência de Triatomíneos a inseticidas visando o fortalecimento do Programa Nacional de Controle da Doença de Chagas, no Brasil.

Descritores: Triatominae; Resistência; Inseticidas; Deltametrina; Controle Vetorial; Microscopia Eletrônica de Varredura. 


\begin{abstract}
Obara MT. Caracterização de resistência a inseticidas em populações da subfamília Triatominae (Hemiptera: Reduviidae), vetores de Trypanosoma cruzi Chagas, 1909./Characterization of insecticide resistance in populations of Triatominae (Hemiptera: Reduviidae), vectors of Trypanosoma cruzi Chagas, 1909. [Thesis]. São Paulo (BR): Faculdade de Saúde Pública da Universidade de São Paulo; 2010.

Introduction - Chagas' disease (CD) is still considered an important public health problem in several Latin American countries. In these areas, at least 12 to 14 million people are infected with Trypanosoma cruzi Chagas, 1909 and approximately 28 million are at risk of contamination. Without vaccines and efficient treatment, control of $\mathrm{CD}$ relies mostly on vector-control with residual spraying of insecticides. Currently, there are records of outbreaks of resistant populations of Triatoma infestans Klug, 1834 to deltamethrin, $\beta$-cypermethrin and $\beta$-cyfluthrin in northern Argentina and southern Bolivia. In Brazil, populations of Triatoma sordida Stål, 1859 has been detected with initial resistance to deltamethrin in the municipalities of Bocaiúva and Coração de Jesus in the State of Minas Gerais. Objectives - Analyze the levels of resistance of Panstrongylus megistus Burmeister, 1835; Triatoma brasiliensis Neiva, 1911 and T. sordida to deltamethrin. Describing the interaction of this compound in the dorsal cuticle of nymphs of the $1^{\text {st }}$ stage. Standardize field bioassays for study of resistance in triatomine populations. Methods - In this thesis, dose-response bioassays were made with reference colony, comparing them with field populations originating from eleven endemic states of Brazil. In addition, the Scanning Electron Microscopy (SEM) was used to study the cuticle of first instar nymphs treated with different concentrations of deltamethrin. Field bioassays were conducted using substrates of mud, brick and wood. The results of dose response bioassays were estimated by Probit analysis. Differences between populations were established by ANOVA and Tukey test. Results - The level resitance to deltamethrin of 38 triatomines populations were evaluated in the biennium 2008-2009. It was detected for the first time, low-level resistance to the population of $P$. megistus,
\end{abstract}


municipality of Serranópolis Iguaçu/PR. However, due to the wide geographical distribution and differences in the behavior of $P$. megistus, it is essential to increase the number of samples, mainly in the Northeast region of the country. The populations of $T$. brasiliensis $\mathrm{TbPIOeF}\left(\mathrm{RR}_{50}=1.94\right)$ and TbPIOeS $\left(\mathrm{RR}_{50}=2.17\right)$, the municipality of Oeiras / IP, showed the highest values of $\mathrm{RR}_{50}$. Probably, the values obtained are in line with the systematic application of chemical insecticides since the 70s. However, it is observed that small changes in susceptibility to insecticides, so far not contributed to the emergence of new cases of CD. In general, levels of resistance in $T$. brasiliensis are low for the counties studied. The high spacial mobility of $T$. brasiliensis can be considered as the main obstacle to the selection of resistant individuals. The other explanation would be the efficient action of the toxicological class of pyrethroid insecticides. $\mathrm{RR}_{50}$ values for the populations of $T$. sordida were smaller than three, allowing to classify them as susceptible to deltamethrin. In SEM the cuticle of the dorsal first instar nymphs of all species is presented consisting of a set of interconnecting cavities formed by sinuous contour lines. This architecture cutaneous probably favors the penetration and distribution of insecticides. In P. megistus notices the formation of "wax blooms" adhered to the surface of intersegmental sutures. It is confirmed that the application of deltamethrin, $25 \mathrm{mg}$ a.i. $/ \mathrm{m}^{2}$ concentration, in substrates of mud, brick and wood eliminates uniformly (100\%), same populations with the highest frequency of resistance. Conclusions - The tests conducted showed that no need to replace the insecticide used in campaigns for vector control of DC in Brazil. However, the temporal changes of susceptibility should be rigorouslys and continuously monitored to adequately guide the planning of control strategies. To this must be established the National Network for Monitoring Insecticide Resistance of Triatominae aiming to strengthen the National Program for Control of Chagas' disease in Brazil.

Descriptors: Triatominae; Resistance; Insecticides; Deltamethrin; Vector Control; Scanning Electron Microscopy 


\section{ÍNDICE}

1 INTRODUÇÃO 24

1.1 DOENÇA DE CHAGAS 24

1.2 EPIDEMIOLOGIA DA DOENÇA DE CHAGAS 25

1.3 IMPORTÂNCIA EPIDEMIOLÓGICA DAS ESPÉCIES 32 ESTUDADAS

1.3.1 Panstrongylus megistus Burmeister, 1835

1.3.2 Triatoma brasiliensis Neiva, 1911

1.3.3 Triatoma sordida Stål, 1859

1.4 HISTÓRICO DO CONTROLE PARA OS VETORES DA DC 40

1.5 TOXICOLOGIA DE INSETICIDAS 52

1.5.1 Toxicocinética $\quad 52$

1.5.2 Toxicodinâmica $\quad 57$

1.6 RESISTÊNCIA DE INSETOS COM IMPORTÂNCIA EM 67 SAÚDE PÚBLICA

$\begin{array}{ll}2 \text { JUSTIFICATIVA } & 79\end{array}$

3 OBJETIVOS

$\begin{array}{ll}3.1 \text { OBJETIVO GERAL } & 81\end{array}$

3.1 OBJETIVOS ESPECÍFICOS $\quad 81$

4 MÉTODOS $\quad 82$

4.1 MATERIAL BIOLÓGICO 82

4.1.1 Insetos suscetíveis $\quad 82$

4.1.2 Insetos para avaliação de resistência $\quad 82$

4.2 DISTRIBUIÇÃO GEOGRÁFICA DE AMOSTRAS 84 RECEBIDAS

4.3 CRIAÇÃO E $\quad$ MANUTENÇÃO $\quad$ DO INSETÁRIO DE 86 TRIATOMÍNEOS

4.4 INSETICIDA QUÍMICO E DILUENTE 89

4.4.1 Inseticida Grau Técnico $\quad 89$

4.4.2 Inseticida Comercial $\quad 89$ 
4.5 PROCEDIMENTOS NO BIOENSAIO DAS AMOSTRAS ESTUDADAS

4.6 ANÁLISE ESTATÍSTICA E CARTOGRÁFICA DOS DADOS 92

4.7 REPRESENTAÇÃO DAS DIFERENTES POPULAÇÕES 95 MONITORADAS

4.8 PROCEDIMENTOS DE MICROSCOPIA ELETRÔNICA DE 98 VARREDURA PARA ESTRUTURA CUTICULAR DE NINFAS DE $1^{\circ}$ ESTÁDIO

4.9 BIOENSAIOS DE CAMPO COM POPULAÇÕES DE T. 100 brasiliensis

\section{RESULTADOS}

5.1 ESTIMAÇÃO DA LINHA-BÁSICA DE SUSCETIBILIDADE 105 E COMPARAÇÕES DAS DIFERENTES POPULAÇÕES DE CAMPO

5.1.1 Comparação da suscetibilidade de ninfas de $1^{\circ}$ estádio de $P$. megistus a deltametrina

5.1.2 Comparação da suscetibilidade de ninfas de $1^{\circ}$ estádio de $T$. brasiliensis a deltametrina

5.1.3 Comparação da suscetibilidade de ninfas de $1^{\circ}$ estádio de $T$. sordida a deltametrina

5.2 DESCRIÇÕES EM MEV DA ESTRUTURA CUTICULAR DE 148 NINFAS DE $1^{\circ}$ ESTÁDIO TRATADAS COM DELTAMETRINA

$\begin{array}{lllllll}5.3 & \text { RESULTADOS DOS BIOENSAIOS DE CAMPO EM } & 160\end{array}$ POPULAÇÕES DE T. brasiliensis

6 DISCUSSÃO

6.1 MONITORAMENTO DE RESISTÊNCIA DE P. megistus A 163 DELTAMETRINA

6.2 MONITORAMENTO DE RESISTÊNCIA DE T. brasiliensis E 166 DE ALGUMAS ESPÉCIES DO COMPLEXO T. brasiliensis

6.3 MONITORAMENTO DE RESISTÊNCIA DE T. sordida A 174 DELTAMETRINA

6.4 APLICAÇÃO DA ESTRUTURA CUTICULAR NO 181 MONITORAMENTO DE RESISTÊNCIA DE TRIATOMÍNEOS 
DE T. brasiliensis

7 CONCLUSÕES

9 REFERÊNCIAS

\section{ANEXOS}

Anexo 1 - Análise de Probitos da linhagem suscetível de $P$. megistus

Anexo 2 - Análise de Probitos da linhagem suscetível de T. brasiliensis

Anexo 3 - Análise de Probitos da linhagem suscetível de T. sordida

Anexo 4 - Modelo de Ofício enviado para 19 Secretarias Estaduais de

Saúde do país solicitando envio de material entomológico

Anexo 5 - Lista de amostras de triatomíneos de campo capturadas, no

Brasil. As três primeiras espécies foram utilizadas como população de referência.

Anexo 6 - Ficha para bioensaios por aplicação tópica sobre ninfas $1^{\circ}$

Anexo 7 - Ficha para bioensaios de campo com ninfas $1^{\circ}$

Anexo 8 - Lista dos Núcleos de Entomologia Médica do Brasil, em ordem alfabética. 


\section{Lista de Tabelas}

Tabela 1 - Classificação dos piretróides baseada na estrutura química, sintomas e efeitos eletrofisiológicos produzidos (GAMMON et al., 1981; GHIASUDDIN e SODERLUND, 1985; SODERLUND e BLOOMQUIST, 1989; BLOMQUIST, 1996; SODERLUND, 2008).

Tabela 2 - Codificação das populações de Panstrongylus megistus. A amostra do Estado da Bahia foi utilizada como linhagem suscetível para os bioensaios dose resposta.

Tabela 3 - Codificação das populações de Triatoma brasiliensis procedentes de diferentes Estados e Municípios do Brasil, em 2010.

Tabela 4 - Codificação das populações de Triatoma sordida procedentes de diferentes Estados e Municípios do Brasil, em 2010.

Tabela 5 - Resultados de monitoramento de resistência de populações de Triatoma sordida.

Tabela 6 - Distribuição do número de exemplares testados por amostra, slope, $\mathrm{DL}_{50}, \mathrm{DL}_{95}, \mathrm{RR}_{50}$ e $\mathrm{RR}_{95}$ de populações de Panstrongylus megistus tratadas com aplicação tópica de 0,2 $\mu \mathrm{l}$ de deltametrina, na superfície dorsal do abdômen de ninfas de $1^{\circ}$ estádio capturadas, no Brasil, em 2008.

Tabela 7 - Distribuição do número de exemplares testados por amostra, slope, $\mathrm{DL}_{50}, \mathrm{DL}_{95}, \mathrm{RR}_{50}$ e $\mathrm{RR}_{95}$ de populações de Triatoma brasiliensis tratadas com aplicação tópica de 0,2 $\mu 1$ de deltametrina, na superfície dorsal do abdômen de ninfas de $1^{\circ}$ estádio capturadas em dezesseis localidades do Brasil, em 2008.

Tabela 8 - Identificação dos padrões cromáticos dos fenótipos recebidos para a avaliação de resistência de populações do complexo brasiliensis.

Tabela 9 - Distribuição do número de exemplares testados por amostra, slope, $\mathrm{DL}_{50}, \mathrm{DL}_{95}, \mathrm{RR}_{50}$ e $\mathrm{RR}_{95}$ de populações de Triatoma sordida tratadas com aplicação tópica de 0,2 $\mu \mathrm{l}$ de deltametrina, na superfície dorsal do abdômen de ninfas de $1^{\circ}$ estádio capturadas em vinte e uma localidades do Brasil, em 2008 e 2009. 
Tabela 10 - Resultados dos valores de $\mathrm{RR}_{50}$ de populações de Triatoma sordida utilizando-se dois valores de $\mathrm{DL}_{50}$. Na tabela, à direita observamse os resultados de PESSOA (2008) e a esquerda os resultados de OBARA (2010). 


\section{Lista de Figuras}

Figura 1 - Distribuição geográfica da doença de Chagas, incluindo os vetores e reservatórios naturais. Fonte: SCHOFIELD (1994).

Figura 2 - "Complexo brasiliensis". A: Triatoma brasiliensis brasiliensis.

B: Triatoma brasiliensis macromelasoma. C: Triatoma melanica. D: Triatoma juazeirensis. Fotos: Rodrigo Méxas, IOC/Fiocruz. Fonte: ARGOLO et al., 2008.

Figura 3 - Distribuição dos municípios brasileiros conforme estratificação de risco para doença de Chagas, 2005. Fonte: SVS/MS.

Figura 4 - Distribuição geográfica das populações de Panstrongylus megistus, Triatoma brasiliensis e Triatoma sordida analisadas durante o período de 2008 e 2009, no Brasil.

Figura 5 - Fotos do sistema de separação dos ovos. A: Suporte com malha de aço. B: Recipiente com suporte no fundo. C: Recipiente com papelão apoiado na superfície da tela. D: Orifícios da tela para passagem dos ovos.

Figura 6 - Foto da parede de madeira, barro e tijolo utilizados nos bioensaios de campo.

Figura 7 - Cones de plásticos utilizados para exposição de ninfas de $1^{\circ}$ estádio em paredes de madeira, barro e tijolo tratadas com deltametrina.

Figura 8 - Resultado da DL $_{50}$ em duas populações de Panstrongylus megistus. As letras indicam populações estatisticamente diferentes $(\mathrm{p}<0,01)$.

Figura 9 - Curva de mortalidade dose resposta, em escala logarítmica, comparando o coeficiente angular de PmREF $(3,70)$ e PmPRSIg $(7,20)$.

Figura 10 - Resultado da $\mathrm{DL}_{50}$ em populações de Triatoma brasiliensis. As letras indicam populações estatisticamente diferentes $(\mathrm{p}<0,01)$.

Figura 11 - Resultado da DL95 em populações de Triatoma brasiliensis. As letras indicam populações estatisticamente diferentes $(\mathrm{p}<0,01)$.

Figura 12 - Curva de mortalidade dose resposta, em escala logarítmica, comparando o coeficiente angular de populações de Triatoma brasiliensis 
procedentes do Estado da Paraíba.

Figura 13 - Curva de mortalidade de populações de Triatoma brasiliensis, em escala logarítmica, para o inseticida deltametrina. A: Comparação entre TbREF (4,51) e TbPBItV (3,52). B: Comparação entre TbREF $(4,51)$ e TbPBSFrS $(4,83)$. C: Comparação entre TbREF $(4,51)$ e TbSJEsL $(4,74)$. D: Comparação entre TbREF $(4,51)$ e TbPBMoO $(4,59)$.

Figura 14 - Curva de mortalidade de populações de Triatoma brasiliensis, em escala logarítmica, para o inseticida deltametrina. E: Comparação entre TbREF $(4,51)$ e TbPBSCrG $(3,49)$. F: Comparação entre TbREF $(4,51)$ e TbPBMagC (3,29). G: Comparação entre TbREF $(4,51)$ e TbPBPiJ $(2,96)$.

Figura 15 - Curva de mortalidade dose resposta, em escala logarítmica, comparando o coeficiente angular de populações de Triatoma brasiliensis procedentes do Estado de Pernambuco.

Figura 16 - Curva de mortalidade de populações de Triatoma brasiliensis, em escala logarítmica, para o inseticida deltametrina. A: Comparação entre TbREF $(4,51)$ e TbPEPeL $(3,21)$. B: Comparação entre TbREF $(4,51)$ e TbPELGrM $(3,36)$. C: Comparação entre TbREF $(4,51)$ e TbPESaS $(3,24)$. D: Comparação entre TbREF (4,51) e TbPESTaJ (3,39).

Figura 17 - Curva de mortalidade dose resposta, em escala logarítmica, comparando o coeficiente angular de populações de Triatoma brasiliensis procedentes do Estado do Piauí.

Figura 18 - Curva de mortalidade de populações de Triatoma brasiliensis, em escala logarítmica, para o inseticida deltametrina. As quatro populações são procedentes de diferentes localidades do município de Oeiras/PI. A: Comparação entre TbREF (4,51) e TbPIOeS (3,70). B: Comparação entre TbREF $(4,51)$ e TsPIOeT $(2,83)$. C: Comparação entre TbREF $(4,51)$ e TbPIOeP $(2,82)$. D: Comparação entre TbREF $(4,51)$ e TbPIOeF $(2,74)$.

Figura 19 - Curva de mortalidade dose resposta, em escala logarítmica, comparando o coeficiente angular de $\operatorname{TbREF}(4,51)$ e $\operatorname{TbRNCaP}(3,17)$.

Figura 20 - Resultado da $\mathrm{DL}_{50}$ em populações de Triatoma sordida. As letras indicam populações estatisticamente diferentes $(\mathrm{p}<0,01)$. 
Figura 21 - Resultado da DL95 em populações de T. sordida. As letras indicam populações estatisticamente diferentes $(p<0,01)$.

Figura 22 - Curva de mortalidade dose resposta, em escala logarítmica, comparando o coeficiente angular de populações de Triatoma sordida procedentes do Estado da Bahia.

Figura 23 - Curva de mortalidade de populações de Triatoma sordida, em escala logarítmica, para o inseticida deltametrina. A: Comparação entre TsREF (4,51) e TsBAXXiR (4,52). B: Comparação entre TsREF (4,51) e TsBACarfB (4,48). C: Comparação entre TsREF $(4,51)$ e TsBARCoB (5,75). D: Comparação entre TsREF $(4,51)$ e TsBACarM $(3,60)$.

Figura 24 - Curva de mortalidade de populações de Triatoma sordida, em escala logarítmica, para o inseticida deltametrina. E: Comparação entre TsREF $(4,51)$ e TsBANReA $(3,85)$. F: Comparação entre TsREF $(4,51)$ e TsBAPaR (3,53). G: Comparação entre TsREF $(4,51)$ e TsBAMaS $(3,28)$. D: Comparação entre TsREF $(4,51)$ e TsBAMuB $(3,55)$.

Figura 25 - Curva de mortalidade dose resposta, em escala logarítmica, comparando o coeficiente angular de populações de Triatoma sordida procedentes do Estado do Mato Grosso do Sul.

Figura 26 - Curva de mortalidade de populações de Triatoma sordida, em escala logarítmica, para o inseticida deltametrina. A: Comparação entre TsREF (4,51) e TsMSTeC (4,27). B: Comparação entre TsREF $(4,51)$ e TsMSRoE (4,23). C: Comparação entre TsREF (4,51) e TsMSCGrA (3,95). D: Comparação entre TsREF $(4,51)$ e TsMSDoM (4,05). E: Comparação entre TsREF $(4,51)$ e TsMSATaJ $(3,15)$.

Figura 27 - Curva de mortalidade dose resposta, em escala logarítmica, comparando o coeficiente angular de populações de Triatoma sordida procedentes do Estado de Goiás.

Figura 28 - Curva de mortalidade de populações de Triatoma sordida, em escala logarítmica, para o inseticida deltametrina. A: Comparação entre TsREF $(4,51)$ e TsGOGGoS $(5,36)$. B: Comparação entre TsREF $(4,51)$ e TsGOSLMBe $(4,18)$. D: Comparação entre TsREF $(4,51)$ e TsGOFiC $(3,12)$. D: Comparação entre TsREF $(4,51)$ e TsGOPoE $(2,89)$. 
Figura 29 - Curva de mortalidade dose resposta, em escala logarítmica, comparando o coeficiente angular de populações de Triatoma sordida procedentes do Estado do Mato Grosso.

Figura 30 - Curva de mortalidade de populações de Triatoma sordida, em escala logarítmica, para o inseticida deltametrina. A: Comparação entre TsREF $(4,51)$ e TsMTSJPoS $(5,72)$. B: Comparação entre TsREF $(4,51)$ e TsMTPoM $(3,25)$.

Figura 31 - Curva de mortalidade dose resposta, em escala logarítmica, comparando o coeficiente angular de TsREF $(4,51)$ e TsMGLoR $(3,47)$.

Figura 32 - Curva de mortalidade dose resposta, em escala logarítmica, comparando o coeficiente angular de TsREF $(4,51)$ e TsTOAToM $(3,15)$.

Figura 33 - Abdômen de ninfas de $1^{\circ}$ estádio de Panstrongylus megistus por meio de MEV. a: controle tratado apenas com acetona (50X). b: controle tratado apenas com acetona (300X). c: aplicação tópica de DL99 4,36 $\mu \mathrm{g}$ /inseto (50X). d: aplicação tópica de $\mathrm{DL}_{99}$ 4,36 $\mu \mathrm{g}$ /inseto (300X). e: aplicação tópica de $10 \mu \mathrm{g} /$ /inseto. f: aplicação tópica de $10 \mu \mathrm{g} /$ /inseto.

Figura 34 - Abdômen de ninfas de $1^{\circ}$ estádio de Triatoma brasiliensis por meio de MEV. g: controle tratado apenas com acetona (50X). h: controle tratado apenas com acetona (300X). i: aplicação tópica de DL $_{99}$ 2,24 $\mu \mathrm{g} /$ inseto (50X). j: aplicação tópica de $\mathrm{DL}_{99}$ 2,24 $\mu \mathrm{g}$ /inseto (300X). k: aplicação tópica de $10 \mu \mathrm{g}$ /inseto. 1: aplicação tópica de $10 \mu \mathrm{g} /$ inseto.

Figura 35 - Abdômen de ninfas de $1^{\circ}$ estádio de Triatoma sordida por meio de MEV. m: controle tratado apenas com acetona (50X). n: controle tratado apenas com acetona (300X). o: aplicação tópica de $\mathrm{DL}_{99}$ 1,91 $\mu \mathrm{g} /$ inseto (50X). p: aplicação tópica de $\mathrm{DL}_{99}$ 1,91 $\mu \mathrm{g}$ /inseto (300X). q: aplicação tópica de $10 \mu \mathrm{g}$ /inseto. r: aplicação tópica de $10 \mu \mathrm{g}$ /inseto.

Figura 36 - Abdômen de ninfas de $1^{\circ}$ estádio de Panstrongylus megistus após aplicação tópica de $30 \mu \mathrm{g} /$ inseto de deltametrina diluído em acetona. Aumento de 500X: detalhes da estrutura do exoesqueleto.

Figura 37 - Abdômen de ninfas de $1^{\circ}$ estádio de Panstrongylus megistus após aplicação tópica de $30 \mu \mathrm{g} /$ inseto de deltametrina diluído em acetona. Aumento de 1500X: Superfície cuticular com extrusões solidificadas (ES) 
aderidas, conforme JUÁREZ e FERNÁNDEZ (2007).

Figura 38 - Abdômen de ninfas de $1^{\circ}$ estádio de Triatoma brasiliensis após aplicação tópica de $30 \mu \mathrm{g} /$ inseto de deltametrina diluído em acetona. Aumento de 500X: detalhes da estrutura do exoesqueleto.

Figura 39 - Abdômen de ninfas de $1^{\circ}$ estádio de Triatoma brasiliensis após aplicação tópica de $30 \mu \mathrm{g} /$ inseto de deltametrina diluído em acetona. Aumento de 1500X: Superfície cuticular aparentemente sem inseticida aderido.

Figura 40 - Abdômen de ninfas de $1^{\circ}$ estádio de Triatoma sordida após aplicação tópica de $30 \mu \mathrm{g} /$ inseto de deltametrina diluído em acetona. Aumento de 500X: detalhes da estrutura do exoesqueleto.

Figura 41 - Abdômen de ninfas de $1^{\circ}$ estádio de Triatoma sordida após aplicação tópica de $30 \mu \mathrm{g}$ /inseto de deltametrina diluído em acetona. Aumento de 1500X: superfície aparentemente sem inseticida aderido.

Figura 42 - Localização geográfica dos municípios baianos de Carinhanha $\left(R_{50}=1,38\right.$ e $\left.R R_{95}=1,71\right)$ e Malhada $\left(R_{50}=2,49\right.$ e $\left.R R_{95}=3,41\right) . A$ distância média entre os municípios é de aproximadamente de $3.5 \mathrm{~km}$. A data de obtenção da imagem foi de 04/06/2007. Fonte: Google Earth 5.0.

Figura 43 - Diagrama esquemático do corte microtômico do tegumento dos insetos ilustrando as principais camadas da cutícula, segundo JUÁREZ e FERNÁNDEZ (2007). Modificado por OBARA (2010). 


\section{Siglas Utilizadas}

ACE - Acetilcolinesterase

AMCHA - Iniciativa dos Países Amazônicos para Prevenção e Controle da Doença de Chagas

ANOVA - Análise de Variância

BHC - Benzenohexacloro

BNDS - Banco Nacional de Desenvolvimento Econômico e Social

${ }^{\circ} \mathrm{C}$ - Grau Celsius

C - Carbono

CEM - Campanha de Erradicação da Malária

CIPEIN - Centro de Investigaciones em Plagas e Insecticidas

CGLAB - Coordenação Geral de Laboratórios de Saúde Pública

$\mathrm{Cl}-$ Cloro

DC - Doença de Chagas

DD - Dose diagnóstica

DDT - Dietildicloro difeniltricloroetano

DENERu - Departamento Nacional de Endemias Rurais

$\mathrm{DL}_{50}$ - Dose letal que mata $50 \%$ da população

DL95 - Dose letal que mata 95\% da população

DL99 - Dose letal que mata 99\% da população

DNA - Ácido desoxiribonucléico

DR - Dose resposta

FIOCRUZ - Fundação do Instituto Oswaldo Cruz 
FUNASA - Fundação Nacional de Saúde

g - Grama

GABA - Ácido gama-amino-butírico

GE - Galinheiros Experimentais

GST - Glucationa - S - Transferases

H - Hidrogênio

$\mathrm{HCH}$ - Hexaclorociclohexano

IBGE - Instituto Brasileiro de Geografia e Estatística

IC 95\% - Intervalo de Confiança 95\%

INCOSUL - Iniciativa do Cone Sul

INERu - Instituto Nacional de Endemias Rurais

IPA - Iniciativa do Pacto Andino

IPCA - Iniciativa dos Países da América Central

$\mathrm{Kdr}$ - "Knockdown resistance"

$\mathrm{m}-$ Metros

$\mathrm{m}^{2}$ - Metro quadrado

MEV - Microscopia Eletrônica de Varredura

MG - miligrama

$\min -$ minutos

$\mathrm{mL}$ - mililitros

mm - milímetros

MoReNAa - Rede Nacional de Monitoramento de Resistência de Aedes aegypti

a Inseticidas

MS - Ministério da Saúde 
ng/inseto - nanogramas por inseto

OPAS - Organização Pan-Americana de Saúde

PCR - Polymerase Chain Reaction

PNCD - Programa Nacional de Controle da Dengue

PNCDCh - Programa Nacional de Controle da Doença de Chagas

RR - Razão de Resistência

SNC - Sistema Nervoso Central

SNM - Serviço Nacional de Malária

SUCAM - Superintendência de Campanhas de Saúde Pública

SVS - Secretaria de Vigilância em Saúde

TA - Tripanosomíase Americana

UDs - Unidades domiciliares

UNESP - Universidade Estadual Paulista "Júlio de Mesquita Filho"

UR - Umidade relativa do ar

USP - Universidade de São Paulo

WHO - World Health Organization

(®) - Marca registrada

$\mu \mathrm{g}-$ microgramas 


\section{INTRODUÇÃO}

\subsection{DOENÇA DE CHAGAS}

A doença de Chagas (DC) ou Tripanossomíase Americana (TA) foi descrita em 1909 por Carlos Chagas, quando atuava no combate a uma epidemia de malária, no interior de Minas Gerais, em um vilarejo chamado Lassance (CHAGAS, 1909).

Atualmente, a observação de lesões típicas da DC em múmias pré-históricas procedentes de países andinos, datadas de 9.000 anos, associadas aos resultados moleculares (PCR) positivos para Trypanosoma cruzi Chagas, 1909 tem comprovado que a infecção humana, provavelmente, é tão antiga quanto a presença do homem nas Américas (GUHL et al., 1999; GUHL et al., 2002; AUFDERHEIDE et al., 2004; TEIXEIRA et al., 2006; COURA e DIAS, 2009).

Cento e um anos após a descoberta da doença, essa enfermidade ainda é endêmica em vários países do Continente Americano, representando a principal causa de lesões cardíacas em jovens e adultos economicamente produtivos (MONCAYO e SILVEIRA, 2009).

De acordo com a Organização Mundial de Saúde estima-se que ainda existam 12 a 14 milhões de pessoas infectadas em larga extensão da América Latina, com cerca de 28 milhões de pessoas expostos ao risco de contaminação, em aproximadamente 15 países latino-americanos (WHO, 2002; SCHOFIELD et al., 2006; MONCAYO e SILVEIRA, 2009). No Brasil, existem aproximadamente 1,8 a 2,5 milhões de pessoas acometidas pela moléstia de Chagas (SCHOFIELD et al., 2006). 


\subsection{EPIDEMIOLOGIA DA DOENÇA DE CHAGAS}

A distribuição geográfica da infecção chagásica humana, incluindo reservatórios silvestres e vetores, estende-se desde os Grandes Lagos da América do Norte até o Sul da Argentina e do Chile (RAMSEY e SCHOFIELD, 2003; JURBERG et al., 2004; COURA e DIAS, 2009). Para MONCAYO (2003) as condições de transmissão estão presentes nas regiões neotropicais, localizadas entre a latitude $42{ }^{\circ}$ Norte e longitude $40{ }^{\circ}$ Sul. A Fig. 1 ilustra a distribuição de reservatórios e vetores e enfatiza os países mais afetados.

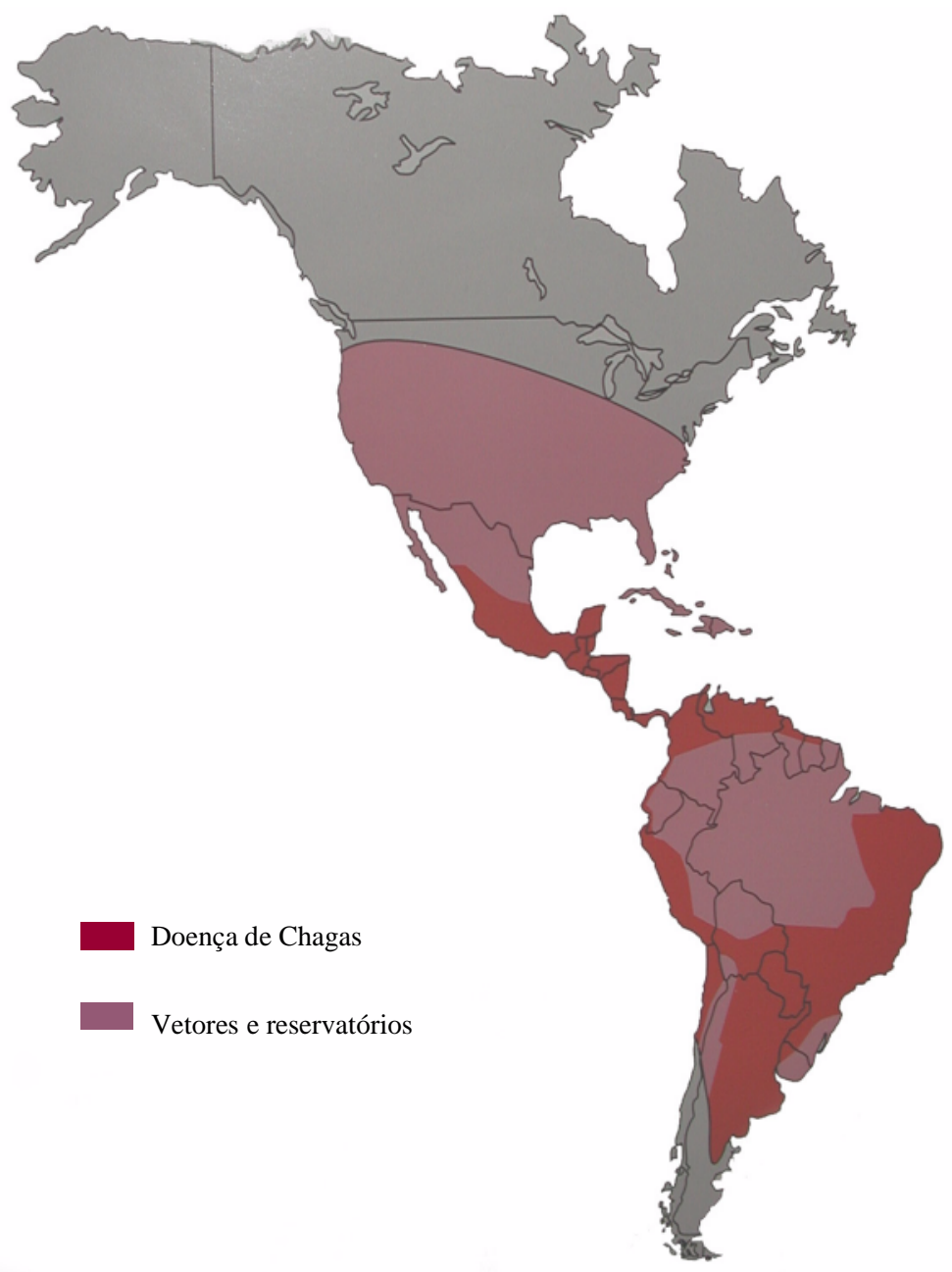

Figura 1 - Distribuição geográfica da doença de Chagas, incluindo os vetores e reservatórios naturais. Fonte: SCHOFIELD (1994). 
Mais de 200 espécies de reservatórios silvestres são suscetíveis à infecção por T. cruzi, dentre eles: marsupiais, carnívoros, quirópteros, lagomorfos, roedores e primatas não humanos. Nesse contexto, a DC pode apresentar dois ciclos epidemiológicos distintos: i) o ciclo silvestre e ii) o ciclo doméstico. O primeiro ciclo é estritamente enzoótico e ocorre na natureza há milhões de anos. Nesse ciclo, $T$. cruzi circula entre os triatomíneos e em uma enorme gama de mamíferos de pequeno e médio portes, que constituem seus reservatórios naturais. O segundo é o ciclo doméstico, antropozoonótico, em que o parasito circula entre o homem e seus animais domésticos por intermédio do vetor sinantrópico (BARRETO, 1979, 1985; LAINSON et al., 1979; SCHENONE et al., 1985).

FORATTINI (1980), CARCAVALLO (1985) e MORENO e CARCAVALLO (1999) mencionaram ainda um terceiro ciclo. Esse ciclo é de caráter peridoméstico, no qual mamíferos como os gambás, que são excelentes reservatórios para T. cruzi, realizam a ligação entre o ciclo silvestre e o doméstico.

As características epidemiológicas, o ciclo de transmissão, o comportamento do vetor e a situação dos programas de controle vetorial e transfusional permitem agrupar os países em quatro categorias distintas, conforme SCHUMUNIS (1994); MONCAYO (2003); DIAS e MACEDO (2005):

Grupo I - Argentina, Bolívia, Brasil, Chile, Equador, Honduras, Paraguai, Peru, Uruguai e Venezuela caracterizam-se pela presença dos ciclos doméstico e peridoméstico com elevada prevalência da infecção humana e manifestações de cardiopatia chagásica, presença de ciclos silvestres em vários ambientes naturais, incluindo Triatoma infestans (Klug, 1834) em áreas restritas da Bolívia, programas de controle vetorial e transfusional implantados com perspectivas de eliminação de 
T. infestans (objetivo atingido no Brasil, Chile e Uruguai) e Rhodnius prolixus (Stål, 1859).

Grupo II - Colômbia, Costa Rica e México caracterizado por ciclos doméstico e peridoméstico com presença de pacientes crônicos com cardiopatia chagásica, ocorrência de doadores infectados, presença de ciclos silvestres e programas de controle inexistentes ou incipientes.

Grupo III - El Salvador, Guatemala, Nicarágua e Panamá com a presença de ciclos silvestre, peridoméstico e doméstico com pouca informação clínica e início das ações de controle vetorial e transfusional.

Grupo IV - Antilhas, Bahamas, Belize, Cuba, Estados Unidos, Guiana, Guiana Francesa, Haiti, Jamaica e Suriname ocorre à presença de ciclos silvestres com casos autóctones raros, pouca informação clínica, ausência de programas de controle vetorial e início de programas de controle transfusional.

Na década de 80, a área endêmica original da DC compreendia 18 países, nos quais $T$. infestans (países do Cone Sul) e $R$. prolixus (países Andinos e da América Central) eram as espécies adaptadas ao domicílio. A prevalência humana pela infecção de $T$. cruzi era de 17 milhões de casos, com cerca de 100 milhões de pessoas expostas ao risco de contaminação representando aproximadamente $25 \%$ de toda a população da América Latina (DIAS, 2009). No Brasil, na mesma época, aproximadamente $36 \%$ de todo o território nacional era considerado área endêmica para DC. Essa área correspondia a 2.493 municípios distribuídos nos Estados de Alagoas, Bahia, Ceará, Espírito Santo, Distrito Federal, Goiás, Maranhão, Minas Gerais, Mato Grosso do Sul, Mato Grosso, Paraíba, Pernambuco, Piauí, Paraná, Rio 
Grande do Norte, Rio Grande do Sul, Sergipe e Tocantins (MONCAYO e SILVEIRA, 2009).

No início dos anos 90, a DC era classificada pelo Banco Mundial como a mais séria das doenças parasitárias na América Latina, com impacto socioeconômico maior que o efeito das outras doenças parasitárias combinadas. Seu custo em Anos de Vida Ajustado à Incapacitação era superado, apenas, pelo conjunto das doenças respiratórias e da Síndrome da Deficiência Imunológica Adquirida (WHO, 1991; SCHOFIELD, 1994; DIAS, 1992, 2000, 2001; AKHAVAN, 1998; SCHMUNIS, 2000).

Nessa época, ocorriam 45.000 mortes anuais, principalmente pela forma cardíaca da DC e a incidência anual era estimada em 700.000 - 800.000 casos novos (WHO, 1991). No Brasil, em 2000, o investimento financeiro para o tratamento de pacientes com arritmias cardíacas (75.000 casos), megaesôfago (45.000 casos), megacólon (30.000 casos) e implantação de marca-passo e cirurgias corretivas (US\$ 5 milhões), totalizavam aproximadamente US\$ 750 milhões por ano (SCHOFIELD et al., 2006; MONCAYO e SILVEIRA, 2009).

Reconhecendo esses aspectos, em junho de 1991, Ministros de Saúde da Argentina, Bolívia, Brasil, Paraguai e Uruguai, apoiados pela Organização Pan Americana de Saúde, criaram uma Comissão Intergovernamental conhecida como a Iniciativa do Cone Sul (INCOSUL) para eliminação da transmissão da doença de Chagas.

Os principais objetivos dessa iniciativa foram a eliminação do principal vetor doméstico - Triatoma infestans, a redução do risco de transmissão transfusional por meio de melhoria da qualidade de controle dos bancos de sangue e a detecção 
precoce de infecção materna, seguida de tratamento específico para o recém-nascido contaminado (SCHOFIELD et al., 2006).

Passados 19 anos após a criação do INCOSUL, não há dúvida de que as estratégias de controle da DC têm obtido excelentes resultados. Houve redução significativa do índice de incidência que, na década de 90, registrava 700.000 novos casos por ano; em 2006 diminui para 41.500. As mortes foram reduzidas de 45.000 para 12.500 e o número de países endêmicos que eram 18 foi reduzido para 15 , em 2006 (WHO, 2006).

De acordo com DIAS et al. (2002), os Estados de Goiás, Mato Grosso, Mato Grosso do Sul, Paraíba, Rio de Janeiro e São Paulo diminuíram significantemente a densidade populacional de $T$. infestans e receberam a certificação de eliminação de T. infestans, em 2000. Nos anos seguintes, com a intensificação das operações nos demais Estados, atingiram-se a interrupção da transmissão e a certificação de eliminação de T. infestans nos Estados de Minas Gerais, Pernambuco, Piauí e Tocantins. Os Estados do Paraná, Rio Grande do Sul e Bahia foram certificados entre 2005 e 2006.

O controle nos bancos de sangue atingiu $100 \%$ de cobertura e o índice de infestação das casas por T. infestans foi reduzido de 166.000 insetos capturados pelos guardas de endemia, nas áreas endêmicas - na década de 70, para pouco mais de 40 exemplares em 2005, na mesma área, o que corresponde a uma redução de infestação de 99,7\% para essa espécie. (DIAS, 2006; FERREIRA e SILVA, 2006; MONCAYO e SILVEIRA, 2009).

A baixa densidade populacional na área rural não seria capaz de sustentar uma transmissão vetorial por T. infestans. Desta forma, no dia 09 de junho de 2006, o 
Brasil recebeu a Certificação Internacional de Eliminação da Transmissão da doença de Chagas por T. infestans concedida pela Organização Pan Americana de Saúde (OPAS) unindo-se ao Uruguai e Chile, certificados em 1997 e 1999, respectivamente (WHO, 1998, 2000).

Estimulados com o sucesso do INCOSUL, em 1997, durante um encontro de especialistas em DC, na Colômbia, foram estabelecidas mais duas iniciativas. A primeira foi a Iniciativa do Pacto Andino (IPA), composta pelos seguintes países: Colômbia, Equador, Peru e Venezuela. A segunda foi a Iniciativa dos Países da América Central (IPCA), formada por El Salvador, Guatemala, Honduras, Nicarágua, Belize, Costa Rica, México e Panamá. Em ambos os casos, foram priorizados a eliminação de $R$. prolixus e Triatoma dimidiata (Latreille, 1811), junto com Rhodnius pallescens Barber, 1932 no Panamá e Rhodnius equadoriensis Lent \& León, 1958 no Norte do Peru.

A transmissão vetorial é a responsável por mais de $70 \%$ das infecções causadas por $T$. cruzi, ocorrendo em vastas áreas da América Central e Sul, mas outros mecanismos de transmissão, tais como: a transfusão de sangue, plasma ou concentrados eritrocíticos e a contaminação transplacentária têm sido documentadas (KIRCHHOFF et al., 1987; GRANT et al., 1987; WHO, 1991; DIAS, 2006, COURA e DIAS, 2009).

A transmissão oral, muito comum entre os reservatórios silvestres, tem sido registrada com bastante freqüência, em áreas anteriormente indenes para transmissão da doença de Chagas humana, como por exemplo, na Região Amazônica.

A partir das primeiras descrições de casos humanos da DC na Amazônia por SHAW et al. (1969) ocorreram até o ano 2000, cerca de 205 casos, sendo 178 
agudos. Dentre esses 178, cerca de 67 casos apresentam-se na forma de microepidemias familiares por transmissão oral, geralmente associada ao consumo de suco de açaí (Euterpe catinga e Euterpe oleracea) contaminado (VALENTE et al., 1999; COURA et al. 2002; NÓBREGA et al., 2009).

Nesse contexto, a DC na Amazônia tem se tornado um problema de saúde pública emergente que necessita ser devidamente compreendido e explorado. Atualmente, observa-se um novo cenário epidemiológico, em áreas da Amazônia Legal, com padrões distintos de transmissão: i) transmissão vetorial, sem domiciliação intra e peridomiciliar. O contato entre homem-vetor ocorre por meio de "visitações freqüentes" das moradias humanas por algumas espécies de triatomíneos, geralmente atraídos pela luz; ii) transmissão vetorial, associado à ocupação profissional. Segundo COURA et al. (1994), no Amazonas, especialmente em Barcelos, moradores locais que sobrevivem da extração das fibras da piassaba são "atacados" por Rhodnius brethesi Matta, 1919, que se abriga na matéria orgânica da palmeira Leopoldina piassaba e; iii) transmissão oral, na qual triatomíneos infectados, possivelmente são triturados, contaminando diversos alimentos, principalmente o suco de açaí (PEREIRA et al., 2009).

Em setembro de 2004 foi criada a Iniciativa dos Países Amazônicos para Prevenção e Controle da Doença de Chagas (AMCHA), composta pelo Brasil, Colômbia, Peru, Equador, Bolívia, Venezuela, Suriname, Guiana e Guiana Francesa, cujos objetivos são elucidar a distribuição da infecção por $T$. cruzi e esclarecer a infestação domiciliar dos potenciais vetores da Região Amazônica e fora dos limites da América Latina (OPAS, 2005a; 2006). 
As medidas de prevenção e controle estão sendo realizadas por meio de ações de Vigilância Sanitária oportunas, em todas as etapas e processos, da produção ao consumo, principalmente do suco de açaí (OPAS, 2009).

\subsection{IMPORTÂNCIA EPIDEMIOLÓGICA DAS ESPÉCIES ESTUDADAS}

\subsubsection{Panstrongylus megistus Burmeister, 1835}

P. megistus foi a primeira espécie incriminada como potencial vetor da DC (CHAGAS, 1909). As populações dessa espécie mostram diferentes níveis de comportamento, em relação à capacidade de adaptação às moradias humanas. Conseqüentemente, a sua importância epidemiológica também varia, conforme as regiões geográficas do país.

Os estudos para avaliação do potencial de domiciliação de $P$. megistus, utilizando Galinheiros Experimentais (GE), evidenciaram a presença de comportamentos distintos em áreas do Estado de São Paulo. Nos municípios de Cássia dos Coqueiros, Guaíra e São João da Boa Vista; localizados no nordeste do Estado de São Paulo e com vegetação formada pela floresta subcaducifólia tropical do oeste observa-se forte domiciliação e tendência invasiva, tanto de ambientes extradomiciliares quanto intradomiciliares (FORATTINI et al., 1977a; 1977b; 1977c; FORATTINI et al., 1978a).

Por outro lado, nos municípios litorâneos de Iguape, Pariquera-Açu e Sete Barras, situados na Serra do Mar, cuja vegetação é formada pela floresta perenifólia 
higrófila ou latifoliada tropical úmida, nota-se o não desenvolvimento da capacidade de adaptação ao ambiente domiciliar, segundo FORATTINI et al. 1978b.

O comportamento exclusivo desse inseto seria o resultado da destruição dos ambientes naturais provocados pelo homem. FORATTINI et al. (1978b) sugerem que com a fragmentação do seu centro de endemismo, a Floresta Tropical Atlântica, P. megistus dispersou-se a partir da Serra do Mar, seguindo em direção oeste na medida que diminuía a aridez. Nessas áreas secas houve a seleção de populações que desenvolveram maior capacidade de adaptação aos ambientes artificiais.

As pesquisas de composição da saliva, durações do ciclo biológico, tamanho dos ovos, variabilidade genética e morfologia da genitália masculina de populações de $P$. megistus reforçaram a hipótese de diferenças entre as populações do sul, sudeste e nordeste (BARBOSA et al., 1999, 2001, 2003, 2004, 2006).

P. megistus apresenta boa capacidade de invasão de ecótopos artificiais e grande potencial de domiciliação e ainda uma alta taxa de infecção natural por $T$. cruzi (FORATTINI et al., 1979; SILVEIRA e VINHAES, 1998; GAUNT e MILES, 2000; CERETTI Jr., 2003).

STEINDEL et al. (1994) avaliando a presença de P. megistus, em nove distritos de Florianópolis, evidenciaram o risco potencial de domiciliação em áreas de floresta perenifólia higrófila costeira do Sistema da Serra do Mar. Os autores confirmaram a presença dessa espécie em pelo menos seis domicílios e três anexos peridomiciliares, localizados em quatro distritos da Ilha de Santa Catarina. A pesquisa de $T$. cruzi revelou $56,5 \%$ de infecção natural nos triatomíneos capturados nos domicílios. 
O encontro de população domiciliada de P. megistus também foi confirmado em áreas com condições ecológicas bastante semelhantes ao de Florianópolis, como por exemplo, no município de Juquiá, Litoral Sul do Estado de São Paulo. Foram capturados três adultos e nove ninfas em uma residência, contudo os autores admitem que nessa região a domiciliação do vetor não foi intensa, em virtude da relativa preservação do meio natural (FORATTINI et al., 1982a).

HOFFMANN (2007) realizando levantamento sobre a situação atual da vigilância entomológica do Programa de Controle da Doença de Chagas na região de Campinas, no Estado de São Paulo, entre 1990 a 2006, observou 5.870 ninfas de $P$. megistus, das quais 2.113 estavam no intradomicílio e 3.757 no peridomicílio. O pesquisador concluiu que essa grande quantidade de ninfas no intradomicílio indica o potencial colonizador dos domicílios rurais dessa espécie.

Na região Centro-Oeste de Minas Gerais, P. megistus é a espécie mais capturada no ambiente domiciliar, como também nos anexos peridomiciliares, representando $99,3 \%$ do total de triatomíneos capturados. Essa espécie foi a única capturada no intradomicílio. A detecção de ninfas de P. megistus ocorreu em 41,4\% das capturas, constituindo-se, atualmente, na espécie vetora mais importante no Estado de Minas Gerais (VILLELA et al., 2005, 2009).

Para PATTERSON et al. (2009) P. megistus devido à sua elevada capacidade de colonização, ampla distribuição geográfica e grande valência ecológica, é considerada hoje o principal vetor autóctone da DC; nas regiões Sul, Sudeste, Nordeste e Central do Brasil.

Ainda, FORATTINI et al. (1983) evidenciaram a rápida capacidade de renovação de populações de $P$. megistus, no ambiente peridomiciliar, após expurgo 
com inseticidas, assim como a elevada capacidade de dispersão ativa mesmo nas fases ninfais. Essas circunstâncias descritas acima motivaram a seleção de $P$. megistus para o presente estudo que contempla a realização de estudos toxicológicos desse importante vetor no Brasil.

\subsubsection{Triatoma brasiliensis Neiva, 1911}

Atualmente, as abordagens taxonômicas, izoenzimáticas, biogeográficas, comportamentais e moleculares permitem concluir que $T$. brasiliensis trata-se de um complexo de espécies que podem ser caracterizados como T. bras. brasiliensis, $T$. bras. macromelasoma, T. melanica e T. juazeirensis (COSTA et al., 1997a, 1997b; COSTA et al., 1998; COSTA et al., 2002; COSTA et al., 2003a; MONTEIRO et al., 2004; COSTA et al., 2006; COSTA et al., 2009; COSTA e FELIX, 2007), conforme mostra a Fig. 2 

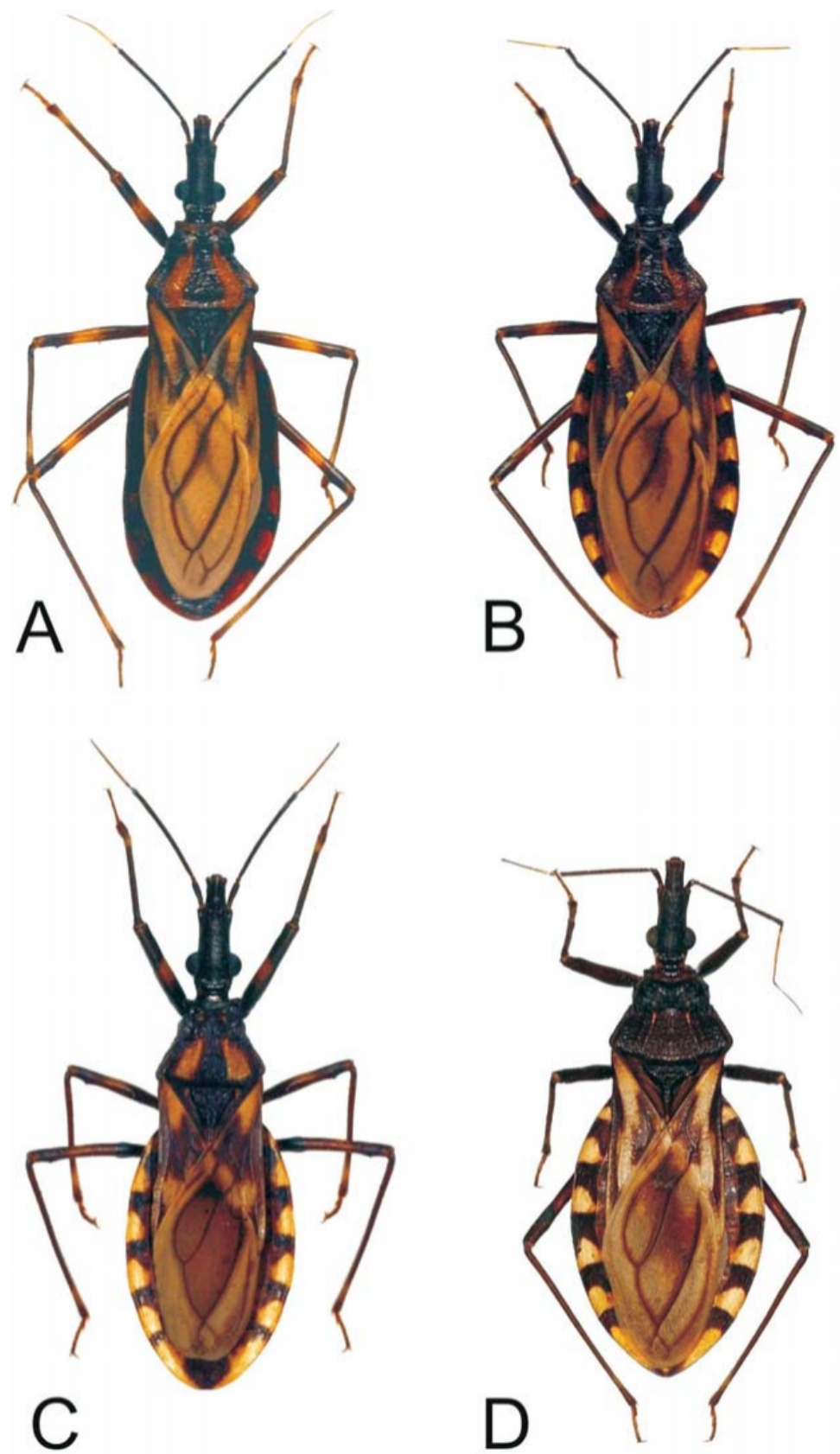

Figura 2 - "Complexo brasiliensis". A: Triatoma brasiliensis brasiliensis. B: Triatoma brasiliensis macromelasoma. C: Triatoma melanica. D: Triatoma juazeirensis. Fotos: Rodrigo Méxas, IOC/Fiocruz. Fonte: ARGOLO et al., 2008. 
$\mathrm{Na}$ natureza, a maioria dos membros do complexo brasiliensis são encontrados em ambientes semi-áridos (Caatinga), principalmente em locas de pedras, associados com diversos roedores, tais como Ceredon rupestris e Cavia aperea (LENT e WYGODZINSKY, 1979).

Porém, podem dispersar-se em direção ao peri e intradomicílio. SARQUIS et al. (2006) pesquisando 121 peridomicílios, em quatro localidades do Ceará, demonstraram significativa preferência de $T$. brasiliensis por abrigos de animais construídos com tijolos e cobertos com telha. Outro estudo utilizando galinheiro experimental comprovou que T. brasiliensis permanece nas proximidades do local de repouso das aves (poleiro), particularmente nas partes mais baixa, seca e quente das paredes (RODRIGUES et al., 1995).

No ambiente domiciliar, T. brasiliensis também formam colônias, às vezes com mais de 100 exemplares (SARQUIS et al., 2006). A infestação domiciliar é um processo multifatorial e as casas localizadas em áreas com elevada alteração antrópica são mais favoráveis à invasão ou colonização de triatomíneos (WALTER et al., 2005).

CARBAJAL de la FUENTE et al. (2007) realizando estudos de dispersão de T. brasiliensis, no nordeste do Brasil, sugeriram que a atração pela luz favorece o processo de infestação que ocorre com maior freqüência, principalmente na estação seca do ano, isto é, durante o período de maio a dezembro.

Certamente, $T$. brasiliensis, hoje, é a mais importante espécie vetora da DC em todo o Nordeste Brasileiro. Estudos epidemiológicos realizados no Estado da Bahia (WALTER et al., 2005), no Ceará (SARQUIS et al., 2004) e no Piauí (SOARES et al., 2000) indicaram que T. brasiliensis é a espécie predominante nos 
ambientes domiciliares e com elevados níveis de infecção natural por $T$. cruzi, configurando em um dos mais eficientes transmissores da DC ao homem.

Além disso, merecem atenção os Estados da Paraíba, Pernambuco e Rio Grande do Norte, onde essa espécie também tem sido encontrada em altas densidades e com porcentagens variadas de infecção natural (COSTA et al., 2003b).

\subsubsection{Triatoma sordida Stål, 1859}

T. sordida, cujo centro de endemismo é o Cerrado, demonstra preferência por ecótopos, tais como cascas de árvores secas ou mortas, em ambiente natural (FORATTINI et al., 1971; FORATTINI, 1980). Comportamento semelhante foi descrito por DIOTAIUTI et al. (1993) que em áreas naturais encontraram T. sordida ocupando árvores secas e mortas, no norte de Minas Gerais (Mato Verde) e Triângulo Mineiro (Itapagipe).

Com a eliminação de $T$. infestans, a espécie $T$. sordida destaca-se, atualmente, como uma das mais importantes, epidemiologicamente, no país, ou seja, tornou-se a espécie vetora mais freqüente da DC capturada em ambiente peridomiciliar (TOLEDO et al., 1997; PIRES et al., 1999).

DIOTAIUTI et al. (1998) avaliando as ações de controle de $T$. sordida, em Porteirinha, Minas Gerais, revelaram que dentre as 406 Unidades Domiciliares (UD) pesquisadas, cerca de 142 (34,9\%) estavam infestadas por T. sordida, sendo que os ecótopos mais freqüentemente infestados foram montes de madeira, cercas, árvores, montes de telha, galinheiros e chiqueiros, em ordem decrescente.

No Estado de Goiás foi realizado um levantamento da distribuição geográfica de triatomíneos em 249.868 UDs em 201 municípios dos 246 existentes. Foram 
capturados 5.555 exemplares de T. sordida no intradomicílio e 38.819 no peridomicílio (OLIVEIRA e SILVA, 2007). Comparando todas as espécies estudadas, T. sordida foi a espécie que apresentou os maiores indicadores de infestação e densidade, além de nítida preferência em infestar o peridomicílio, provavelmente, pelo comportamento ornitofílico da espécie; como mencionado em outros estudos (FORATTINI et al., 1982b; DIOTAIUTI et al., 1995; CROCCO e CATALÁ, 1997).

Certamente, o aumento da densidade populacional de triatomíneos no peridomicílio representa um grande risco para a população, uma vez que existe a possibilidade de invasão ou colonização do ambiente intradomiciliar.

Recentemente, em Macaúbas, na Bahia, houve sete casos agudos de DC, dos quais dois pacientes evoluíram para óbito. A investigação entomológica incriminou T. sordida como potencial vetor responsável pela ocorrência dos casos. Foi encontrado população intradomiciliar na pia da cozinha. Nesse local eram armazenados os alimentos que, provavelmente foram contaminados e ingeridos pelos moradores da residência (DIAS et al., 2008).

A reinfestação do peridomicílio das unidades domiciliares, a partir de focos silvestres de algumas espécies vetoras de $T$. cruzi sempre persistirá e de maneira duradoura, na medida em que houver falta ou descontinuidade das ações de controle químico. Portanto, torna-se urgente e necessário a implantação e o acompanhamento adequado do perfil de suscetibilidade de triatomíneos por níveis mais centrais de referência, a fim de evitar o surgimento de populações resistentes no país. 


\subsection{HISTÓRICO DO CONTROLE PARA OS VETORES DA DC}

No Brasil, as primeiras tentativas profiláticas para a DC ocorreram no início dos anos 20, porém, sem resultados muitos satisfatórios. As paredes das habitações infestadas por P. megistus eram aquecidas pelo fogo de lança chamas militares ou tratadas por substâncias como querosene e soda cáustica (DIAS et al., 2002).

DIAS et al. (1924) ressaltam que dentre as técnicas utilizadas, na época, a de maior efetividade foi a aplicação de gás cianídrico em casas infestadas de barbeiros. As moradias rurais eram envolvidas em duplo manto de lona e, logo em seguida o gás era injetado, sendo que em menos de dez minutos já se observavam a morte de escorpiões, ratos, aranhas, incluindo os barbeiros.

A maioria dessas técnicas foi descartada pela impossibilidade de aplicação em larga escala, principalmente em grandes aglomerados de casas, assim como pela pouca ou nenhuma persistência dessas substâncias no ambiente.

Com o surgimento dos inseticidas sintéticos na década de 40, um novo campo se abriu, não só para o controle de triatomíneos, como também para os demais insetos de importância em saúde pública. Ainda, em 1943, um importante evento marcou a história do controle dos vetores da DC: a Fundação Oswaldo Cruz inaugurou o “Centro de Estudos e Profilaxia da DC”, em Bambuí - área endêmica do Estado de Minas Gerais - sob direção do Dr. Henrique Aragão e chefiado pelo Dr. Emanuel Dias (DIAS e PINTO, 1952).

O primeiro inseticida sintético de efeito prolongado com propriedade residual foi o dietildicloro difeniltricloroetano (DDT), cujo efeito inseticida foi descoberto por Paul Müller, na Suíça, em 1939. Durante a Segunda Guerra Mundial, esse organoclorado foi utilizado em grande escala nas frentes de batalha, contra piolhos 
humanos, pulgas dos ratos e mosquitos e que, quando aplicado em paredes e tetos das casas, permanecia ativo contra os insetos por vários meses (WHO, 1987).

O lançamento do DDT significou para muitos uma revolução no controle de pragas e seria responsável, juntamente com os adubos químicos, pelo suposto milagre da agricultura com safras recordes e produção em solos praticamente estéreis.

Em 1945, quando chegou o DDT no Brasil, se criou grande expectativa em relação à sua possível eficácia no combate aos vetores da DC. Expectativa logo frustrada pelos ensaios de campo de LENT e OLIVEIRA (1944) que demonstraram que a ação tóxica do DDT processa-se mais rapidamente em adultos do que em formas jovens. Nas ninfas a velocidade de penetração através do tegumento do inseto é muito lenta e no ovo, inexistente, resultando em uma reinfestação, em torno de 3 a 4 meses. As ninfas emergiam normalmente sobre placas de Petri polvilhadas com DDT demonstrando a inexistência da ação desse inseticida no desenvolvimento embrionário dos vetores da enfermidade de Chagas.

PEDREIRA de FREITAS (1950) também chamou a atenção sobre o efeito parcial do DDT sobre os triatomíneos. Esse autor observou que nas casas do Estado de Goiás, nas quais o Serviço Nacional de Malária (SNM) havia aplicado DDT, foi capturado um dos maiores focos de $P$. megistus, justamente por eliminar apenas certa porcentagem da população.

DIAS et al. (1952); PINTO e BICALHO (1952) e PEDREIRA de FREITAS (1963) apontaram a ineficácia do DDT alertando que as casas que eram borrifadas, rotineiramente, com esse produto apresentavam grande quantidade de triatomíneos capturados durante as pesquisas entomológicas. 
Com o fracasso inesperado do DDT no controle dos vetores da DC, a outra opção de escolha foi o Gammexane P 530 (BHC). BUSVINE e BARNES (1947) alcançaram resultados muito mais positivos no combate aos triatomíneos. Esses autores verificaram, em condições de laboratório, a intensa mortalidade de $R$. prolixus quando expostos à ação do isômero gama hexaclorociclohexano (Gammexane).

As pesquisas em laboratório foram logo confirmadas por ROMAÑA e ABALOS (1948), na Argentina, que observaram a potente ação tóxica do BHC contra populações domiciliadas de triatomíneos quando alteraram a concentração de $250 \mathrm{mg}$ por $\mathrm{m}^{2}$ para $500 \mathrm{mg}$. Esses autores constataram que, com essa concentração, as casas se mantiveram livres da infestação, até quase seis meses depois de tratada.

No Brasil, DIAS e PELLEGRINO (1948), em ensaios de campo realizados, em Água Comprida/MG verificaram que o Gammexane foi capaz de controlar populações intradomiciliares de vetores da DC. Comprovaram também que esse inseticida quando aplicado na dose de $1,0 \mathrm{~g}$ de princípio ativo por $\mathrm{m}^{2}$ de parede, em pelo menos dois ciclos de borrifações, separados por intervalos de 30-60 dias, preservavam a casa livre de triatomíneos até cinco meses depois de tratadas.

A aplicação do BHC foi, portanto, levada avante devido à necessidade de resultados rápidos. A primeira grande campanha contra os transmissores da DC utilizando o "novo inseticida" foi conduzida pelo SNM, em março de 1950, nas cafuas da área rural de Bambuí/MG. As superfícies de paredes e tetos de 228 moradias foram aspergidas com BHC a 10\%. Gastaram-se 2.131 litros de inseticida distribuídos em 23.465 metros quadrados, cuja dose média foi de $700 \mathrm{mg} / \mathrm{m}^{2}$. Esse trabalho foi realizado durante $15-20$ dias, tendo como resultado 4.679 triatomíneos capturados em 92 casas, do total das 228 selecionadas (DIAS e PINTO, 1952). 
PINTO e BICALHO (1952) obtiveram uma redução na população de triatomíneos da ordem de $90 \%$, depois de quatro meses de tratamento. Esses resultados referem-se às extensas campanhas no Estado de Minas Gerais com o “Gammexane”, na forma de pó molhável, cuja dose utilizada por $\mathrm{m}^{2}$ era de $500 \mathrm{mg}$, aplicados em toda a extensão e profundidade de cada fresta ou rachadura, localizadas tanto nas dependências internas, quanto nas externas.

Outros autores obtiveram resultados muito favoráveis com a aplicação de “Gammexane”, em diversos países, tais como: Uruguai (OSIMANI et al., 1950); Chile (NEGHME, 1950); Venezuela (NIETO-CAICEDO, 1950) e Equador (MONTALVAN, 1952).

Foi a partir dessas campanhas que surgiram as normas gerais empregadas rotineiramente em um levantamento municipal, no que diz respeito ao número de agentes, material necessário, transporte, divisão de trabalho, disposição de itinerário e as técnicas de captura de triatomíneos. Ainda foi possível definir a metodologia de aplicação do inseticida no interior das casas, onde se procurava borrifar os locais estratégicos que serviam de esconderijo para os triatomíneos, assim como a periodicidade do intervalo das aplicações (DIAS et al., 1952;, SALGADO e PINTO, 1952, BUSTAMANTE e GUSMÃO, 1954).

No início da década de 50, novos e potentes produtos químicos foram lançados no mercado, como o dieldrin. Em pouco tempo, ensaios de campo visando o controle de populações de $R$. prolixus, na Venezuela, e de $T$. dimidiata, na Guatemala, foram conduzidos. Os sanitaristas venezuelanos utilizaram o dieldrin pela primeira vez em 1952, no Estado de Trujillo, em 60.000 casas. Após isso, sua utilização foi ampliada para mais 12 Estados, com cerca de 300.000 casas infestadas. Na Guatemala, áreas 
com índice de infestação de $68 \%$ por $T$. dimidiata, depois da aplicação de dieldrin, os insetos não mais foram encontrados, durante quatro meses depois do tratamento (PERLOWAGORA-SZUMLEWICZ, 1956).

Em meados de 1954, o Serviço Nacional de Malária decidiu experimentar o dieldrin em substituição ao BHC, baseado nos resultados de trabalhos realizados na Venezuela e Guatemala contra $R$. prolixus e $T$. dimidiata, respectivamente. Os ensaios foram realizados nas localidades do Córrego do Arroz e Bálsamo, situados no município de Anápolis, Estado de Goiás. No entanto, os autores chamam a atenção para os efeitos tóxicos do dieldrin que provocaram casos graves de intoxicação, não apenas em aplicadores, como também em burros, cachorros, gatos e aves. Assim, devido à elevada toxicidade e alto custo, a direção do SNM suspendeu o seu emprego e continuou com o uso do BHC nas ações de controle dos vetores da DC (PERLOWAGORA-SZUMLEWICZ 1956; BUSTAMANTE e CARVALHO, 1957).

A década de 50 foi marcada por notáveis avanços no conhecimento da DC não só pela fundação do Departamento Nacional de Endemias Rurais (DENERu), em 1956, e poucos anos mais tarde pela Campanha de Erradicação da Malária (CEM), mas também pelo Instituto Nacional de Endemias Rurais (INERu) - instituição dedicada à investigação de diversas enfermidades daquela época (entre elas a doença de Chagas), cujo controle passou a estar a cargo do DENERu.

Os inseticidas organoclorados, no final dos anos 60, devido aos diversos questionamentos, tais como: elevada toxicidade para homens e animais domésticos, custo operacional relativamente alto, necessidade de replicações freqüentes e sua inativação pelo barro das paredes foram, gradativamente, sendo substituídos pelos organofosforados e carbamatos. 
Em 1973, no município de Castro Alves/BA, o organofosforado malathion passou a ser utilizado em estudos de campo e laboratório solicitados pela Diretoria do INERu. SHERLOCK e MUNIZ (1975) e SHERLOCK et al. (1976) recomendaram esse inseticida para ser usado em amplas campanhas de controle de triatomíneos, principalmente por apresentar ação ovicida.

Apesar da magnitude do problema representado pela doença de Chagas e de se dispor de tecnologia comprovadamente eficaz, entre 1950 e 1975, as atividades de controle foram apenas pontuais e descontínuas, portanto, não impedindo a reinfestação de áreas já tratadas (SILVEIRA, 2000). Exceção feita ao Estado São Paulo, onde as atividades de tratamento químico contra os triatomíneos domiciliados foram desenvolvidas a partir da década de 1950 (WANDERLEY et al., 2006).

Nessa época, no Estado de São Paulo as atividades de controle químico se dividiram em duas fases, sendo que a primeira fase ocorreu entre 1950 a 1959 e foi caracterizada por ações de menor abrangência e intermitentes. A seguda fase que se estendeu de 1959 a 1967, as ações de controle dos vetores da DC foram realizados concomitantemente com as atividades de controle da malária, em áreas com sobreposição das duas endemias, durante a Campanha de Erradicação da Malária (CEM).

A partir de 1964 foi introduzida a fase de "arrastão" que se caracterizou pelo tratamento de $\mathrm{BHC}$ em todas as casas e anexos com presença de triatomíneos. Em 1968, diferentemente do restante do país, esse Estado adotou o "expurgo seletivo" de focos residuais, onde utilizava a presença de triatomíneos como indicador necessário à aplicação do BHC resultando em gasto menor do que a repetição das borrifações em todas as casas e apresentando ainda outras vantagens, como por exemplo: a de 
promover a educação sanitária despertando o interesse dos moradores pelas borrifações (PEDREIRA de FREITAS, 1963; WANDERLEY et al., 2006).

No final dos anos 70, o Estado de São Paulo reduziu significantemente a infestação por $T$. infestans sendo considerado pioneiro no controle dessa espécie e servindo de exemplo para o Brasil. O último registro de $T$. infestans infectado por $T$. cruzi, no Estado de São Paulo, ocorreu em 1978 (WANDERLEY et al., 2006; HOFFMANN, 2007).

Em 1967, foi criada a Superintendência de Campanhas de Saúde Pública (SUCAM), que absorveu as funções do antigo DENERu. Dessa forma, o planejamento e a execução das ações de intervenção da DC passaram a ser de responsabilidade dessa instituição.

A partir de 1975, as atividades de controle da DC foram redimensionadas e a metodologia de trabalho sofreu redefinições para delimitar a área com risco de transmissão vetorial e a magnitude do problema. Foram promovidos inquéritos sorológicos e entomológicos de âmbito nacional, que indicaram uma estimativa de soroprevalência de $4,2 \%$ de média de positividade na população brasileira com a presença de 44 espécies de triatomíneos, das quais 31 capturadas no intradomicílio.

Em 1977, o modelo de controle da DC foi normatizado para o Brasil tendo como componentes três fases sucessivas de trabalho: i) fase preparatória; ii) fase de ataque e iii) fase de vigilância epidemiológica (MS, 1985; DIAS, 1987; DIAS et al., 2002; MONCAYO e SILVEIRA, 2009).

A fase preparatória é dividida em duas partes: a primeira parte consiste no reconhecimento geográfico que tem como objetivo a quantificação de todos os elementos que compõem uma determinada área. Todas as informações sobre as 
unidades domiciliares, as vias de acesso, meios de comunicação e condições epidemiológicas e sanitárias devem ser mapeadas e registradas. A segunda parte é o conhecimento da fauna triatomínica e os índices de infecção natural para T. cruzi.

A fase de ataque consiste no tratamento, em massa, de todas as localidades positivas para triatomíneos com inseticida residual, em pelo menos dois ciclos de borrifação. Essa atividade necessita de avaliações periódicas e deve se manter até que as condições de transmissão não estejam mais presentes, isto é, a eliminação total de populações intradomiciliares, no caso de espécies introduzidas como T. infestans e $R$. prolixus.

A fase de vigilância é de caráter permanente e necessita da participação da comunidade. Embora exista uma busca ativa do vetor é necessário implantar rede de postos de informação, na qual a população deve assumir o compromisso de notificar a ocorrência de novos focos de infestação. Essa última etapa torna-se a mais difícil, devido à inexistência de metodologias que permitam a detecção dos vetores em baixa densidade populacional.

Em 1983, foi assinado um contrato entre a SUCAM e o Banco Nacional de Desenvolvimento Econômico e Social (BNDS) destinando 10 bilhões de cruzeiros provenientes do imposto de caráter social, o chamado FINSOCIAL. Com esse complemento orçamentário, o programa atingiu, pela primeira vez, a integral cobertura da área endêmica do país que compreendia dois mil municípios, em 19 Estados, beneficiando 47 milhões de pessoas (LIMA, 1983).

Ainda nesse ano, foi instituído em caráter pioneiro no país, o uso de piretróides de síntese, em larga escala, sobretudo em áreas onde o BHC era menos eficaz, em função do comportamento dos vetores predominantes na região, como $T$. 
brasiliensis e T. pseudomaculata. Esses inseticidas são aplicados nas paredes internas do intradomicílio e nos anexos periodomiciliares, principalmente, em locais que possa haver focos de triatomíneos (SILVEIRA, 2000; SILVEIRA, 2004; DIAS e MACEDO, 2005).

Outros mecanismos profiláticos, como a melhoria das condições das habitações também são utilizados; porém, em função do número de domicílios que devem ser beneficiados e da própria extensão da área de transmissão autóctone, tornase pouco viável e fora do alcance das ações próprias do setor de saúde (MS, 1985).

A partir de 1986, houve uma redução na luta antichagásica devido a uma nova epidemia de dengue no Estado do Rio de Janeiro com a circulação do sorotipo 1, que logo se propagou para a Região Nordeste (NOGUEIRA et al., 1999, SCHATZMAYR, 2000; BARBOSA da SILVA et al., 2002).

Em abril de 1990, a Fundação Nacional de Saúde (FUNASA) foi criada e passou a ser responsável pela coordenação das ações de controle da DC. Historicamente, a FUNASA caracterizava-se por uma estrutura verticalizada, semimilitar, com rígida organização e abundância de equipamentos, recursos humanos e financeiros. A partir de 1999, a "Reforma Sanitária" promovida a partir da Portaria n 1.399 do Ministério da Saúde descentralizou as ações de epidemiologia e controle de endemias para os Estados e Municípios, (SCHMUNIS e DIAS, 2000). As Secretarias Estaduais de Saúde passaram a coordenar e supervisionar as ações realizadas pelas entidades municipais. Em 2004, a Portaria $\mathrm{n}^{\circ} 1.399$ foi revogada pela Portaria $\mathrm{n}^{\circ}$ 1.172 que estabeleceu melhor as competências dos Estados, Municípios e o Distrito Federal e a sistemática de financiamento destinado às endemias, assim como às penalidades para o descumprimento das responsabilidades. 
Para DIAS et al. (2002) a transferência das responsabilidades de ações de vigilância e controle da DC para as Secretarias Estaduais e Municipais de Saúde representa um grande desafio, uma vez que, não é acompanhado pela formação de corpo técnico capacitado, dotado de conhecimento técnico-científico suficiente para orientar e apoiar a gestão local, por exemplo, em situações raras como os surtos de transmissão oral.

Em março de 2005, o Estado de Santa Catarina foi acometido com 24 casos de infecção humana por T. cruzi. Todos os pacientes ingeriram acidentalmente suco de caldo de cana contaminado. Esse surto teve repercussão internacional não só em função da forma de contaminação, mas também pela gravidade e manifestação clínica atípica dos casos. Provocou também a necessidade de mudanças dos modelos anteriores de Vigilância Epidemiológica da DC (MS, 2005).

Nesse mesmo ano, houve a estratificação de risco para DC que contou com a participação de 14 Estados do país. Os critérios utilizados para determinação do risco de transmissão da DC foram variáveis entomológicas, ambientais, demográficas e de morbidade; conforme descritos no CONSENSO BRASILEIRO EM DOENÇA DE CHAGAS, 2005.

Para cada variável foram atribuídos diferentes valores em uma escala de 0 a 5. Após os cálculos foram gerados estratos de alto, médio e baixo risco, ajustados a realidade de cada Estado. Aproximadamente 491 municípios foram classificados como de alto risco, 1350 municípios de médio risco e 1151 de baixo risco; conforme demonstra a Fig. 3. 


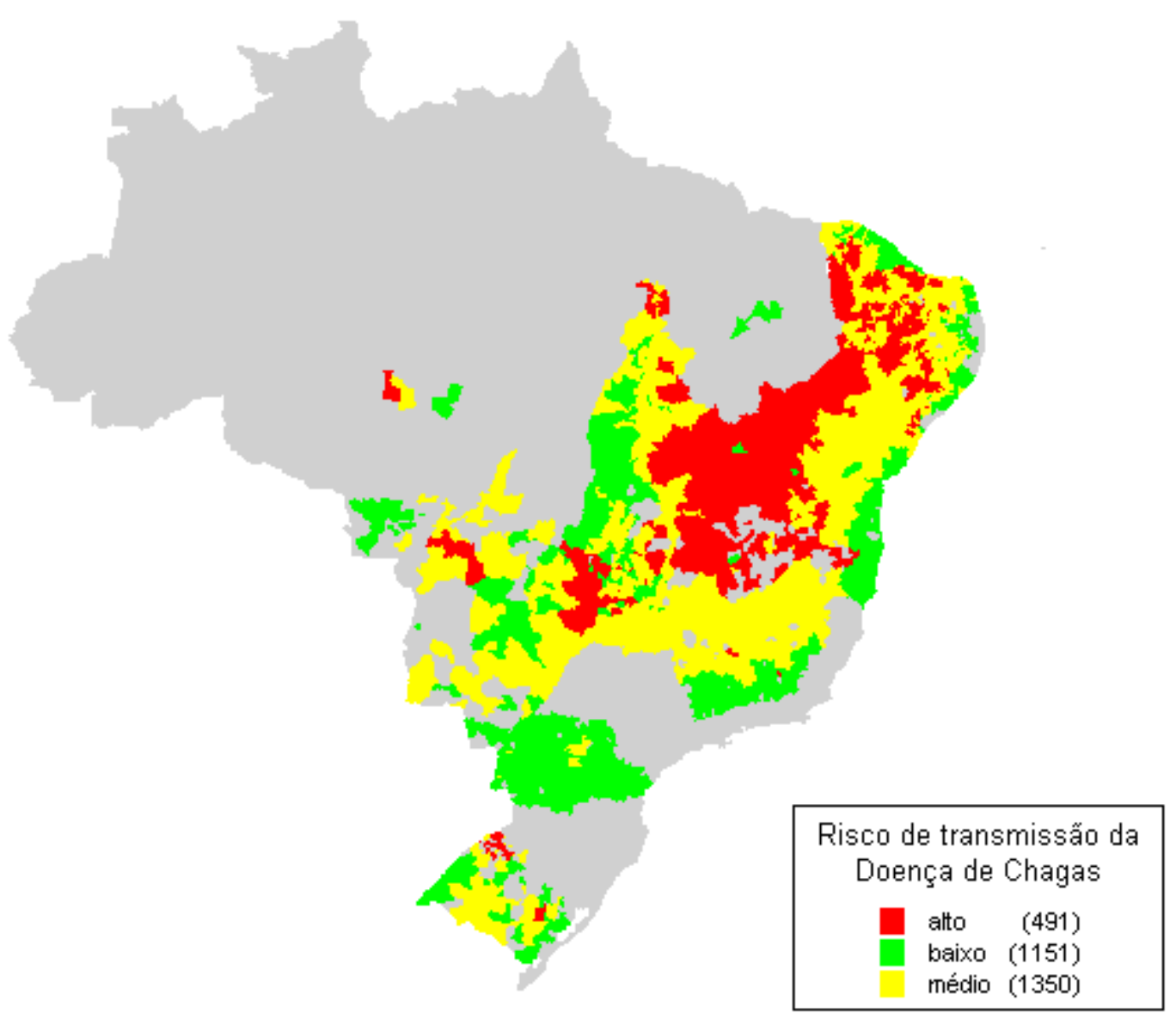

Figura 3 - Distribuição dos municípios brasileiros conforme estratificação de risco para doença de Chagas, 2005. Fonte: SVS/MS.

Atualmente, o Programa Nacional de Controle da Doença de Chagas (PNCDC) está inserido dentro da Secretaria de Vigilância em Saúde (SVS) do Ministério da Saúde. No ano de 2009, o PNCDC recebeu R\$29.400.000,00 dos quais $35 \%$ foram gastos com a vigilância e controle do vetor considerado de grande importância epidemiológica, em função do risco potencial na cadeia de transmissão vetorial e oral da DC.

Os recursos gastos com os vetores são destinados basicamente na aquisição de equipamentos e manutenção de pessoal, que tem atuado de forma sistemática nos 491 municípios, considerados de alto risco. 
Hoje, os grandes desafios são a sustentabilidade dos níveis de controle atingidos, uma vez que, com a descentralização das ações de controle da DC para a gestão municipal poderá ocorrer uma redução da prioridade das ações, como também a perda de reconhecimento da importância da doença.

A situação confortável de baixa transmissão poderá gerar progressiva diminuição de vontade política e perda de competência técnica para realização das atividades de controle, levando a uma recrudescência da moléstia que se dará, possivelmente, de forma lenta e progressiva, mais propriamente nos bolsões de pobreza e nas regiões politicamente menos representativas.

Para FERREIRA e SILVA (2006), os desafios ainda existentes no controle da DC são a falta de equipamentos e recursos financeiros, imprescindíveis para a continuidade das atividades de controle no país.

Ainda, a interpretação errônea dos gestores, educadores e pesquisadores de que a "Doença de Chagas está com os dias contados" poderá levar a uma descontinuidade das ações de controle. Se essa situação ocorrer, a presença de populações de triatomíneos no peridomicílio pode sinalizar para uma iminente domiciliação das espécies secundárias, como também da reinfestação do T. infestans (DIOTAIUTI et al., 1994; DIAS, 1998). 


\subsection{TOXICOLOGIA DE INSETICIDAS}

\subsubsection{Toxicocinética}

\subsubsection{Interação dos vetores com os inseticidas}

Devido à inexistência, não só de uma vacina suficientemente segura e eficaz, como também de expectativa de melhoria da progressão clínica da doença entre os portadores crônicos, a estratégia básica de controle da transmissão da DC é o combate aos vetores. O controle químico é realizado por meio de aplicação periódica e sistemática de inseticida de ação residual no intra e peridomicílio (DIAS, 1997).

O primeiro passo da interação é o encontro entre os triatomíneos com as superfícies tratadas com o inseticida. A partir desse momento, o inseticida invade o organismo desencadeando uma série de eventos moleculares. Assim, os inseticidas são absorvidos, distribuídos, armazenados, metabolizados e excretados. O estudo desses processos é um dos objetivos da toxicocinética (STARK e BANKS, 2003).

\subsubsection{Penetração, distribuição e excreção}

Existem vários modos de penetração de inseticidas no interior do corpo dos insetos: penetração, ingestão e inalação pelos espiráculos. A penetração é o mecanismo mais comum, uma vez que, a maioria dos inseticidas sintéticos apresenta característica lipofílica, portanto, são dissolvidos facilmente na superfície cerosa da cutícula dos insetos.

O ingresso dos inseticidas para dentro do corpo dos insetos ocorre por meio 
do tegumento em várias regiões delgadas (membranas das articulações e membranas intersegmentares). MATSUMURA (1963) e GRISSON et al. (1989) sugerem que alguns inseticidas (DDT, fenvalerato e malathion) quando aplicados na parede do corpo acumulam-se no tegumento, posteriormente, são adsorvidos pela parede de quitina e em seguida distribuídos livremente pela hemolinfa.

Por outro lado, SUGIURA et al. (2008) assumem que a rapidez com que determinados inseticidas atingem o sítio alvo é favorecido pelas rotas de penetração via espiráculos. Por exemplo, os inseticidas piretróides utilizados, em várias partes do mundo, além da baixa toxicidade em mamíferos apresentam alto poder de paralização (efeito "Knockdown”) seguida de morte dos insetos. Essa última característica demonstra sua rápida ação do Sistema Nervoso Central (SNC) sugerindo que sua rota de entrada seja pelos espiráculos. GEROLT $(1965,1969)$ também aponta os espiráculos como sendo a principal porta de entrada para o inseticida dieldrin.

Em T. infestans a penetração ocorre de modo mais eficiente por meio da fina superfície não esclerotinizada da cutícula. Também depende das propriedades físicas e químicas das substâncias e dos solventes usados na aplicação (FÓNTAN e ZERBA 1987).

Depois de atravessar o tegumento, a hemolinfa distribui o inseticida por todo o organismo. Por causa das características lipofílicas, as moléculas de inseticida somente poderão ser excretadas após sofrerem uma série de modificações químicas que alteram sua polaridade. Estas transformações são realizadas pelas enzimas detoxificantes. 


\subsubsection{Enzimas metabólicas que conferem resistência}

Os insetos coevoluem e se adaptam a diversos ecótopos, como por exemplo, à copa das árvores. Muitas espécies de plantas produzem uma variedade de substâncias tóxicas, especificamente, para se defender contra o ataque dos insetos fitófagos.

A maioria dessas toxinas naturais são lipofílicas sendo rapidamente metabolizadas e removidas pelo sistema excretor dos insetos.

O principal mecanismo que protege os insetos de uma infinidade de toxinas que ingerem periodicamente é a atividade de enzimas detoxificantes.

BRODIE e MAICKEL (1962) destacam duas características principais das enzimas detoxificantes: 1) converter substratos liposolúveis em produtos hidrosolúveis fáceis de excretar e, 2) são muito inespecíficas. Sua atividade está associada a funções normais de metabolização de outros xenobióticos.

O metabolismo de moléculas xenobióticas em um organismo é bifásico sendo divididas em enzimas de fase 1 e de fase 2 . As enzimas de fase 1 atuam diretamente sobre a substância exógena. As reações de fase 1 são oxidações, reduções e hidrólises. Geralmente, essas reações introduzem grupos funcionais reativos na molécula, o que dará origem a substratos para as enzimas de fase 2. As reações de fase 2 são conjugações que combinam os grupos funcionais com metabólitos endógenos solúveis em água.

Três principais classes de enzimas que contribuem para eliminação ou inativação das substâncias tóxicas circulantes nos insetos são: citocromo P450 (oxigenase de função mista), Glutationa $-\mathrm{S}$ - Transferases (GST) e Esterases. A elevada expressão dessas enzimas é um dos mecanismos que contribui para a 
resistência a inseticidas.

Citocromo P450 - O sistema microsomal monooxigenase citocromo P450 é um dos mais importantes mecanismos metabólitos conhecidos ocorrendo em vários grupos de animais, plantas e microorganismos. São encontrados, normalmente, no retículo endoplasmático, mas também ocorrem nas mitocôndrias.

Conforme HODGSON (1983) existem três principais componentes desse sistema: NADPH - citocromo c P450 reductase, citocromo $b_{5}$ e o citocromo P450 (enzima com um grupo hemo, cujo nome é derivado de um espectro de absorbância de $450 \mathrm{~nm}$ produzido pela molécula quando se liga ao monóxido de carbono).

O citocromo P450 cataliza diversas reações oxidativas envolvendo compostos endógenos e exógenos. Por esse motivo, também é conhecido como oxidase de função mista ou monooxigenases.

O mecanismo de ação do citocromo P450 implica a quebra de uma molécula de oxigênio. Um dos átomos é reduzido à água e outro oxida o substrato. Os elétrons são provenientes do NADPH:

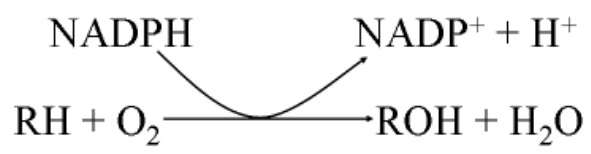

Nos insetos, a primeira descrição do citocromo P450 foi realizada por RAY (1967). Dentro dos insetos, as atividades das monooxigenases se manifestaram em maior intensidade em locais de maior trânsito e acesso de inseticidas: tubo digestivo, corpo gorduroso e túbulos de Malphigi (HODGSON, 1983).

Muito embora o citocromo P450 seja encontrado em todos os estágios de desenvolvimento, a seqüência das atividades varia drasticamente durante as fases de 
cada etapa. Nos ovos, a seqüência de atividades baixas ou até mesmo nulas é muito comum. Em períodos sucessivos de muda de larvas e ninfas ocorre um aumento, porém diminui rapidamente no momento da muda. Na pupação e durante o período pupal é nula. Em adultos emergidos é elevado, entretanto em adultos alimentados aparece em baixas atividades (HODGSON, 1983).

SODERLUND e BLOMQUIST (1989) ressaltam que o aumento dos níveis de citocromo P450 de um organismo pode ser induzido pela exposição crônica a certos compostos lipofílicos, como por exemplo inseticidas.

$\mathrm{O}$ citocromo $\mathrm{P} 450$, juntamente, com as outras enzimas do sistema é o responsável pelo aumento do metabolismo oxidativo de todas as classes de inseticidas, exceto os ciclodienos.

Glutationa - S - Transferases (GST) - são enzimas multifuncionais que conjugam moléculas exógenas com metabólitos endógenos (aminoácidos, glucation, glucosa). A GST apresenta elevada especificidade pela glucationa reduzida (GSH). Essas enzimas catalisam a conjugação do grupo SH da glutationa reduzida, que após combinada apresenta maior especificidade para um segundo substrato.

A conjugação da glutationa com os grupos eletrofílicos de compostos xenobióticos, catalisada pela GST, torna os produtos da reação menos tóxicos e mais hidrosolúveis favorecendo à excreção.

A Glutationa - S - Transferases apresenta distintas propriedades físicas e detoxificantes, conseqüentemente, desempenha papel fisiológico importante na metabolização de compostos gerados intracelularmente, como também de inseticidas organofosforados e organoclorados (DDT).

Esterases - o modo de ação consiste na adição de uma molécula de água a 
grupos carboxiester, fosfoester, carboxilamida e epóxi. Vários inseticidas apresentam grupamento éster na sua estrutura química (organofosforados, carbamatos e piretróides), portanto, sofrem reações de hidrólise. Durante a hidrólise se rompem as ligações éster e da molécula de água. Metade do éster se converte em ácido e a outra em álcool.

As enzimas que catalisam estas reações são conhecidas como Hidrolases ou Esterases. São também chamadas de Carboxilesterases quando hidrolisam compostos que apresentam ésteres carboxílicos na sua composição como organofosforados, por exemplo, o malathion.

As esterases são classificadas em esterase alfa (est $\alpha$ ) e esterase beta (est $\beta$ ) sendo que podem atuar isoladas ou em conjunto, em populações resistentes. A classificação dessas esterases é baseada no grau de mobilidade em gel de poliacrilamida e na preferência por anaftil ou ßnaftil acetato (HEMINGWAY e RANSON, 2000).

\subsubsection{Toxicodinâmica}

O estudo da interação das moléculas de inseticidas com seus sítios de ação e suas conseqüências é o objetivo da toxicodinâmica (STARK e BANKS, 2003). Apenas uma pequena parcela do inseticida alcançará o alvo molecular para exercer sua ação tóxica.

Todos os inseticidas sintéticos interferem no funcionamento do SNC. São considerados neurotóxicos e afetam a transmissão dos impulsos nervosos dos insetos, de modo que têm sido utilizados amplamente nos programas de controle de doenças transmitidas por vetores. 


\subsubsection{Inseticidas químicos}

\subsection{Inseticidas organoclorados}

Os organoclorados são inseticidas que contém, principalmente, $\mathrm{Cl}, \mathrm{H}$, e $\mathrm{C}$. Possuem estabilidade química elevada por apresentarem várias ligações $\mathrm{H}-\mathrm{C}, \mathrm{C}-\mathrm{Cl}$ e C-C entre suas moléculas.

São classificados em quatro grupos: difenil-alifáticos, hexaclorociclohexano, ciclodienos e policloroterpenos.

Difenil-alifáticos - o DDT é o mais conhecido; porém incluem-se mais quatro análogos relacionados ao DDT (dicofol, etileno, clorobenzilato e metoxicloro). O dicofol é um acaricida semelhante ao clorobenzilato. O etileno é utilizado para impregnação de madeira protegendo-a contra o ataque de cupins e o metoxicloro é um inseticida de jardins. Por serem altamente lipofílicos acumulam-se nos tecidos gordurosos do corpo.

Hexaclorociclohexano $(\mathrm{HCH})$ - também conhecido como benzenohexacloro (BHC) é considerado o mais antigo dos sintéticos clorados. Os isômeros do $\mathrm{HCH}$ são: alfa, beta, gama, delta e épsilon. Após diversos trabalhos de laboratório para separar e identificar esses isômeros, somente o isômero gama apresenta propriedades inseticida. O lindano é um produto comercializado que contém $99 \%$ de isômero gama.

Ciclodienos - a primeira parte do nome refere-se à estrutura cíclica, em forma de anel. A segunda (dieno) significa que tem dupla ligação. A maioria dos ciclodienos foi sintetizada depois da Segunda Guerra Mundial. O aldrin e o dieldrin sintetizados em 1948 são exemplos desse grupo. Geralmente, são persistentes e 
estáveis no solo e relativamente estáveis à ação da luz solar. Também são equitóxicos, isto é, apresentam efeitos iguais para mamíferos, insetos e aves.

Quanto ao modo de ação, os ciclodienos atuam no mecanismo de inibição dos receptores de GABA (ácido gama-amino-butírico). Esses receptores, em condições normais, aumentam a permeabilidade dos neurônios aos íons cloreto após ligação do neurotransmissor. Os ciclodienos impedem a entrada dos íons cloreto nos neurônios.

Policloroterpenos - o toxafeno e o estrobane foram desenvolvidos em $1947 \mathrm{e}$ 1951, respectivamente. São utilizados sempre em combinação com o DDT, uma vez que sozinhos têm poucas qualidades inseticidas. Somente esses dois policloroterpenos foram produzidos (WARE, 2000).

\subsection{Inseticidas organofosforados}

O termo organofosforados refere-se a todos os inseticidas que contém fósforo. Foram desenvolvidos na década de 40, mas são utilizados até hoje, tanto na agricultura como em saúde pública. São classificados em três subgrupos: os alifáticos (malathion, vidrin, vapona, etc), os derivados de fenil (etil e metil parathion, fenitrotion, etc) e os heterocíclicos (chlorpirifos, chlorpirifos metil, etc).

Quando comparados aos organoclorados são biodegradáveis, não se acumulam nos tecidos, contudo apresentam baixa persistência, o que torna obrigatório novos ciclos de aplicação. A falta de persistência se deve pela presença de ligações éster ${ }^{1}$. Essas ligações são facilmente hidrolizáveis produzindo álcool e o

\footnotetext{
${ }^{1}$ Os ésteres se formam pela reação entre um ácido e um álcool. O processo inverso de formação dos ésteres que retorna ao ácido e ao álcool de origem chama-se hidrólise. A hidrólise ocorre facilmente em meios ácidos e alcalinos, de origem aquática ou do solo. Também se produz por ação de enzimas.
} 
ácido de origem.

\subsection{Inseticidas carbamatos}

Assim como os inseticidas organofosforados são derivados do ácido fosfórico, os carbamatos são derivados do ácido carbâmico. São solúveis em solventes orgânicos, inodoros e sistêmicos para as plantas, uma vez que são relativamente solúveis em água. Apresentam elevado custo e persistência de 1 a 3 meses no meio ambiente (BRAGA e VALLE, 2007a).

Sua comercialização se iniciou nos anos 60 sendo que os mais utilizados em saúde pública são: o propoxur, o carbaril e o bendiocarb.

\subsection{Inseticidas piretróides}

No século XVII, os habitantes dos Montes Caucasianos conheceram as propriedades inseticidas das flores de crisântemo quando os utilizaram no combate de piolho do corpo.

Em 1924, os químicos suíços Hermann Staudinger e Leopold Ruzilka revelaram as primeiras características estruturais das piretrinas, sendo que, anos depois foram premiados com o Nobel por seus avanços nos diversos campos da química. As piretrinas são encontradas em toda parte, principalmente, nas folhas de plantas herbáceas da família Compositae. Das espécies Chrysantemum cineraraefolium e $C$. coccineum pertencentes a essa família são extraídas substâncias naturais que são utilizadas para produção de diversos piretróides sintéticos (ALZOGARAY, 1996). 
Durante a Primeira Guerra Mundial os japoneses dominaram o mercado do cultivo de crisântemos. O declínio dos japoneses ocorreu nos anos 30 quando se descobriu que o extrato de piretro produzido no Quênia apresentava maior concentração de piretrinas por unidade de peso seco (MCLAUGHLIN, 1973).

CASIDA (1980) destacou que o clima equatorial favorece um florescimento dos crisântemos, durante sete a onze meses por ano. Assim, nas décadas seguintes, o cultivo e a produção de piretro foram importantes no Quênia, Ruanda, Equador e Nova Guiné.

Nos anos 40, os Estados Unidos declararam o piretro como material estratégico de guerra devido à sua grande utilidade no combate aos mosquitos transmissores da malária. Várias tentativas de cultivo de crisântemos em território norte americano fracassaram. A dificuldade para obtenção de matéria prima, durante a guerra, induziu os Estados Unidos e a Inglaterra a sintetizar derivados das moléculas naturais.

Com os esforços iniciados, durante a Segunda Guerra Mundial, foi lançado no mercado americano o primeiro piretróide: a aletrina, em 1948. Sua síntese era muito complexa necessitando de 22 reações químicas para obtenção do produto final. Esse inseticida representou a primeira geração dessa família.

Naqueles anos, os desafios enfrentados pelos químicos eram sintetizar novas moléculas que reunissem as seguintes propriedades: i) eficazes contra os insetos, mesmo quando empregadas em baixas concentrações; ii) não serem tóxicas ao homem e animais domésticos; iii) serem de fácil obtenção de manipulação; iv) apresentar ação rápida e estabilidade ao ar livre e; v) serem econômicos. 
Após 20 anos, foi obtido o primeiro piretróide com características ideais e toxicidade em mamíferos menor que as piretrinas. Esse composto foi chamado de resmetrina (ELLIOT et al., 1967).

Além da resmetrina, outros compostos foram sintetizados entre 1960 e início dos anos 70, tais como: tetrametrina, bioresmetrina, bioaletrina e phonotrina representando a segunda geração dessa família.

Os piretróides de terceira geração (fenvalerato e permetrina) surgiram entre 1972 e 1973 e foram os primeiros a serem utilizados na agricultura, por serem mais eficazes e fotoestáveis.

Modificações estruturais posteriores, como por exemplo, incorporação de grupo ciano a estrutura dos piretróides permitiu um aumento considerável na ação inseticida. A deltametrina é um dos cianopiretróides amplamente efetiva contra importantes pragas agrícolas, sanitárias e domésticas.

As modificações estruturais sistemáticas de distintas partes das moléculas de piretrinas produziram compostos altamente efetivos em doses baixas, que incluem a bifentrina, lambdacialotrina, cipermetrina, ciflutrina, fenpropatrina, flucitrinato, fluvalinato, teflutrina, tralometrina e zeta-cipermetrina. Todos esses inseticidas, juntamente com a deltametrina correspondem à quarta geração e a mais atual desse grupo (ZERBA, 1999a).

A presença ou ausência de um grupo ciano ligado ao carbono $\alpha$, o tipo de sintomatologia e os efeitos fisiológicos produzidos classificam os piretróides em Tipo 1 e Tipo 2. As principais diferenças estão contidas na Tab. 1. 
Tabela 1 - Classificação dos piretróides baseada na estrutura química, sintomas e efeitos eletrofisiológicos produzidos (GAMMON et al., 1981; GHIASUDDIN e SODERLUND, 1985; SODERLUND e BLOOMQUIST, 1989; BLOMQUIST, 1996; SODERLUND, 2008).

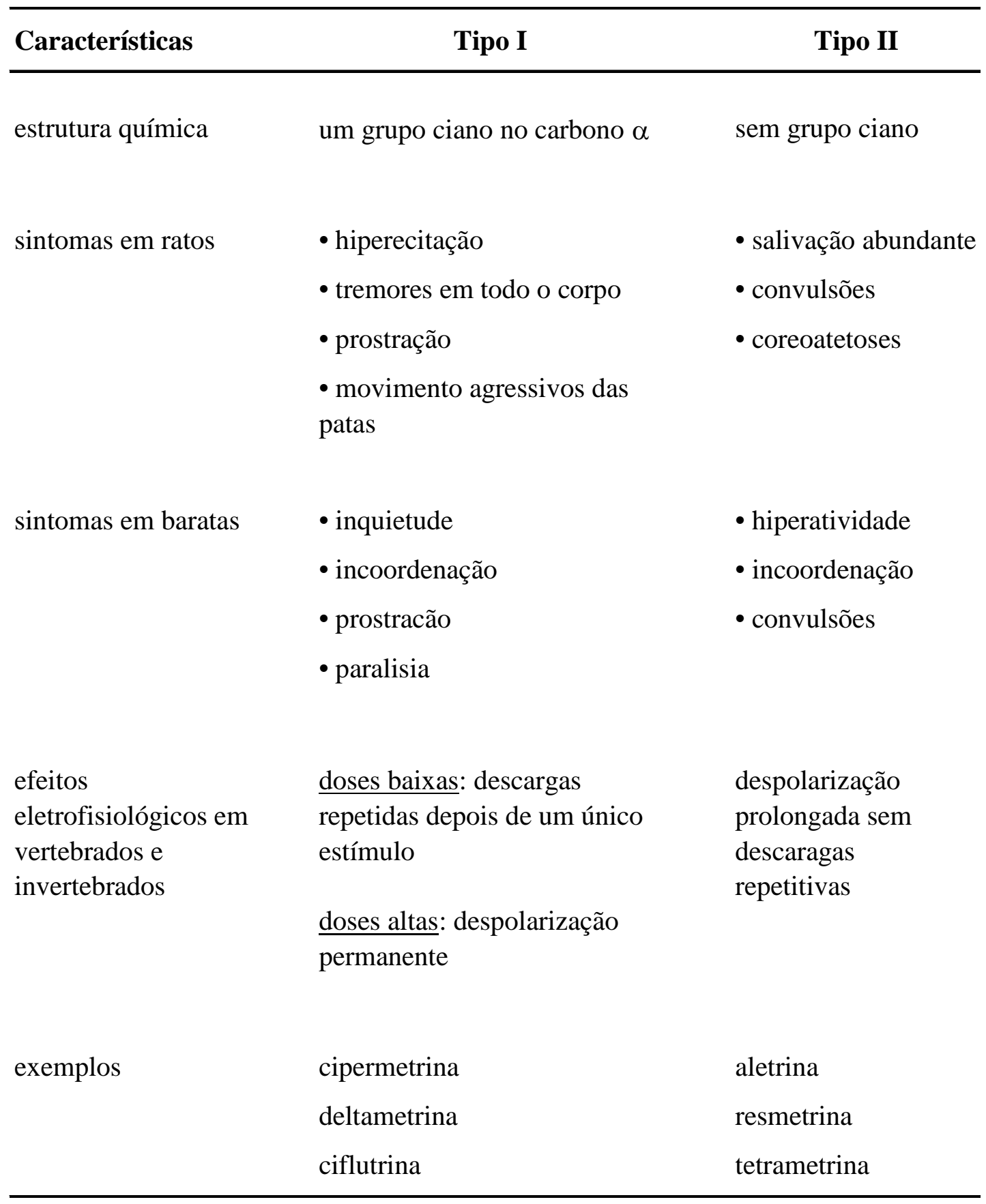


Hoje, as combinações de estruturas moleculares dos piretróides resultam em produtos mais fotoestáveis e com maior ação inseticida, portanto aumentando o seu uso com uma larga margem de segurança, tanto no meio agrícola quanto na saúde pública. Somente em 1995, o uso de piretróides representou aproximadamente $23 \%$ do crescimento do mercado mundial de inseticidas (SODERLUND, 2008).

Certamente, a expansão do uso de inseticidas vem acompanhada pelas constantes questões sobre o potencial de evolução de resistência em populações com importância em saúde pública. Dentre essas populações citamos os triatomíneos.

\subsubsection{Alteração do sítio-alvo dos inseticidas químicos}

Os quatro grupos principais de inseticidas atuam no SNC, em diferente sítioalvo. Os inseticidas organofosforados e os carbamatos atuam sobre a enzima acetilcolinesterase enquanto os organoclorados e piretróides mantém abertos os canais de sódio. A simples modificação de um amino-ácido, tanto nos canais, quanto na acetilcolinesterase, pode causar uma redução na sensibilidade aos inseticidas levando a uma diminuição da afinidade entre o inseticida e seu sítio ativo. (BROGDON e McALLISTER, 1998).

Acetilcolinesterase (ACE) - a acetilcolina liberada na fenda sináptica é a responsável pela propagação do estímulo nervoso. Esse neurotransmissor provoca abertura dos canais de sódio da membrana do nervo pós-sináptico.

Após o término do estímulo, a acetilcolina é removida pela ACE. Os organofosforados e carbamatos agem inibindo a ACE que regula os níveis de acetilcolina. $\mathrm{O}$ acúmulo de acetilcolina nas junções nervosas impede a interrupção de propagação do impulso elétrico. Consequentemente, o SNC continuará sendo 
estimulado, desencadeando o processo de paralisia, podendo culminar com a morte do inseto (WARE, 2000).

Um dos mecanismos de resistência a inseticidas organofosforados e carbamatos ocorre quando há uma alteração ou diminuição à sensibilidade da ACE (VILLATE e BACHMANN, 2002). Esses inseticidas não serão mais capazes de inibir à $\mathrm{ACE}$ permitindo a interrupção normal do estímulo.

Desde a primeira descrição de alteração da ACE, no ácaro Tetranychus urticae, em 1964, mais de 20 espécies pertencentes a seis diferentes ordens apresentaram diminuição da ação letal de pesticidas ocasionadas pelas modificações estruturais na ACE (SMISSAERT, 1964; FOURNIER e MUTERO, 1994).

Canais de Sódio - os inseticidas piretróides e organoclorados (DDT) atuam nos canais de sódio, distribuídos ao longo do axônio, prolongando a abertura ou impedindo o fechamento normal desses canais após a transmissão do impulso nervoso, causando um fluxo excessivo de íons $\mathrm{Na}^{+}$para o interior da célula nervosa. $\mathrm{O}$ acúmulo excessivo de íons $\mathrm{Na}^{+}$resulta num completo descontrole nervoso central e periférico do inseto. As descargas produzirão sintomas de intoxicação, hiperexcitabilidade, perda de postura e, consequentemente, a morte do inseto (BLOOMQUIST, 1996; WARE, 2000).

A resistência ocorre pela redução de sensibilidade do canal de sódio a esses compostos. A inibição do efeito de inseticidas provocado pela insensibilidade dos canais de sódio foi registrada pela primeira vez em Musca domestica, no ano de 1976 (FARHAM et al., 1987).

A resistência a todos os análogos de piretróides e DDT envolvendo modificações no canal de sódio também é conhecido como mecanismo "knockdown" 
(kdr). Esse tipo de resistência é melhor caracterizado em moscas, nas quais incluem alelos de resistência designados como kdr e super kdr (CHANG e PLAPP, 1983, BLOOMQUIST, 1996).

Receptores do ácido gama-aminobutírico (GABA) - apesar dos primeiros registros a dieldrin (ciclodieno) serem de 1950, envolvendo receptores de GABA, os mecanismos de resistência ainda não foram totalmente esclarecidos (BRAGA e VALLE, 2007a).

Nos insetos, os receptores de GABA estão presentes nas junções neuromusculares e no SNC. Em condições normais, esses receptores desencadeiam o mecanismo inibitório que restabelece o estado de repouso do SNC. Após a transmissão normal de um impulso nervoso ocorre a ligação de GABA ao seu receptor pós-sináptico que provoca um aumento da permeabilidade da membrana e conseqüentemente a entrada de íons cloreto (HEMINGWAY e RANSON, 2000).

Os inseticidas ciclodienos e policloroterpenos, assim como as avermectinas, atuam sobre os receptores GABA impedindo a entrada de íons cloreto para o meio intracelular, com isto antagonizando o efeito "inibitório" de GABA e provocando impulsos espontâneos que geram convulsões, paralisia e morte.

A resistência ocorre pela diminuição da sensibilidade dos receptores de GABA aos inseticidas. 


\subsection{RESISTÊNCIA DE INSETOS COM IMPORTÂNCIA EM SAÚDE}

\section{PÚBLICA}

O uso de inseticidas, em larga escala, iniciou-se após a década de 40. As propriedades inseticidas do DDT e dos compostos organofosforados foram descobertas entre 1939 e 1945 e os carbamatos e piretróides entre 1950 e 1960.

Durante esse período, em várias partes do globo terrestre, a introdução de inseticidas sintéticos resultou em forte pressão de seleção em diversas populações taxonomicamente diferentes. Poucas décadas depois, mais de 500 espécies de insetos apresentaram populações resistentes para um ou mais inseticidas (TABASHNIK e ROUSH, 1990).

A resistência a inseticidas é definida pela Organização Mundial de Saúde como sendo uma característica herdável, portanto genética, que confere um aumento na tolerância a um pesticida, ou grupo de pesticidas, de modo que os indivíduos resistentes sobrevivem à concentração $d o(s)$ componente(s) que seriam normalmente letais para a maioria dos indivíduos de uma população da mesma espécie (suscetível) (WHO, 1957, 1992).

Frequentes aplicações de um mesmo inseticida podem selecionar indivíduos de uma população que resistem às doses recomendadas. Os indivíduos sobreviventes ao se reproduzirem transferem o material genético para a próxima geração. Após vários ciclos de "seleção" ocorre um aumento da prevalência de genes resistentes e o tratamento com inseticidas torna-se ineficiente contra o inseto alvo.

A resistência pode surgir de diferentes maneiras dependendo da natureza dos mecanismos de resistência. Quando uma enzima detoxificante atua em mais de um tipo de inseticida da mesma classe pode ocorrer uma resistência cruzada, por 
exemplo, se uma população é resistente a um tipo de piretróide, habitualmente, poderá conferir resistência contra todo o grupo de piretróides. Outro exemplo de resistência cruzada é a insensibilidade da acetilcolinesterase para organofosforados e carbamatos (HEMINGWAY, 1982; NAUEN, 2007).

A co-ocorrência de dois mecanismos de resistência caracteriza-se como uma resistência múltipla, por exemplo, em inseticidas organofosforados poderá ocorrer insensibilidade da acetilcolinesterase combinada com aumento da detoxificação por meio de enzimas (BRATTSTEN, 1989; METCALF, 1989; NAUEN, 2007).

Os indivíduos resistentes existem em baixas proporções nas populações silvestres e para sua detecção é necessária a realização de testes chamados bioensaios que consistem em experimentos laboratoriais, os quais utilizam organismos vivos.

Quando um estímulo é aplicado, geralmente, o organismo responde. Os bioensaios fornecem parâmetros para quantificar a (s) resposta (s). Tradicionalmente, a detecção de resistência é realizada por meio de verificação da dose resposta (DR), a qual é realizada com, aproximadamente, quatro a cinco doses que produzem mortalidade de 0 a $99 \%$.

Alternativamente, o método da dose diagnóstica (DD), também é utilizado para revelar populações resistentes. A DD é a estimativa da $\mathrm{DL}_{95}$ da população suscetível multiplicada por um fator 2 ou 3. A vantagem da técnica de DD é a rapidez, isto é, pode ser utilizada em poucos indivíduos, possibilitando a análise de um maior número de populações. HALLIDAY e BURNHAM (1990) dividem a técnica de DD em duas categorias (perfeita e não perfeita), dependendo do tempo em que a dose mata todos os suscetíveis e nenhum resistente (perfeita) ou mata ambos os genótipos (não perfeita). 
A resistência é expressa por meio da razão da $\mathrm{DL}_{50}$ ou $\mathrm{DL}_{95}$ da população estudada pela população sensível. Estatisticamente, a $\mathrm{DL}_{50}$ ou $\mathrm{DL}_{95}$ são medidas de relação entre a dose e a resposta, cuja função é estimar a dose que causa 50\% ou 95\% de mortalidade em uma determinada população. A magnitude da resistência é medida por meio da Razão de Resistência (RR). A RR estima quantas vezes a população estudada é mais resistente que a população de referência (PESSOA, 2008).

O monitoramento de resistência envolve comparações das $\mathrm{DL}_{50}, \mathrm{DL}_{95}$ e o coeficiente angular da curva DR das populações coletadas no campo com a linhagem de laboratório.

O coeficiente angular da curva DR é o inverso do desvio padrão da distribuição fenotípica de tolerância a um inseticida. Assim, um valor de coeficiente angular elevado indica redução na variação fenotípica em resposta para um inseticida em uma determinada população. Em outras palavras, o coeficiente angular é um indicador de progressão de resistência e de variação fenotípica na tolerância a um inseticida (CHILCUTT e TABASHNIK, 1995).

ROUSH e MILLER (1986) consideram a DL95 e o coeficiente angular como os melhores indicadores para a resistência; porém, sofrem influência do tamanho da amostra. Conforme os autores, na maioria dos casos, é necessário um grande número de amostras para detectar baixas freqüências de resistência. Por exemplo, para detectar resistência com um intervalo de confiança de 95\% em uma população, cuja freqüência é de $1 \%$ é necessária uma amostra de 300 indivíduos.

ROBERTSON et al. (1984) estudando a influência do tamanho da amostra, na estimativa de precisão das DLs, sugerem que preferencialmente se utilizem um tamanho de amostra de 240 indivíduos ou mais em um experimento de curva DR. Os 
autores mencionam ainda que, no mínimo 120 indivíduos são necessários para estimar precisamente a $\mathrm{DL}_{50}$ e $\mathrm{DL}_{95}$ de um estudo dentro de um limite de confiança de 95\%. Quando a resistência é comum, ou seja, com uma frequência maior que 10\%, o tamanho de amostra de 100 indivíduos será suficiente para detectar resistência.

Hoje, o controle químico de populações de insetos com importância em saúde pública tem sido prejudicado pela emergência de populações com elevados níveis de resistência. A resistência de populações de baratas, pertencentes à espécie Blattella germanica é um problema comum em várias partes do mundo (ZHAI e ROBINSON, 1992; ANSPAUGH et al., 1994; LEE et al., 2000).

Os mecanismos de alteração no canal de sódio, o aumento da atividade enzimática do citocromo P450 e esterases estão envolvidos no surgimento de resistência cruzada para deltametrina e permetrina em populações de Pediculus humanus capitatis, oriundos da Argentina, Israel e sul da Flórida (HEMINGWAY et al., 1999; PICOLLO et al., 2000; LEE et al., 2003; VASSENA et al., 2003; GONZÁLEZ-AUDINO et al., 2005).

LOFGREN et al. (1958) e MYAMBA et al. (2002) mostraram que os testes de suscetibilidade em percevejos de cama, Cimex hemipterus e $C$. lectularius tem comprovado resistência a piretróides e DDT em populações procedentes de Yokosuka (Japão), Flórida e Ohio (USA) e adjacências de Tanga (Tanzânia).

Paralelamente, o controle do muscídeo Haematobia irritans nas fazendas localizadas em Santa Fé, na Argentina, tem se mostrado insatisfatório devido ao aparecimento de resistência a cipermetrina envolvendo a insensibilidade dos canais de sódio, sítio-alvo dos piretróides (GUGLIELMONE et al., 2002). 
Nos mosquitos vetores, pertencentes à família Culicidae, diversos casos de resistência a diferentes classes de inseticidas químicos e biológicos tem sido reportados em várias partes do mundo (AMIN E PEIRIS, 1990; RODCHAROEN e MULLA, 1994; NIELSEN-LEROUX et al., 1997; CHANDRE et al., 1997, 1998; CHEIKH et al., 1998; GONZÁLEZ et al., 1999; WHIRTH et al., 2000; CAMPOS e ANDRADE, 2001; N'GUESSAN et al., 2003; YUAN et al., 2003).

Na Turquia, verificou-se um aumento nos níveis de Glutationa - S Transferase em algumas populações de Anopheles sacharovi. Provavelmente, essa alteração conferiu resistência ao organofosforado malathion (HEMINGWAY et al., 1992). MATAMBO et al. (2007) observou situação semelhante, no Sudão, para $A$. arabiensis que demonstrou altas porcentagens de sobrevivência para bendiocarb (33\%), malathion (16\%) e deltametrina (12\%).

O principal vetor da malária, na África, o A. gambie apresentou elevados níveis de resistência para dieldrin. Estudos moleculares detectaram a presença de mutação nos receptores de GABA, nas populações originárias do oeste da África (BROOKE et al., 2006). A. funestus, outro importante vetor da malária, na África do Sul, também manifestou alterações na suscetibilidade à piretróides implicando sérios problemas nas operações de controle da malária, especialmente, no sudeste de Moçambique (HARGREAVES et al., 2000).

O mosquito Culex tritaeniorhynchus, importante vetor do vírus da Encefalite Japonesa, tem revelado extraordinárias RR para temefós $(125,000)$, fenitrothion $(26,500)$, fenthion $(22,929)$ e malathion $(6,000)$ em Toyama, no Japão. A insensibilidade da acetilcolinesterase a esses compostos foi o principal fator da resistência, conforme TAKAHASHI e YASUTOMI (1987). No Siri-Lanka, 
populações dessa mesma espécie indicaram elevados níveis de GST e resistência a organofosforados (KARUNARATNE e HEMINGWAY, 2000).

Em Cuba e no oeste da África, mosquitos da espécie C. quinquefaciatus sofreram pressão de inseticida e desenvolveram a capacidade de resistir aos tratamentos com malathion e deltametrina, respectivamente (BISSET et al., 1991; MAGNIN et al., 1988).

No Brasil, as populações de $C$. quinquefaciatus capturadas às margens do Rio Pinheiro, na cidade de São Paulo, evidenciaram Razão de Resistência de 11,2 para o inseticida fenitrothion. Foi constatada resistência múltipla relacionada à alteração na sensibilidade da acetilcolinesterase, agrupado com aumento da atividade enzimática das esterases (BRACCO et al., 1999).

Em mosquitos, talvez o mecanismo mais comum de resistência seja devido a alterações nos níveis de enzimas esterases, as quais degradam uma ampla variedade de inseticidas. Diversos pesquisadores demonstraram o envolvimento dessas enzimas no surgimento de resistência a organofosforados, carbamatos e piretróides (AMIN e PEIRIS, 1980; PASTER et al., 1981; HEMINGWAY et al., 1990; HEMINGWAY e KARUNARATNE, 1998).

Certamente, dentro do gênero Aedes, a espécie Aedes aegypti tem sido amplamente estudada em relação aos aspectos fisiológicos e bioquímicos da resistência a inseticidas químicos. Somente na região do Caribe, amostras de mais de 45 países já foram analisadas. Os resultados confirmaram elevados níveis de resistência para organofosforados, principalmente malathion, fenthion e temefós (RAWLINS e WAN, 1995; GEORGHIOU et al., 1987). 
No Brasil, BRAGA et al. (2004) descobriram populações de A. aegypti resistentes ao organofosforado temephós em 12 municípios distribuídos nos Estados de Rio de Janeiro, Alagoas e Sergipe. Esse inseticida é utilizado no controle de larvas do mosquito A. aegypti no país.

Em relação aos adulticidas, os organofosforados utilizados pelo Programa Nacional de Controle da Dengue (PNCD) foram sendo, periodicamente, substituídos por piretróides desde 1999. Apesar do recente uso dos piretróides no controle de $A$. aegypti, há relatos de populações com alteração de suscetibilidade para essa classe de inseticida, devido à mutações no sítio-alvo (PEREIRA da CUNHA et al., 2005).

Atualmente, o PNCD tem indicado a substituição dos inseticidas utilizados na rotina, com base nas informações fornecidas pelo programa de monitoramento de resistência de A. aegypti. O programa foi criado e incorporado ao PNCD desde 1999 (MACORIS et al., 1999; BRAGA et al., 2004; LIMA et al., 2003).

Diante desse cenário, espécies sinantrópicas de triatomíneos dos gêneros Panstrongylus, Triatoma e Rhodnius formam, ainda hoje, os maiores desafios em saúde pública.

Embora pesquisas importantes tenham surgido para detectar, quantificar e compreender os possíveis mecanismos de resistência em triatomíneos, os inseticidas químicos ainda se mantém absolutamente necessários para os programas de controle.

Nesse contexto, a eficiência dos inseticidas empregados na rotina ou $\mathrm{o}$ desenvolvimento de resistência devem sempre ser avaliados, como medida de segurança para a população envolvida, também como uma economia para os cofres públicos. 
Apesar das contínuas e intensivas campanhas de controle contra os vetores da DC, poucos estudos têm sido realizados para detectar mudanças na suscetibilidade de populações triatomínicas em relação aos inseticidas utilizados no seu controle.

De acordo com NOCERINO e HERNÁNDEZ (1986) a primeira evidência bem documentada de resistência de uma espécie de triatomíneo foi em $R$. prolixus para o dieldrin. Durante 1976 e 1977, populações de $R$. prolixus e $T$. maculata capturadas em diversas regiões da Venezuela foram expostas a diferentes doses de organoclorados, organofosforados e carbamatos. Primeiramente, a resistência a dieldrin foi detectada no Estado de Trujillo, seguida de fentión e propoxur para os Estados de Yaracuy, Tachira, Cojedes e Portuguesa.

Anos depois, NELSON e COLMENARES (1979) constataram elevadas taxas de resistência para BHC e dieldrin por meio de aplicação tópica em populações de $R$. prolixus procedentes de Santo Domingo, Colômbia.

O problema de resistência a inseticidas dos vetores da DC foi colocado em segundo plano por vários anos, não sendo informadas falhas no controle atribuídas ao problema. Em 1994, a Organização Mundial de Saúde preocupada com o tema financiou e organizou um Workshop com diversos especialistas para desenvolverem um protocolo de avaliação de susceptibilidade e resistência a inseticidas para $T$. infestans e $R$. prolixus (WHO, 1994).

A aplicação dessa metodologia permitiu avaliar amostras de $T$. infestans procedente do Rio Grande do Sul, Brasil e R. prolixus do Estado de Carabobo, Venezuela. A população de T. infestans capturada no sul do Brasil apresentou resistência deltametrina $(7,0 \mathrm{X}), \beta$-ciflutrina $(3,6 \mathrm{X})$ e a cipermetrina $(3,3 \mathrm{X})$, mas 
sucetível a $\beta$-cipermetrina e lambdacialotrina. Em $R$. prolixus maior resistência foi detectada para cipermetrina (12,4X) (VASSENA et al., 2000).

VASSENA e PICOLLO (2003) estudando alterações na susceptibilidade de populações de $T$. infestans a deltametrina registraram níveis de resistência incipiente em quatro amostras procedentes das províncias de Catamarca $\left(\mathrm{RR}_{50}=2,6\right)$, San Luis $\left(R_{50}=3,0\right)$, Mendoza $\left(R_{50}=3,8\right)$ e Salta $\left(R_{50}=5,6\right)$.

GONZÁLEZ-AUDINO et al. (2004) comparando população resistente (Salta) com outra suscetível (CIPEIN - Centro de Investigaciones em Plagas e Insecticidas), mediante ensaios bioquímicos, constataram diferenças significativas nos níveis de atividade das enzimas esterase e monooxigenases (P450) entre as duas amostras, sugerindo que essas duas enzimas contribuem para as causas do fenômeno de resistência.

Após relato de autoridades sanitárias responsáveis pelo controle de vetores, do Norte da Argentina (Departamento de San Martín), sobre a ineficácia de aplicações de deltametrina e outros inseticidas piretróides em habitações infestadas por T. infestans, nova região foi descoberta com presença de populações resistentes.

PICOLLO et al. (2005) comprovaram resistência a deltametrina em todas as amostras provenientes de ElChorro, La Toma, El Sauzal e Salvador Mazza. O valor da Razão de Resistência foi de 99,0; 86,9; 50,5 e 133,1, respectivamente. Os ensaios bioquímicos apontaram maior atividade de oxidases de função mista e esterases, nas amostras resistentes.

ORIHUELA et al. (2008) estudando populações resistentes de T. infestans capturados em duas áreas do norte da Argentina (Salta e La Rioja) e uma área da Bolívia (Yacuiba) observaram aumento dos níveis de atividade das esterases nas 
populações argentinas, o oposto da população de Yacuiba que apresentou baixa atividade de esterases na degradação de piretróides. Apesar da diminuição de frequência e distribuição da atividade enzimática das esterases, a Razão de Resistência foi de 154,4 , ou seja, elevada para essa população. Os autores atribuem a divergência desses resultados à diferenciação molecular entre populações de $T$. infestans da Bolívia e da Argentina/Brasil, proposto por MONTEIRO et al. (1999).

Os estudos sobre a resistência em ovos de T. infestans também foi realizada em 2008. Nesse ano, houve o primeiro registro de resistência em ovos de populações de T. infestans oriundas de Salvador Mazza, Argentina (TOLOZA et al., 2008). A $\mathrm{DL}_{50}$ de deltametrina aplicada topicamente em ovos foi de $658,1 \mathrm{ng} / \mathrm{ovo}$ e $\mathrm{RR}_{50}=$ 114,28 .

No Brasil, PESSOA (2008) registrou níveis de resistência incipiente em populações de T. sordida capturadas nos municípios de Presidente Juscelino; Bocaiúva e Coração de Jesus, no Estado de Minas Gerais. Esse autor encontrou valores de $\mathrm{RR}_{50}$ de 5,5 para a população do município de Presidente Juscelino; 6,2 para a população do município de Bocaiúva e 6,8 para a população do município de Coração de Jesus. Ainda, nesse mesmo trabalho, o autor destacou que não houve diferença significativa em ensaios biológicos realizados com ninfas da geração F1 e F2 e na aplicação tópica de inseticidas do dorso ou no ventre.

SONODA (2009) analisou, por meio de ensaios biológicos, o perfil de resistência de populações de $T$. infestans procedentes de quatro municípios (Doutor Maurício Cardoso, Guarani das Missões, Mato Queimado e Três de Maio) do Estado do Rio Grande do Sul, juntamente com amostras da Bolívia (Yacuiba) e Argentina (Salvador Mazza). Ainda, esse autor avaliou populações intra e peridomiciliares de 
T. brasiliensis, provenientes de cinco localidades do município de Tauá, no Estado do Ceará. Os resultados dos ensaios biológicos, tanto de $T$. infestans quanto de $T$. brasiliensis caracterizaram as amostras como sendo suscetíveis a deltametrina (SONODA, 2009; SONODA et al., 2009).

Recentemente, a Microscopia Eletrônica de Varredura (MEV) foi adotada para analisar a resistência de triatomíneos a piretróides. Dessa maneira, surge uma nova linha de pesquisa para uma melhor compreensão dos mecanismos de resistência dos vetores de DC.

Hoje, a MEV tem sido utilizada para separar espécies de difícil distinção, assim como para elucidar aspectos filogenéticos e de classificação de Triatominae. Análises ultraestruturais, vistas pela $\mathrm{MEV}$, permitiram detectar diferenças morfológicas significativas em diversas estruturas, tais como: fosseta esponjosa (HARIDASS e ANANTHAKRIHNAN, 1980); sulco estridulatório (DI LUCIANO, 1981); segmentos abdominais ventrais de ninfas de $5^{\circ}$ estádio (ROSA et. al., 1992); escutelo (CARCAVALLO e GALINDEZ-GIRÓN, 1995; CARCAVALLO et. al., 1996; OBARA et al., 2007a); tubérculo antenífero (SILVA et. al., 2002) e Processo do I Urotergito (OSÓRIO-QUINTERO, 2002).

A utilização do MEV, em estudos macroscópicos e exocoriais de ovos de triatomíneos foi, preconizado por BARATA (1979), primeiramente, para espécies do gênero Rhodnius Stål, 1859. Posteriormente, a utilização da ultraestrutura exocorial, associada à morfologia de ninfas foi ampliada para espécies dos demais gêneros (GONÇALVES et. al., 1985; COSTA et al., 1991; JURBERG et al., 1991, 1993, 2002; JUBERG e VOGEL, 1994; JURBERG e CAMPOS, 1995; ROCHA et. al. 
1996; ROSA et al., 2000; OBARA, 2003; OBARA et al., 2007b; 2007c; SANTOS et al., 2009).

Outro caráter informativo é a morfologia, a distribuição, o número e o arranjo de cerdas e sensilas das antenas e do rostro de triatomíneos. Essas estruturas quando analisadas em MEV possibilitaram diferenciações intra-específicas entre gêneros e espécies de triatomíneos (CATALÁ e SCHOFIELD, 1994; CATALÁ, 1994, 1996, 1997; GRACCO e CATALÁ, 2000; CATALÁ e DUJARDIN, 2001; CARBAJAL de La FUENTE e CATALÁ, 2002; CATALÁ et al., 2004; MORENO et al., 2006).

Certamente, a incorporação da tecnologia de MEV em estudos de monitoramento de resistência de Triatominae permitirá ampliar os conhecimentos sobre os mecanismos envolvidos na resistência e sua interação. Essas importantes informações fornecerão subsídios para a elaboração das estratégias de controle dos vetores da DC.

Recentemente, PEDRINI et al. (2009) comprovaram por meio de MEV que populações resistentes de $T$. infestans apresentam maior espessura do exoesqueleto, quando comparadas com populações suscetíveis. Os autores analisaram fragmentos da cutícula de ninfas de $4^{\circ}$ estádio e concluíram que nas populações resistentes, a largura é de $32,1 \pm 5,9 \mu \mathrm{m}$, enquanto que nas populações suscetíveis o valor diminui para 17,8 $\pm 5,4 \mu \mathrm{m}$. Os autores sugerem que o mecanismo de penetração apresenta relação com a resistência de $T$. infestans a deltametrina, na Argentina. 


\section{JUSTIFICATIVA}

Na década de 90, as iniciativas deram início à "erradicação da transmissão vetorial da DC”, em várias regiões endêmicas, mediante a uma forte pressão de tratamento com inseticidas piretróides.

No Brasil, ao menos nos últimos vinte anos, não há nenhuma informação sobre o potencial genético de resistência dos triatomíneos. Com o estabelecimento de populações resistentes, em determinados países, faz-se necessário, não só estudo mais aprofundado sobre "perfil de resistência" dos triatomíneos, em relação aos inseticidas químicos utilizados no seu controle, como também cuidado e atenção especial das autoridades sanitárias.

Assim sendo, a presente pesquisa contempla o estudo das espécies com maior capacidade de domiciliação e que, portanto, representam maior risco para a transmissão da doença, tais como: P. megistus, T. brasiliensis e T. sordida quanto aos mecanismos biológicos de resistência, e ainda, representa um programa contínuo que deverá ser parte integrante do Programa Nacional de Controle da Doença de Chagas do Brasil.

A detecção rápida e precoce de populações resistentes é de extrema importância para o Programa Nacional de Controle da Doença de Chagas, uma vez que terá tempo para implantar estratégias alternativas de controle, como também selecionar inseticidas adequados antes de iniciar as operações de campo.

Ainda, o encontro de indícios de resistência permitirá um melhor entendimento dos elementos que favorecem, não só a reemergência de populações expostas ao tratamento, como também a recolonização por meio de migrações de 
uma espécie ou de outras espécies provenientes de ambientes peridomiciliares ou silvestres.

Dessa maneira, a implantação de programa de monitoramento de resistência dos vetores da doença de Chagas é imprescindível, não só no Brasil, mas também em toda a América Latina. 


\section{OBJETIVOS}

\subsection{OBJETIVO GERAL}

Analisar os níveis de resistência de populações naturais de Panstrongylus megistus, Triatoma brasiliensis e Triatoma sordida ao piretróide deltametrina empregado no Programa de Controle da Doença de Chagas.

\subsection{OBJETIVOS ESPECÍFICOS}

Caracterizar o perfil de suscetibilidade de populações de Panstrongylus megistus, Triatoma brasiliensis e Triatoma sordida de regiões endêmicas tratadas com inseticidas piretróides;

$\checkmark$ Recomendar a dose diagnóstica ideal para bioensaios de laboratório utilizados no monitoramento de resistência de populações de Panstrongylus megistus, Triatoma brasiliensis e Triatoma sordida;

$\checkmark$ Descrever a interação de diferentes concentrações de deltametrina na estrutura cuticular do tórax de ninfas de $1^{\circ}$ estádio;

$\checkmark$ Padronizar bioensaios de campo para avaliação do efeito de deltametrina;

$\checkmark$ Avaliar o efeito do tratamento residual com a dose recomendada no campo em "populações resistentes" caracterizadas em laboratório;

$\checkmark$ Estabelecer padrão de normas para análise dos procedimentos efetuados nos bioensaios para estudo de resistência de populações de triatomíneos. 


\section{MÉTODOS}

\subsection{MATERIAL BIOLÓGICO}

4.1.1 Insetos suscetíveis - As populações suscetíveis foram definidas conforme critérios estabelecidos no protocolo da Organização Mundial da Saúde (1994) que descrevem que toda população mantida sob condições de laboratório por pelo menos 5 gerações sem exposição a inseticidas e/ou população iniciada de áreas sem aplicação de inseticidas podem ser utilizadas como linhagens suscetíveis de referência. Neste trabalho foram selecionadas três populações consideradas, por esses critérios, como suscetíveis: P. megistus (Sento Sé/BA), T. brasiliensis (Umari/CE) e T. sordida (Cordeiros/BA) (Fig. 4).

As populações suscetíveis de $T$. brasiliensis e $T$. sordida foram procedentes do insetário do Laboratório de Parasitologia do Departamento de Ciências Biológicas da Universidade Estadual Paulista "Júlio de Mesquita Filho"/UNESP, cujo responsável é o Dr. João Aristeu da Rosa e que anteriormente foi mantida, desde os anos 80, pelo Departamento de Epidemiologia no Serviço Especial de Saúde de Araraquara/SESA da Faculdade de Saúde Pública/USP. A linhagem de $T$. brasiliensis iniciou sua criação em 21/02/1984, oriunda de Umari, no Ceará, enquanto T. sordida começou em 08/03/1982, proveniente de Cordeiros, na Bahia.

A população suscetível de $P$. megistus foi concedida pelo Dr. José Rodrigues Coura do Departamento de Medicina Tropical/FIOCRUZ/RJ. Essa população foi iniciada em 27/07/1987, a partir de exemplares procedentes do povoado de Quixadá, no município de Sento Sé, na Bahia.

4.1.2 Insetos para avaliação de resistência - Para este estudo os insetos foram obtidos a partir de amostras de campo. Para isso foram enviados 
documentos oficiais (Anexo 4) da Secretaria de Vigilância em Saúde do Ministério da Saúde para as Secretarias Estaduais de Saúde de Alagoas, Bahia, Ceará, Espírito Santo, Distrito Federal, Goiás, Maranhão, Minas Gerais, Mato Grosso do Sul, Mato Grosso, Paraíba, Pernambuco, Piauí, Paraná, Rio Grande do Norte, Rio Grande do Sul, Sergipe, São Paulo e Tocantins solicitando captura, acondicionamento e envio de espécies de P. megistus, T. brasiliensis e T. sordida.

Os triatomíneos foram capturados em áreas endêmicas tratadas com inseticidas, nas quais os Programas Estaduais de Controle da doença de Chagas realizam aplicações contínuas e sistemáticas com inseticidas de ação residual.

A seleção dos municípios para as atividades de captura foi decisão de cada Secretaria Estadual de Saúde; porém obedeceram, aos seguintes critérios: i) a realização de um programa específico de controle de vetores; ii) antecedentes históricos de controle de outros vetores dentro da mesma área geográfica; iii) uso de inseticidas com finalidades agrícolas na mesma área, onde se localiza os vetores e iv) uso doméstico de inseticidas.

Após a seleção dos municípios, equipes de entomologia realizaram busca ativa em unidades domiciliares (intra e peridomicílio) com auxílio de pinça, lanterna e desalojante PIRISA ${ }^{\circledR}$. Esse produto conhecido como extrato de piretro possui ingrediente ativo derivado de piretrinas e piretróides.

Os espécimes vivos foram acondicionados em pequenos recipientes de plástico ( $8 \mathrm{~cm}$ de altura $\times 7 \mathrm{~cm}$ de diâmetro) com papel filtro no fundo, juntamente com um papel dobrado, com forma semelhante a uma sanfona, cuja função é aumentar a superfície de contato oferecendo melhor abrigo aos insetos e preservando a umidade no interior do frasco. 
Os recipientes foram devidamente acondicionados no interior de caixas térmicas de isopor e enviados para o Laboratório de Entomologia Médica da Coordenação Geral de Laboratórios de Saúde Pública/CGLAB da Secretaria de Vigilância em Saúde do Ministério da Saúde/SVS/MS, localizado no Núcleo de Medicina Tropical da Universidade de Brasília.

As amostras recebidas possuíam fichas de campo contendo o local de captura (Localidade, Município e Estado); data da captura; nome do coletor e tipo de hábitat. Essas fichas também informavam coordenadas geográficas (latitude e longitude) e algumas também os antecedentes de controle do local da captura.

\subsection{DISTRIBUIÇÃO GEOGRÁFICA DE AMOSTRAS RECEBIDAS}

Durante o período de novembro de 2007 a setembro de 2009 foram recebidos um total de 55 populações (Anexo 5), procedentes de 51 municípios, distribuídos em 11 Unidades Federadas. A Fig. 4 destaca a distribuição geográfica das populações estudadas de acordo com os Estados do Brasil. Ainda, nessa mesma figura é possível observar a distribuição e a procedência das populações de referência de $P$. megistus, T. brasiliensis e T. sordida utilizadas neste trabalho. 


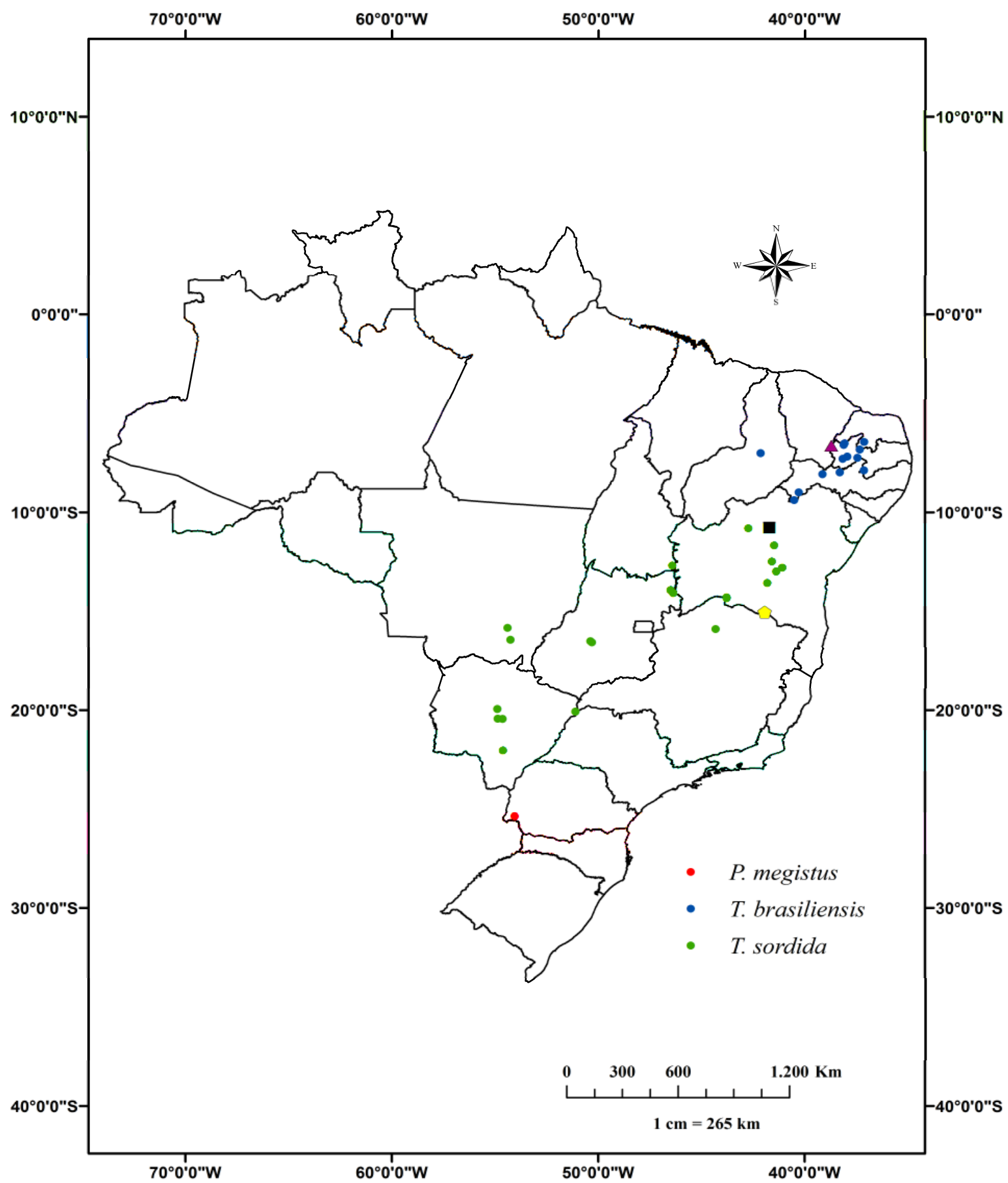

Figura 4 - Distribuição geográfica das populações de Panstrongylus megistus, Triatoma brasiliensis e Triatoma sordida analisadas durante o período de 2008 e 2009, no Brasil.

Notas:

População de referência de $P$. megistus capturada no município de Sento Sé/BA.

População de referência de T. brasiliensis capturada no município de Umari/CE.

População de referência de $T$. sordida capturada no município de Cordeiros/BA. 


\subsection{CRIAÇÃO E MANUTENÇÃO DE POPULACÕES DE TRIATOMÍNEOS EM INSETÁRIO}

As amostras para estudo de resistência (populações de campo), assim como as linhagens suscetíveis, foram criadas e mantidas no insetário do Laboratório de Entomologia Médica da CGLAB/SVS/MS sob condições de temperatura e umidade controladas por meio de aquecedor e umidificador de ar. Esses equipamentos conservaram a temperatura entre $28-30^{\circ} \mathrm{C}$ e umidade relativa do ar de $60 \%-70 \%$.

Após o recebimento, cada população foi identificada por meio de chave dicotômica contida em LENT e WYGODZINSKY (1979). Em seguida foram acondicionadas em recipiente de plástico transparente de $15 \mathrm{~cm}$ diâmetro por $18 \mathrm{~cm}$ de altura, com fundo recoberto com folhas de papel filtro Qualy ${ }^{\circledR}$, para a retenção da umidade gerada pelas fezes e urina. Para facilitar a alimentação e permitir melhor abrigo e maior mobilidade dos triatomíneos, a superfície de contato foi ampliada por meio de papelão recortado em forma de sanfona. As ninfas e os adultos da mesma população foram separados em diferentes frascos, previamente identificados.

A abertura dos recipientes foi vedada com pano de malha fina presa por meio de um elástico e coberta com um tecido mais grosso.

A cada 15 dias, os ovos de cada população eram retirados e acondicionados em frascos plásticos transparentes de $220 \mathrm{~mL}$. Feito isso, eram rotulados e armazenados em estufa, modelo 112 FC da ELETROlab ${ }^{\circledR}$ com umidificador termoperíodo e fotoperíodo, programados com umidade de $70 \%$, temperatura de $28^{\circ} \mathrm{C} \pm 1{ }^{\circ} \mathrm{C}$ e $12: 12(\mathrm{~N}: \mathrm{D}) \mathrm{h} . \mathrm{O}$ armazenamento em estufa teve por fim tornar simultânea a eclosão das ninfas de cada população estudada. Diariamente, as datas das eclosões das ninfas eram registradas visando à obtenção de geração F1 
padronizada para cada população, em relação ao tamanho e a idade cronológica e fisiológica, para posterior tratamento com deltametrina.

No interior dos recipientes com adultos foi instalado um sistema de coleta de ovos, enquanto que nos potes com ninfas eram colocados apenas papelão. Esse instrumento de "isolamento de ovos" foi desenvolvido para facilitar a separação dos ovos de insetos mortos e exúvias que se misturavam no interior dos potes, dificultando obtenção dos ovos e a manutenção das populações.

Para a confecção do "aparato" foi cortado um cano de PVC de $150 \mathrm{~mm}$ com 3 cm de largura. Em uma das extremidades foi aderido tela de malha de aço de $5 \mathrm{~mm}$ utilizando cola Araldite ${ }^{\circledR}$ (Fig. 5 A). Os orifícios da tela permitiram a passagem dos ovos que eram depositados livremente no interior dos recipientes. Após secos, foram colocados no interior dos recipientes com a parte da tela voltada para cima, de modo que os insetos, juntamente com o papelão permanecessem apoiados na superfície da tela (Fig. 5 B e C). À medida que os insetos realizavam a oviposição, os ovos, ultrapassavam a tela (Fig. 5 D) e permaneciam preservados no fundo do recipiente, facilitando o acesso e a retirada dos mesmos 

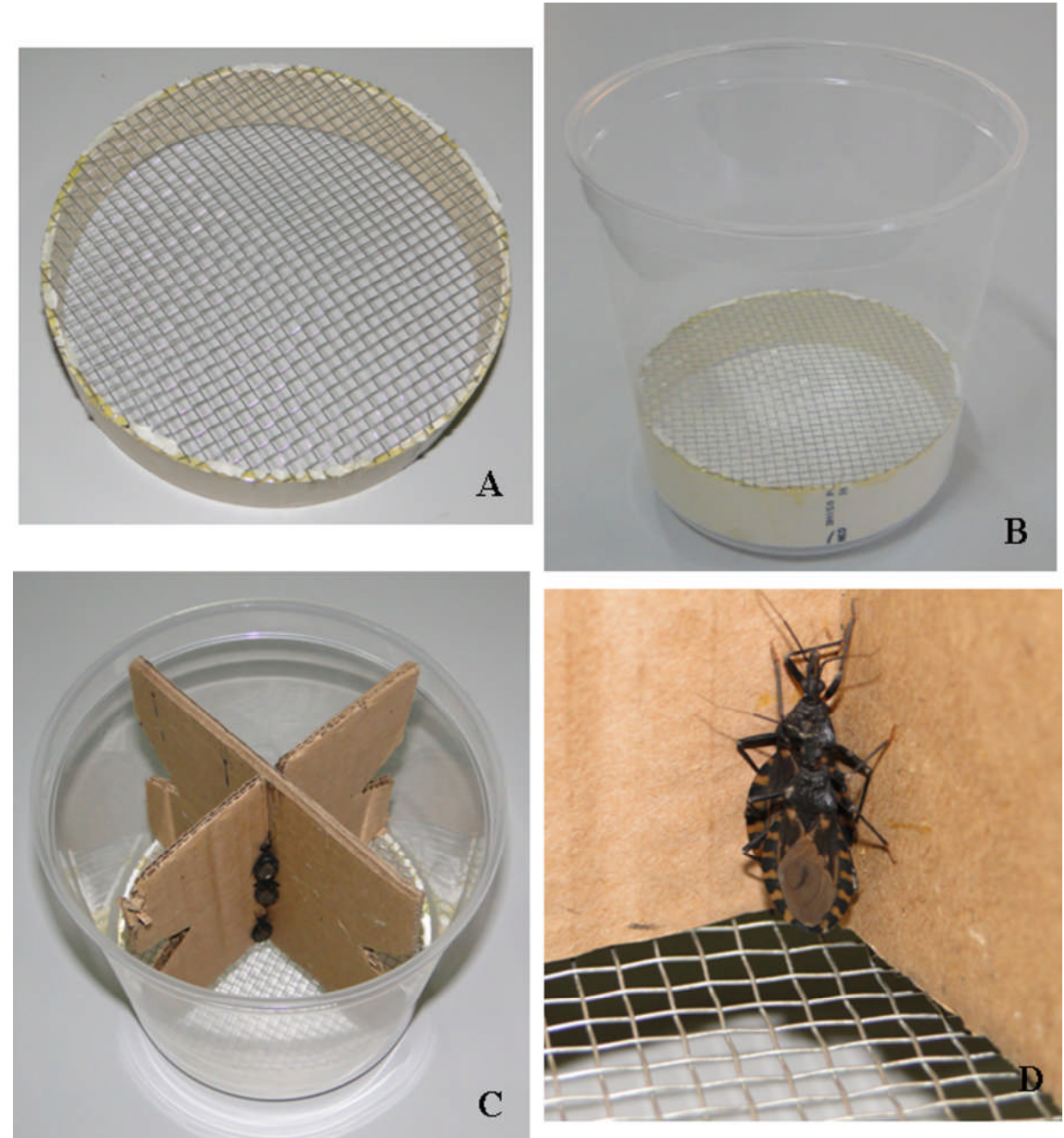

Figura 5 - Fotos do sistema de separação dos ovos. A: Suporte com malha de aço. B: Recipiente com suporte no fundo. C: Recipiente com papelão apoiado na superfície da tela. D: Orifícios da tela para passagem dos ovos. 


\subsection{INSETICIDA QUÍMICO E DILUENTE}

\subsubsection{Inseticida Grau Técnico}

A amostra de inseticida utilizado nos bioensaios foi o piretróide deltametrina $[(\mathrm{S})-\alpha-$ ciano -3 - fenoxibenzil $(1 \mathrm{R})-\mathrm{cis}-3-(2,2-$ dibromovinil $)-2,2$ dimetil ciclopropano carboxilato] com grau de pureza de 98,24\%, concedida pela Bayer® (Brasil) e a acetona P. A. $\left(\mathrm{CH}_{3}\right)_{2} \mathrm{CO}$, da VETEC®.

\subsubsection{Inseticida Comercial}

O inseticida utilizado para os bioensaios de campo foi o produto comercial DeltaGard® - WG 250 a 25\% da Bayer®, cuja composição química é (S)-alfa-cianom-fenoxibenzil-(1R, 3R)-3-(2,2-dibromovinil)-2,2-dimetil icloropropano carboxilato.

\subsection{PROCEDIMENTOS NO BIOENSAIO DAS AMOSTRAS}

\section{ESTUDADAS}

Neste estudo, os ensaios biológicos foram realizados conforme metodologias descritas pela Organização Mundial da Saúde (1994) e PICOLLO et al. (2005). Inicialmente, foram selecionadas três populações de referência, conforme critérios estabelecidos no item 4.1.1 deste trabalho.

Em seguida, o inseticida deltametrina, em pó, foi diluído em acetona (PA) para preparação da solução mãe. Nesta parte um total de 10,2 mg de deltametrina foi pesado em balança eletrônica de precisão automática AG 200 da GEHAKA ${ }^{\circledR}$. Após 
isso, foi acrescentado $10 \mathrm{~mL}$ de acetona, sendo misturada por agitador Vortex Genie, modelo K 550G, durante 1 minuto.

Em seguida, a solução mãe foi fracionada em seis concentrações iniciais que variaram entre 0,$30 ; 0,50 ; 0,75 ; 1,00 ; 1,50$ e $2,00 \mu \mathrm{g} / \mathrm{mL}$ para estimar a curva de dose de inseticida versus a mortalidade de insetos.

Feito isso, foram selecionadas, aleatoriamente, ninfas de $1^{\circ}$ estádio entre cinco a sete dias de idade, em jejum. Os ensaios biológicos consistiam na aplicação tópica de $0,2 \mu \mathrm{L}$ de solução de deltametrina no dorso do abdômen de ninfas utilizando microseringa de $10 \mu \mathrm{L}$, modelo $1701 \mathrm{~N}$ provida de dispensador com 50 repetições, modelo PB600-1, ambos da Halmilton ${ }^{\circledR}$. Nos insetos do grupo controle foi aplicado o mesmo volume de acetona.

Neste trabalho foram utilizadas, pelo menos cinco concentrações do piretróide deltametrina para estimar as taxas de mortalidade entre 0 e $100 \%$.

Para cada concentração foram utilizadas, pelo menos 20 ninfas, assim o número total de ninfas utilizadas era pelo menos 100 para cada população de campo.

Para os bioensaios dose resposta das populações de campo foi necessária a utilização de doses intermediárias de 0,$10 ; 1,75 ; 2,20 ; 2,50 ; 2,70 ; 3,00 ; 3,50 ; 4,00$; 4,70 e 5,00 $\mu \mathrm{g} / \mathrm{mL}$, a fim de aprimorar os resultados atingidos. Todos os ensaios foram repetidos pelo menos cinco vezes, em diferentes dias.

As doses iniciais e as intermediárias foram preparadas em tubos de microcentrifugação de $2 \mathrm{~mL}$ da Axygen ${ }^{\circledR}$ com auxílio de pipetas automáticas P1000, P200, P100 e P10 da Pipetman ${ }^{\circledR}$. 
A partir dos resultados da curva de mortalidade foram determinados os parâmetros estatísticos Dose Letal $50\left(\mathrm{DL}_{50}\right)$ que é a dose que deverá matar $50 \%$ da população analisada e a Dose Letal 95 (DL 95$)$ que irá matar 95\% da população.

As aplicações tópicas foram executadas por um único pesquisador sob microscópio estereoscópico LEICA ${ }^{\circledR}$ (ZOOM 2000), em aumento de 10,5X para aumentar a confiabilidade na distribuição do inseticida.

Os ensaios biológicos de material capturado em campo foram realizados com ninfas obtidas da primeira e segunda geração (F1 e F2).

Após a aplicação do inseticida, as ninfas foram transferidas para frascos plásticos pequenos $(220 \mathrm{~mL})$ com papel filtro no fundo e cobertos com tampa. Em seguida, foram mantidas em ambiente com temperatura e umidade controladas $\left(26^{\circ} \mathrm{C}\right.$ $\left.\pm 2^{\circ} \mathrm{C} ; 60 \% \pm 10 \% \mathrm{UR}\right)$.

A leitura de mortalidade foi realizada após 24 horas de exposição do inseticida por uma única pessoa. Nessa parte, as ninfas eram transferidas para o interior de placa de Petri com disco de papel filtro de $7 \mathrm{~cm}$ de diâmetro, no fundo. Ao mesmo tempo, as ninfas eram colocadas no centro do disco, sendo mecanicamente estimuladas por pinça entomológica de ponta fina. Após o estímulo, eram observadas por 50 segundos.

As ninfas que atingiram a borda do disco, no período de até 50 segundos, sem alteração nos movimentos de locomoção foram consideradas vivas (normais). Por outro lado, os insetos foram considerados mortos (intoxicados) quando não apresentaram atividade locomotora própria, ou seja, fortes sintomas de desequilíbrio ou totalmente incapazes de andar do centro até a borda de um disco de papel, quando 
estimulados com a ponta da pinça, durante esse mesmo período. Os dados de mortalidade foram registrados em fichas específicas (Anexo 6).

\subsection{ANÁLISE ESTATÍSTICA E CARTOGRÁFICA DOS DADOS}

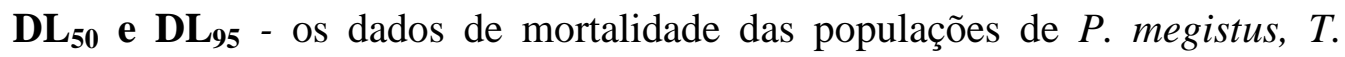
brasiliensis e $T$. sordida, obtidos nos bioensaios, foram utilizados para estimar a concentração que mata $50 \%\left(\mathrm{DL}_{50}\right)$ e $95 \%\left(\mathrm{DL}_{95}\right)$ das amostras estudadas. Nesta etapa do trabalho, o cálculo da $\mathrm{DL}_{50}$ e $\mathrm{DL}_{95}$ de cada população foi baseado na Análise de Probito (LITCHFIELD e WILCOXON, 1949) e foi realizado pelo programa Basic Probit Analysis.

Análise de Variância (ANOVA) - estimativas de variação das DL $_{50}$ e DL95 entre as populações foram comparadas pela técnica de Análise de Variância (ANOVA) e pelo teste de Tukey $(\mathrm{p}<0,01)$. Gráficos de diagramas de caixa, ilustrando diferenças nas médias, erros padrão e desvios padrão permitiram identificar populações diferentes, além de definir grupos de possíveis semelhanças.

Na Análise de Variância os resultados dos bioensaios foram testados quanto à hipótese de nulidade de que as estimativas de $\mathrm{DL}_{50}$ e $\mathrm{DL}_{95}$ de cada população eram iguais contra a hipótese alternativa de que pelo menos uma das médias de cada parâmetro era diferente, estabelecendo-se o nível de significância $\alpha=5 \%$, conforme as fórmulas a seguir: 


\begin{tabular}{llllll}
\hline $\begin{array}{l}\text { Fonte de } \\
\text { variação }\end{array}$ & Soma dos quadrados & $\begin{array}{l}\text { Graus de } \\
\text { liberdade }\end{array}$ & $\begin{array}{l}\text { Quadrado } \\
\text { médio }\end{array}$ & $F$ & $F_{\alpha}$ \\
\cline { 1 - 1 } $\begin{array}{l}\text { Entre } \\
\text { espécies }\end{array}$ & $S Q E=\sum_{i=1}^{k} \frac{T_{i}^{2}}{n}-\frac{T^{2}}{n k} k-1$ & $s_{\mathrm{E}}^{2}=\frac{S Q E}{k-1}$ & $F=\frac{s_{\mathrm{E}}^{2}}{s_{\mathrm{R}}^{2}}$ & $F_{k-1, k(n-1, \alpha)}$ \\
\cline { 1 - 2 } Residual & $S Q R=Q-\sum_{i=1}^{k} \frac{T_{i}^{2}}{n}$ & $k(n-1)$ & $S_{\mathrm{R}}^{2}=\frac{S Q R}{k(n-1)}$ & \\
\hline Total & $S Q T=Q-\frac{T^{2}}{n k}$ & $n k-1$ & & \\
\hline
\end{tabular}

Fonte: Costa Neto (2002)

Sendo:

$\mathrm{T} i=$ soma dos valores da $\mathrm{i}$ - ésima amostra;

$\mathrm{T}=$ soma total dos valores;

$\mathrm{Q}=$ soma total dos quadrados.

Teste de Tukey - para comparações múltiplas, visando localizar espécies ou grupos de espécies diferentes, usou-se o teste de Tukey que calcula os níveis de significância descritivos para diferenças entre pares sucessivos das médias estudadas. Valores de $\mathrm{p}$ menores ou iguais a $5 \%$ identificaram as diferenças existentes. $\mathrm{O}$ programa STATISTICA ${ }^{\circledR}$ foi utilizado para ambas às análises. As doses foram expressas em nanograma de ingrediente ativo por ninfa tratada (ng/inseto).

Razão de Resistência (RR) - foi obtida por meio do quociente da $\mathrm{DL}_{50}$ da população de campo pela $\mathrm{DL}_{50}$ da linhagem susceptível. Quanto maior a Razão de Resistência, maior foi a magnitude da resistência, ou seja, a RR indica a quantidade de vezes que a população de campo é mais resistente que a população de referência.

O cálculo da $\mathrm{RR}_{95}$ seguiu o mesmo procedimento. As $\mathrm{RR}_{50}, \mathrm{RR}_{95}$ e o Intervalo de Confiança de $95 \%$ foram calculados e comparados com a cepa de referência usando o programa POLO PC (LeOra software, 1987). 
Coeficiente angular - nessa análise também foi possível definir o coeficiente angular da curva dose resposta, também conhecido como "Slope". Esse parâmetro representa a homogeneidade da população. Os menores valores do coeficiente angular indicam populações menos homogêneas, conseqüentemente, sugerem maior variabilidade genotípica. A elevada variação genética de uma determinada população pode aumentar a "probabilidade" de seleção de indivíduos que "carregam" os alelos de resistência, quando pressionados com inseticidas. Por outro lado, os maiores coeficientes angulares podem sugerir menor variação genotípica na resposta da população ao inseticida.

Para cada população foi possível estimar e comparar as variações genotípicas e a progressão de resistência utilizando os padrões de inclinação da reta no gráfico, baseado no coeficiente angular.

O cálculo da inclinação da reta no gráfico foi realizado com auxílio do GRAPH PAD Prism $^{\circledR}$ versão 4.0 (Graph Pad software INC, San Diego, CA).

Análise Cartográfica - para a ilustração dos municípios monitorados foram obtidas malhas digitais das bases cartográficas do Instituto Brasileiro de Geografia e Estatística (IBGE), sendo que a escala utilizado foi de 1:1.000.000. Nessa etapa o software utilizado para o geoprocessamento foi o ArcView GIS 3.2 (ERI, 2004) e para a confecção dos cartogramas o software utilizado foi ArcMap 9.2. 


\subsection{REPRESENTAÇÕES DAS DIFERENTES POPULAÇÕES}

\section{MONITORADAS}

As diferentes populações de T. brasiliensis, T. sordida e P. megistus foram representadas por siglas para proporcionar um melhor entendimento e interpretação dos resultados. A codificação foi realizada, de acordo com a seguinte orientação: iniciais do nome da espécie estudada (Triatoma brasiliensis: Tb) seguida do Estado procedente (Piauí: PI), depois a primeira letra maiúscula do nome do município acrescida da segunda letra em minúscula (Oeiras: Oe). Por fim, a inicial maiúscula da primeira localidade de captura (Sapé: S). As populações selecionadas como cepa de referência receberam terminações "REF", após as primeiras iniciais do nome da espécie.

As Tabelas 2, 3 e 4 destacam as diferentes procedências das amostras estudadas, assim como as abreviações de cada população, incluindo a linhagem suscetível.

Tabela 2 - Codificação das populações de Panstrongylus megistus. A amostra do Estado da Bahia foi utilizada como linhagem suscetível para os bioensaios dose resposta.

\begin{tabular}{llcc}
\hline Estado & Município & Localidade & Sigla \\
\hline Bahia & Sento Sé & Pov. Quixadá & PmREF \\
Paraná & Serranópolis do Iguaçu & $\ldots$ & PmPRSIg \\
\hline
\end{tabular}

Nota: Pov.: Povoado. 
Tabela 3 - Codificação das populações de Triatoma brasiliensis procedentes de diferentes Estados e Municípios do Brasil, em 2010.

\begin{tabular}{lllc}
\hline Estado & Município & Localidade & Sigla \\
\hline Ceará & Umari & $\ldots$ & TbREF \\
Paraíba & Itaporanga & F. Vaca Morta & TbPBItV \\
Paraíba & Mãe d' Água & F. Cacimba de Pedra & TbPBMAgC \\
Paraíba & Monteiro & F. Olho d' Água das Dores & TbPBMoO \\
Paraíba & Piancó & S. Junco de Cima & TbPBPiJ \\
Paraíba & Santa Cruz & S. Goiabeira & TbPBSCrG \\
Paraíba & São Francisco & S. São Luiz & TbPBSFrS \\
Paraíba & São José de Espinharas & F. Laranjeiras & TbPBSJEsL \\
Pernambuco & Lagoa Grande & F. Morada Nova & TbPELGrM \\
Pernambuco & Petrolina & F. Lagoas e Pov. Capim & TbPEPeL \\
Pernambuco & Salgueiro & S. Santana e Quixabeiras & TbPESaS \\
Pernambuco & Serra Talhada & F. Jardim e Nova & TbPESTaJ \\
Piauí & Oeiras & S. Pau de Chapada & TbPIOeP \\
Piauí & Oeiras & S. Tabocas & TbPIOeT \\
Piauí & Oeiras & S. Formosa II & TbPIOeF \\
Piauí & Oeiras & S. Sapé & TbPIOeS \\
Rio Grande do Norte & Caicó & S. Pedra do Sino e F. Laginha & TbRNCaP \\
\hline
\end{tabular}

Notas: F.: Fazenda e S.: Sítio. 
Tabela 4 - Codificação das populações de Triatoma sordida procedentes de diferentes Estados e Municípios do Brasil, em 2010.

\begin{tabular}{|c|c|c|c|}
\hline Estado & Município & Localidade & Sigla \\
\hline Bahia & Cordeiros & $\ldots$ & TsREF \\
\hline Bahia & Cafarnaum & Pov. Boa Vista do Canal & TsBACafB \\
\hline Bahia & Carinhanha & F. Micaela & TsBACarM \\
\hline Bahia & Malhada & F. Serra do João Alves & TsBAMaS \\
\hline Bahia & Mucugê & F. Bonfim e Lage & TsBAMuB \\
\hline Bahia & Nova Redenção & F. Alto Verde & TsBANReA \\
\hline Bahia & Palmeiras & F. Rio Preto e P. Pecuária & TsBAPaR \\
\hline Bahia & Rio de Contas & F. Boa Vista & TsBARCoB \\
\hline Bahia & Xique Xique & A. Roçado I e Gado Bravo & TsBAXXiR \\
\hline Goiás & Firminópolis & Pov. Córrego Seco e Diamantina & TsGOFiC \\
\hline Goiás & Guarani do Goiás & F. Samambaia e Barreirão & TsGOGGoS \\
\hline Goiás & Posse & F. Emburana & TsGOPoE \\
\hline Goiás & São Luis Montes Belos & F. Empedrado I & TsGOSLMBeE \\
\hline Mato Grosso & Poxoréo & F. Modelo e S. Santa Fé & TsMTPoM \\
\hline Mato Grosso & São José do Povo & S. Serrinha e Cascata & TsMTSJPoS \\
\hline Mato Grosso do Sul & Campo Grande & Pov. Aguão & TsMSCGrA \\
\hline Mato Grosso do Sul & Aparecida do Taboado & F. José Rodrigues & TsMSATaJ \\
\hline Mato Grosso do Sul & Douradina & S. Maria Curadeira & TsMSDoM \\
\hline Mato Grosso do Sul & Rochedo & F. Estância Ermelinda & TsMSRoE \\
\hline Mato Grosso do Sul & Terenos & Pov. Colônia Velha & TsMSTeC \\
\hline Minas Gerais & Lontra & Pov. Rodeador & TsMGLoR \\
\hline Tocantins & Aurora do Tocantins & F. Mucambo e Veneranda & TsTOAToM \\
\hline
\end{tabular}

Notas: A.: Assentamento; F.: Fazenda; Pov.: Povoado e S.: Sítio. 
4.8 PROCEDIMENTOS DE MICROSCOPIA ELETRÔNICA DE VARREDURA PARA ESTRUTURA CUTICULAR DE NINFAS DE $1^{\circ}$ ESTÁDIO

Neste processo foram selecionadas cinco ninfas de $1^{\circ}$ estádio com cinco a sete dias de idade, sem alimentação. As ninfas pertenciam à linhagem suscetível de $P$. megistus, $T$. brasiliensis e $T$. sordida. A ausência de contato com inseticidas foi o critério para seleção dessas populações.

Aplicação tópica de $0,2 \mu \mathrm{l}$ de deltametrina, diluído em acetona, foi realizada na superfície dorsal das ninfas sob microscópio estereoscópico com luz artificial. As concentrações da $\mathrm{DL}_{99}$ foram de $4,36 \mu \mathrm{g} /$ inseto para $P$. megistus, 2,24 $\mu \mathrm{g}$ /inseto para $T$. brasiliensis e 1,91 $\mu \mathrm{g}$ /inseto para $T$. sordida (Anexo 1, $2 \mathrm{e}$ $3)$.

Ainda, doses maiores de $10 \mu \mathrm{g}$ /inseto e $30 \mu \mathrm{g} /$ inseto também foram aplicadas para verificar deposição de partículas de inseticidas e/ou alterações físicas. Na população controle foi aplicado apenas acetona.

Após a exposição, as ninfas foram transferidas para placas de Petri, onde permaneceram por três horas para evaporação do solvente. Feito isso as ninfas mortas foram aderidas por meio de esmalte de unha (incolor) em toros de alumínio medindo $10 \mathrm{~mm}$ de diâmetro e $5 \mathrm{~mm}$ de altura, para metalização com ouro carbono em metalizador Sputter Coater SCD 050 da BAL-TEC, por 2,0 min. As ninfas utilizadas como controle foram sacrificadas no interior de frasco de vidro contendo algodão embebido em clorofórmio. 
Após a metalização, as amostras foram examinadas e fotografadas em Microscópio Eletrônico de Varredura Topcon® SM -300.

As fotografias sempre foram executadas na mesma região da superfície do tórax (região à direita da área mediana do abdômen).

Os aumentos adotados para detecção de partículas de inseticida e detalhes da superfície da cutícula foram estabelecidos em: 50X na caracterização do aspecto geral do abdômen, como também de seu tamanho aproximado; 300X na observação do aspecto da superfície dorsal e de seus elementos; 500X na formação de detalhes da estrutura do exoesqueleto e 1500X para a visualização partículas de inseticidas.

Finalmente, depois de selecionadas e tratadas com "software" de imagens, foram descritas e comparadas qualitativamente, como demonstram os resultados obtidos. 


\subsection{BIOENSAIOS DE CAMPO COM POPULAÇÕES DE $T$.}

\section{brasiliensis}

Os bioensaios de campo foram realizados, somente com populações de $T$. brasiliensis, devido principalmente a pouca quantidade de exemplares fêmeas de $P$. megistus e $T$. sordida que não permitiram a produção suficiente de ninfas de $1^{\circ}$ estádio para a exposição em diferentes paredes.

Para a padronização dos bioensaios de campo foram construídas: a) três paredes de barro (taipa), b) três de tijolos sem reboco e c) três de madeira sem pintura (Fig. 6).

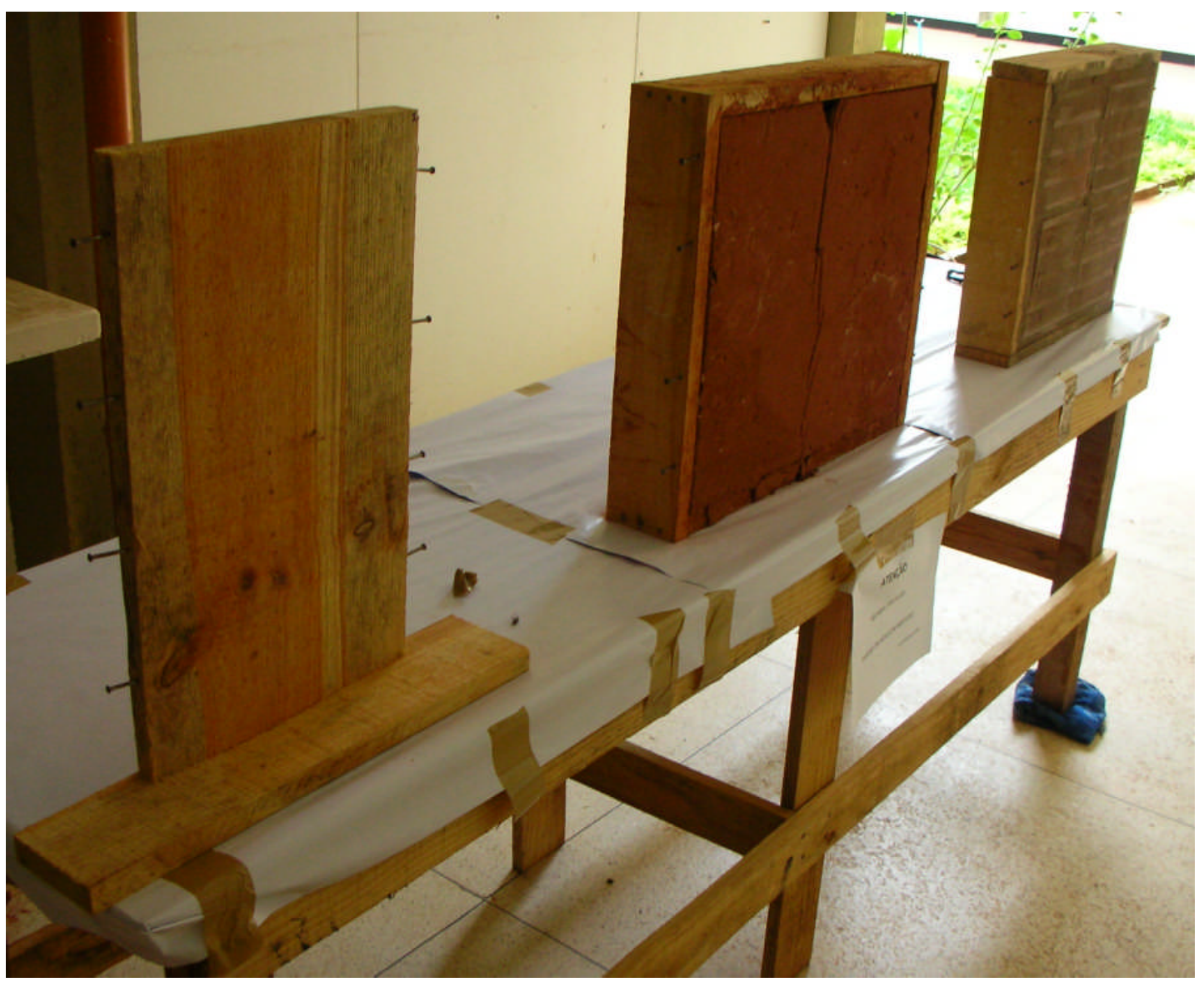

Figura 6 - Foto da parede de madeira, barro e tijolo utilizados nos bioensaios de campo. 
Para a construção das paredes de barro foram feitos moldes de tábuas com 50 $\mathrm{cm}$ de comprimento por $50 \mathrm{~cm}$ de altura e $10 \mathrm{~cm}$ de largura. No interior dos moldes eram sobrepostos, primeiramente, uma camada de barro seguida de pedaços de bambu e outra camada de barro. Feito isso, foram deixados ao sol, durante quinze dias para secagem e reprodução das condições do ambiente.

Para a confecção dos moldes das paredes de tijolos foram utilizadas as mesmas medidas das de barro. Quatro unidades de tijolos, aderidas por meio de cimento, foram utilizadas para construção de cada parede de tijolo.

Para as paredes de madeira foi feito construção de tábuas com $50 \mathrm{~cm}$ de altura por $30 \mathrm{~cm}$ de comprimento, sendo sustentadas por meio de base fixa de mesmo material.

Em seguida, cada parede foi alinhada sobre uma mesa, com uma distância superior a $30 \mathrm{~cm}$ entre elas, para não haver sobreposição da faixa de inseticida durante a aplicação.

O tratamento residual foi realizado em todas as paredes utilizando-se bomba Hudson - X - Pert com capacidade de dez litros. Antes de cada aplicação, a bomba foi calibrada, conforme a metodologia descrita pela Organização Mundial da Saúde (2006). Depois da calibração, uma parede seca foi tratada distante do local dos testes para verificar se a bomba seguia um padrão constante de liberação do produto, ou seja, sem irregularidades.

O produto manufaturado foi dissolvido primeiramente em uma proveta e, logo em seguida, colocado na bomba. Cada sachê de 5 g contém $25 \%$ de principio ativo, sendo que para cada aplicação foi preparada uma nova carga do produto. 
O mesmo ritmo de trabalho realizado pelos antigos "guardas" da SUCAM foi empregado, a fim de garantir que o bico Teejet 8002 liberasse uma descarga média, de aproximadamente $760 \mathrm{ml} / \mathrm{min}$., à pressão de 55 psi (3,8 bar).

Nessas condições, todas as superfícies receberam, de maneira uniforme, $25 \mathrm{mg}$ i.a. $/ \mathrm{m}^{2}$, dispersados em faixas verticais de $75 \mathrm{~cm}$ de largura. A largura da faixa foi assegurada mantendo-se $45 \mathrm{~cm}$ de distância da superfície da parede tratada.

Após isso, foram selecionadas três populações de triatomíneos procedentes do município de Oeiras, no Estado do Piauí. A primeira população de T. brasiliensis foi capturada no Sítio Tabocas (TbPIOeT). A segunda população foi capturada no Sítio Formosa II (TbPIOeF) e terceira população foi oriunda do Sítio Sapé (TbPIOeS).

Para avaliar a ação do inseticida foram utilizadas 30 ninfas em cada parede, totalizando 120 ninfas expostas, nas diferentes superfícies tratadas com inseticida. Foram realizados quatro bioensaios de campo em dias independentes.

Cada população foi exposta em cones de plásticos desenvolvidos para avaliação de suscetibilidade de mosquitos em paredes segundo parâmetros definidos pela Organização Mundial de Saúde (Fig. 7).

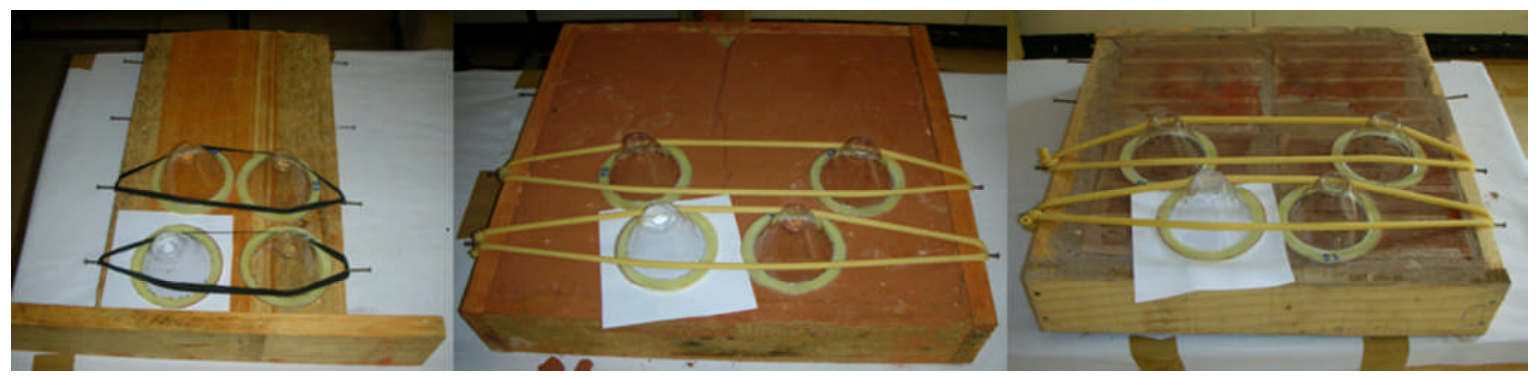

Figura 7 - Cones de plásticos utilizados para exposição de ninfas de $1^{\circ}$ estádio em paredes de madeira, barro e tijolo tratadas com deltametrina. 
As provas foram realizadas com ninfas de $1^{\circ}$ estádio, em jejum, com cinco a sete dias de idade. Foram utilizadas ninfas de $1^{\circ}$ estádio para aumentar a sensibilidade dos bioensaios.

O período de exposição foi de uma hora. As ninfas vivas foram retiradas por meio de capturador de Castro (CONSOLI e LOURENÇO de OLIVEIRA, 1994) e acondicionadas em potes plásticos pequenos, previamente, identificados. A leitura de mortalidade foi realizada 24 h e 72 h após a exposição. Os dados de mortalidade foram registrados em fichas específicas (Anexo 7).

Para cada teste, foi utilizado um grupo controle, com cerca de 30 ninfas manipuladas e expostas da mesma forma; porém, entre o cone e a parede havia um pedaço de cartolina de papel que impedia o contato das ninfas com as superfícies tratadas. 


\section{RESULTADOS}

Os resultados obtidos estão apresentados em três partes. A primeira contém a da estimação da linha-básica de suscetibilidade e as comparações das diferentes populações de campo (cap. 5.1), seguido das descrições da estrutura cuticular das ninfas de $1^{\circ}$ estádio em MEV (cap. 5.2) e finalmente dos bioensaios de parede com a espécie T. brasiliensis (cap. 5.3).

$\mathrm{Na}$ primeira parte foram estimadas e comparadas as $\mathrm{DL}_{50}, \mathrm{DL}_{95}$ e o coeficiente angular da linhagem suscetível com as diferentes populações de campo. Ainda, as $\mathrm{RR}_{50}$ e $\mathrm{RR}_{95}$ foram avaliadas para quantificar o nível de resistência à deltametrina nas espécies recebidas.

Na segunda parte estão descritos as observações das ninfas tratadas com diferentes concentrações de deltametrina em MEV. Por fim, foram averiguadas por meio bioensaios de campo, o perfil de suscetibilidade de três populações de $T$. brasiliensis que apresentaram as maiores Razões de Resistência nos bioensaios de laboratório. Muito embora o monitoramento de resistência a deltametrina tenha sido proposto para $P$. megistus, $T$. brasiliensis e $T$. sordida, foi possível estudar, quanto aos ensaios de campo, apenas algumas populações de T. brasiliensis, devido ao número insuficiente de ninfas de $1^{\circ}$ estádio de $P$. megistus e $T$. sordida. 


\subsection{ESTIMAÇÃO DA LINHA-BÁSICA DE SUSCETIBILIDADE E COMPARAÇÕES DAS DIFERENTES POPULAÇÕES DE CAMPO}

No biênio 2008-2009, diferentes populações de triatomíneos procedentes de 35 municípios do país foram avaliadas quanto ao perfil de resistência a deltametrina. O trabalho consistiu, inicialmente, na exposição de ninfas de $1^{\circ}$ estádio a cinco ou seis doses que produziram mortalidade entre 0 a 100\% dos exemplares. Esses ensaios foram do tipo dose-resposta, que objetivaram quantificar a resistência nas populações estudadas.

Na primeira etapa foi obtida a medida de dose que causou $50 \%\left(\mathrm{DL}_{50}\right)$ e $95 \%$ (DL 95$)$ de mortalidade na população de referência. Em seguida, também foram estimadas uma medida de dose $\mathrm{DL}_{50}$ e $\mathrm{DL}_{95}$ para cada população de campo.

Na segunda etapa, os valores da $\mathrm{DL}_{50}$ e $\mathrm{DL}_{95}$ foram utilizados para determinar as diferentes Razões de Resistências $\left(\mathrm{RR}_{50}\right.$ e $\left.\mathrm{RR}_{95}\right)$. Os valores da $\mathrm{RR}_{50}$ e $\mathrm{RR}_{95}$ foram considerados significantemente diferentes quando não houve sobreposição dos limites dos intervalos de confiança, no nível de $95 \%$ da população de referência com as amostras de campo.

Para um melhor entendimento sobre a diferença entre os valores da $R_{50} \mathrm{e}$ $\mathrm{RR}_{95}$, a Tab. 5, mostra uma situação sobre os resultados de monitoramento de resistência de $T$. sordida com três populações A, B e C. A população A foi utilizada como população de referência, cujo valor dos limites do intervalo de confiança de $95 \%$ variou entre 0,90 a 1,10 para a $\mathrm{RR}_{50}$. 
Tabela 5 - Resultados de monitoramento de resistência de populações de Triatoma sordida.

\begin{tabular}{|c|c|c|c|c|c|c|}
\hline População & $\mathbf{N}$ & Slope & DL $_{50}$ ng/inseto (95\% IC) & DL $_{95}$ ng/inseto (95\% IC) & $\mathbf{R R}_{50}(95 \% \mathrm{IC})$ & $\mathrm{RR}_{95}(95 \% \mathrm{IC})$ \\
\hline $\bar{A}$ & 800 & $4,51 \pm 0,34$ & $0,58(0,54-0,63)$ & $1,35(1,20-1,57)$ & $1,00(\mathbf{0 , 9 0}-\mathbf{1 , 1 0})$ & $1,00(0,82-1,20)$ \\
\hline B & 700 & $3,15 \pm 0,35$ & $0,78(0,70-0,86)$ & $2,60(2,09-3,61)$ & $1,33(\mathbf{1 , 1 7}-\mathbf{1}, \mathbf{5 1})$ & $1,91(1,42-2,57)$ \\
\hline $\mathrm{C}$ & 900 & $3,28 \pm 0,24$ & $1,46(1,33-1,58)$ & $4,62(4,00-5,56)$ & $2,49(\mathbf{2 , 2 3}-\mathbf{2}, \mathbf{7 8})$ & $3,41(2,76-4,21)$ \\
\hline
\end{tabular}

$A R_{50}$ da população $A$ é estatisticamente diferente da população $B$, uma vez que não houve sobreposição dos limites do IC95\%. Na população B o valor dos limites do intervalo de confiança de $95 \%$ variou entre 1,17 a 1,51.

A população $C$, em relação à $R_{50}$, também apresenta diferença estatisticamente significativa com a população A e B, devido a não sobreposição dos limites do intervalo de confiança de 95\%. O valor dos limites do IC95\% variou entre 2,23 a 2,78 na população $\mathrm{C}$.

Por fim, para cada população foram estimadas as variações do coeficiente angular que proporcionaram diferentes padrões de inclinações da reta no gráfico. Espera-se que nas populações que apresentaram menores valores de coeficiente angular, maior será a probabilidade de seleção de indivíduos que carregam alelos que conferem resistência. 
5.1.1 Comparação da suscetibilidade de ninfas de $1^{\circ}$ estádio de $P$. megistus a deltametrina

A suscetibilidade para deltametrina da linhagem de referência (PmREF) de Sento Sé/BA foi determinada e comparada com a população de campo de Serranópolis do Iguaçu/PR (PmPRSIg). Obteve-se um valor de $\mathrm{DL}_{50}$ de 1,02 ng/inseto para a linhagem de referência e 2,01 ng/inseto para a população de campo (Tab. 6).

Apesar da diferença estatisticamente significativa entre os valores de $\mathrm{DL}_{50}$ (teste $\mathrm{t}=-6,44 ; \mathrm{p}<0,01)$ da linhagem de referência PmREF e a população do município de Serranópolis do Iguaçu (PmPRSIg) (Fig. 8), os resultados indicaram, pela primeira vez, baixos níveis de resistência para deltametrina. Os valores da $\mathrm{RR}_{50}$ e $\mathrm{RR}_{95}$ para a população de Serranópolis do Iguaçu (PmPRSIg) foram de 1,97 e 1,19, respectivamente.

O coeficiente angular da população PmPRSIg com valor de 7,20 indicou ser a população de maior homogeneidade, em comparação a população de referência (PmREF) e as demais populações (Fig. 9, Tabs. 6, 7 e 9). Esse valor sugere que essa população apresenta pequena variabilidade genética e reduzidas chances de modificar sua RR em curto prazo.

Em resumo, os valores de $\mathrm{RR}_{50}$ e $\mathrm{RR}_{95}$ obtidos neste trabalho para P. megistus indicaram a necessidade de prosseguir o monitoramento de resistência para acompanhamento dos níveis resistência, conforme critérios estabelecidos pela Organização Pan-Americana de Saúde (2005b). Conforme esses critérios, valores de 
RR menores que cinco devem dar seguimento, não só ao monitoramento, como também às ações de controle utilizando o mesmo composto químico.

Ressalta-se que as populações de $P$. megistus procedentes dos municípios de Cafelândia/SP, Caconde/SP, Divinolândia/SP, Castro Alves/BA e Vicente Pires/DF não foram analisadas devido a pouca quantidade de material recebido, principalmente em relação ao número de exemplares fêmea que impossibilitaram a geração de ninfas F1 em número suficiente para o monitoramento. 
Tabela 6 - Distribuição do número de exemplares testados por amostra, slope, $\mathrm{DL}_{50}, \mathrm{DL}_{95}, \mathrm{RR}_{50}$ e $\mathrm{RR}_{95}$ de populações de Panstrongylus megistus tratadas com aplicação tópica de $0,2 \mu \mathrm{l}$ de deltametrina, na superfície dorsal do abdômen de ninfas de $1^{\circ}$ estádio capturadas, no Brasil, em 2008.

\begin{tabular}{ccccccc}
\hline População & N & Slope \pm DP & DL $_{\mathbf{5 0}}$ ng/inseto (95\% IC) & DL $_{\mathbf{9 5}}$ ng/inseto (95\% IC) & RR $_{\mathbf{5 0}}(\mathbf{9 5 \%}$ IC) & RR $_{\mathbf{9 5}}(\mathbf{9 5 \%}$ IC) \\
\hline PmREF & 800 & $3,70 \pm 0,31$ & $1,02(0,95-1,11)$ & $2,85(2,42-3,57)$ & $1,00(0,89-1,11)$ & $1,00(0,76-1,30)$ \\
PmPRSIg & 560 & $7,20 \pm 0,68$ & $2,01(1,90-2,13)$ & $3,41(3,11-3,87)$ & $1,97(1,77-2,15)$ & $1,19(0,95-1,48)$ \\
\hline
\end{tabular}

Notas:

PmREF - População de Referência

DL - Dose Letal em nanogramas por inseto

95\% IC - Intervalo de Confiança 95\%

RR - Razão de Resistência

DP - Desvio Padrão 


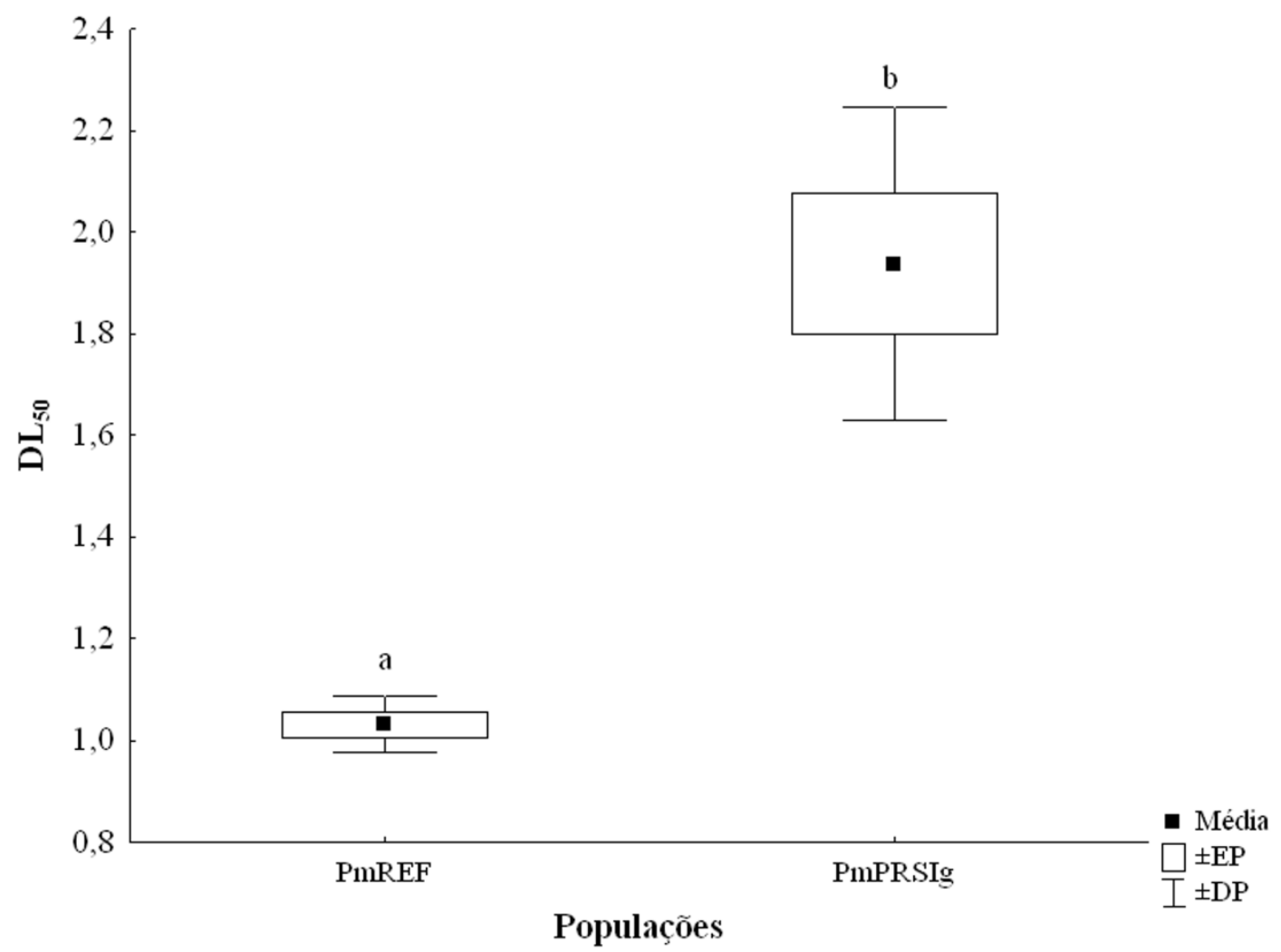

Figura 8 - Resultado da $\mathrm{DL}_{50}$ em duas populações de Panstrongylus megistus. As letras indicam populações estatisticamente diferentes $(\mathrm{p}<0,01)$. 


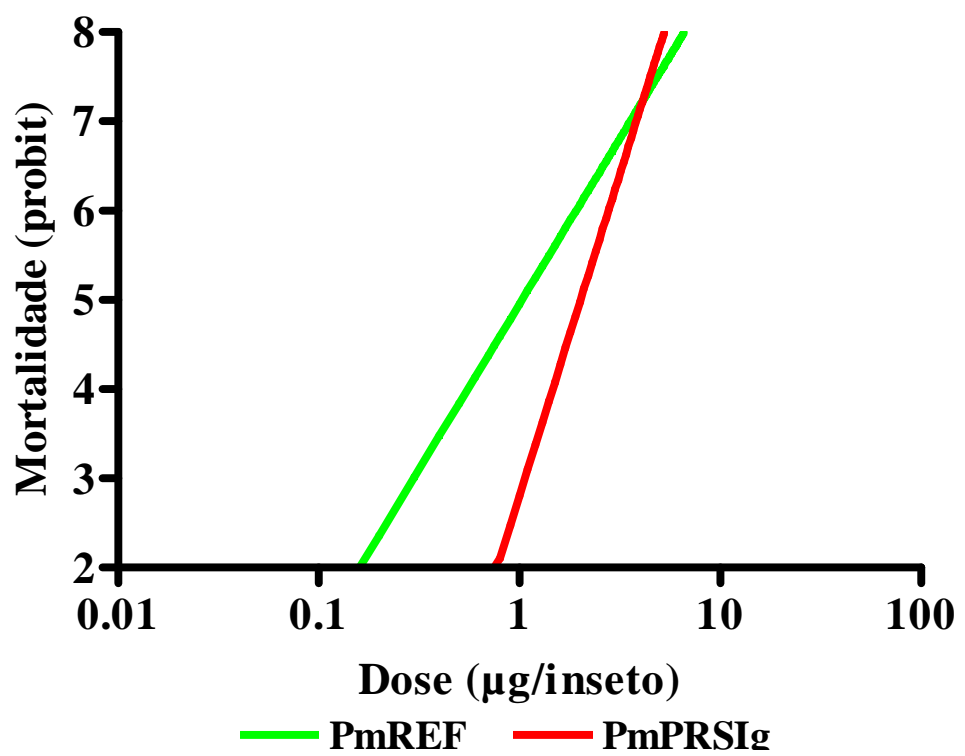

Figura 9 - Curva de mortalidade dose resposta, em escala logarítmica, comparando o coeficiente angular de PmREF $(3,70)$ e PmPRSIg $(7,20)$. 
5.1.2 Comparação da suscetibilidade de ninfas de $1^{\circ}$ estádio de $T$. brasiliensis a deltametrina

Com relação ao estabelecimento da linha básica de suscetibilidade para a linhagem de referência (TbREF) de Umari/CE, os valores estimados foram de 0,68 ng/inseto para a $\mathrm{DL}_{50}$ e $1,58 \mathrm{ng} /$ inseto para $\mathrm{DL}_{95}$. O valor do coeficiente angular da população de referência foi de 4,51 (Tab. 7).

Os valores de $\mathrm{DL}_{50}$ das diferentes populações de campo variaram de 0,68 ng/inseto a 1,48 ng/inseto. O menor valor correspondeu a população do município de Itaporanga (TbPBItV) e o maior valor a população do município de Oeiras, particularmente do Sítio Sapé (TbPIOeS) (Tab. 7). A população do município de Itaporanga (TbPBItV) apresentou um valor de $\mathrm{DL}_{50}$ igual a 0,68 ng/inseto, semelhantemente, a população de referência TbREF.

Os resultados estimados para $\mathrm{DL}_{50}$ e $\mathrm{DL}_{95}$ das diferentes populações de campo, a partir da exposição de ninfas de $1^{\circ}$ estádio a deltametrina podem ser visualizados na Tab. 7 . 
Tabela 7 - Distribuição do número de exemplares testados por amostra, slope, $\mathrm{DL}_{50}, \mathrm{DL}_{95}, \mathrm{RR}_{50}$ e $\mathrm{RR}_{95}$ de populações de Triatoma brasiliensis tratadas com aplicação tópica de $0,2 \mu \mathrm{l}$ de deltametrina, na superfície dorsal do abdômen de ninfas de $1^{\circ}$ estádio capturadas em dezesseis localidades do Brasil, em 2008.

\begin{tabular}{|c|c|c|c|c|c|c|}
\hline População & $\mathbf{N}$ & Slope \pm DP & DL $_{50}$ ng/inseto (95\% IC) & DL $_{95}$ ng/inseto (95\% IC) & $\mathrm{RR}_{50}(95 \% \mathrm{IC})$ & $\mathrm{RR}_{95}(95 \% \mathrm{IC})$ \\
\hline TbREF & 910 & $4,51 \pm 0,37$ & $0,68(0,64-0,73)$ & $1,58(1,37-1,91)$ & $1,00(0,91-1,09)$ & $1,00(0,79-1,26)$ \\
\hline TbPBItV & 770 & $3,52 \pm 0,47$ & $0,68(0,57-0,78)$ & $2,01(1,72-2,59)$ & $1,00(0,85-1,18)$ & $1,27(0,99-1,63)$ \\
\hline TbPBSJEsL & 700 & $4,74 \pm 0.46$ & $0.73(0,67-0,78)$ & $1,62(1,42-1,94)$ & $1,06(0,96-1,17)$ & $1,02(0,82-1,27)$ \\
\hline TbPBSFrS & 700 & $4,83 \pm 0,46$ & $0,74(0,69-0,79)$ & $1,63(1,44-1,95)$ & $1,09(0,99-1,20)$ & $1,03(0,82-1,28)$ \\
\hline TbPESaS & 700 & $3,24 \pm 0,26$ & $0,77(0,69-0,84)$ & $2,49(2,14-3,04)$ & $1,13(1,00-1,27)$ & $1,57(1,23-1,99)$ \\
\hline TbPEPeL & 900 & $3,21 \pm 0,26$ & $0,79(0,71-0,86)$ & $2,58(2,22-3,16)$ & $1,16(1,03-1,30)$ & $1,63(1,28-2,07)$ \\
\hline TbPBPiJ & 400 & $2,96 \pm 0.38$ & $0,81(0,69-0,93)$ & $2,94(2,28-4,39)$ & $1,19(1,01-1,40)$ & $1,85(1,30-2,63)$ \\
\hline TbPBMoO & 700 & $4,59 \pm 0,43$ & $0,82(0,76-0,88)$ & $1,88(1,62-2,30)$ & $1,20(1,09-1,32)$ & $1,18(0,93-1,49)$ \\
\hline TbPBMAgC & 700 & $3,29 \pm 0,31$ & $0,83(0,75-0,90)$ & $2,62(2,20-3,36)$ & $1,21(1,08-1,36)$ & $1,65(1,27-2,16)$ \\
\hline TbRNCaP & 800 & $3,17 \pm 0.23$ & $0,85(0.76-0.93)$ & $2,80(2,44-3,34)$ & $1,24(1,09-1,40)$ & $1,77(1,41-2,22)$ \\
\hline TbPESTaJ & 900 & $3,39 \pm 0,38$ & $0,85(0,77-0,95)$ & $2,61(2,06-3,75)$ & $1,25(1,11-1,41)$ & $1,65(1,19-2,28)$ \\
\hline TbPBSCrG & 700 & $3,49 \pm 0,26$ & $0,97(0,89-1,04)$ & $2,86(2,48-3,45)$ & $1,41(1,27-1,57)$ & $1,80(1,43-2,28)$ \\
\hline TbPELGrM & 800 & $3,36 \pm 0,32$ & $1,10(0,99-1,22)$ & $3,41(2,85-4,39)$ & $1,61(1,43-1,82)$ & $2,15(1,64-2,81)$ \\
\hline TbPIOeP & 900 & $2,82 \pm 0,20$ & $1,12(1,01-1,23)$ & $4,30(3,61-5,40)$ & $1,66(1,47-1,87)$ & $2,85(2,19-3,71)$ \\
\hline TbPIOeT & 900 & $2,83 \pm 0,21$ & $1,20(1,08-1,32)$ & $4,56(3,84-5,71)$ & $1,75(1,55-1,98)$ & $2,88(2,23-3,72)$ \\
\hline TbPIOeF & 900 & $2,74 \pm 0,19$ & $1,33(1,20-1,46)$ & $5,29(4,38-6,74)$ & $1,94(1,73-2,19)$ & $3,43(2,55-4,38)$ \\
\hline TbPIOeS & 1100 & $3,70 \pm 0,29$ & $1,48(1,38-1,61)$ & $4,13(3,51-5,14)$ & $2,17(1,96-2,40)$ & $2,61(2,03-3,35)$ \\
\hline
\end{tabular}

Notas:

TbREF - População de Referência

DL - Dose Letal em nanogramas por inseto

95\% IC - Intervalo de Confiança 95\%

RR - Razão de Resistência

DP - Desvio Padrão 
Os resultados das análises estatísticas indicaram que houve diferença significativa entre as $\mathrm{DL}_{50}\left(\mathrm{ANOVA} \mathrm{F}_{16,74}=18,1 ; \mathrm{p}<0.01\right)$ e as $\mathrm{DL}_{95}\left(\mathrm{ANOVA} \mathrm{F}_{16,74}\right.$ $=19,9 ; \mathrm{p}<0.01)$ das populações estudadas.

A linhagem de referência TbREF apresentou diferença estatisticamente significativa em relação a $\mathrm{DL}_{50}$ para as populações dos municípios de Santa Cruz (TbPBSCrG), Lagoa Grande (TbPELGrM), Serra Talhada (TbPESTaJ), Oeiras, Sítio Pau de Chapada (TbPIOeP), Oeiras, Sítio Tabocas (TbPIOeT), Oeiras, Sítio Formosa II (TbPIOeF), Oeiras, Sítio Sapé (TbPIOeS) e Caicó/RN (TbRNCaP), como mostra a Fig. 10 .

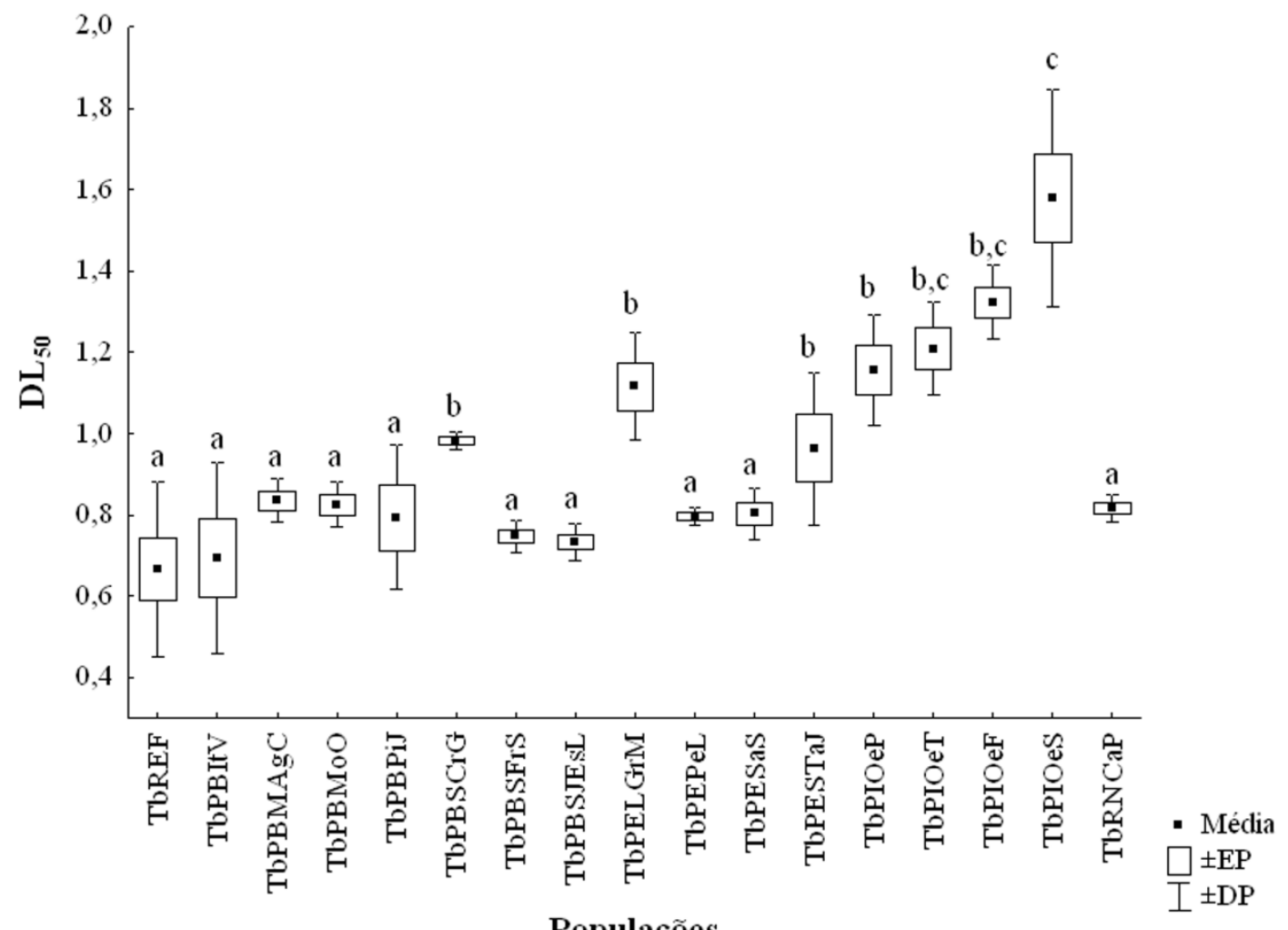

Figura 10 - Resultado da $\mathrm{DL}_{50}$ em populações de Triatoma brasiliensis. As letras indicam populações estatisticamente diferentes $(\mathrm{p}<0,01)$. 
Quanto à comparação da $\mathrm{DL}_{50}$ foi possível diferenciar três grupos de populações: num primeiro grupo destacamos as populações de Itaporanga/PB (TbPBItV), Mãe d'água/PB (TbPBMAgC), Monteiro/PB (TbPBMoO), Piancó/PB (TbPBPiJ), São Francisco/PB (TbPBSFrS), São José de Espinharas/PB (TbPBSJEsL), Petrolina/PE (TbPEPeL) e Salgueiro/PE (TbPESaS) que apresentaram variação de $\mathrm{DL}_{50}$ em uma faixa estreita de valores, muito próximos à linhagem suscetível TbREF (Fig. 10).

Num segundo grupo, constam as populações de Santa Cruz/PB (TbPBSCrG), Lagoa Grande/PE (TbPELGrM), Serra Talhada/PE (TbPESTaJ), Caicó/RN (TbRNCaP) e Oeiras/PI (TbPIOeP, TbPIOeT, TbPIOeF e TbPIOeS) que apresentaram diferenças com a população de referência. As populações TbPIOeT e TbPIOeF que pertencem ao segundo grupo formam um terceiro, juntamente com TbPIOeS. Esse último grupo obteve os maiores valores de $\mathrm{DL}_{50}$, conforme mostra a Fig. 10.

Quanto às estimativas da DL $_{95}$ foi possível diferenciar, estatisticamente, quatro grupos de municípios. No primeiro grupo estão contidas as populações de triatomíneos de Itaporanga/PB (TbPBItV), Mãe d'água/PB (TbPBMAgC), Monteiro/PB (TbPBMoO), Petrolina/PE (TbPEPeL), Salgueiro/PE (TbPESaS), Serra Talhada/PE (TbPESTaJ) e Caicó/RN (TbRNCaP), que apresentaram valores de DL95 similares à população de referência (Fig. 11).

O segundo grupo é formado por populações de triatomíneos procedentes dos municípios de Piancó/PB (TbPBPiJ), Santa Cruz/PB (TbPBSCrG) e Lagoa Grande/PE (TbPELGrM). O terceiro grupo que apresentou os menores valores é composto pelas populações dos municípios de São Francisco (TbPBSFrS) e São José 
de Espinharas (TbPBSJEsL), ambos no Estado da Paraíba. Porém, o quarto grupo foi o que apresentou os maiores valores de $\mathrm{DL}_{95}$, representados pelas quatro localidades do município de Oeiras, no Piauí (TbPIOeP, TbPIOeT, TbPIOeF e TbPIOeS) (Fig. $11)$.

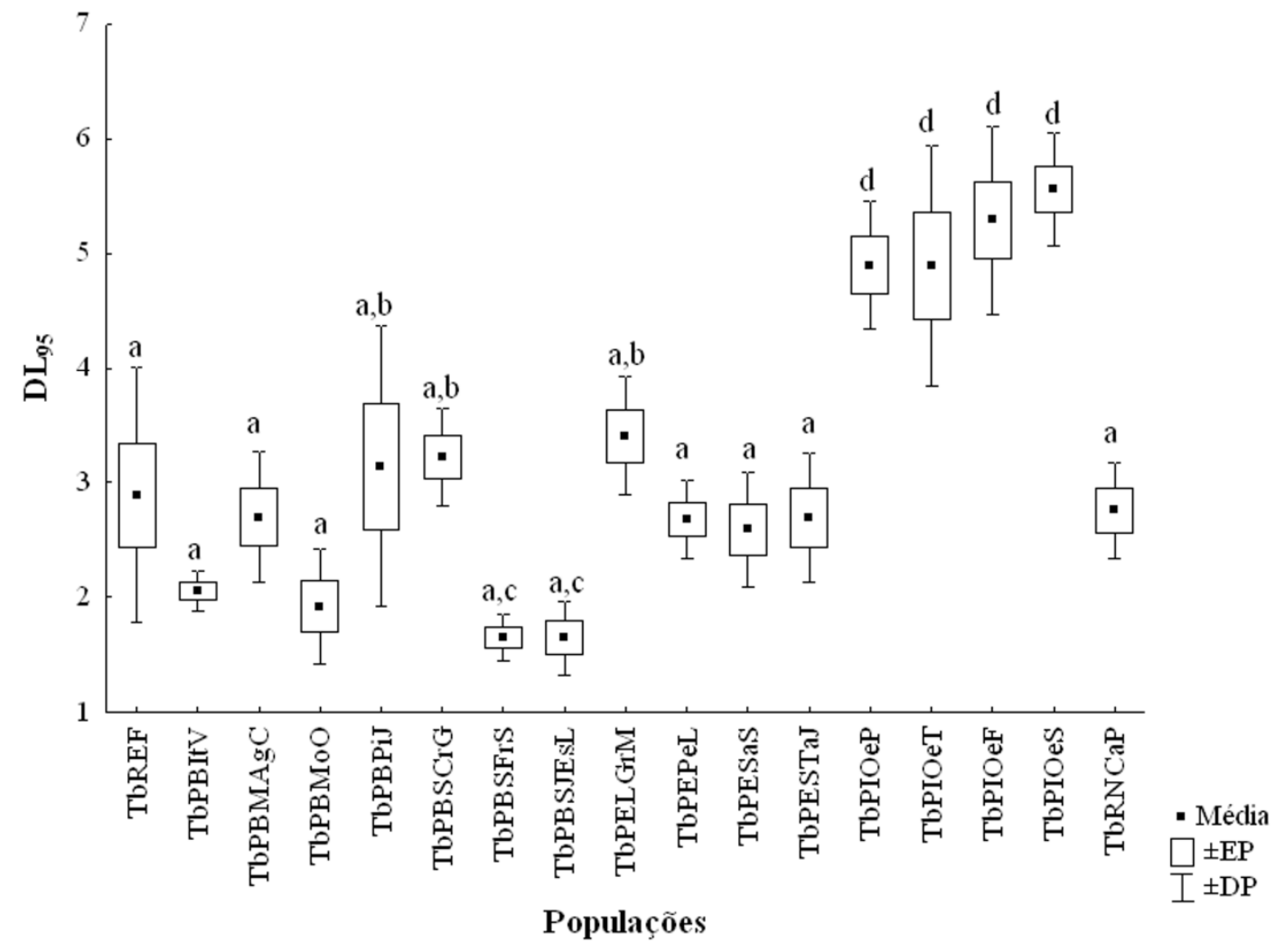

Figura 11 - Resultado da DL95 em populações de Triatoma brasiliensis. As letras indicam populações estatisticamente diferentes $(\mathrm{p}<0,01)$.

Os testes de toxicidade para as diferentes populações de T. brasiliensis, em relação à linhagem de referência ( $\mathrm{DL}_{50}$ de 0,68 ng/inseto), apresentaram os seguintes valores de $\mathrm{RR}_{50}$ em ordem crescente: 1,00 para o município de Itaporanga (TbPBItV); 1,06 para o município de São José de Espinharas (TbPBSJEsL); 1,09 para o município de São Francisco (TbPBSFrS); 1,13 para o município de Salgueiro 
(TbPESaS); 1,16 para o município de Petrolina (TbPEPeL); 1,19 para o município de Piancó (TbPBPiJ); 1,20 para o município de Monteiro (TbPBMoO); 1,21 para o município de Mãe d'água (TbPBMAgC); 1,24 para o município de Caicó (TbRNCaP); 1,25 para o município de Serra Talhada (TbPESTaJ); 1,41 para o município de Santa Cruz (TbPBSCrG); 1,61 para o município de Lagoa Grande (TbPELGrM); 1,66 para o município de Oeiras, Sítio Pau de Chapada (TbPIOeP); 1,75 para o município de Oeiras, Sítio Tabocas (TbPIOeT); 1,94 para o município de Oeiras, Sítio Formosa II (TbPIOeF) e 2,17 para o município de Oeiras, Sítio Sapé (TbPIOeS) (Tab. 7).

Os níveis de resistência das populações de triatomíneos dos municípios de Itaporanga/PB (TbPBItV), São José de Espinharas/PB (TbPBSJEsL), São Francisco/PB (TbPBSFrS), Salgueiro/PE (TbPESaS), Petrolina/PE (TbPEPeL), Piancó/PB (TbPBPiJ), Monteiro/PB (TbPBMoO), Mãe d'água/PB (TbPBMAgC) e Caicó/RN (TbRNCaP) não foram significantemente diferentes da população de referência, devido à sobreposição dos limites do Intervalo de Confiança de 95\%. No entanto, para as populações de Serra Talhada/PE (TbPESTaJ), Santa Cruz/PB (TbPBSCrG), Lagoa Grande/PE (TbPELGrM) e Oeiras/PI (TbPIOeP, TbPIOeT, TbPIOeF e TbPIOeS) constata-se diferença significativa em relação à $R_{50}$ da população TbREF. Os resultados obtidos indicaram níveis baixos ou incipientes de resistência para deltametrina, ou seja, a maioria das populações apresentou $R R_{50}$ inferiores a 2,0 (Tab. 7).

As $\mathrm{RR}_{95}$ estimadas para cada população de campo por meio de aplicação tópica de deltametrina em ninfas de $1^{\circ}$ estádio revelaram os seguintes valores, em ordem crescente: 1,02 para o município de São José de Espinharas (TbPBSJEsL); 
1,03 para o município de São Francisco (TbPBSFrS); 1,18 para o município de Monteiro (TbPBMoO); 1,27 para o município de Itaporanga (TbPBItV); 1,57 para o município de Salgueiro (TbPESaS); 1,63 para o município de Petrolina (TbPEPeL); 1,65 para o município de Serra Talhada (TbPESTaJ) e Mãe d'água (TbPBMAgC); 1,77 para o município de Caicó (TbRNCaP); 1,80 para o município de Santa Cruz (TbPBSCrG); 1,85 para o município de Piancó (TbPBPiJ); 2,15 para o município de Lagoa Grande (TbPELGrM); 2,61 para o município de Oeiras, Sítio Sapé (TbPIOeS); 2,85 para o município de Oeiras, Sítio Pau de Chapada (TbPIOeP); 2,88 para o município de Oeiras, Sítio Tabocas (TbPIOeT) e 3,43 para o município de Oeiras, Sítio Formosa II (TbPIOeF) (Tab. 7).

Apesar das diferenças significativas entre o valor de $\mathrm{RR}_{95}$ da população de referência TbREF com as amostras de campo dos municípios de Petrolina/PE (TbPEPeL), Mãe d'água/PB (TbPBMAgC), Caicó/RN (TbRNCaP), Santa Cruz/PB (TbPBSCrG), Piancó/PB (TbPBPiJ), Lagoa Grande/PE (TbPELGrM) e Oeiras/PI (TbPIOeS, TbPIOeP, TbPIOeT e TbPIOeF); nota-se pequenos níveis de resistência para deltametrina.

Os valores do coeficiente angular das amostras do Estado da Paraíba (Fig. 12) demonstraram que as populações de triatomíneos de São Francisco (TbPBSFrS) com 4,83; São José de Espinharas (TbPBSJEsL) com 4,74 e Monteiro (TbPBMoO) com 4,59 reproduziram perfis de inclinação da reta similares a população de referência TbREF com 4,51, como pode ser observado na Fig. 13 B, C e D. Entretanto, as populações de triatomíneos de Santa Cruz (TbPBSCrG) com 3,49; Mãe d'água (TbPBMAgC) com 3,29 e Piancó (TbPBPiJ) com 2,96 (Fig. 14 E, F e G) são mais heterogêneas, em comparação com as anteriores, uma vez que possuem menores 
valores de coeficiente angular. Esses resultados permitem supor que exista maior número de indivíduos resistentes distribuídos nessas populações.

Neste estudo também merece destaque a população procedente do município de Itaporanga/PB (TbPBItV) que demonstrou variação do coeficiente angular menor que a população TbREF (Fig. 13 A). Além disso, conforme mencionado anteriormente, a população de triatomíneo de Itaporanga apresentou um valor de $\mathrm{RR}_{50}$ igual a 1,00 , assim como $\mathrm{DL}_{50}$ igual a $0,68 \mathrm{ng} /$ inseto, semelhantemente a população de referência TbREF.

Assim, os resultados obtidos sugerem que a população do município de Itaporanga/PB (TbPBItV) poderá ser utilizada como população padrão de suscetibilidade, em estudos futuros de monitoramento de resistência de triatomíneos a inseticidas utilizados no seu controle. 


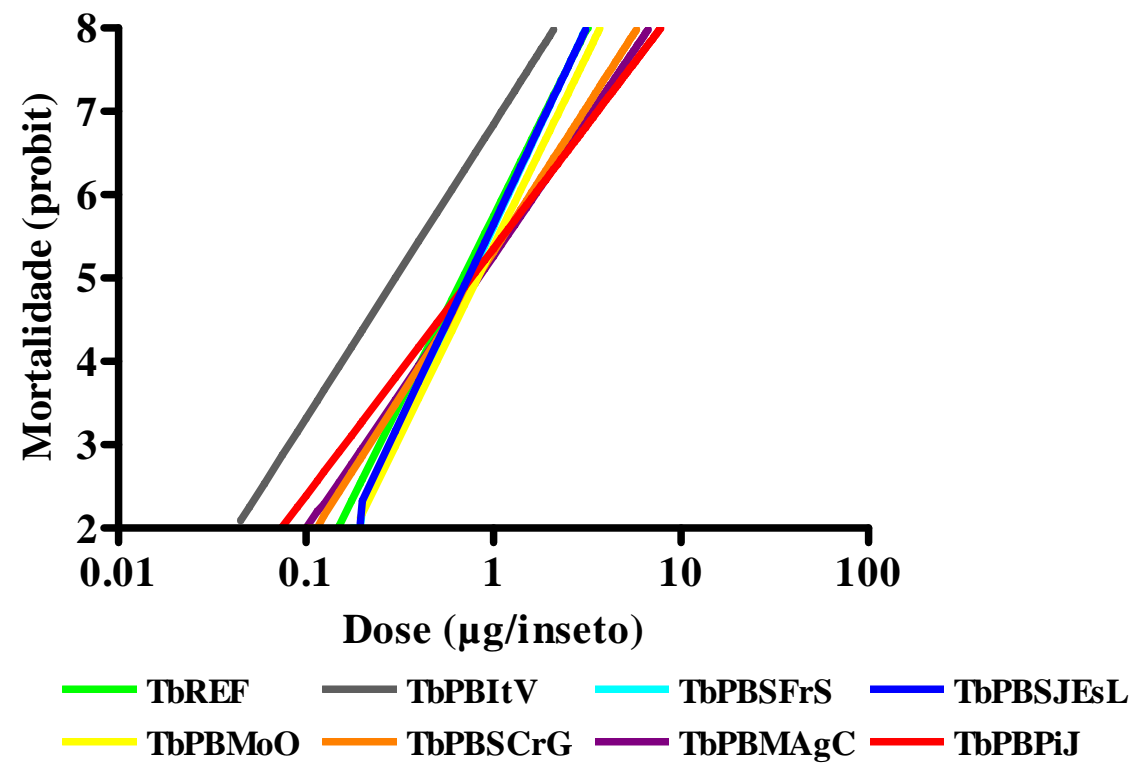

Figura 12 - Curva de mortalidade dose resposta, em escala logarítmica, comparando o coeficiente angular de populações de Triatoma brasiliensis procedentes do Estado da Paraíba. 

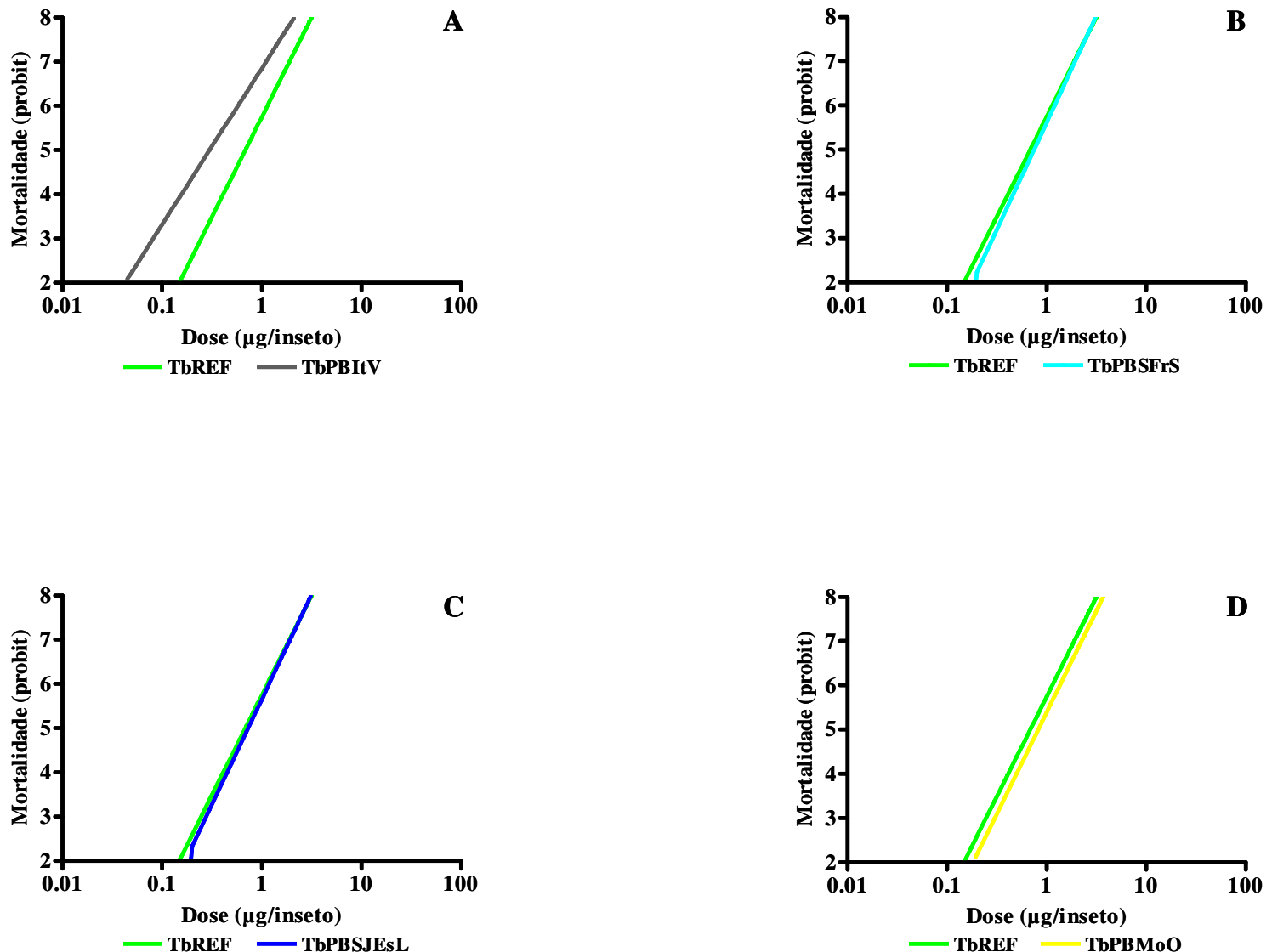

Figura 13 - Curva de mortalidade de populações de Triatoma brasiliensis, em escala logarítmica, para o inseticida deltametrina. A: Comparação entre TbREF $(4,51)$ e TbPBItV (3,52). B: Comparação entre TbREF (4,51) e TbPBSFrS (4,83). C: Comparação entre TbREF $(4,51)$ e TbSJEsL $(4,74)$. D: Comparação entre TbREF $(4,51)$ e TbPBMoO $(4,59)$. 

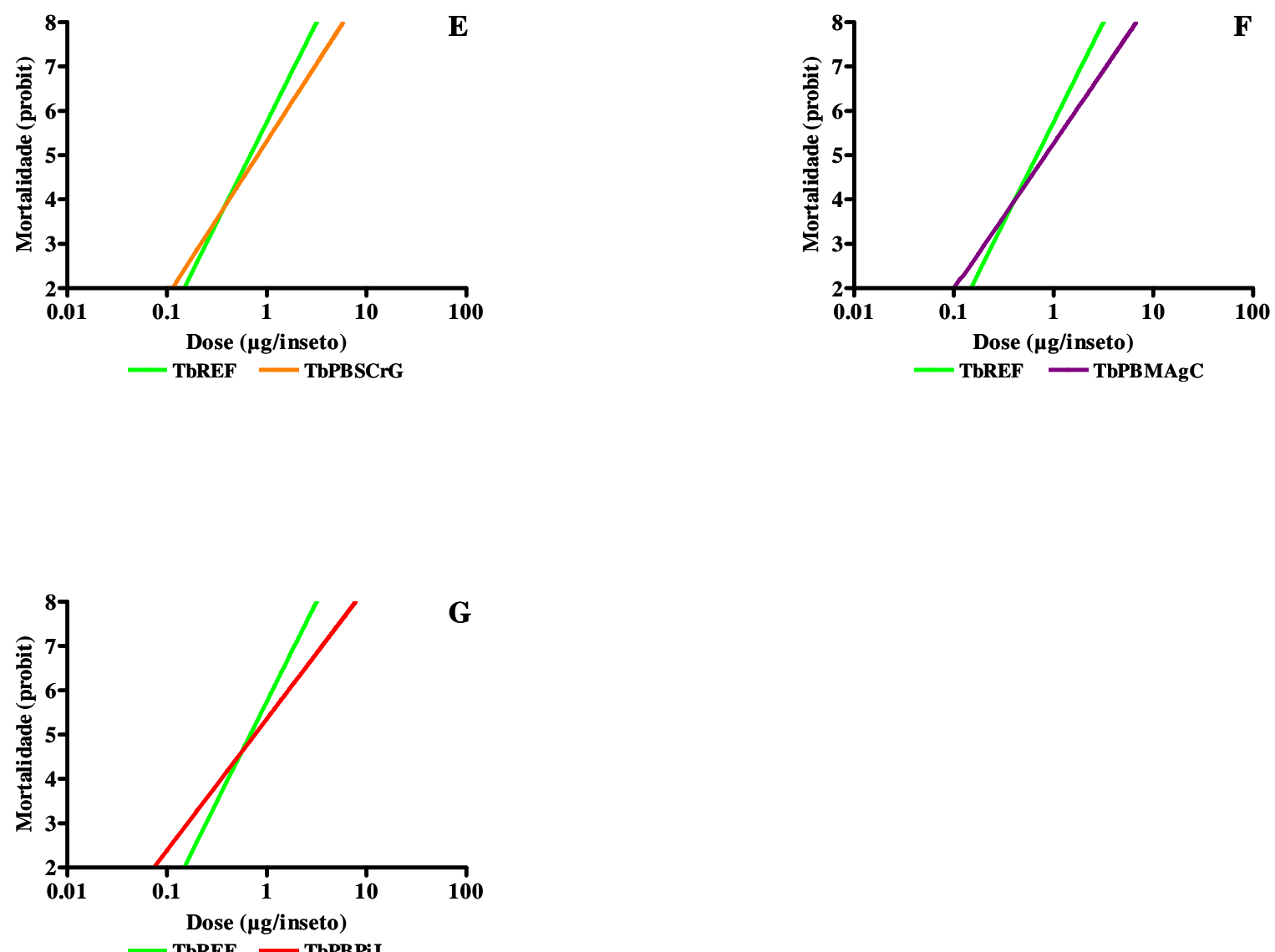

Figura 14 - Curva de mortalidade de populações de Triatoma brasiliensis, em escala logarítmica, para o inseticida deltametrina. E: Comparação entre TbREF $(4,51)$ e TbPBSCrG (3,49). F: Comparação entre TbREF (4,51) e TbPBMagC (3,29). G: Comparação entre TbREF $(4,51)$ e TbPBPiJ $(2,96)$. 
Os valores do coeficiente angular para as amostras do Estado de Pernambuco foram de 3,21 para a população do município de Petrolina (TbPEPeL); 3,24 para a população do município de Salgueiro (TbPESaS); 3,26 para a população do município de Lagoa Grande (TbPELGrM) e 3,39 para a população do município de Serra Talhada (TbPESTaJ).

Os valores obtidos indicaram que as populações pernambucanas apresentam padrões semelhantes de variação da inclinação na reta no gráfico, em comparação com a população de referência, cujo valor é de 4,51 (Figs. 15 e 16 A, B, C e D). No entanto, admite-se que os menores valores do coeficiente angular das populações de triatomíneos de Petrolina (TbPEPeL); Salgueiro (TbPESaS); Lagoa Grande(TbPELGrM) e Serra Talhada (TbPESTaJ) possam sugerir uma maior variabilidade genética, em comparação com a população de referência e que, portanto estão mais sujeitas a alterações na suscetibilidade a inseticidas.

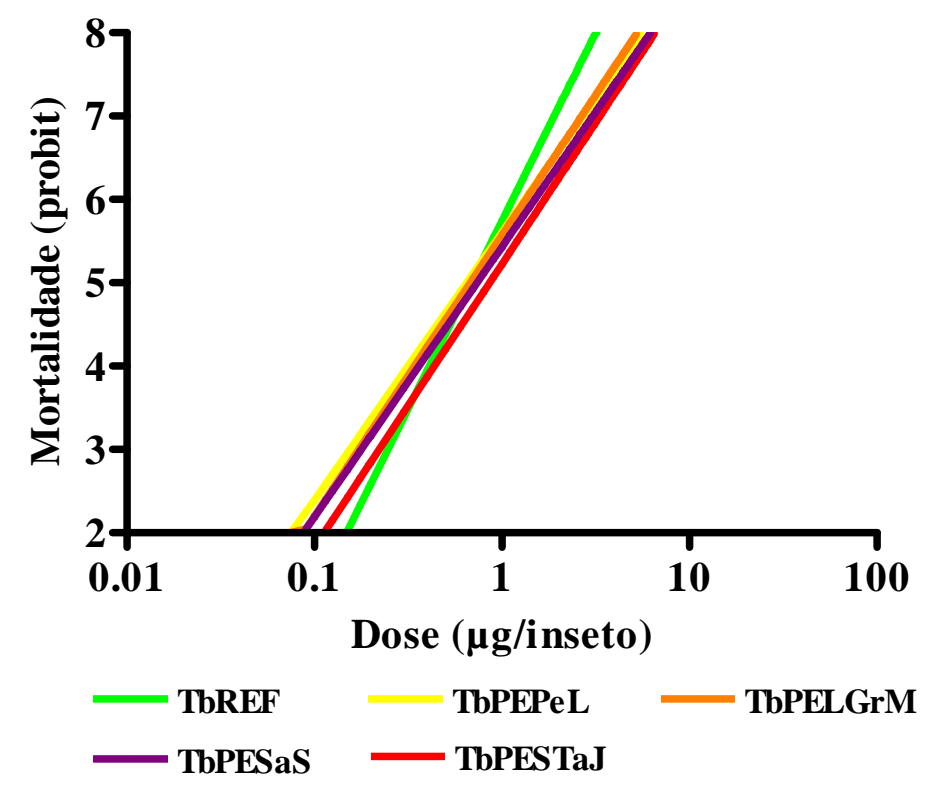

Figura 15 - Curva de mortalidade dose resposta, em escala logarítmica, comparando o coeficiente angular de populações de Triatoma brasiliensis procedentes do Estado de Pernambuco. 

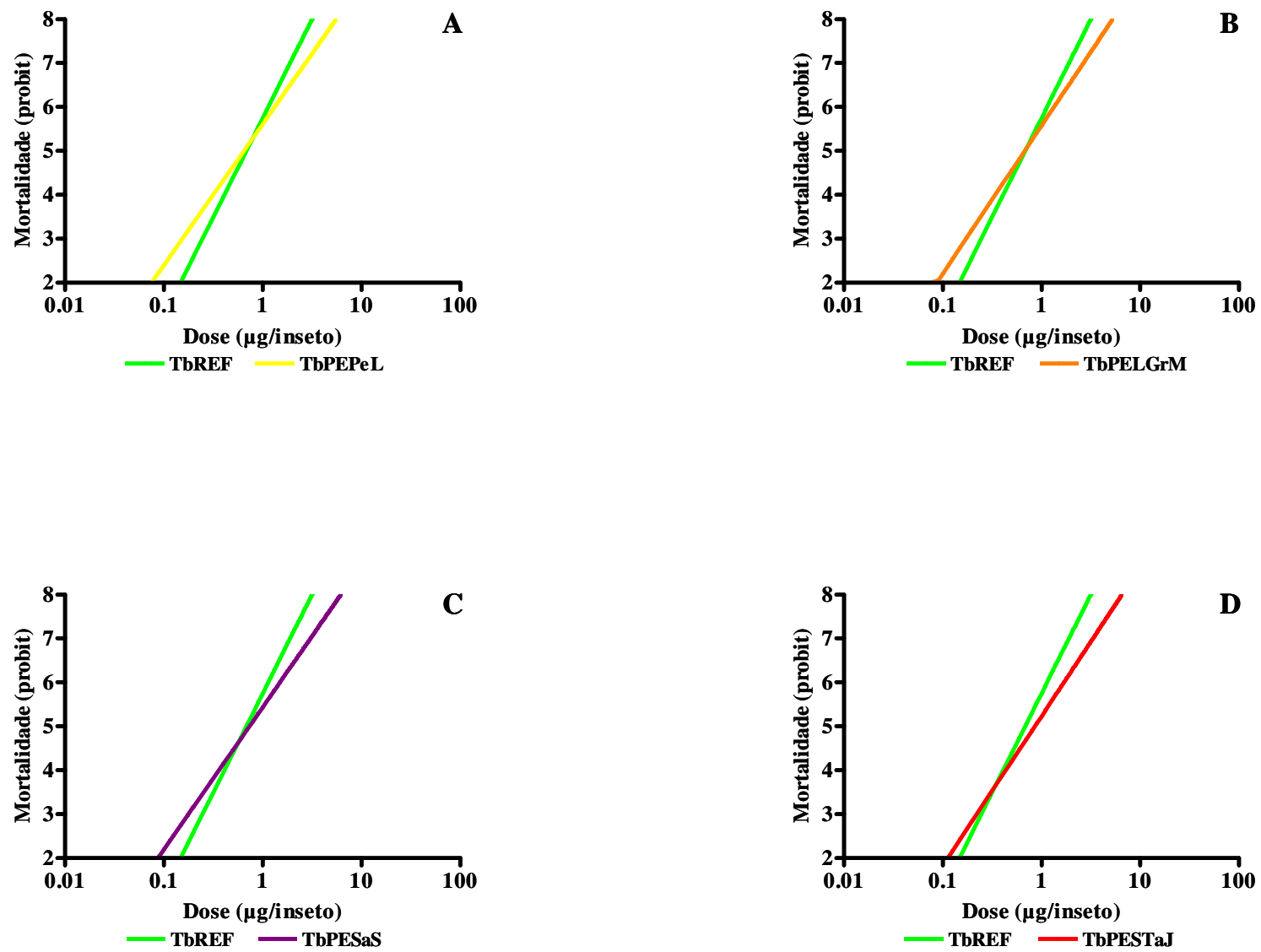

Figura 16 - Curva de mortalidade de populações de Triatoma brasiliensis, em escala logarítmica, para o inseticida deltametrina. A: Comparação entre TbREF $(4,51)$ e TbPEPeL (3,21). B: Comparação entre TbREF (4,51) e TbPELGrM (3,36). C: Comparação entre TbREF $(4,51)$ e TbPESaS $(3,24)$. D: Comparação entre TbREF $(4,51)$ e TbPESTaJ $(3,39)$. 
Com relação ao coeficiente angular das populações do Estado do Piauí, particularmente do município de Oeiras (Fig. 17), nota-se que a população da localidade do Sítio Sapé (TbPIOeS) apresentou um valor do coeficiente angular de 3,70, conferindo um aspecto de inclinação da reta similar a população de referência (Figs. 17, 18 A).

Por outro lado, as populações do Sítio Pau de Chapada (TbPIOeP), do Sítio Tabocas (TbPIOeT) e do Sítio Formosa II (TbPIOeF) apresentaram valores de coeficiente angular de 2,82, 2,83 e 2,74, respectivamente (Figs. 18 B, C e D). Esses resultados sugerem maior heterogeneidade e apreciáveis probabilidades de seleção de indivíduos resistentes, ao longo dos anos. Observa-se também semelhanças na variabilidade do perfil de heterogeneidade, principalmente entre TbPIOeP e TbPIOeF (Figs. $18 \mathrm{C}$ e D).

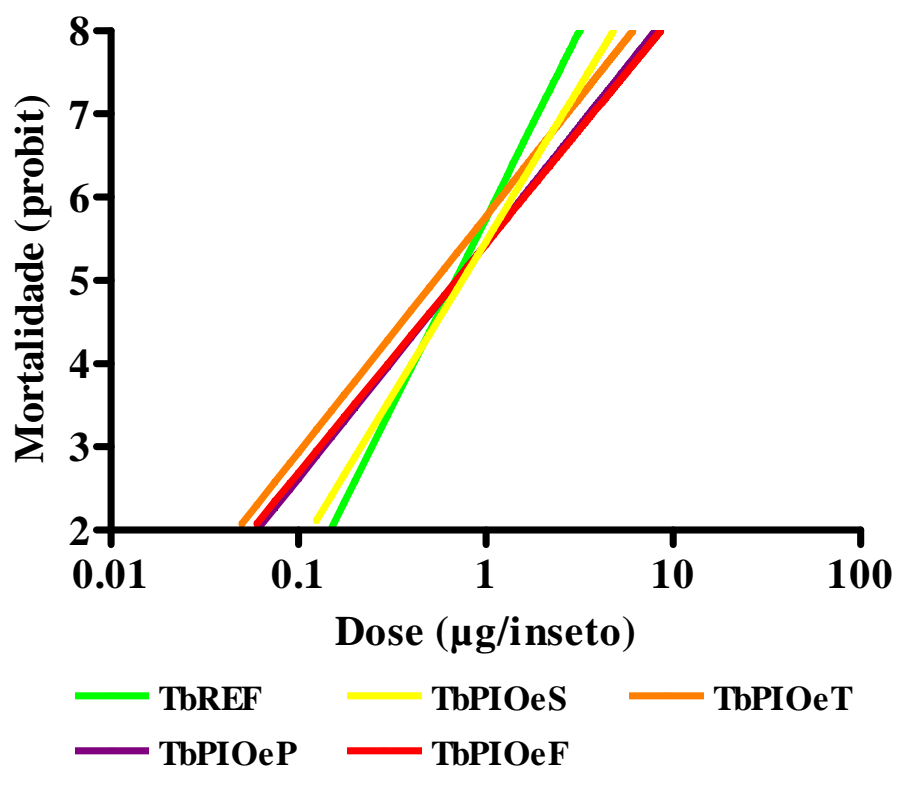

Figura 17 - Curva de mortalidade dose resposta, em escala logarítmica, comparando o coeficiente angular de populações de Triatoma brasiliensis procedentes do Estado do Piauí. 

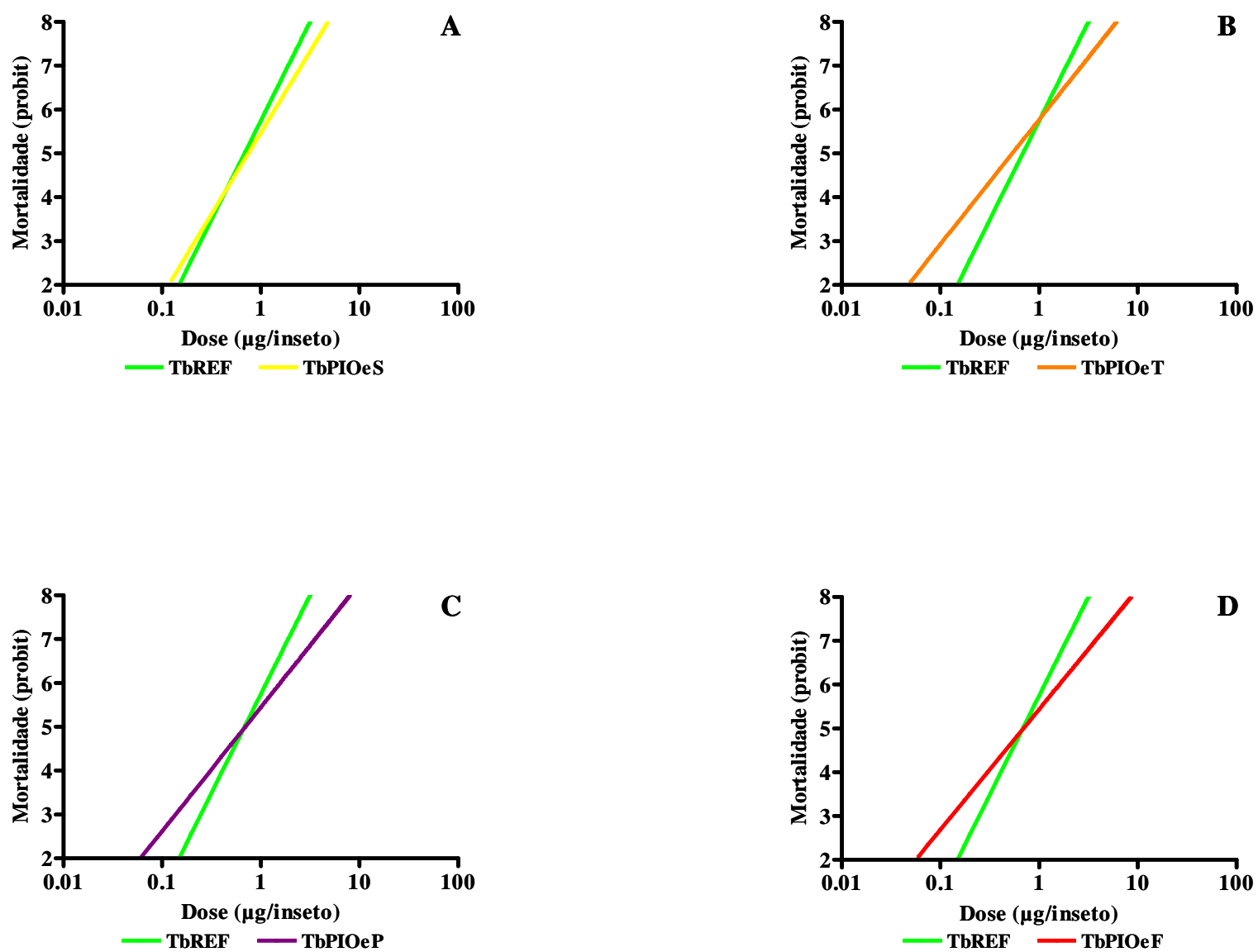

Figura 18 - Curva de mortalidade de populações de Triatoma brasiliensis, em escala logarítmica, para o inseticida deltametrina. As quatro populações são procedentes de diferentes localidades do município de Oeiras/PI. A: Comparação entre TbREF $(4,51)$ e TbPIOeS (3,70). B: Comparação entre TbREF $(4,51)$ e TsPIOeT $(2,83)$. C: Comparação entre TbREF $(4,51)$ e TbPIOeP $(2,82)$. D: Comparação entre TbREF $(4,51)$ e TbPIOeF $(2,74)$. 
A população do município de Caicó (TbRNCaP) apresentou um valor do coeficiente angular de 3,17 sugerindo maior variação genética que a população de referência, portanto, maior probabilidade de seleção de resistência. A comparação entre essas duas populações pode ser observada na Fig. 19.

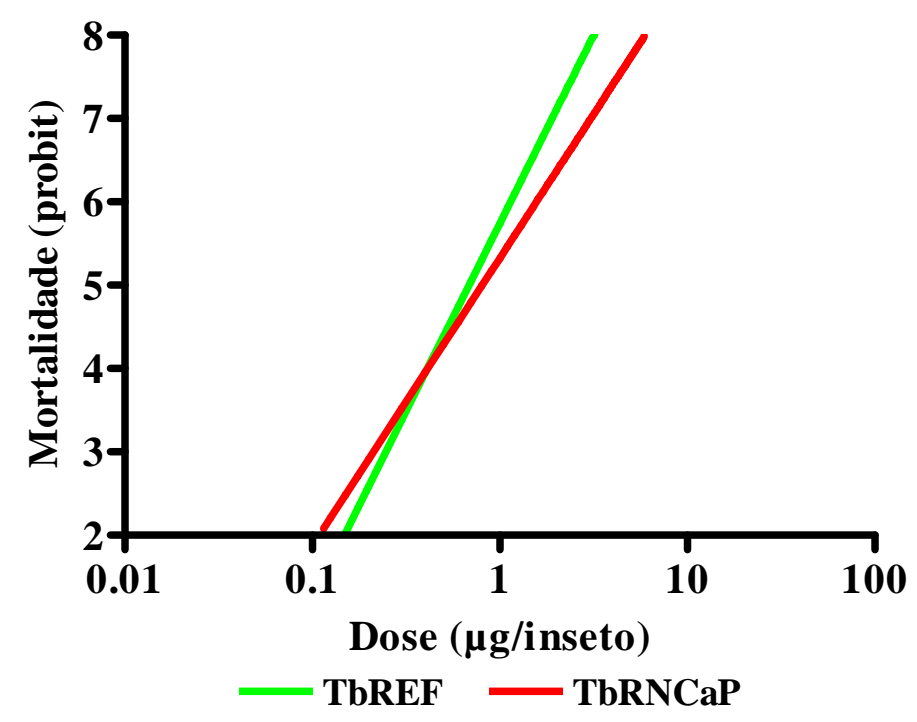

Figura 19 - Curva de mortalidade dose resposta, em escala logarítmica, comparando o coeficiente angular de TbREF $(4,51)$ e $\operatorname{TbRNCaP}(3,17)$. 
O desenvolvimento deste trabalho permitiu que se trabalhasse com populações de T. brasiliensis procedentes de várias regiões do nordeste do Brasil. Após o recebimento, cada amostra foi submetida à identificação taxonômica por meio de chave dicotômica, contida em LENT e WYGODZINSKY (1979). Os resultados da identificação mostraram diferentes padrões cromáticos, principalmente em pernas e tórax, preconizados por ARGOLO et al. (2008).

Assim, para diminuir os possíveis erros de identificação dos diferentes fenótipos das espécies do complexo T. brasiliensis, parte das amostras foram enviadas para o Laboratório de Biodiversidade Entomológica do Instituto Oswaldo Cruz, no Rio de Janeiro, Brasil. A responsável por esse laboratório é a Dra. Jane Costa que realizou as identificações taxonômicas, conforme NEIVA et al. (2008).

Os resultados do diagnóstico demonstraram padrões similares e formas intermediárias entre os membros desse complexo (COSTA, J Comunicação pessoal).

Na Tab. 8 podem ser observados os resultados das identificações. 
Tabela 8 - Identificação dos padrões cromáticos dos fenótipos recebidos para a avaliação de resistência de populações do complexo brasiliensis.

\begin{tabular}{|c|c|c|}
\hline População & Fenótipo & Diagnose \\
\hline TbPBItV & bras. escuro & padrão similar a $T$. $b$. brasiliensis \\
\hline TbPBMAgC & bras. escuro & padrão similar a $T$. $b$. brasiliensis \\
\hline TbPBMoO & bras. escuro & padrão similar a $T$. $b$. brasiliensis \\
\hline TbPBPiJ & bras. escuro & padrão similar a $T . b$. brasiliensis \\
\hline TbPBSCrG & bras. escuro & padrão similar a $T$. $b$. brasiliensis \\
\hline TbPBSFrS & bras. escuro & padrão similar a $T$. $b$. brasiliensis \\
\hline TbPBSJEsL & bras. escuro & padrão similar a $T$. $b$. brasiliensis \\
\hline TbPELGrM & mac/juaz & $\begin{array}{l}\text { padrão intermediário entre } T . b . \\
\text { macromelasoma e } T . \text { juazeirensis }\end{array}$ \\
\hline TbPEPeL & juaz & padrão similar ao T. juazeirensis \\
\hline TbPESaS & mac/marrom & $\begin{array}{l}\text { padrão intermediário entre } T . b \text {. } \\
\text { macromelasoma e } T . b \text {. brasiliensis }\end{array}$ \\
\hline TbPESTaJ & juaz mcfp & $\begin{array}{l}\text { padrão similar ao } T \text {. juazeirensis com } \\
\text { manchas claras finas no protorax }\end{array}$ \\
\hline TbPIOeP & bras. escuro & padrão similar a $T . b$. brasiliensis \\
\hline TbPIOeT & bras. escuro & padrão similar a $T$. b. brasiliensis \\
\hline TbPIOeF & bras. escuro & padrão similar a $T$. $b$. brasiliensis \\
\hline TbPIOeS & bras. escuro & padrão similar a $T$. $b$. brasiliensis \\
\hline TbRNCaP & bras. escuro & padrão similar a $T$. $b$. brasiliensis \\
\hline
\end{tabular}

Apesar da variabilidade fenotípica detectada nas populações de Lagoa Grande/PE (TbPELGrM), Petrolina (TbPEPeL), Salgueiro (TbPESaS) e Serra Talhada (TbPESTaJ) (Tab. 8), observou-se que os resultados das $\mathrm{RR}_{50}$ para essas populações foram de 1,$61 ; 1,16 ; 1,13$ e 1,25, respectivamente (Tab. 7). Esses valores indicam baixos níveis de resistência, independente, dos padrões cromáticos dos fenótipos recebidos. 
5.1.3 Comparação da suscetibilidade de ninfas de $1^{\circ}$ estádio de $T$. sordida a deltametrina

As estimativas de $\mathrm{DL}_{50}$ e DL95 da linhagem de referência (TsREF) foram de 0,58 ng/inseto e 1,35 ng/inseto, respectivamente. $\mathrm{O}$ valor do coeficiente angular foi de 4,51 .

A ação triatomicida de deltametrina foi avaliada em 21 populações de $T$. sordida procedentes de diferentes municípios da região Centro-Oeste do Brasil. Os testes toxicológicos revelaram uma variação entre $0,61 \mathrm{ng} /$ inseto a 1,59 ng/inseto e 1,41 ng/inseto a 4,62 ng/inseto para $\mathrm{DL}_{50}$ e DL 95 , respectivamente. As estimativas de variação para DL $_{50}$ e DL 95 das diferentes populações de campo podem ser observadas na Tab. 9. 
Tabela 9 - Distribuição do número de exemplares testados por amostra, slope, $\mathrm{DL}_{50}, \mathrm{DL}_{95}, \mathrm{RR}_{50}$ e $\mathrm{RR}_{95}$ de populações de Triatoma sordida tratadas com aplicação tópica de $0,2 \mu 1$ de deltametrina, na superfície dorsal do abdômen de ninfas de $1^{\circ}$ estádio capturadas em vinte e uma localidades do Brasil, em 2008 e 2009.

\begin{tabular}{|c|c|c|c|c|c|c|}
\hline População & $\mathbf{N}$ & Slope \pm DP & $\mathrm{DL}_{50}$ ng/inseto (95\% IC) & DL $_{95}$ ng/inseto (95\% IC) & $\mathrm{RR}_{50}(95 \% \mathrm{IC})$ & $\mathbf{R R}_{95}(\mathbf{9 5 \%} \mathrm{IC})$ \\
\hline TsREF & 800 & $4,51 \pm 0,34$ & $0,58(0,54-0,63)$ & $1,35(1,20-1,57)$ & $1,00(0,90-1,10)$ & $1,00(0,82-1,20)$ \\
\hline TsBAXXiR & 800 & $4,52 \pm 0,34$ & $0,61(0,56-0,66)$ & $1,41(1,24-1,67)$ & $1,05(0,94-1,17)$ & $1,04(0,85-1,27)$ \\
\hline TsMSCGrA & 800 & $3,95 \pm 0,31$ & $0,61(0,56-0,67)$ & $1,61(1,39-1,95)$ & $1,05(0,94-1,18)$ & $1,19(1,96-1,47)$ \\
\hline TsMTPoM & 880 & $3,25 \pm 0,31$ & $0,64(0,57-0,71)$ & $2,06(1,76-2,56)$ & $1,10(0,96-1,25)$ & $1,52(1,21-1,91)$ \\
\hline TsMSTeC & 560 & $4,27 \pm 0,42$ & $0,69(0,61-0,77)$ & $1,69(1,48-2,03)$ & $1,19(1,04-1,35)$ & $1,24(1,01-1,53)$ \\
\hline TsGOFiC & 1040 & $3,12 \pm 0,20$ & $0,70(0,63-0,78)$ & $2,37(1,99-2,94)$ & $1,20(1,05-1,37)$ & $1,75(1,38-2,21)$ \\
\hline TsMTSJPoS & 700 & $5,72 \pm 0,52$ & $0,70(0,66-0,75)$ & $1,37(1,23-1,57)$ & $1,20(1,09-1,32)$ & $1,01(0,84-1,20)$ \\
\hline TsMSRoE & 800 & $4,23 \pm 0,37$ & $0,70(0,63-0,77)$ & $1,73(1,53-2,04)$ & $1,21(1,07-1,36)$ & $1,28(1,05-1,55)$ \\
\hline TsGOSLMBeE & 700 & $4,18 \pm 0,43$ & $0,71(0,65-0,76)$ & $1,75(1,51-2,18)$ & $1,21(1,08-1,35)$ & $1,29(1,03-1,62)$ \\
\hline TsGOGGoS & 700 & $5,36 \pm 0,48$ & $0,75(0,70-0,80)$ & $1,55(1,37-1,79)$ & $1,29(1,17-1,42)$ & $1,13(0,94-1,36)$ \\
\hline TsBACarfB & 800 & $4,48 \pm 0,36$ & $0,77(0,72-0,83)$ & $1,80(1,60-2,11)$ & $1,32(1,20-1,47)$ & $1,33(1,10-1,61)$ \\
\hline TsMSATaJ & 700 & $3,15 \pm 0,35$ & $0,78(0,70-0,86)$ & $2,60(2,09-3,61)$ & $1,33(1,17-1,51)$ & $1,91(1,42-2,57)$ \\
\hline TsBACariM & 960 & $3,60 \pm 0,29$ & $0,81(0,74-0,87)$ & $2,31(2,01-2,79)$ & $1,38(1,24-1,53)$ & $1,71(1,38-2,11)$ \\
\hline TsMGLoR & 800 & $3,47 \pm 0,31$ & $0,84(0,77-0,92)$ & $2,53(2,14-3,17)$ & $1,45(1,29-1,62)$ & $1,86(1,47-2,36)$ \\
\hline TsMSDoM & 560 & $4,05 \pm 0,37$ & $0,85(0,78-0,92)$ & $2,17(1,87-2,66)$ & $1,45(1,30-1,62)$ & $1,60(1,28-1,99)$ \\
\hline TsGOPoE & 880 & $2,89 \pm 0,24$ & $0,86(0,76-0,96)$ & $3,20(2,70-4,02)$ & $1,48(1,29-1,69)$ & $2,36(1,86-2,99)$ \\
\hline TsBANReA & 800 & $3,85 \pm 0,32$ & $0,86(0,80-0,93)$ & $2,31(2,00-2,81)$ & $1,48(1,33-1,64)$ & $1,71(1,37-2,12)$ \\
\hline TsBAPaR & 900 & $3,53 \pm 0,27$ & $1,02(0,90-1,15)$ & $3,00(2,62-3,56)$ & $1,75(1,52-2,02)$ & $2,21(1,80-2,72)$ \\
\hline TsTOAToM & 800 & $3,15 \pm 0,39$ & $1,04(0,87-1,18)$ & $3,47(2,94-4,48)$ & $1,79(1,51-2,11)$ & $2,56(2,01-3,26)$ \\
\hline TsBARCoB & 700 & $5,75 \pm 0,49$ & $1,16(1,10-1,23)$ & $2,25(2,03-2,60)$ & $1,99(1,81-2,18)$ & $1,66(1,38-1,99)$ \\
\hline TsBAMaS & 900 & $3,28 \pm 0,24$ & $1,46(1,33-1,58)$ & $4,62(4,00-5,56)$ & $2,49(2,23-2,78)$ & $3,41(2,76-4,21)$ \\
\hline TsBAMuB & 560 & $3,55 \pm 0,29$ & $1,59(1,44-1,74)$ & $4,62(3,92-5,73)$ & $2,71(2,40-3,06)$ & $3,40(2,69-4,30)$ \\
\hline
\end{tabular}

Notas:

TsREF - População de Referência

DL - Dose Letal em nanogramas por inseto

95\% IC - Intervalo de Confiança 95\%

RR - Razão de Resistência

DP - Desvio Padrão 
Na Análise de Variância (ANOVA) foi detectada diferença significativa entre a DL ${ }_{50}\left(\right.$ ANOVA $\left._{21,92}=30,4 ; p<0.01\right)$ e a DL $_{95}\left(\right.$ ANOVA $\left._{21,92}=15,5 ; p<0.01\right)$ das populações estudadas.

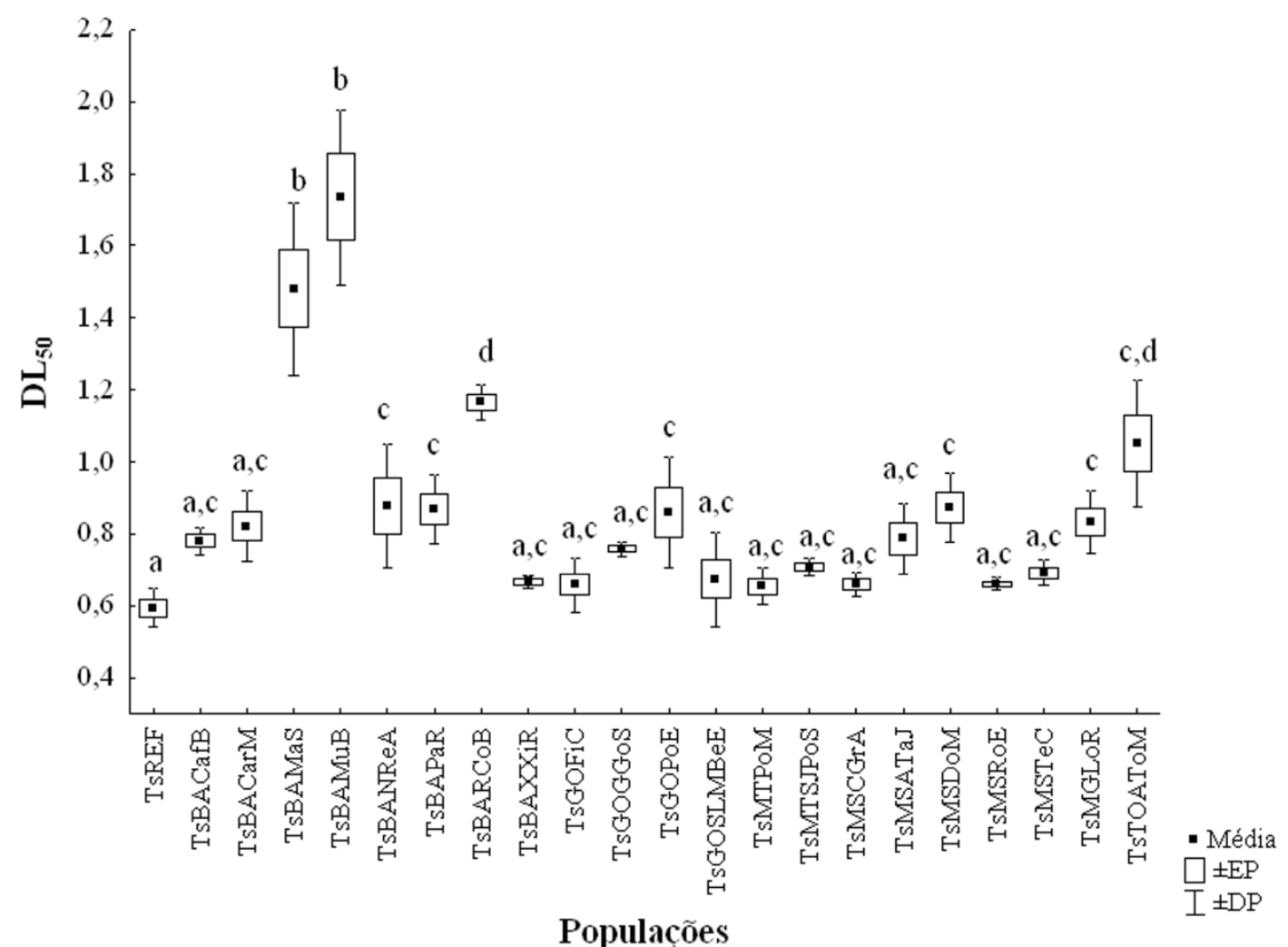

Figura 20 - Resultado da $\mathrm{DL}_{50}$ em populações de Triatoma sordida. As letras indicam populações estatisticamente diferentes $(\mathrm{p}<0,01)$.

A população de referência de Cordeiros/BA (TsREF) com DL $_{50}$ igual a 0,58 ng/inseto apresentou diferença estatisticamente significativa em relação às populações de Malhada/BA (TsBAMaS), Mucugê/BA (TsBAMuB), Nova Redenção/BA (TsBANReA), Palmeiras/BA (TsBAPaR), Rio de Contas/BA (TsBARCoB), Posse/GO (TsGOPoE), Douradina/MS (TsMSDoM), Lontra/MG (TsMGLoR) e Aurora do Tocantins/TO (TsTOAToM) (Fig. 20). 
Ainda, observa-se diferença significativa entre os triatomíneos capturados nesses nove municípios citados acima, o que permite agrupá-los em três grupos distintos: o primeiro grupo é composto pelos municípios de Malhada/BA (TsBAMaS) e Mucugê/BA (TsBAMuB); o segundo grupo é formado pelos municípios de Rio de Contas/BA (TsBARCoB) e Aurora do Tocantins/TO (TsTOAToM). O terceiro grupo é constituído pelos municípios de Nova Redenção/BA (TsBANReA), Palmeiras/BA (TsBAPaR), Posse/GO (TsGOPoE), Douradina/MS (TsMSDoM), Lontra/MG (TsMGLoR) e Aurora do Tocantins/TO (TsTOAToM) (Fig. 20).

Nota-se também a formação de quarto grupo caracterizado por não apresentar diferença estatisticamente significativa com a população de referência. Nesse grupo estão incluídas as populações de triatomíneos dos municípios de Xique-Xique/BA (TsBAXXiR), Campo Grande/MS (TsMSCGrA), Poxoréo/MT (TsMTPoM), Terenos/MS (TsMSTeC), Firminópolis/GO (TsGOFiC), São José do Povo/MT (TsMTSJPoS), Rochedo/MS (TsMSRoE), São Luís dos Montes Belos/GO (TsGOSLMBeE), Guarani de Goiás/GO (TsGOGGoS), Cafarnaum/BA (TsBACarfB), Aparecida do Taboado/MS (TsMSATaJ) e Carinhanha/BA (TsBACariM) (Fig. 20).

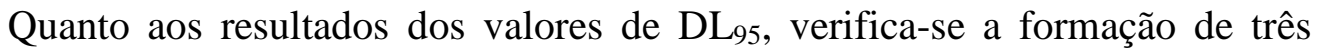
grupos diferentes, as quais estão expressas na Fig. 21. No primeiro grupo estão as populações, cujos valores de DL95 apresentaram diferenças estatisticamente significativas com a população de referência. Esse grupo é composto pelas populações Malhada/BA (TsBAMaS), Mucugê/BA (TsBAMuB), Palmeiras/BA 
(TsBAPaR), Posse/GO (TsGOPoE), Lontra/MG (TsMGLoR) e Aurora do Tocantins/TO (TsTOAToM) (Fig. 21).

No segundo grupo estão contidas as populações de triatomíneos capturadas nos municípios de Cafarnaum/BA (TsBACarfB), Carinhanha/BA (TsBACariM), Nova Redenção/BA (TsBANReA), Rio de Contas/BA (TsBARCoB), XiqueXique/BA (TsBAXXiR), Firminópolis/GO (TsGOFiC), Guarani de Goiás/GO (TsGOGGoS), São Luís de Mntes Belos/GO (TsGOSLMBeE), Poxoréo/MT (TsMTPoM), São José do Povo/MT (TsMTSJPoS), Campo Grande/MS (TsMSCGrA), Aparecida do Taboado/MS (TsMSATaJ), Douradina/MS (TsMSDoM), Rochedo/MS (TsMSRoE) e Terenos/MS (TsMSTeC) que não revelaram diferenças significativas com a população de referência quanto aos valores de $\mathrm{DL}_{95}$.

No terceiro grupo constaram as populações de triatomíneos coletadas nos municípios de Carinhanha/BA (TsBACariM), Nova Redenção/BA (TsBANReA), Palmeiras/BA (TsBAPaR), Rio de Contas/BA (TsBARCoB), Posse/GO (TsGOPoE), Poxoréu/MT (TsMTPoM), Aparecida do Taboado/MS (TsMSATaJ), Douradina/MS (TsMSDoM), Terenos/MS (TsMSTeC) e Lontra/MG (TsMGLoR); que apesar de não se diferenciarem estatisticamente da população de referência podem formar um grupo intermediário com base nos valores semelhantes de DL95 e que de certa forma permite diferenciá-los do primeiro grupo, conforme podemos observar na Fig. 21. 


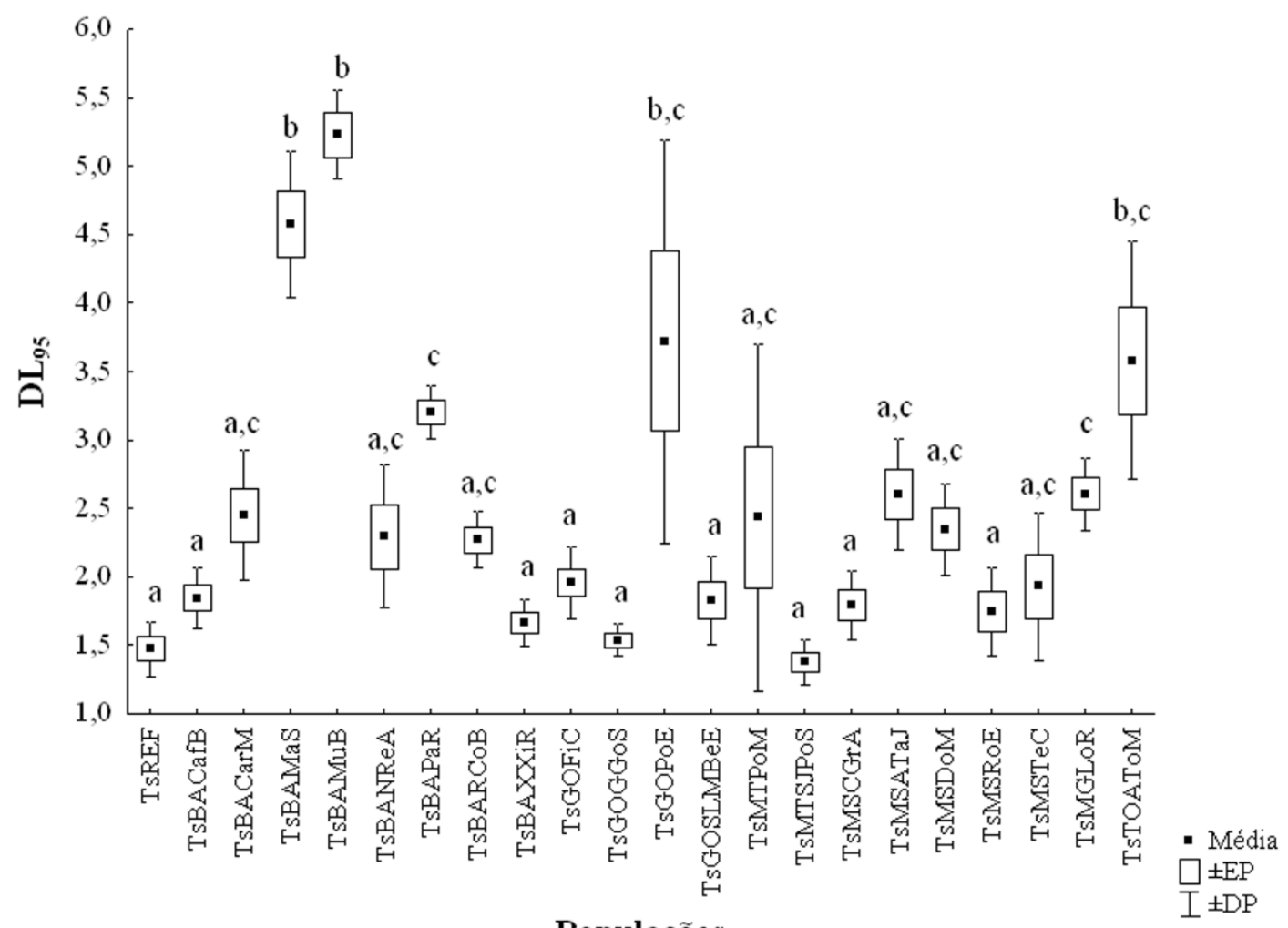

Populações

Figura 21 - Resultado da DL 95 em populações de $T$. sordida. As letras indicam populações estatisticamente diferentes $(p<0,01)$.

Os valores de $\mathrm{RR}_{50}$ demonstraram uma variação de 1,05 a 2,71. Na Tab. 9 podem ser observados os seguintes valores de $R_{50}$ para cada população estudada, em ordem crescente: 1,05 para o município de Xique Xique (TsBAXXiR) e Campo Grande (TsMSCGrA); 1,10 para o município de Poxoréu (TsMTPoM); 1,19 para o município de Terenos (TsMSTeC); 1,20 para o município de Firminópolis (TsGOFiC) e São José do Povo (TsMTSJPoS); 1,21 para o município de Rochedo (TsMSRoE) e São Luís dos Montes Belos (TsGOSLMBeE); 1,29 para o município de Guarani de Goiás (TsGOGGoS); 1,32 para o município de Cafarnaum (TsBACarfB); 1,33 para o município de Aparecida do Taboado (TsMSATaJ); 1,38 para o município de Carinhanha (TsBACariM); 1,45 para o município de Lontra 
(TsMGLoR) e Douradina (TsMSDoM); 1,48 para o município de Posse (TsGOPoE) e Nova Redenção (TsBANReA); 1,75 para o município de Palmeiras (TsBAPaR); 1,79 para o município de Aurora do Tocantins (TsTOAToM); 1,99 para o município de Rio de Contas (TsBARCoB); 2,49 para o município de Malhada (TsBAMaS) e 2,71 para o município de Mucugê (TsBAMuB).

Estatisticamente, as populações de triatomíneos capturadas nos municípios de Guarani do Goiás/GO (TsGOGGoS), Cafarnaum/BA (TsBACarfB), Aparecida do Taboado/MS (TsMSATaJ), Carinhanha/BA (TsBACariM), Lontra/MG (TsMGLoR), Douradina/MS (TsMSDoM), Posse/GO (TsGOPoE), Nova Redenção/BA (TsBANReA), Palmeiras/BA (TsBAPaR), Aurora do Tocantins/TO (TsTOAToM), Rio de Contas/BA (TsBARCoB), Malhada/BA (TsBAMaS) e Mucugê/BA (TsBAMuB) apresentaram diferenças significativas na $R_{50}$, quando os limites de confiança foram sobrepostos no nível de 95\% (Tab. 9).

Para a $\mathrm{RR}_{95}$, o menor valor foi atribuído para a população TsBAXXiR capturada no município de Xique Xique/BA, cuja $\mathrm{RR}_{95}$ foi igual a 1,04 , enquanto o maior valor foi para a população TsBAMaS do município de Malhada, com $\mathrm{RR}_{95}$ igual a 3,41. Esses valores podem ser observados na Tab. 9 que também apresenta as diferentes $R R_{95}$, calculadas para cada população estudada. Em relação a $R R_{95}$, as populações de triatomíneos que apresentaram diferenças significativas com a população de referência, TsREF, pertencem aos municípios de Posse/GO (TsMTPoM), Firminópolis/GO (TsGOFiC), Aparecida do Taboado/MS (TsMSATaJ), Carinhanha/BA (TsBACariM), Lontra/MG (TsMGLoR), Douradina/MS (TsMSDoM), Posse/GO (TsGOPoE), Nova Redenção/BA (TsBANReA), Palmeiras/BA (TsBAPaR), Aurora do Tocantins/TO (TsTOAToM), 
Rio de Contas/BA (TsBARCoB), Malhada/BA (TsBAMaS) e Mucugê/BA (TsBAMuB).

Quanto aos valores de coeficiente angular, as populações de triatomíneos do Estado da Bahia (Fig. 22) apresentaram uma variação de 3,28 a 5,75. O menor valor corresponde a população TsBAMaS procedente do município de Malhada/BA, enquanto que o maior valor foi para a população TsBARCoB do município de Rio de Contas/BA.

As populações de triatomíneos dos municípios de Xique Xique (TsBAXXiR) e Cafarnaum (TsBACarfB) apresentaram valores do coeficiente angular correspondentes a 4,52 e 4,48, respectivamente. Esses valores estabeleceram padrões de variação de mortalidade muito semelhante à população de referência, portanto, com elevados níveis de suscetibilidade a deltametrina (Figs. 23 A e B).

As populações de triatomíneos dos municípios de Carinhanha (TsBACariM), Nova Redenção (TsBANReA), Palmeiras (TsBAPaR), Malhada (TsBAMaS) e Mucugê (TsBAMuB) (Figs. 23 D, Figs. 24 E, F, G e H) apresentaram coeficientes angulares menores, quando comparadas com a população de referência; logo, sugerese a possibilidade de maior variabilidade genética dessas populações. Esses resultados indicam apreciável tendência para seleção de indivíduos resistentes, merecendo destaque por parte dos órgãos de controle. 


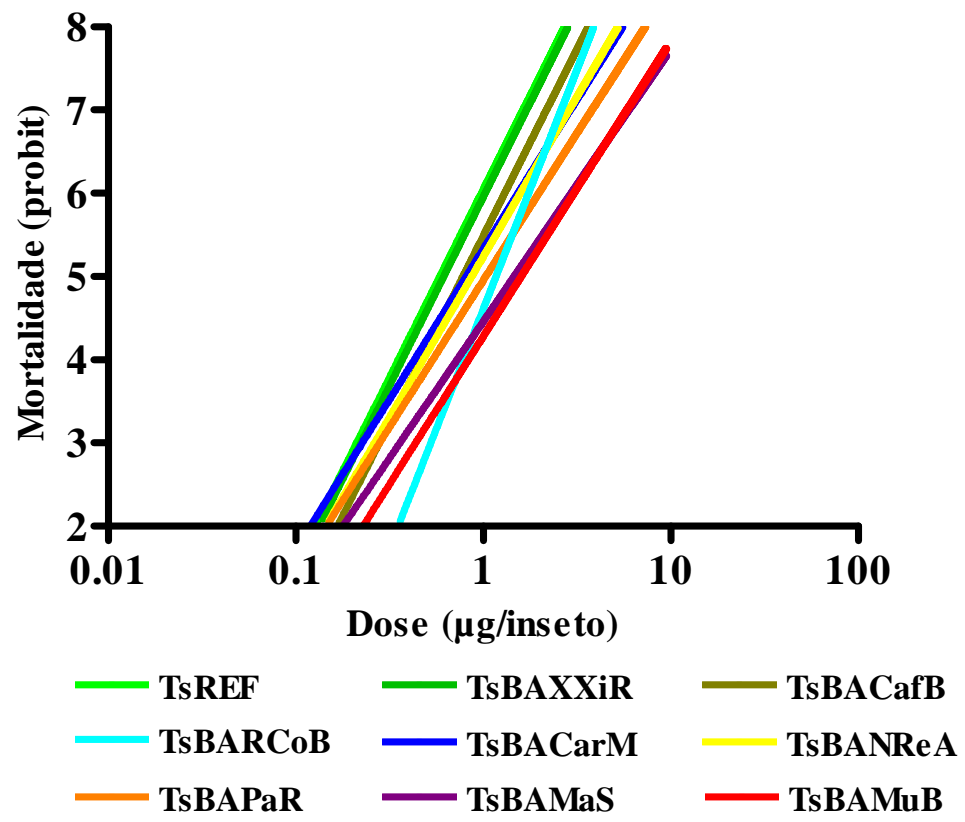

Figura 22 - Curva de mortalidade dose resposta, em escala logarítmica, comparando o coeficiente angular de populações de Triatoma sordida procedentes do Estado da Bahia. 

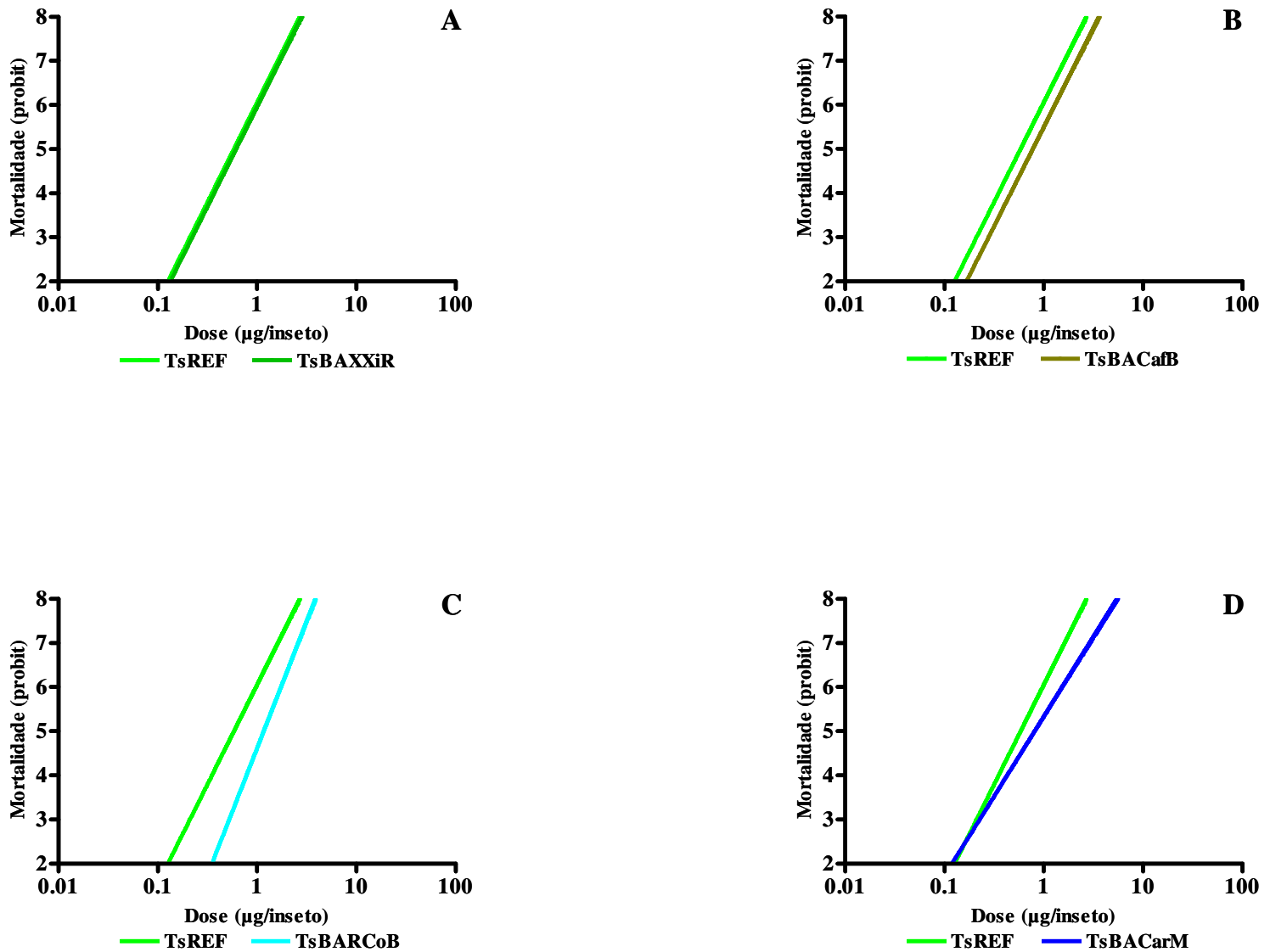

Figura 23 - Curva de mortalidade de populações de Triatoma sordida, em escala logarítmica, para o inseticida deltametrina. A: Comparação entre TsREF $(4,51)$ e TsBAXXiR (4,52). B: Comparação entre TsREF (4,51) e TsBACarfB (4,48). C: Comparação entre TsREF $(4,51)$ e TsBARCoB $(5,75)$. D: Comparação entre TsREF $(4,51)$ e TsBACarM $(3,60)$. 

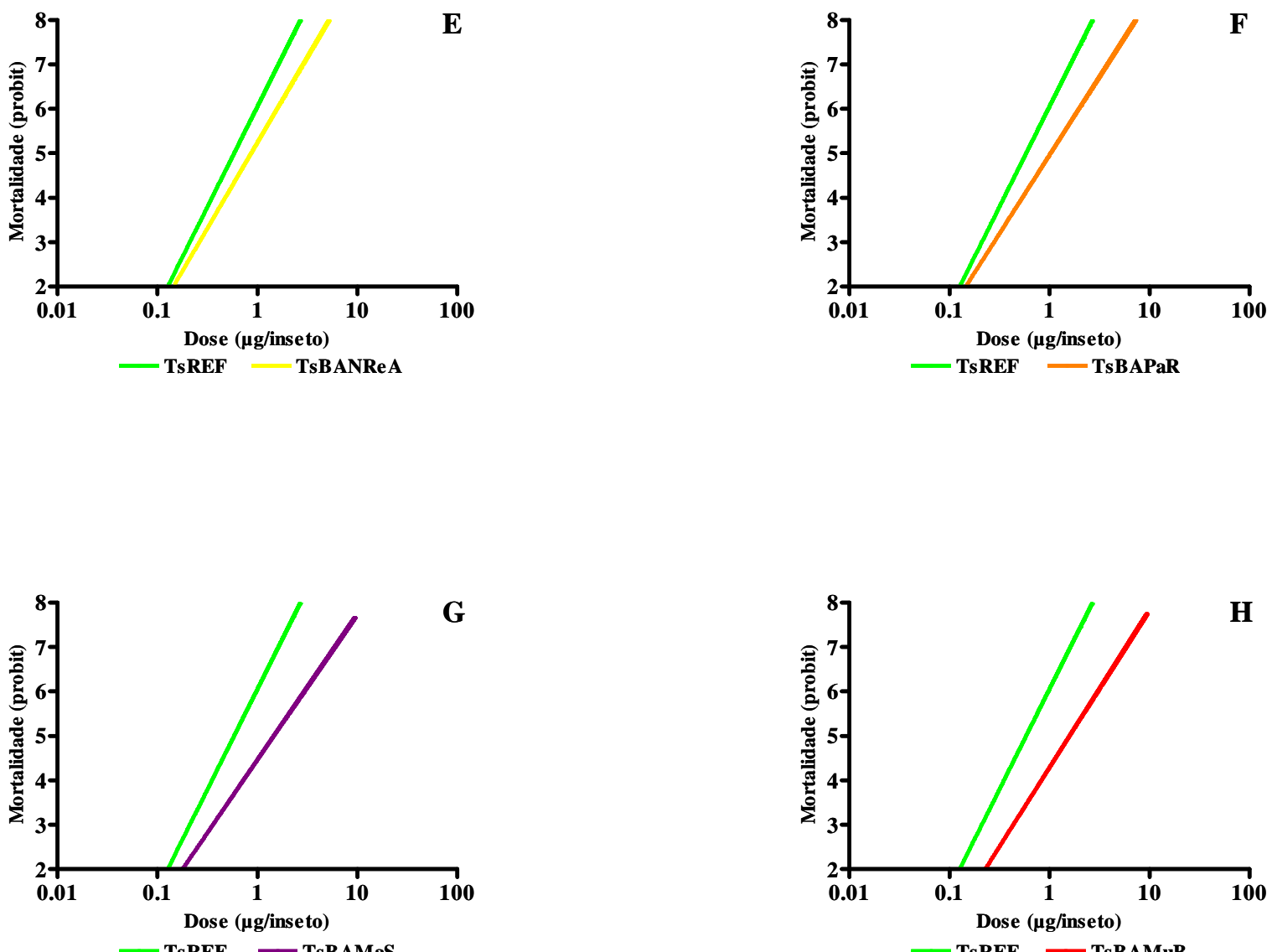

Figura 24 - Curva de mortalidade de populações de Triatoma sordida, em escala logarítmica, para o inseticida deltametrina. E: Comparação entre TsREF $(4,51)$ e TsBANReA (3,85). F: Comparação entre TsREF $(4,51)$ e TsBAPaR (3,53). G: Comparação entre TsREF $(4,51)$ e TsBAMaS $(3,28)$. H: Comparação entre TsREF $(4,51)$ e TsBAMuB $(3,55)$. 
As variações do coeficiente angular das diferentes populações do Estado do Mato Grosso do Sul seguiram padrões similares da população de referência, com poucas variações na inclinação da reta (Fig. 25).

As populações de triatomíneos dos municípios de Terenos (TsMSTeC) (Fig. 26 A), Rochedo (TsMSRoE) (Fig. 26 B), Campo Grande (TsMSCGrA) (Fig. 26 C) e Douradina (TsMSDoM) (Fig. 26 D) exibiram coeficientes angulares de inclinação da reta com pouca heterogeneidade, portanto refletindo em populações com altos níveis de suscetibilidade.

No entanto, dentro desse grupo, a população TsMSATaJ, oriunda do município de Aparecida do Taboado foi considerada a mais heterogênea quando comparada a população de referência (Fig. 26 E). Tal fato pode indicar maior probabilidade de tolerância à inseticida desta população sul mato-grossense.

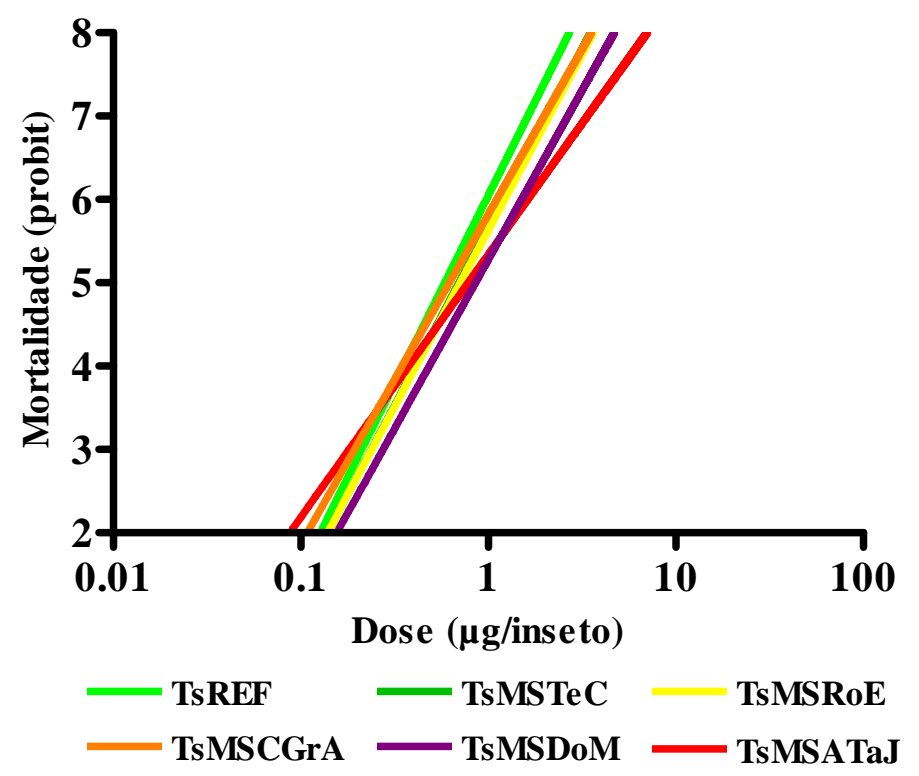

Figura 25 - Curva de mortalidade dose resposta, em escala logarítmica, comparando o coeficiente angular de populações de Triatoma sordida procedentes do Estado do Mato Grosso do Sul. 

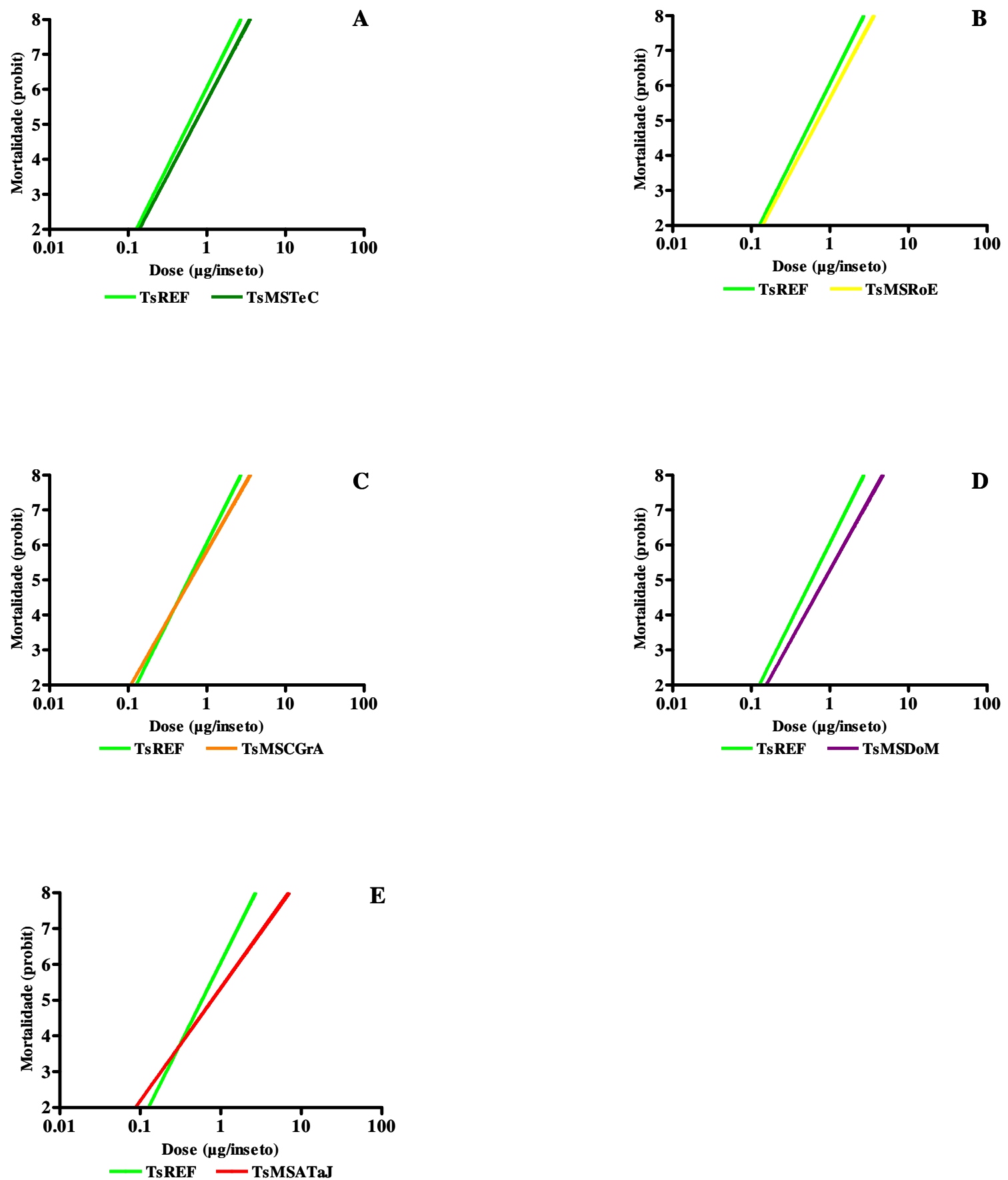

Figura 26 - Curva de mortalidade de populações de Triatoma sordida, em escala logarítmica, para o inseticida deltametrina. A: Comparação entre TsREF $(4,51)$ e TsMSTeC (4,27). B: Comparação entre TsREF (4,51) e TsMSRoE (4,23). C: Comparação entre TsREF $(4,51)$ e TsMSCGrA $(3,95)$. D: Comparação entre TsREF $(4,51)$ e TsMSDoM $(4,05)$. E: Comparação entre TsREF $(4,51)$ e TsMSATaJ $(3,15)$. 
Os valores do coeficiente angular para as populações de triatomíneos do Estado de Goiás (Fig. 27) demonstraram os seguintes valores: 2,89 para o município de Posse (TsGOPoE); 3,12 para o município de Firminópolis (TsGOFiC); 4,18 para o município de São Luís de Montes Belos (TsGOSLMBeE) e 5,36 para o município de Guarani de Goiás (TsGOGGoS). As populações TsGOPoE e TsGOFiC procedentes dos municípios de Posse/GO e Firminópolis/GO foram as que apresentaram menores coeficientes angulares (Figs. 28 C e D). Logo, são consideradas mais heterogêneas e com maiores chances de tolerar o tratamento com inseticidas químicos. Por outro lado, as populações com menores taxas de variação na suscetibilidade foram oriundas dos municípios de São Luís de Montes Belos (TsGOSLMBeE) e Guarani de Goiás (TsGOGGoS) (Figs. 28 A e B), semelhantemente a população de referência.

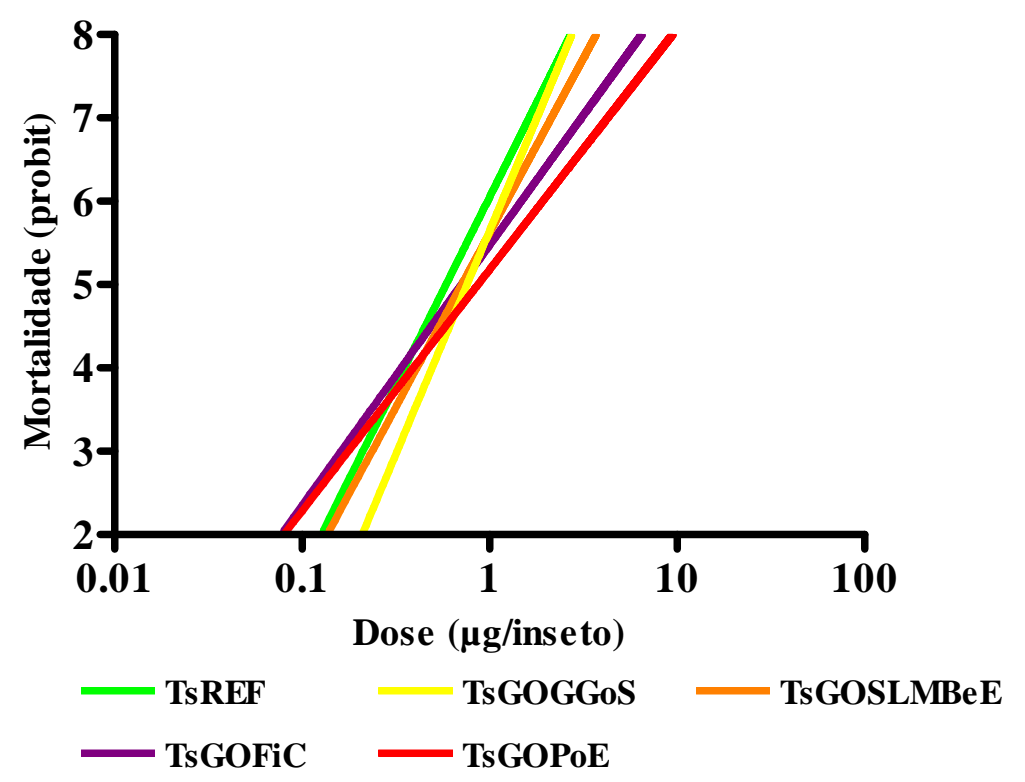

Figura 27 - Curva de mortalidade dose resposta, em escala logarítmica, comparando o coeficiente angular de populações de Triatoma sordida procedentes do Estado de Goiás. 

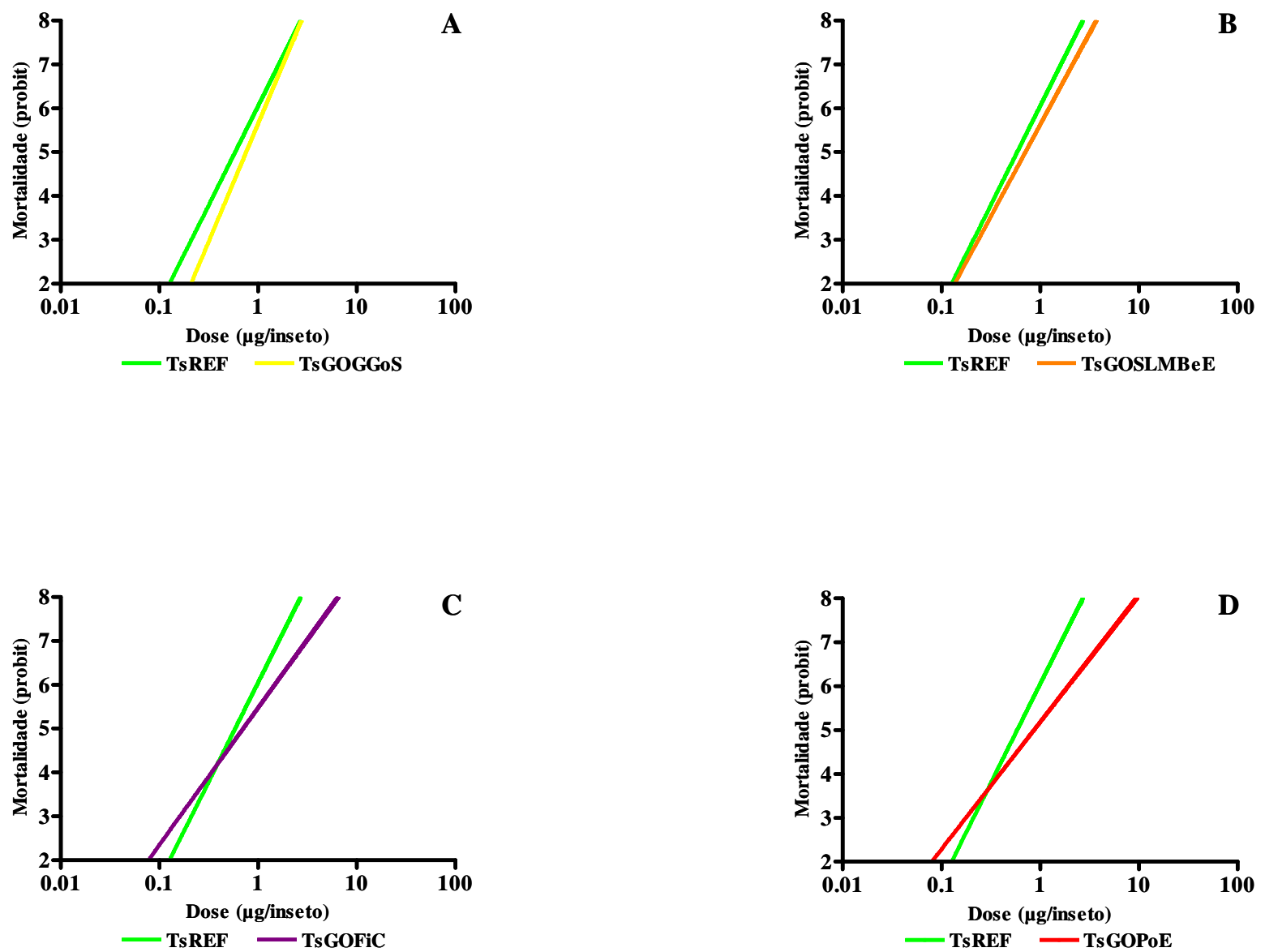

Figura 28 - Curva de mortalidade de populações de Triatoma sordida, em escala logarítmica, para o inseticida deltametrina. A: Comparação entre TsREF (4,51) e TsGOGGoS (5,36). B: Comparação entre TsREF $(4,51)$ e TsGOSLMBe $(4,18)$. D: Comparação entre TsREF $(4,51)$ e TsGOFiC $(3,12)$. D: Comparação entre TsREF $(4,51)$ e TsGOPoE $(2,89)$.

Os valores do coeficiente angular para as populações de triatomíneos dos municípios de São José do Povo (TsMTSJPoS) e Poxoréu (TsMTPoM) foram de 5,72 e 3,25, respectivamente. A população de São José do Povo (TsMTSJPoS) apresenta uma inclinação de reta no gráfico com maior nível de homogeneidade. Espera-se que a suscetibilidade desta população seja próxima a linhagem de referência (Figs. 29 e 30 A). Porém, a população de Poxoréu (TsMTPoM) (Fig. 30 B) apresenta menor homogeneidade sugerindo maior probabilidade de progressão de resistência. 


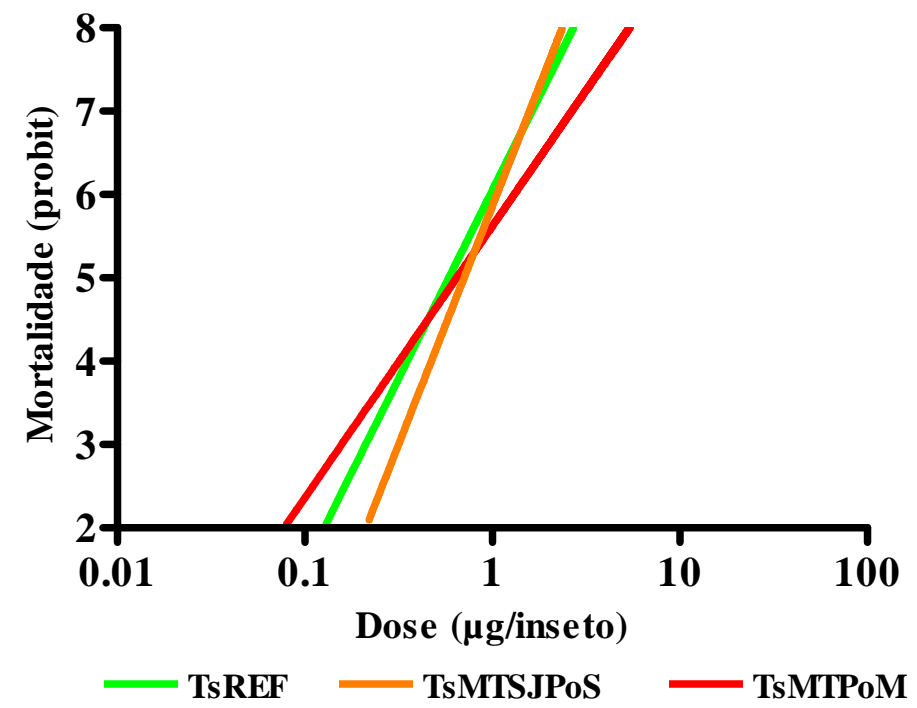

Figura 29 - Curva de mortalidade dose resposta, em escala logarítmica, comparando o coeficiente angular de populações de Triatoma sordida procedentes do Estado do Mato Grosso.
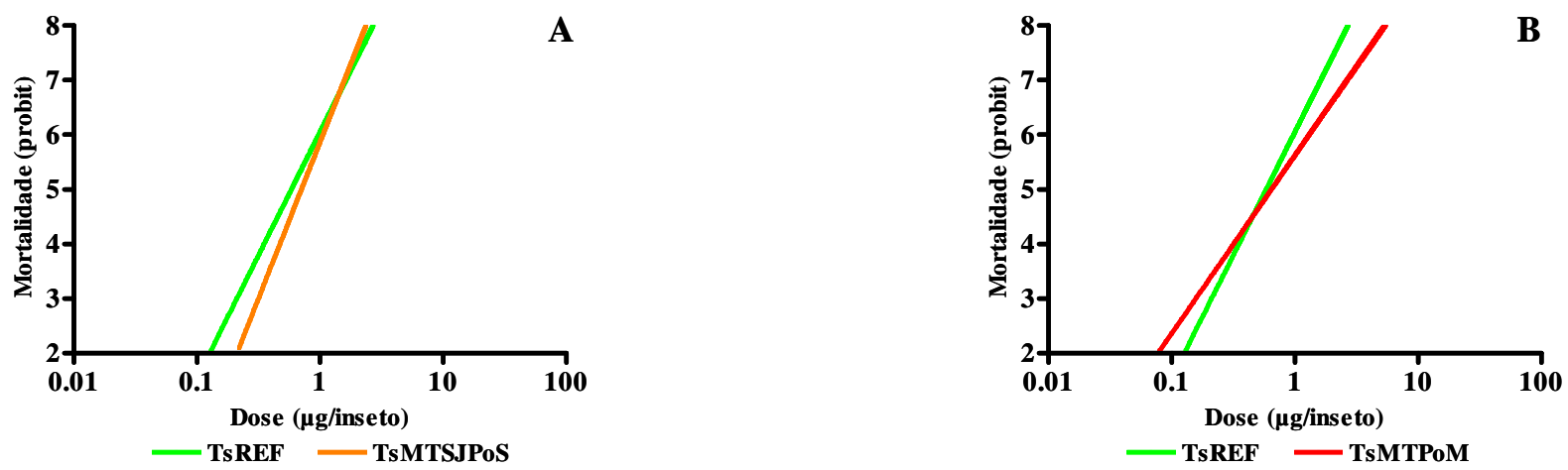

Figura 30 - Curva de mortalidade de populações de Triatoma sordida, em escala logarítmica, para o inseticida deltametrina. A: Comparação entre TsREF (4,51) e TsMTSJPoS $(5,72)$. B: Comparação entre TsREF $(4,51)$ e TsMTPoM $(3,25)$. 
A população de triatomíneo do município de Lontra, no Estado de Minas Gerais, (TsMGLoR) apresentou um valor de coeficiente angular de 3,47 que confere inclinação da reta menor que a população de referência (Fig. 31). Esse valor sugere maior oportunidade de seleção de indivíduos resistentes.

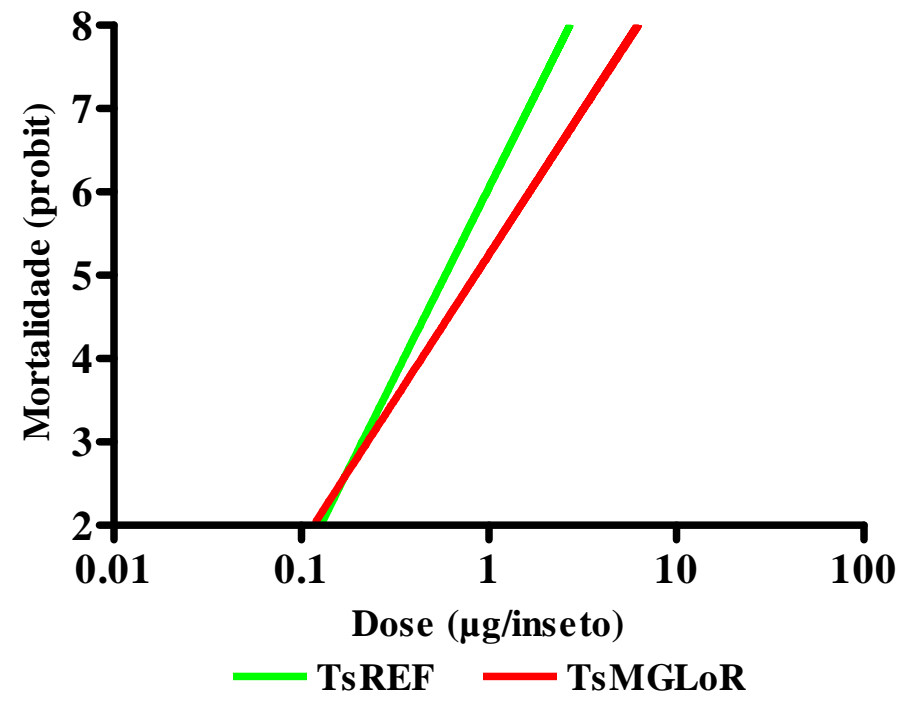

Figura 31 - Curva de mortalidade dose resposta, em escala logarítmica, comparando o coeficiente angular de TsREF $(4,51)$ e TsMGLoR $(3,47)$. 
O valor de coeficiente angular da população de triatomíneo procedente do município de Aurora do Tocantins/TO (TsTOAToM), foi de 3,15 representando ser mais heterogênea que a população de referência (Fig. 32). Com esse resultado espera-se que exista uma distribuição maior de indivíduos resistentes nessa população.

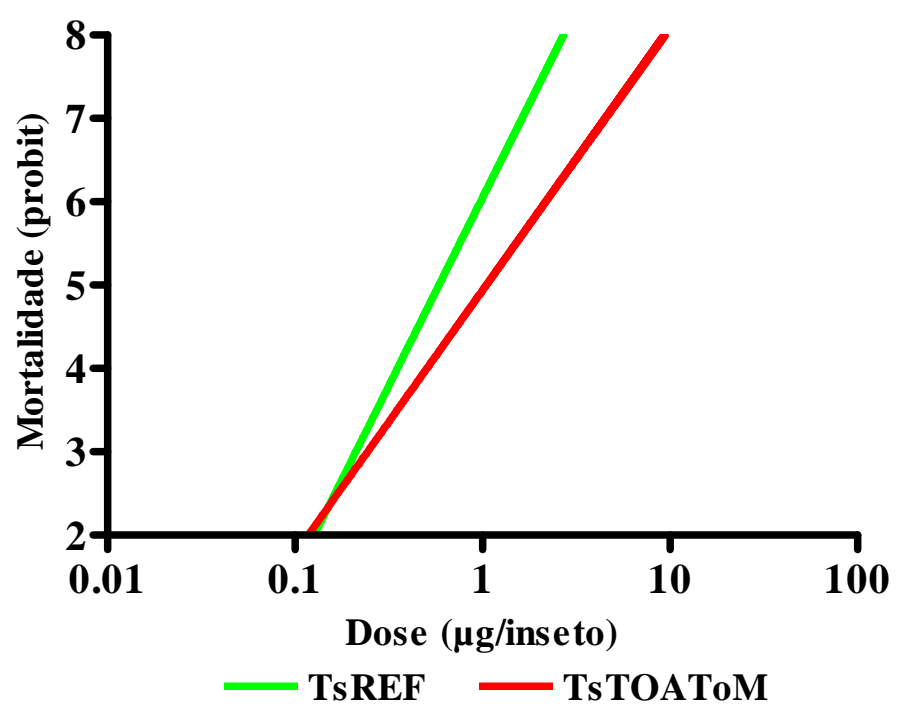

Figura 32 - Curva de mortalidade dose resposta, em escala logarítmica, comparando o coeficiente angular de TsREF $(4,51)$ e TsTOAToM $(3,15)$. 


\subsection{DESCRIÇÕES EM MEV DA ESTRUTURA CUTICULAR DE NINFAS DE $1^{\circ}$ ESTÁDIO TRATADAS COM DELTAMETRINA}

Todas as superfícies tratadas foram comparadas com o controle que recebeu apenas acetona (Fig. 33 a, b; Fig. 34 g, h; Fig. 35 m, n). A acetona manteve inalteradas as características do exoesqueleto da população normal, devido a sua rápida evaporação em condições ambientais.

No aumento de $300 \mathrm{X}$, a cutícula de ninfas de $1^{\circ}$ estádio de $P$. megistus apresenta aspecto "estrelado" com sensilas longas e finas. A base da inserção das cerdas é pouco evidente (Fig. 33 b, d, f), diferentemente, de T. brasiliensis, que possui textura com cavidades mais afastadas, sem contorno definido e com base da inserção das sensilas proeminente. As irregularidades das cavidades não atingem o ápice da base da inserção. O ápice tem aspecto liso (Fig. 34 h, j, 1).

A superfície cuticular de T. sordida (Fig. 35) é semelhante ao de $T$. brasiliensis (Fig. 34), porém, pode ser diferenciada pelas irregularidades que atingem todo o corpo da base da inserção das sensilas em T. sordida.

No aumento de 500X, as diferenças acima citadas, em relação às características morfológicas da inserção das sensilas podem ser observadas com mais detalhes (Figs. 36, 38 e 40).

$\mathrm{Na}$ aplicação das diferentes $\mathrm{DL}_{99}$ em $P$. megistus (4,36 $\left.\mu \mathrm{g} / \mathrm{inseto}\right), T$. brasiliensis (2,24 $\mu \mathrm{g} / \mathrm{inseto})$ e $T$. sordida $(1,91 \mu \mathrm{g} /$ inseto $)$ não foram constatadas alterações físicas, formação de cristais de inseticidas e deposição de materiais (Fig. 33 c, d; Fig. 34 i, j; Fig. 35 o, p). As DL99 para cada espécie podem ser visualizadas no Anexo 1, 2 e 3, deste trabalho. 
$\mathrm{Na}$ aplicação de concentração de $10 \mu \mathrm{g}$ /inseto não foram observadas diferenças significativas na aparência das superfícies torácicas das espécies estudadas (Fig. 33 e, f; Fig. 34 k, 1; Fig. 35 q, r; Figs. 37, 39 e 41).

No entanto, em P. megistus (Fig. 37), utilizando aumento de 1500X para a concentração de $30 \mu \mathrm{g} /$ inseto foi possível detectar a formação de "partículas arredondadas" aderidas à superfície das suturas intersegmentares, as quais apresentam semelhança morfológica com as extrusões solidificadas, descritas por JUÁREZ e FERNÁNDEZ (2007).

A interação entre as diferentes concentrações de deltametrina na estrutura cuticular do tórax de ninfas de $1^{\circ}$ estádio permitiram deduzir que a penetração e a distribuição do inseticida diluído em acetona atuam de maneira rápida, na cutícula dos insetos. Esses processos, provavelmente acontecem no sistema de cavidades intercomunicantes que possuem estruturas formadas por linhas sinuosas e que constituem o exoesqueleto de ninfas de $1^{\circ}$ estádio de $P$. megistus, $T$. brasiliensis e $T$. sordida; estudadas nesta tese (Figs. 37, 39 e 41).

A possibilidade de deslocamento das partículas de inseticidas em direção ao interior dos "canais intercomunicantes" não pode ser rejeitada, uma vez, que cortes histológicos com posterior visualização em MEV não foram realizados. Certamente, há poucos estudos que utilizam MEV para analisar a resistência de triatomíneos, portanto, novos caminhos poderão se abrir por meio das análises de diferentes espécies e até mesmo associadas a outras ferramentas, tais como: a bioquímica, a histologia e a biologia molecular.

Os ensaios biológicos permitem a detecção e quantificação de resistência aos diferentes grupos de inseticidas, sendo utilizadas para responder a seguinte questão: 
Este produto é capaz de controlar esta população de insetos vetores nesta localidade, neste momento?

A partir do momento que a resistência é detectada levantam-se outras perguntas: Esta resistente a qual produto? O que eu faço agora?

Nesse contexto acima os métodos bioquímicos e moleculares tem a função de detectar e avaliar qual o mecanismo de resistência específico que está influenciando o aumento das atividades das enzimas detoxificantes e os processos metabólicos que favorecem a eliminação ou inativação dos inseticidas no interior dos insetos. Esses métodos podem revelar antecipadamente o aparecimento de indivíduos alterados nas populações de vetores, assim como determinar padrões de resistência cruzada para os tipos particulares de inseticidas.

Os métodos histológicos podem ser úteis para detectar a presença de poros, orifícios e canais que se comunicam com o meio interno dos insetos e que, talvez possam desempenhar um papel muito importante no processo de penetração e absorção dos inseticidas. Assim, as técnicas histógicas juntamente com a MEV permitirão o esclarecimento de questões fundamentais, tais como: existe associação de outro mecanismo que confere resistência aos vetores da DC, como por exemplo, a redução na penetração? 

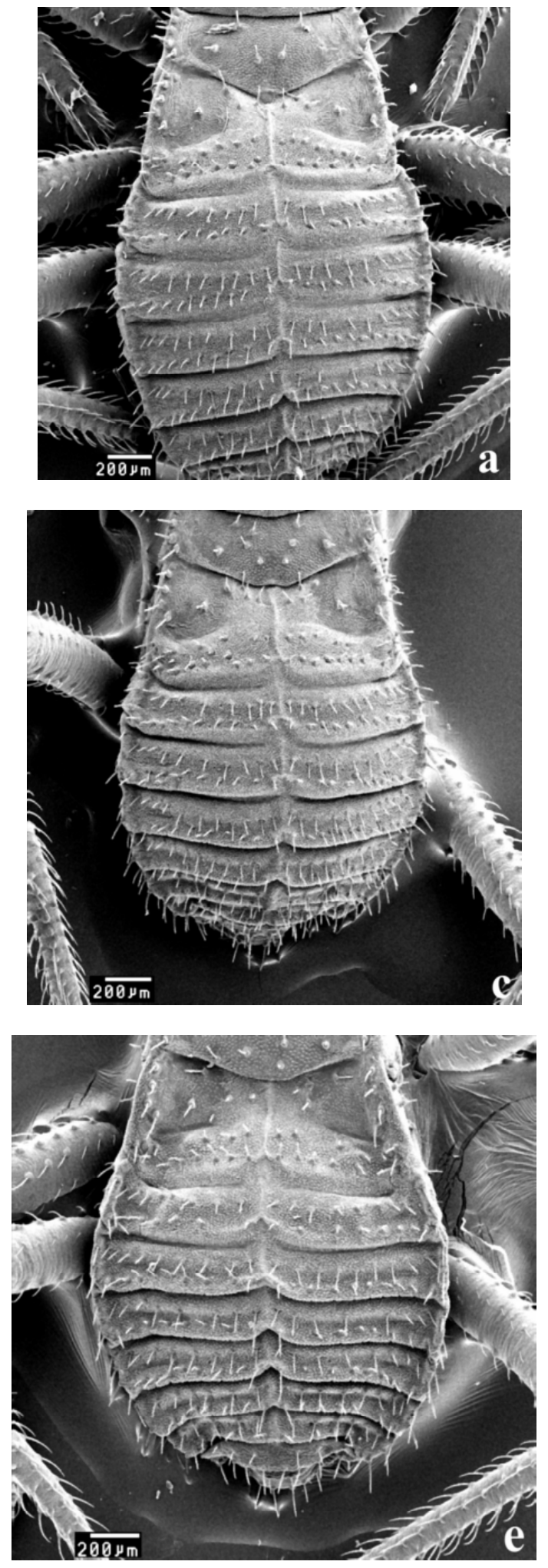
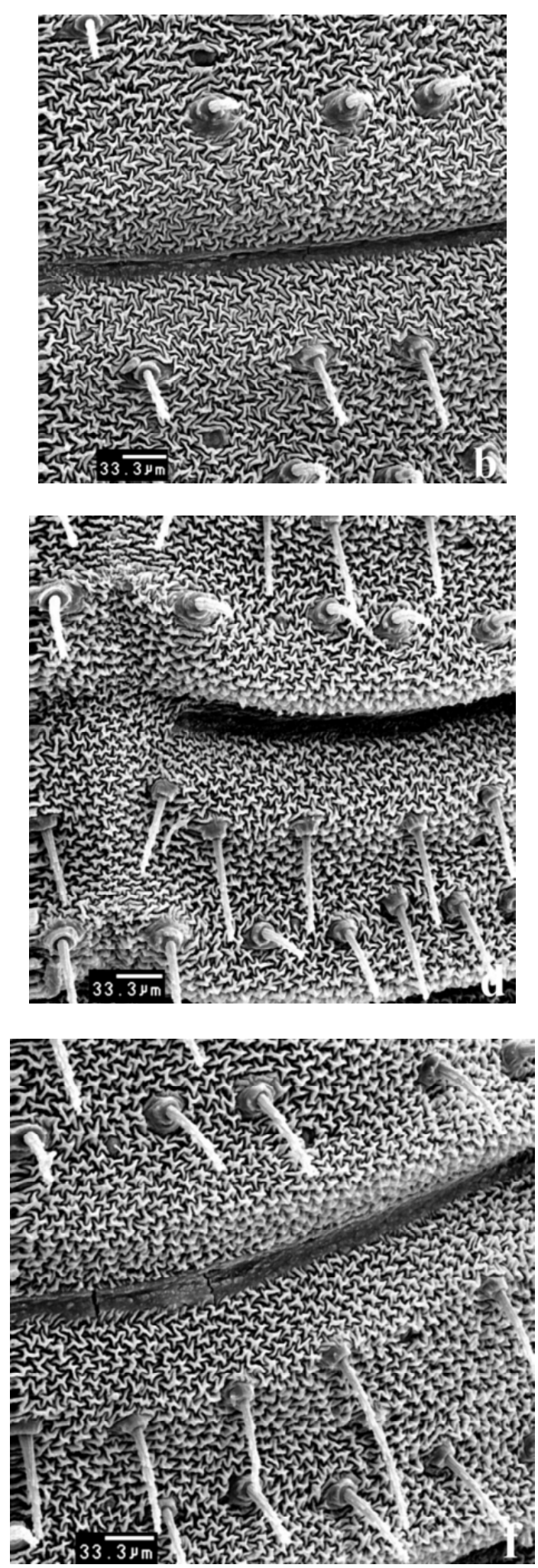

Figura 33 - Abdômen de ninfas de $1^{\circ}$ estádio de Panstrongylus megistus por meio de MEV. a: controle tratado apenas com acetona (50X). b: controle tratado apenas com acetona (300X). c: aplicação tópica de DL99 4,36 $\mu \mathrm{g} /$ inseto (50X). d: aplicação tópica de $\operatorname{DL}_{99} 4,36 \mu \mathrm{g} /$ inseto (300X). e: aplicação tópica de $10 \mu \mathrm{g} /$ /inseto. f: aplicação tópica de $10 \mu \mathrm{g} /$ inseto. 

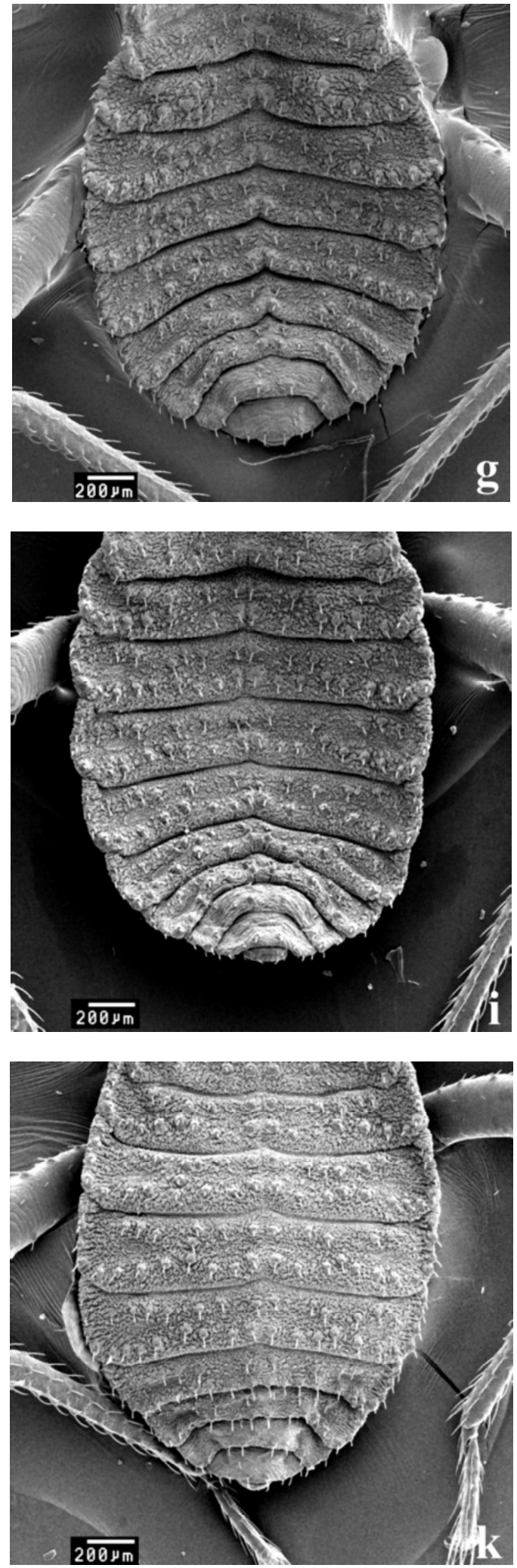
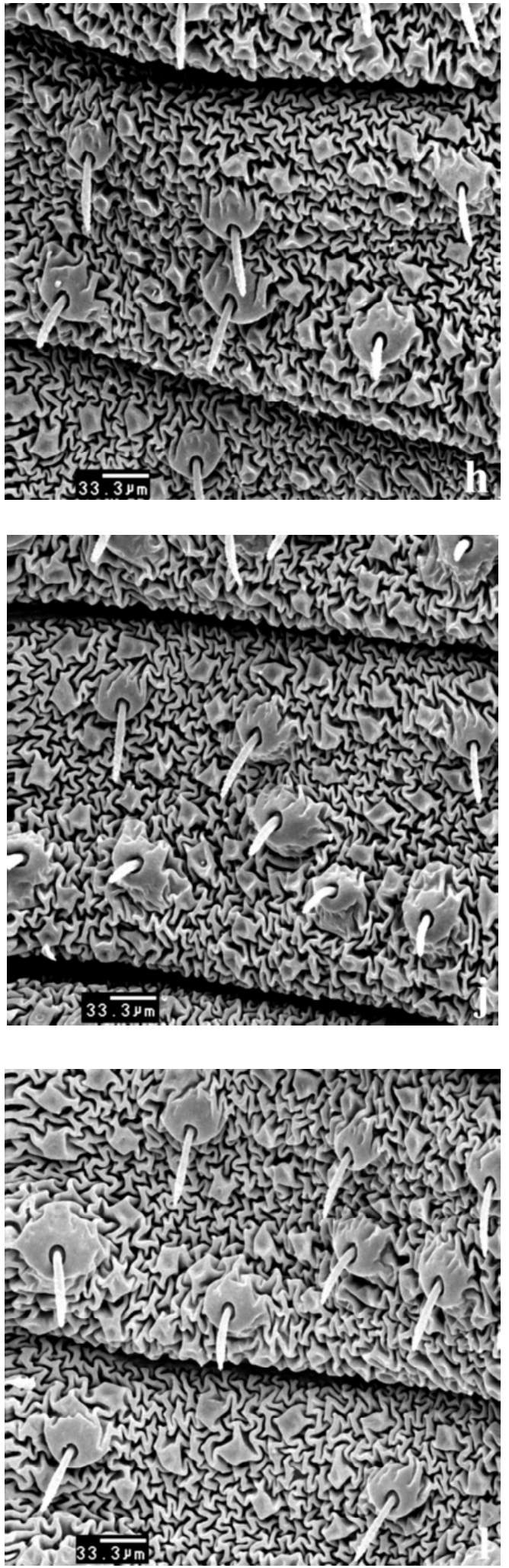

Figura 34 - Abdômen de ninfas de $1^{\circ}$ estádio de Triatoma brasiliensis por meio de MEV. g: controle tratado apenas com acetona (50X). h: controle tratado apenas com acetona (300X). i: aplicação tópica de DL $992,24 \mu \mathrm{g} /$ inseto (50X). j: aplicação tópica de DL99 2,24 $\mu \mathrm{g}$ /inseto (300X). k: aplicação tópica de $10 \mu \mathrm{g} /$ inseto. 1: aplicação tópica de $10 \mu \mathrm{g} /$ inseto. 

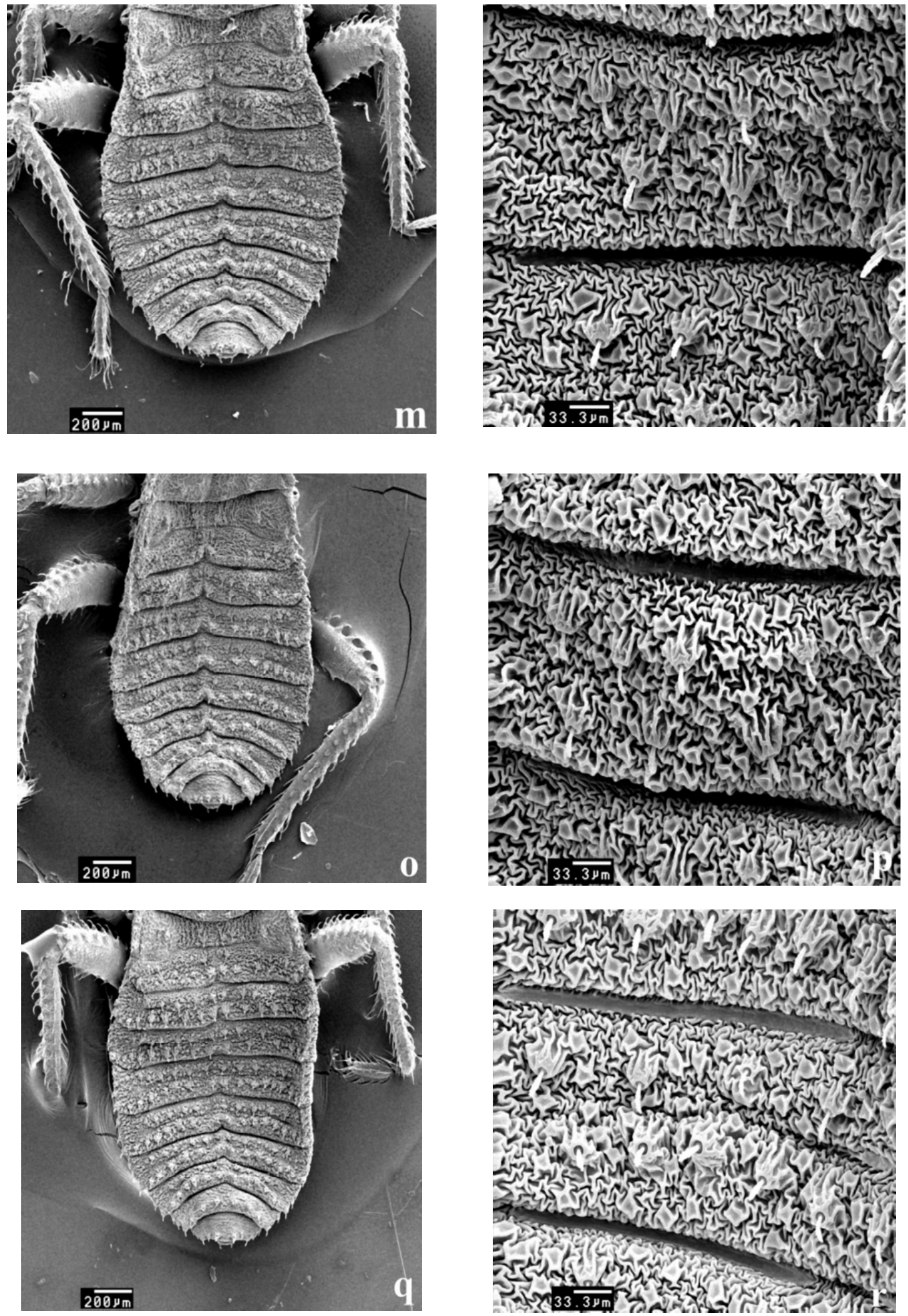

Figura 35 - Abdômen de ninfas de $1^{\circ}$ estádio de Triatoma sordida por meio de MEV. $\mathrm{m}$ : controle tratado apenas com acetona $(50 \mathrm{X})$. $\mathrm{n}$ : controle tratado apenas com acetona (300X). o: aplicação tópica de $\mathrm{DL}_{99} 1,91 \mu \mathrm{g} /$ inseto (50X). p: aplicação tópica de DL 99 $1,91 \mu \mathrm{g} /$ /inseto $(300 \mathrm{X})$. q: aplicação tópica de $10 \mu \mathrm{g} /$ inseto. r: aplicação tópica de 10 $\mu \mathrm{g} / \mathrm{inseto.}$ 


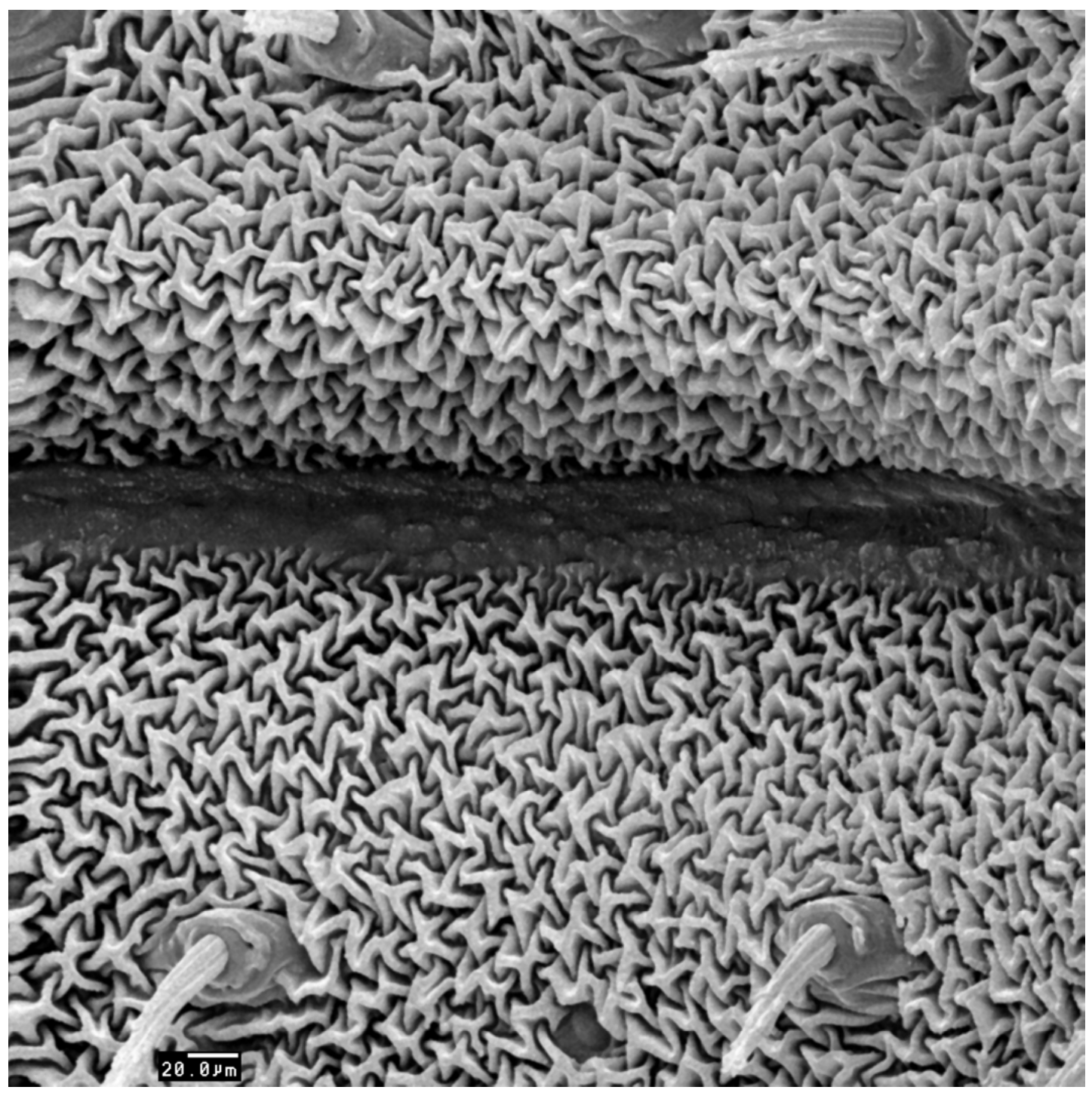

Figura 36 - Abdômen de ninfas de $1^{\circ}$ estádio de Panstrongylus megistus após aplicação tópica de $30 \mu \mathrm{g} /$ inseto de deltametrina diluído em acetona. Aumento de 500X: detalhes da estrutura do exoesqueleto. 


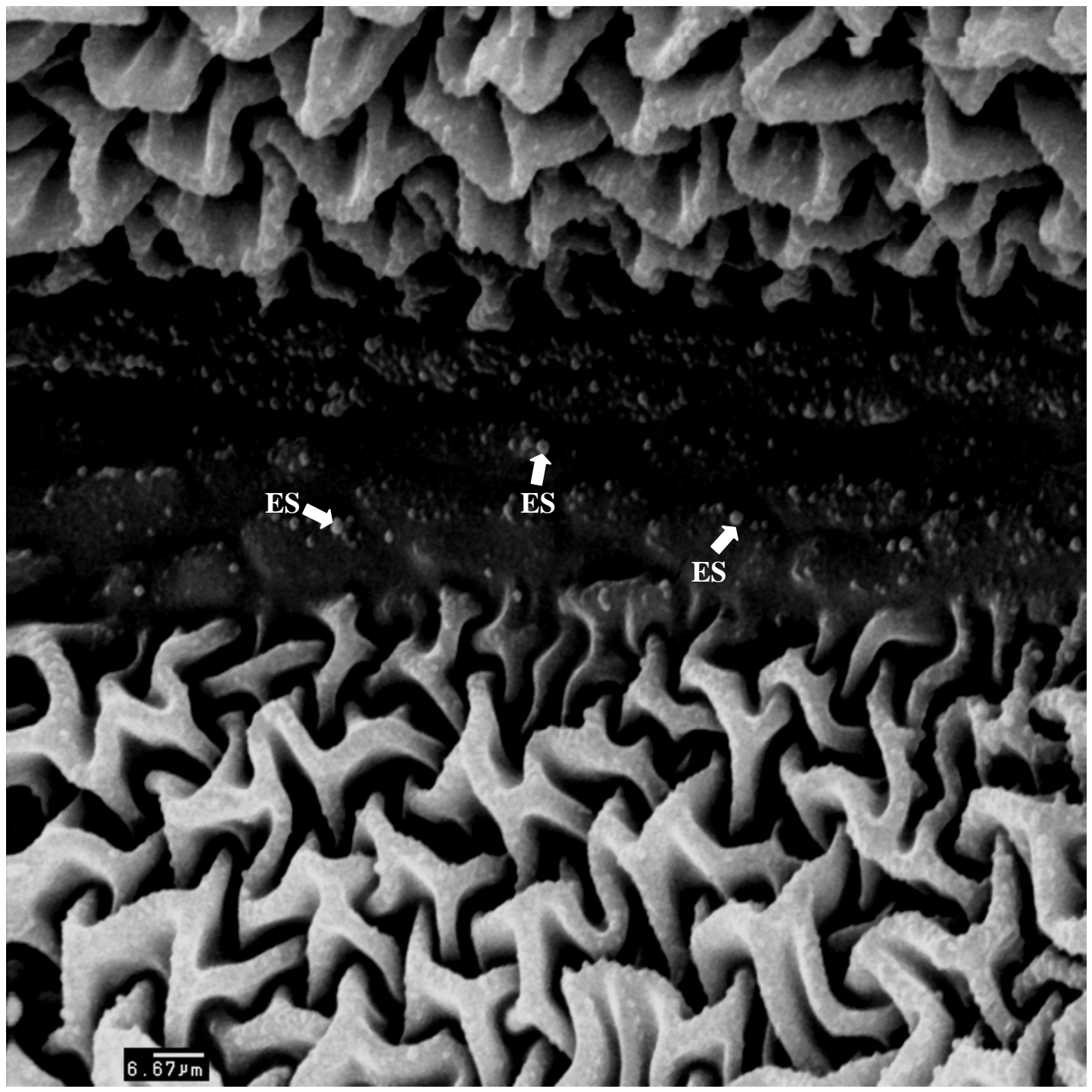

Figura 37 - Abdômen de ninfas de $1^{\circ}$ estádio de Panstrongylus megistus após aplicação tópica de $30 \mu \mathrm{g}$ /inseto de deltametrina diluído em acetona. Aumento de 1500X: Superfície cuticular com extrusões solidificadas (ES) aderidas, conforme JUÁREZ e FERNÁNDEZ (2007). 


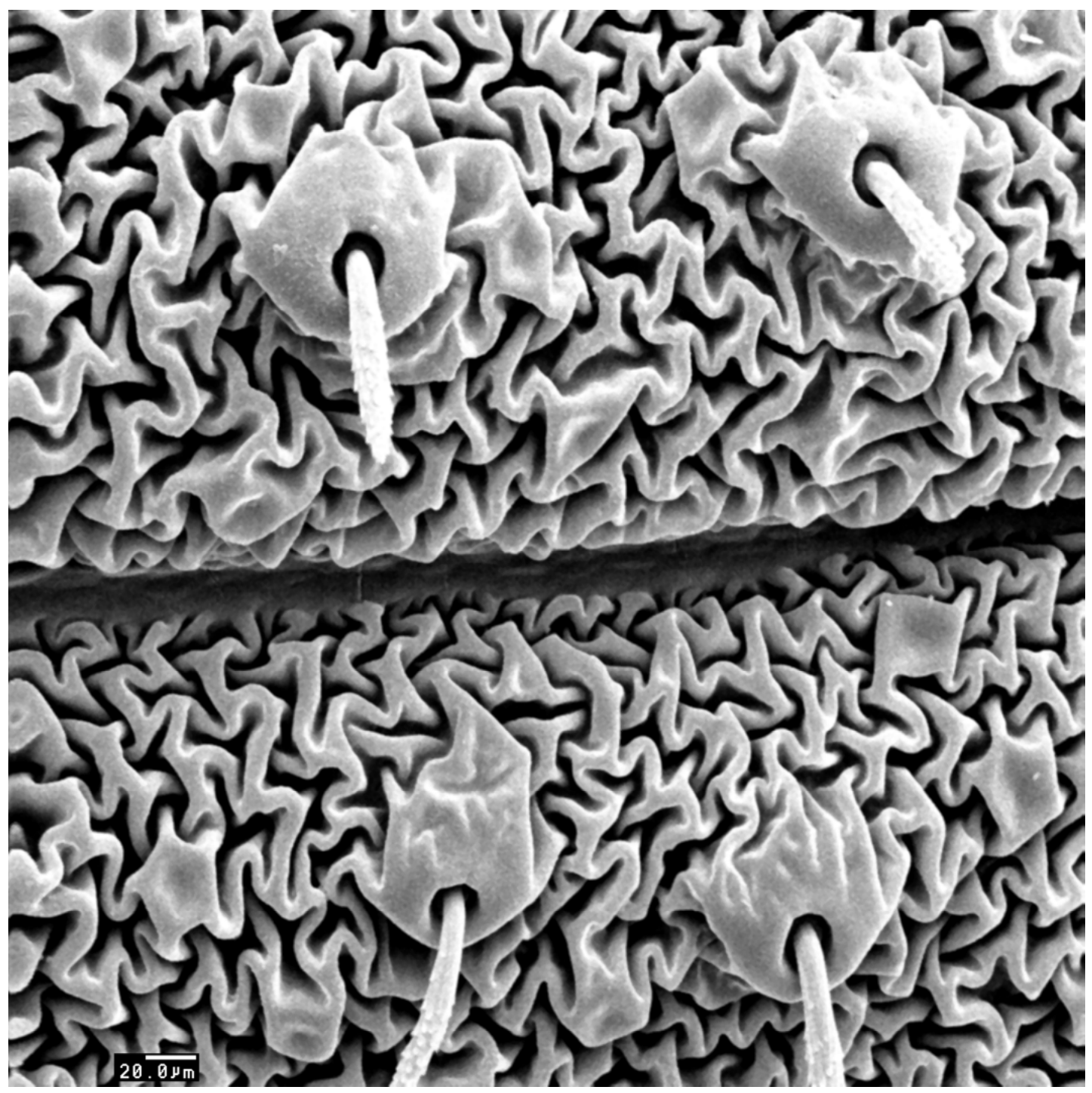

Figura 38 - Abdômen de ninfas de $1^{\circ}$ estádio de Triatoma brasiliensis após aplicação tópica de $30 \mu \mathrm{g} /$ inseto de deltametrina diluído em acetona. Aumento de 500X: detalhes da estrutura do exoesqueleto. 


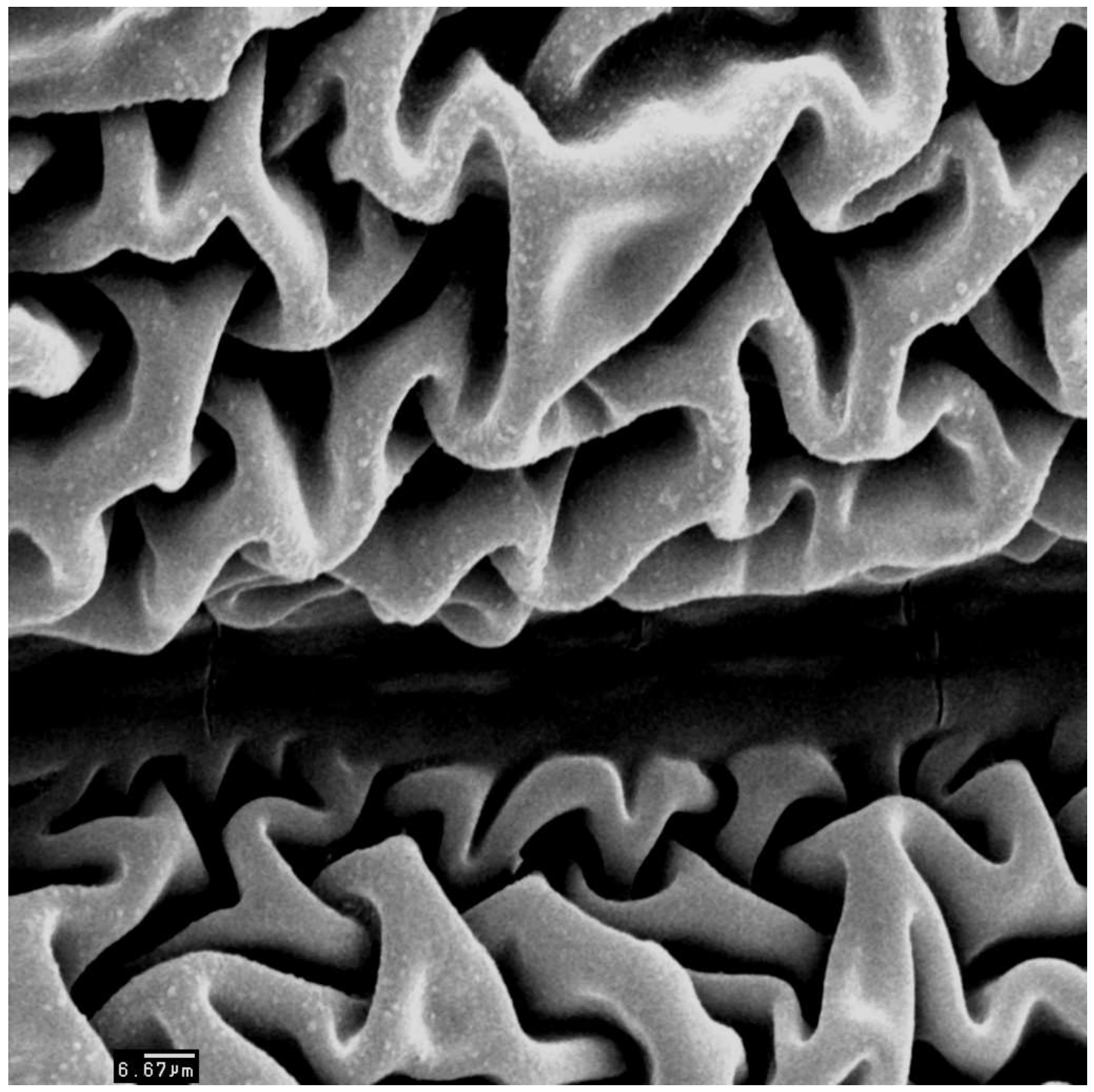

Figura 39 - Abdômen de ninfas de $1^{\circ}$ estádio de Triatoma brasiliensis após aplicação tópica de $30 \mu \mathrm{g}$ /inseto de deltametrina diluído em acetona. Aumento de 1500X: Superfície cuticular aparentemente sem inseticida aderido. 


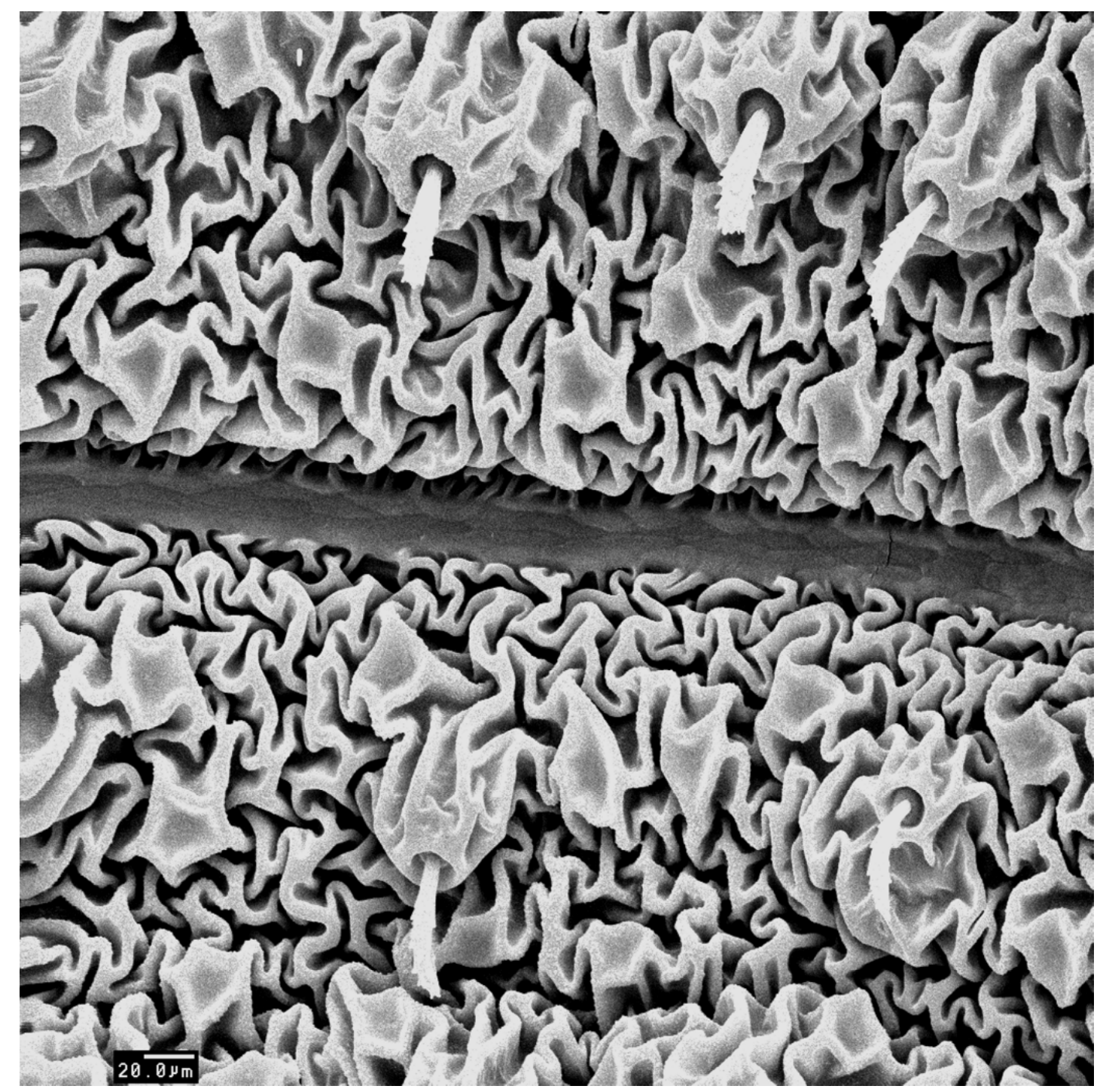

Figura 40 - Abdômen de ninfas de $1^{\circ}$ estádio de Triatoma sordida após aplicação tópica de $30 \mu \mathrm{g} /$ inseto de deltametrina diluído em acetona. Aumento de 500X: detalhes da estrutura do exoesqueleto. 


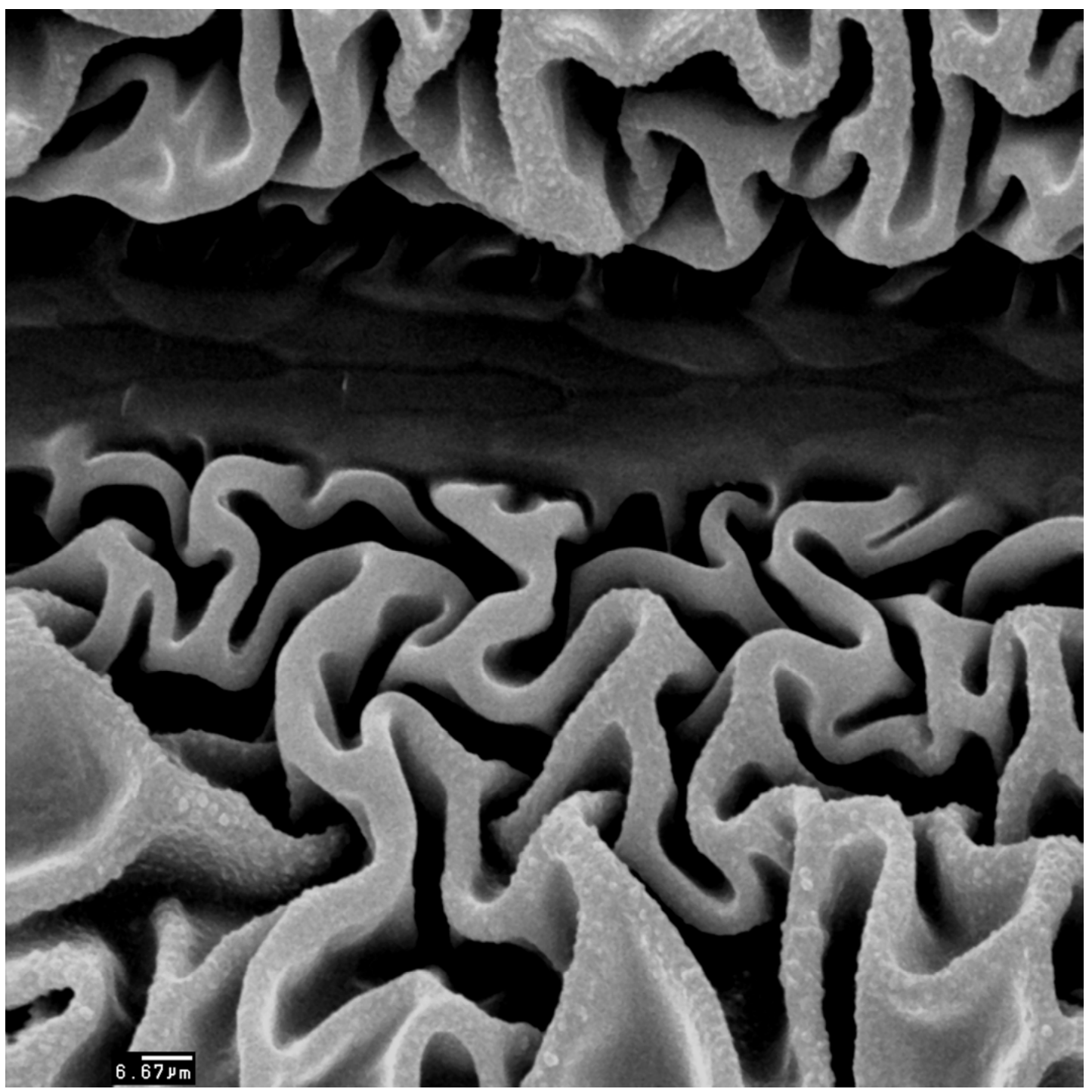

Figura 41 - Abdômen de ninfas de $1^{\circ}$ estádio de Triatoma sordida após aplicação tópica de $30 \mu \mathrm{g} /$ inseto de deltametrina diluído em acetona. Aumento de 1500X: superfície aparentemente sem inseticida aderido. 


\subsection{RESULTADOS DOS BIOENSAIOS DE CAMPO COM}

\section{POPULAÇÕES DE T. brasiliensis}

Os bioensaios de campo foram dirigidos apenas para algumas populações de T. brasiliensis, uma vez que não foi possível a obtenção de número suficiente de ninfas de $1^{\circ}$ estádio de $P$. megistus e $T$. sordida para a exposição aos diferentes substratos.

As três populações de $T$. brasiliensis selecionadas foram coletadas no município de Oeiras, no Estado do Piauí. Apesar de pertencerem ao mesmo município, diferem-se em relação às localidades; ou seja, primeira população foi capturada no Sítio Tabocas (TbPIOeT), a segunda no Sítio Formosa II (TbPIOeF) e a terceira população foi no Sítio Sapé (TbPIOeS). Essas populações apresentaram as maiores $\mathrm{RR}_{50}$ e $\mathrm{RR}_{95}$, motivos pelos quais foram escolhidas para as provas de campo.

Os resultados dos bioensaios de campo demonstraram alta mortalidade para as três populações estudadas quando expostas em substratos de barro (taipa), madeira sem pintura e tijolo sem reboco, previamente tratados com deltametrina WG 250, a $25 \mathrm{mg}$ i.a. $/ \mathrm{m}^{2}$.

Os resultados da taxa de mortalidade foi de $100 \%$ para todas as populações de campo nas diferentes superfícies estudadas. A mortalidade da população controle foi zero, portanto não houve a necessidade de corrigir os dados obtidos. 


\section{DISCUSSÃO}

Nesta investigação foram estimados, por meio de bioensaios dose resposta, os níveis de resistência de três espécies de triatomíneos, potencialmente, vetoras da DC procedentes de 11 Estados, do Brasil. Esses resultados foram confirmados por meio dos bioensaios de campo. Simultaneamente foram desenvolvidas observações sobre as características ultra-estruturais do tegumento abdominal de ninfas de $1^{\circ}$ estádio tratadas com deltametrina. Assim como se realizou a comparação das $R R_{50}$ e $R R_{95}$ das diferentes populações de campo com a linhagem suscetível.

Além disso, para cada população foi determinado o perfil do coeficiente angular que representa a variação da homogeneidade da amostra. Quanto menor o valor do coeficiente angular, maior será a inclinação da reta no gráfico; portanto, menos homogênea será a população.

O grau de homogeneidade é inversamente proporcional ao nível de variação genética. Dessa forma, quanto menor a homogeneidade, o grau de variação será maior, consequentemente a probabilidade de ocorrência de indivíduos resistentes também aumentará. Ainda, a padronização de uma única população de referência é discutida para subsidiar futuros estudos de suscetibilidade de triatomíneos aos inseticidas utilizados no seu controle.

Os parâmetros estabelecidos para interpretação das Razões de Resistência em monitoramento de resistência de triatomíneos obedeceram aos seguintes critérios, conforme OPAS (2005b):

- $\mathrm{RR} \leq 5$ considera-se que as diferenças de suscetibilidade estão sendo produzidas por variações individuais. Recomenda-se a continuidade do monitoramento de resistência para o acompanhamento dos níveis de resistência e o 
prosseguimento às ações de controle com o mesmo inseticida que está sendo utilizado.

- $5 \leq \mathrm{RR} \leq 20$ considera-se que existe resistência em progresso, sendo necessário avaliar as falhas de controle no campo. Caso sejam confirmadas as falhas no controle é necessário mudar para outro inseticida com distinto modo de ação. Se as falhas no controle não se confirmarem, o mesmo inseticida continuará a ser utilizado. Contudo será necessário intensificar o monitoramento de resistência realizando avaliações entomológicas com 1 a 12 meses após a borrifação.

- $\mathrm{RR} \geq 20$ considera-se que a resistência já está estabelecida, na qual é recomendada a troca de inseticidas por outro de distinto modo de ação.

A partir do primeiro registro de resistência de $R$. prolixus a dieldrin, na Venezuela, ressalta-se que diversas pesquisas de suscetibilidade de triatomíneos têm detectado elevados níveis de resistência aos piretróides deltametrina, $\beta$-cipermetrina e $\beta$-ciflutrina em populações de T. infestans procedentes do Norte da Argentina e Sul do Brasil e Bolívia (NOCERINO e HERNÁNDEZ, 1986; VASSENA et al., 2000; VASSENA e PICOLLO, 2003; GONZÁLEZ-AUDINO et al., 2004; PICOLLO et al., 2005; ORIHUELA et al., 2008; TOLOZA et al., 2008).

Nesse contexto, o presente trabalho fornece valiosas informações sobre os níveis de suscetibilidade de três espécies sinantrópicas transmissoras de $T$. cruzi, no Brasil. A seguir são discutidos os resultados dos bioensaios de laboratório e campo de cada espécie, assim como a proposta de utilização de novas ferramentas para estudos de monitoramento de resistência de triatomíneos. 


\subsection{MONITORAMENTO DE RESISTÊNCIA DE P. megistus A} DELTAMETRINA

OLIVEIRA FILHO et al. (1999) comparando a eficácia do princípio ativo de piretróides, por meio de aplicação tópica de $1 \mu 1$ de solução do inseticida, em ninfas de $5^{\circ}$ estádio de $P$. megistus, $T$. infestans e $R$. prolixus recomendaram a não utilização de alfacipermetrina $\left(\mathrm{DL}_{50}=109,0 \mu \mathrm{g} / \mathrm{ninfa}\right)$, ciflutrina $\left(\mathrm{DL}_{50}=41,9\right.$ $\mu \mathrm{g} /$ ninfa) e deltametrina $\left(\mathrm{DL}_{50}=287,8 \mu \mathrm{g} / \mathrm{ninfa}\right.$ ) em ações de controle químico de $P$. megistus. Certamente, pela utilização de concentrações maiores e de diferentes estádios de desenvolvimento, os resultados dos autores não podem ser comparados com os obtidos neste trabalho.

Os resultados obtidos no presente trabalho indicam, pela primeira vez, a baixa resistência de $P$. megistus ao piretróide deltametrina $\left(\mathrm{RR}_{50}=1,97\right)$. Porém, os valores encontrados para $P$. megistus, assim como para outras espécies devem ser limitados para as amostras estudadas, portanto não são válidos para outras localidades, municípios e/ou estados.

O maior valor de coeficiente angular foi para a população de Serranópolis do Iguaçu/PR (PmPRSIg) com 7,20; consequentemente essa população possui pouca variabilidade genética, quando comparada com a população de referência (Fig. 9). De acordo com BROGDON e MCALLISTER (1998) as interpretações sobre o valor do coeficiente angular permitem inferências sobre o nível de variabilidade genética de uma determinada população. Conforme esses autores, as populações com pouca variabilidade genética possuem reduzidas chances de modificar sua RR, enquanto 
que as populações com grande variabilidade genética apresentam maiores chances de alterar sua RR, em relação ao inseticida utilizado ao longo do tempo.

O elevado valor do coeficiente angular de $P$. megistus sugere pouca variabilidade genética. Provavelmente, a probabilidade de alteração no nível de resistência dessa população seja menor, talvez por causa da redução na distribuição de indivíduos com alelos de resistência.

Por outro lado, embora tenha sido observado um alto grau de homogeneidade, ocorrem diferenças no comportamento de $P$. megistus que merecem atenção. Conforme mencionado anteriormente, em certas regiões, essa espécie habita ecótopos naturais. Em outras, apresenta forte adaptação aos domicílios humanos e anexos. Em direção ao norte-nordeste do Estado de São Paulo, observa-se domiciliação dessa espécie à medida que se segue rumo ao Estado de Minas Gerais, Bahia e áreas do Nordeste. Ao sul do Estado de São Paulo, a espécie é encontrada na maioria das vezes ocupando ecótopos naturais (FORATTINI, 1972).

Assim, o Estado de São Paulo representa área de transição entre as duas áreas geográficas distintas que possuem diferentes aspectos comportamentais de $P$. megistus. Os estudos para avaliação do potencial de domiciliação de P. megistus, utilizando Galinheiros Experimentais (GE), evidenciaram a presença de comportamentos distintos em áreas do Estado de São Paulo. Nos municípios de Cássia dos Coqueiros, Guaíra e São João da Boa Vista; localizados no nordeste do Estado de São Paulo e com vegetação formada pela floresta subcaducifólia tropical do oeste observam-se forte domiciliação e tendência invasiva, tanto de ambientes extradomiciliares quanto intradomiciliares (FORATTINI et al., 1977a; 1977b; 1977c; FORATTINI et al., 1978a). 
Por outro lado, nos municípios litorâneos de Iguape, Pariquera-Açu e Sete Barras, situados na Serra do Mar, cuja vegetação é formada pela floresta perenifólia higrófila ou latifoliada tropical úmida, nota-se o não desenvolvimento da capacidade de adaptação ao ambiente domiciliar, segundo FORATTINI et al. 1978b.

O comportamento exclusivo desse inseto seria o resultado da destruição dos ambientes naturais provocados pelo homem. FORATTINI et al. (1978b) sugerem que com a fragmentação do seu centro de endemismo, a Floresta Tropical Atlântica, P. megistus dispersou-se a partir da Serra do Mar, seguindo em direção oeste na medida que diminuía a aridez. Nessas áreas secas houve a seleção de populações que desenvolveram maior capacidade de adaptação aos ambientes artificiais.

FORATTINI (1980) delimitando a distribuição do fenômeno da domiciliação triatomínica, nas diferentes regiões ecológicas brasileiras, caracterizou o sudeste do Estado do Paraná como área livre de infestação domiciliar por triatomíneos. Dessa forma, pode se considerar que o município de Serranópolis do Iguaçu, localizado na parte sudoeste do Estado não está incluído na área de distribuição silvestre do vetor. Portanto, a população analisada neste trabalho (PmPRSIg) apresenta certo grau de domiciliação sofrendo ações sistemáticas de controle.

Além disso, devido à análise de somente uma população de $P$. megistus, torna-se necessária a ampliação do número de amostras, principalmente de áreas do nordeste do país, na qual essa espécie é encontrada infestando o ambiente domiciliar.

Os conhecimentos existentes até agora a respeito do monitoramento de resistência de $P$. megistus e de outras espécies triatomínicas, de importância médica brasileira, necessitam ser melhor conhecidos. Os resultados sobre o perfil de 
resistência, atualmente disponíveis, além de esparsos são em geral isolados e, em alguns casos inexistentes.

Dessa maneira, os procedimentos laboratoriais e de campo, disponibilizados neste trabalho, serão de fundamental importância para novos estudos de resistência de populações de triatomíneos.

6.2 MONITORAMENTO DE RESISTÊNCIA DE T. brasiliensis E DE ALGUMAS ESPÉCIES DO COMPLEXO T. brasiliensis

Na Argentina, em 1995, iniciou-se ampla avaliação de resistência de $T$. infestans a inseticidas, baseada em um programa de colaboração entre o Centro de Investigaciones em Plagas e Insecticidas/CIPEIN e o Ministério da Saúde Argentino. Do total das treze províncias avaliadas, cinco (San Juan, Catamarca, San Luis, Mendoza e Salta) apresentaram níveis de resistência incipientes, provavelmente devido ao uso intensivo de piretróides, nos últimos anos. Os valores da $\mathrm{RR}_{50}$ foram de: 1,8 para San Juan; 2,6 para Catamarca; 3,0 para San Luis; 3,8 para Mendoza e 5,6 para Salta (VASSENA e PICOLLO, 2003).

Nesta pesquisa, duas populações piauienses de T. brasiliensis $\mathrm{TbPIOeF}\left(\mathrm{RR}_{50}\right.$ $=1,94)$ e TbPIOeS $\left(R_{50}=2,17\right)$ apresentaram valores próximos aos das populações argentinas de San Juan $(1,8)$ e Catamarca $(2,6)$ de $T$. infestans. Essas populações foram capturadas no município de Oeiras/PI, considerada área endêmica de transmissão de DC.

Em 1976, os estudos clínicos e epidemiológicos comprovaram uma soropositividade para infecção chagásica em 12,1\% dos moradores de duas 
localidades (Colônia e Oeiras) do município de Oeiras/PI. Nos domicílios, $T$. brasiliensis foi o único triatomíneo capturado com um índice de infecção natural de 4,9\% (CORREIA-LIMA, 1976).

Nesse contexto, tratando-se de uma área de transmissão ativa, onde há pelo menos trinta anos realizam-se ações sistematizadas de controle, possivelmente os valores de resistência obtidos para essas populações sejam o resultado da aplicação frequentes de inseticidas, desde a década de 70.

Por outro lado vale ressaltar que, até o momento, as pequenas alterações de suscetibilidade a inseticidas não contribuíram para a emergência de novos casos da DC. Por exemplo, no município de Oeiras, em 1996, apesar do encontro de 576 exemplares de $T$. brasiliensis (371 no intradomicílio e 205 no peridomicílio) com um índice de infecção natural de 5,5\% para T. cruzi, a prevalência da infecção chagásica, em menores de 10 anos de idade, foi de apenas $0,5 \%$. Tal fato evidencia claramente o êxito do controle da transmissão da infecção na área mencionada (COURA et al., 1996).

Recentemente, SONODA (2009) também detectou baixos níveis de resistência de $T$. brasiliensis ao piretróide deltametrina em populações procedentes do município de Tauá, no Estado do Ceará. Esse autor avaliou populações intradomiciliares (Cachoeira dos Pedrosas, Cachoeira do Júlio, Dormideira e Mutuca), peridomiciliares (Cachoeira dos Pedrosas, Dormideira, Morada Nova do Thomas e Mutuca) e silvestre (Cachoeira dos Pedrosas).

Conforme esse autor, os valores de $\mathrm{RR}_{50}$ das populações intradomiciliares foram de 1,16 para Cachoeira dos Pedrosas; 1,58 para Mutuca; 1,74 para Cachoeira do Júlio e 1,79 para Dormideira, enquanto os valores para as populações silvestres e 
peridomiciliares foram de 1,00 para Cachoeira dos Pedrosas (silvestre); 1,26 para Cachoeira dos Pedrosas (peri); 1,58 para Mutuca e 1,74 para Morada Nova do Thomas. Esses resultados permitiram a classificação de todas as amostras como altamente suscetíveis a deltametrina.

Neste trabalho, a população de triatomíneo do município de Itaporanga/PB (TbPBItV) apresentou um valor de $\mathrm{RR}_{50}$ igual a 1,00 ng/inseto (Tab. 7). Nota-se que na avaliação de SONODA (2009) a população silvestre de Cachoeira dos Pedrosas apresentou valor idêntico de $\mathrm{RR}_{50}$. Essas populações, cujos valores correspondem a 1,00 ng/inseto, apresentaram padrões de suscetibilidade iguais ou até menores que a linhagem de referência, portanto, em estudos futuros poderão ser utilizados como população de referência.

Além disso, os resultados de SONODA (2009) para a população intradomiciliar de Cachoeira dos Pedrosas $\left(\mathrm{RR}_{50}=1,16\right)$ e peridomiciliar de Cachoeira dos Pedrosas $\left(R_{50}=1,26\right)$ e Morada Nova do Thomas $\left(R_{50}=1,74\right)$ encontram-se equivalentes para nossas populações de Petrolina/PE (1,16 ng/inseto), Serra Talhada/PE $\left(\mathrm{RR}_{50}=1,25\right)$ e do Sítio Tabocas $\left(\mathrm{RR}_{50}=1,75\right)$, respectivamente. Dessa maneira, ao contrário das expectativas, pode-se concluir que para alguns municípios da região Nordeste a suscetibilidade de $T$. brasiliensis encontra-se elevada.

Os baixos níveis de resistência a deltametrina estimados para T. brasiliensis são promissores e, possivelmente podem ser explicados por dois principais motivos: i) introdução massiva de genes suscetíveis e, ii) eficiente ação toxicológica dos inseticidas da classe dos piretróides.

De acordo com ALZOGARAY (1998) durante o processo evolutivo nos genomas das populações naturais ocorrem diversas mutações ao acaso, as quais são 
direcionadas, harmoniosamente pela interação entre os fenótipos e o meio ambiente. Se a interação favorecer a sobrevivência de indivíduos mutantes, a frequência das mutações irá aumentar.

A utilização de compostos químicos para o controle de vetores é uma pressão seletiva que favorece a sobrevivência de indivíduos resistentes. A continuidade da pressão, ao longo das gerações pode gerar a eliminação dos indivíduos suscetíveis. Sabe-se que a freqüência inicial de um alelo de resistência em uma população natural varia de $10^{-5}$ a $10^{-2}$ (METACALF, 1989).

Quando ocorre a introdução de novos indivíduos suscetíveis, especialmente, de triatomíneos de áreas silvestres, as quais nunca tiveram contato com inseticidas, o intercâmbio genético pode provocar uma diminuição da frequência de fenótipos resistentes. Em outras palavras, o processo de migração de indivíduos suscetíveis favorece a diluição dos genes resistentes nos cruzamentos naturais entre espécies de uma mesma população. Em casos extremos poderá ocorrer o desaparecimento dos indivíduos resistentes.

Hoje, os trabalhos de biologia molecular comprovam a elevada permuta de material genético entre populações domésticas e peridomésticas de T. brasiliensis, assim, como entre populações peridomésticas e silvestres (BORGES et al., 2000a; 2000b, 2005).

DIOTAIUTI et al. (2000) observaram, no município de Independência, Estado do Ceará, altíssimas taxas de dispersão de espécimens de T. brasiliensis que invadem as casas voando, demonstrando grande potencial de recolonização do ambiente artificial, a partir de focos silvestres e peridomiciliares. Depois de quatro 
meses, após a borrifação, cerca de 9,7\% das UD estavam positivas, dentre as 277 pesquisadas.

Além disso, resultados como esses sustentam a hipótese de que a elevada mobilidade espacial de T. brasiliensis pode ser considerada como principal obstáculo para a seleção de indivíduos resistentes.

Originalmente, $T$. brasiliensis dispersou-se, a partir dos centros de endemismo de Ibiapaba e Cariris-Araripe, ocupando nichos existentes por todo o domínio da caatinga (FORATTINI, 1980).

Em muitas regiões do Nordeste, a ação antrópica favoreceu o processo de ocupação dos ecótopos artificiais. No entanto, deve-se considerar a persistência de populações de $T$. brasiliensis no ambiente natural, as quais se dispersam com rapidez e facilidade para o ambiente artificial. Essa mobilidade espacial influi poderosamente na introdução de genes suscetíveis contribuindo de maneira decisiva na diluição dos genótipos resistentes.

Diferentemente de $T$. infestans que possui distribuição restrita ao ambiente domiciliar, portanto, não apresenta reinfestações por migrações de espécimes oriundas de focos silvestres, com exceção de algumas áreas da Bolívia (FORATTINI, 1980).

Outro fator não menos importante é que os inseticidas usados, atualmente, nas campanhas de controle dos vetores da DC apresentam alto impacto inicial nas populações intradomiciliares de triatomíneos (OLIVEIRA FILHO, 1981; OLIVEIRA FILHO et al., 2000).

Nos últimos anos, novas gerações de piretróides, que combinam elevada ação inseticida com baixa toxicidade para mamíferos e organismos não alvos, têm sido 
purificadas e produzidas, a partir de diferentes misturas de isômeros. Essa nova geração de inseticidas do grupo dos cianopiretróides são muito mais tóxicos que os organoclorados ou organofosforados (ZERBA, 1999b).

O piretróide deltametrina aqui estudado faz parte dessa nova geração e tem sido amplamente utilizado no controle dos vetores da DC em toda a América Latina. Assim, esse composto poderia eliminar facilmente as populações autóctones que realizam elevado intercâmbio genético.

Os efeitos produzidos pela deltametrina foram caracterizados por ALZOGARAY e ZERBA (1997) e ALZOGARAY e ZERBA (2001) em ninfas de $3^{\circ}$ estádio de $T$. infestans e $R$. prolixus, respectivamente. As avaliações de toxicidade de deltametrina sobre essas espécies permitiram a classificação dos sintomas de intoxicação em cinco fases: latência, excitação, incoordenação, tetanização e prostração.

A primeira fase, latência, corresponde ao tempo em que as moléculas de piretróides atingem o sítio alvo. A próxima etapa, excitação, foi caracterizada por um importante aumento na atividade locomotora das ninfas.

$\mathrm{Na}$ terceira fase, incoordenação, a hiperatividade locomotora dos insetos começa a diminuir. A sintomatologia típica dessa fase é a paralização do terceiro par de pernas, mas outros sintomas também foram exibidos: tremores leves, movimentos direcionados para trás, elevação do corpo e suaves contrações dos três pares de pernas, antenas e probóscide. A incoordenação é o primeiro passo do efeito knockdown.

A quarta fase, tetanização, foi caracterizada por violentos movimentos convulsivos dos três pares de pernas. 
Na última fase, prostração, foi observada paralisia dos três pares de pernas, movimentos lentos e ocasionais e ausência de movimentos.

Em ninfas de $1^{\circ}$ estádio de $T$. infestans resistentes à hiperatividade locomotora provocada pelos efeitos dos inseticidas deltametrina, lambdacialotrina e tetrametrina diminui significantemente quando comparadas com populações normais (SFARA et al., 2006).

Nos resultados obtidos nesta tese também constatou-se o aparecimento desses sintomas, poucos minutos após a aplicação do inseticida.

Para as variações da $\mathrm{DL}_{50}$ observa-se que das sete populações de triatomíneos dos municípios de Itaporanga (TbPBItV), Mãe d'água (TbPBMAgC), Monteiro (TbPBMoO), Piancó (TbPBPiJ), Santa Cruz (TbPBSCrG), São Francisco (TbPBSFrS) e São José de Espinharas (TbPBSJEsL), apenas o município de Santa Cruz (TbPBSCrG) apresentou diferenças significativas com a população de referência (Fig. 10).

Quanto às quatro populações do Estado de Pernambuco procedentes dos municípios de Lagoa Grande (TbPELGrM), Petrolina (TbPEPeL), Salgueiro (TbPESaS) e Serra Talhada (TbPESTaJ); diferenciaram-se da população de referência, somente os municípios de Lagoa Grande (TbPELGrM) e Serra Talhada (TbPESTaJ) (Fig. 10).

Em relação ao município de Oeiras/PI, todas as quatro populações pertencentes às localidades do Sítio Pau de Chapada (TbPIOeP), Sítio Tabocas (TbPIOeT), Sítio Formosa II (TbPIOeF) e Sítio Sapé (TbPIOeS) apresentaram diferenças significativas, tanto nos valores de $\mathrm{DL}_{50}$ quanto nos de $\mathrm{DL}_{95}$, quando comparadas com a população de referência (Figs. 10 e 11). 
Os resultados obtidos para a variação da $\mathrm{DL}_{50}$ sustentam as diferenças nos valores das $\mathrm{RR}_{50}$. Assim, as população de triatomíneo do município de Santa Cruz (TbPBSCrG: $\mathrm{RR}_{50}=1,41$ ) do Estado da Paraíba; as populações triatomínicas de Lagoa Grande (TbPELGrM: $\left.R_{50}=1,61\right)$ e Serra Talhada (TbPESTaJ: $\left.R_{50}=1,25\right)$ do Estado de Pernambuco e as populações de triatomíneos do município de Oeiras, Sítio Pau de Chapada (TbPIOeP: $R_{50}=1,66$ ), Sítio Tabocas (TbPIOeT: $R_{50}=1,75$ ), Sítio Formosa II (TbPIOeF: $\left.\mathrm{RR}_{50}=1,94\right)$ e Sítio Sapé $\left(\mathrm{TbPIOeS}: \mathrm{RR}_{50}=2,17\right)$ possuem diferenças significativas com a população de referência (Fig. 10 e Tab. 7).

Apesar dessas diferenças, os resultados obtidos indicam níveis de resistência baixos ou incipientes para deltametrina, conforme classificação referida em OPAS (2005b) e VASSENA e PICOLLO (2003).

PICOLLO et al. (2005) detectaram elevados níveis de resistência para $T$. infestans sob ação de deltametrina; em populações das localidades de El Chorro, La Toma, El Sauzal e Salvador Mazza na Província de Salta/Argentina. Os níveis de $\mathrm{RR}_{50}$ foram de 99,$0 ; 86,9 ; 50,5$ e 133,1 ; respectivamente.

Baseado nesses valores, os autores demonstraram que $\mathrm{RR}_{50} \geq 50$, obtidos por meio de aplicação tópica em ninfas de $1^{\circ}$ estádio, já se observavam sinais claros de falhas de controle no campo, enquanto que $\mathrm{RR}_{50} \leq 8$ indicavam que as populações resistentes estão na fase inicial de prejuízos para as ações de controle de campo.

Quanto ao grau de variabilidade genética, obtidos por meio dos diferentes valores de coeficiente angular, observou-se que das 16 populações de T. brasiliensis estudadas; apenas os municípios de Monteiro/PB (TbPBMoO), São José de Espinharas/PB (TbPBSJEsL) e São Francisco (TbPBSFrS) apresentaram coeficiente angular maior que a linhagem de referência, sugerindo em menor variabilidade 
genética dessas três populações, em comparação com a população de referência (Tab. 7; Figs. 13 B, C, D).

O restante das amostras estudadas, ou seja, 13 populações apresentaram valores de coeficiente angular inferiores ao da linhagem de referência sugerindo, portanto, uma maior variabilidade genética (Tab. 7, Fig. 13 A; Figs. 14 E, F, G; Figs. 16 A, B, C, D; Figs. 18 A, B, C, D; Fig. 19). Essas populações com alto nível de variabilidade genética possuem maiores chances de selecionar indivíduos resistentes e alterar os níveis de suscetibilidade aos inseticidas utilizados.

\subsection{MONITORAMENTO DE RESISTÊNCIA DE $T$. sordida A} DELTAMETRINA

PESSOA (2008) caracterizou a suscetibilidade de 14 populações de $T$. sordida procedentes dos municípios de Monte Azul, Coração de Jesus, Bocaiúva, Presidente Juscelino, Monjolos e Buenópolis; do Estado de Minas Gerais. Esse autor encontrou cinco populações com níveis de resistência incipiente, ou seja, $R_{50} \geq 5$ : 1) município de Coração de Jesus, Fazenda Domingada $\left(R_{50}=5,4\right)$; 2) município de Coração de Jesus, Fazenda Barriguda $\left(\mathrm{RR}_{50}=6,8\right)$; 3) município de Bocaiúva, Fazenda Chaves $\left(\mathrm{RR}_{50}=5,8\right)$; 4) município de Bocaiúva, Fazenda Félix I $\left(\mathrm{RR}_{50}=6,2\right)$ e 5) município de Presidente Juscelino $\left(\mathrm{RR}_{50}=5,5\right)$.

A partir desses resultados, o autor da pesquisa destacou a necessidade da prática de monitoramento de resistência com populações dessas mesmas localidades, em anos sucessivos, assim como a realização de bioensaios de laboratório quando a taxa de sobrevivência for igual ou superior a $10 \%$. 
A população de referência utilizada nos estudos de PESSOA (2008) foi procedente do município de Uberaba, no Estado de Minas Gerais. O autor obteve um valor de $\mathrm{DL}_{50}$ igual a 0,065 ng i. a./ninfa para população de referência, enquanto que os resultados deste trabalho apontaram para $\mathrm{DL}_{50}$ maior, cujo valor foi de 0,58 ng/inseto. A população de referência demonstrou baixo nível de suscetibilidade, podendo ser considerada, até mesmo resistente, quando comparada com a utilizada por PESSOA (2008).

Ressalta-se que os parâmetros de RR são calculados a partir dos valores da $\mathrm{DL}_{50}$ da população de referência, consequentemente a variabilidade desses valores poderá interferir nos resultados do monitoramento e nas tomadas de decisões feitas pelo Programa Nacional de Controle da Doença de Chagas para o manejo de inseticidas, caso haja resistência estabelecida.

Por exemplo, nos resultados obtidos neste trabalho todas as populações foram classificadas como suscetíveis, conforme OPAS (2005b). Os valores de $\mathrm{RR}_{50}$ foram menores que três, utilizando a população de referência de $T$. sordida (TsREF) com $\mathrm{DL}_{50}=0,58 \mathrm{ng}$ /inseto (Tab. 10). O cálculo para obtenção da $\mathrm{RR}_{50}$ foi realizado por meio do quociente da $\mathrm{DL}_{50}$ da população de campo pela $\mathrm{DL}_{50}$ da população de referência.

Por sua vez, com a utilização da linhagem suscetível de PESSOA (2008), cujo valor foi de $\mathrm{DL}_{50}=0,065 \mathrm{ng}$ i.a./ninfa as amostras seriam classificadas como resistentes, inclusive com recomendações de troca de inseticidas para algumas populações (Tab. 10).

Neste trabalho, a população utilizada como população de referência (TsREF) foi obtida no início da década de 80 . Assim, muito embora, essa população tenha se 
originado de ambiente nunca exposto ao tratamento de inseticidas, a população fundadora dessa população pode ter chegado ao laboratório com presença de indivíduos resistentes.

Para esse trabalho utilizou-se população de referência procedente do município de Cordeiros, no Estado da Bahia. No passado, essa área pode ter sido submetida à forte pressão de diferentes classes de inseticidas, principalmente para o controle de T. infestans, assim como de outros insetos transmissores de doença ao homem. Nesse contexto, ressalta-se que a nossa linhagem de referência, talvez tenha sido isolada já com alguns indícios de resistência. 
Tabela 10 - Resultados dos valores de $\mathrm{RR}_{50}$ de populações de Triatoma sordida utilizando-se dois valores de $\mathrm{DL}_{50}$. Na tabela, à direita observam-se os resultados de PESSOA (2008) e a esquerda os resultados de OBARA (2010).

\begin{tabular}{lcc}
\hline População & DL $_{\mathbf{5 0}} \mathbf{n g}$ /inseto $(\mathbf{9 5 \%} \mathbf{~ I C )}$ & $\mathbf{R R}_{\mathbf{5 0}}$ \\
\hline TsREF & $0,58^{a}$ & \\
TsBAXXiR & $0,61(0,56-0,66)$ & 1,05 \\
TsMSCGrA & $0,61(0,56-0,67)$ & 1,05 \\
TsMTPoM & $0,64(0,57-0,71)$ & 1,1 \\
TsMSTeC & $0,69(0,61-0,77)$ & 1,19 \\
TsGOFiC & $0,70(0,63-0,78)$ & 1,2 \\
TsMTSJPoS & $0,70(0,66-0,75)$ & 1,2 \\
TsMSRoE & $0,70(0,63-0,77)$ & 1,21 \\
TsGOSLMBeE & $0,71(0,65-0,76)$ & 1,21 \\
TsGOGGoS & $0,75(0,70-0,80)$ & 1,29 \\
TsBACarfB & $0,77(0,72-0,83)$ & 1,32 \\
TsMSATaJ & $0,78(0,70-0,86)$ & 1,33 \\
TsBACariM & $0,81(0,74-0,87)$ & 1,38 \\
TsMGLoR & $0,84(0,77-0,92)$ & 1,45 \\
TsMSDoM & $0,85(0,78-0,92)$ & 1,45 \\
TsGOPoE & $0,86(0,76-0,96)$ & 1,48 \\
TsBANReA & $0,86(0,80-0,93)$ & 1,48 \\
TsBAPaR & $1,02(0,90-1,15)$ & 1,75 \\
TsTOAToM & $1,04(0,87-1,18)$ & 1,79 \\
TsBARCoB & $1,16(1,10-1,23)$ & 1,99 \\
TsBAMaS & $1,46(1,33-1,58)$ & 2,49 \\
TsBAMuB & $1,59(1,44-1,74)$ & 2,71 \\
\hline & &
\end{tabular}

\begin{tabular}{lcc}
\hline População & DL $_{\mathbf{5 0}}$ ng/inseto $(\mathbf{9 5 \%} \mathbf{I C})$ & $\mathbf{R R}_{\mathbf{5 0}}$ \\
\hline TsREF & $0,065^{b}$ & \\
TsBAXXiR & $0,61(0,56-0,66)$ & 9,38 \\
TsMSCGrA & $0,61(0,56-0,67)$ & 9,38 \\
TsMTPoM & $0,64(0,57-0,71)$ & 9,84 \\
TsMSTeC & $0,69(0,61-0,77)$ & 10,61 \\
TsGOFiC & $0,70(0,63-0,78)$ & 10,76 \\
TsMTSJPoS & $0,70(0,66-0,75)$ & 10,76 \\
TsMSRoE & $0,70(0,63-0,77)$ & 10,76 \\
TsGOSLMBeE & $0,71(0,65-0,76)$ & 10,92 \\
TsGOGGoS & $0,75(0,70-0,80)$ & 11,53 \\
TsBACarfB & $0,77(0,72-0,83)$ & 11,84 \\
TsMSATaJ & $0,78(0,70-0,86)$ & 12 \\
TsBACariM & $0,81(0,74-0,87)$ & 12,46 \\
TsMGLoR & $0,84(0,77-0,92)$ & 12,92 \\
TsMSDoM & $0,85(0,78-0,92)$ & 13,07 \\
TsGOPoE & $0,86(0,76-0,96)$ & 13,23 \\
TsBANReA & $0,86(0,80-0,93)$ & 13,23 \\
TsBAPaR & $1,02(0,90-1,15)$ & 15,69 \\
TsTOAToM & $1,04(0,87-1,18)$ & 16 \\
TsBARCoB & $1,16(1,10-1,23)$ & 24,61 \\
TsBAMaS & $1,46(1,33-1,58)$ & 22,46 \\
TsBAMuB & $1,59(1,44-1,74)$ & 24,46 \\
\hline
\end{tabular}

Notas:

${ }^{a}$ - DL $\mathrm{DL}_{50}$ utilizada por OBARA (2010)

${ }^{b}-\mathrm{DL}_{50}$ utilizada por PESSOA (2008)

95\% IC - Intervalo de Confiança 95\%

RR - Razão de Resistência 
Também, destaca-se a dificuldade de interpretação dos limiares de RR, com a utilização de duas ou mais linhagens de referência. Assim, sugere-se a padronização, o mais breve possível, de população de referência para o monitoramento de triatomíneos, evitando dessa maneira possíveis erros de interpretação.

As populações de triatomíneos dos municípios de Malhada (TsBAMaS) e Mucugê (TsBAMuB), na Bahia, foram as que obtiveram os maiores valores de $\mathrm{DL}_{50}$ e DL95 possibilitando separação com os municípios de Cafarnaum (TsBACarfB), Carinhanha (TsBACariM), Nova Redenção (TsBANReA), Palmeiras (TsBAPaR), Rio de Contas (TsBARCoB) e Xique Xique (TsBAXXiR) (Figs. 20 e 21).

Nesta tese, merece destaque a separação entre os municípios baianos de Malhada e Carinhanha. Esses dois municípios apresentam localização geográfica muito próxima, no entanto, houve diferença estatisticamente significativa para todos os parâmetros avaliados (Tab. 9 e Figs. 20, 21, 22, 23 D, 24 G). Sabe-se que os processos de seleção e adaptação têm relação com a estrutura geográfica das populações.

A formação de barreiras geográficas pode ser a possível causa para essa discordância. A Cordilheira dos Andes constitui uma barreira natural que mantem isolado Eratyrus mucronatus Stål, 1859 de Eratyrus cuspidatus Stål, 1859. E. mucronatus habita a parte oriental, enquanto que E. cuspidatus a ocidental (GALVÃO et al., 1998).

O deserto tropical da península de Santa Elena separa Triatoma dimidiata (Latreille), 1811 de outras regiões do Equador (ABAD-FRANCH et al., 2001). No Brasil, o Rio São Francisco representa uma barreira geográfica que afasta $T$. $b$. macromelasoma de T. juazeirensis (COSTA et al., 2009). 
Coincidentemente, o Rio São Francisco também pode ter provocado o afastamento das populações de T. sordida de Carinhanha e Malhada (Fig. 42). Talvez, a divergência dos diferentes parâmetros de mortalidade tenha sido favorecida pelo isolamento geográfico dessas populações.

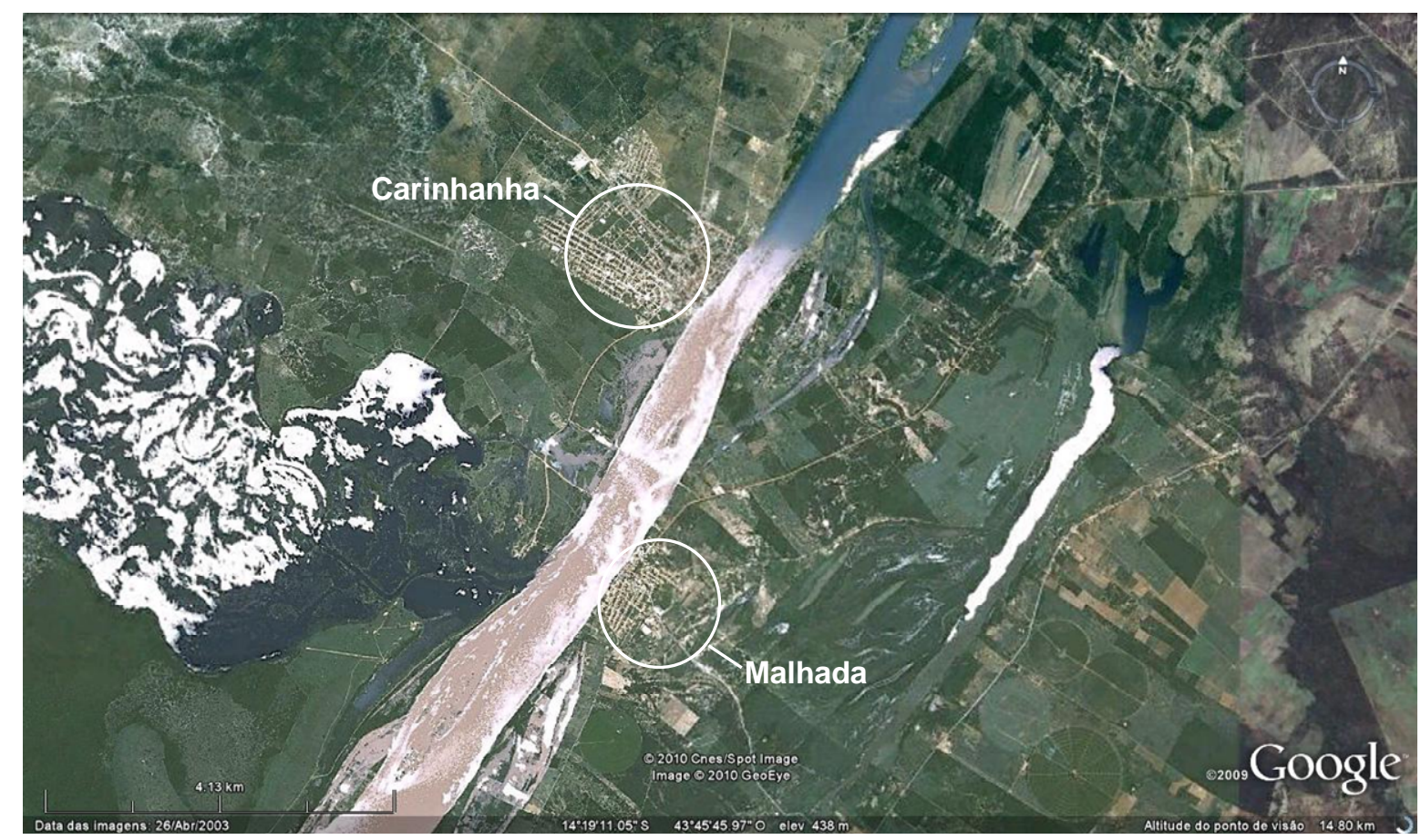

Figura 42 - Localização geográfica dos municípios baianos de Carinhanha $\left(\mathrm{RR}_{50}=1,38 \mathrm{e}\right.$ $\left.\mathrm{RR}_{95}=1,71\right)$ e Malhada $\left(\mathrm{RR}_{50}=2,49\right.$ e $\left.\mathrm{RR}_{95}=3,41\right)$. A distância média entre os municípios é de aproximadamente de $3.5 \mathrm{~km}$. A data de obtenção da imagem foi de 04/06/2007. Fonte: Google Earth 5.0.

Para as populações do Estado de Goiás houve diferenças para o município de Posse (TsGOPoE), que apresentou os maiores valores de DL 50 e DL95 (Figs. 20 e 21).

Das cinco populações estudadas do Estado do Mato Grosso do Sul, o município de Douradina $\left(\mathrm{DL}_{50}=0,85 \mathrm{ng} /\right.$ inseto e $\left.\mathrm{RR}_{50}=1,45\right)$ apresentou diferenças com a população de referência (Tab. 9 e Fig. 20). Os municípios de Lontra (TsMGLoR) e Aurora do Tocantins (TsTOAToM) também apresentaram diferenças com a população de referência (Figs. 20 e 21). 
Apesar disso, as estimativas das Razões de Resistência atribuídas para as populações de campo de $T$. sordida demonstraram elevadas taxas de mortalidade, portanto, baixos níveis de resistência para deltametrina.

No Brasil, o sucesso das campanhas de controle contra o principal vetor da DC, T. infestans, culminaram na Certificação Internacional de Eliminação da Transmissão da Doença de Chagas pelo T. infestans, em junho de 2006.

A aplicação de inseticidas visando à eliminação de populações intradomiciliares e peridomiciliares de $T$. infestans, aparentemente, tem ocasionado grande impacto no controle de populações sinantrópicas de $T$. sordida.

MONTEIRO et al. (2009) analisando 181 exemplares de T. sordida capturadas em áreas do Cerrado (municípios de Espinosa e Mamonas), da Caatinga (município de Januária) e da Floresta do Paraná (município de Corinto) confirmaram, nas quatro populações, a presença de dois alelos para as mesmas áreas polimórficas que favorecem o modo de ação dos inseticidas utilizados nas campanhas de controle da DC.

Do total das 21 populações de $T$. sordida ressalta-se que as quatro populações de triatomíneos dos municípios de Xique Xique/BA (TsBAXXiR), Rio de Contas/BA (TsBARCoB), Guarani de Goiás/GO (TsGOGGoS) e São José do Povo/MT (TsMTSJPoS) propiciaram coeficiente de inclinação da reta semelhante a população de referência indicando alta suscetibilidade a deltametrina (Tab. 9 e Figs. 23 A, B; 28 A, B; 30 A).

As demais populações apresentaram coeficientes angulares menores que da população de referência, portanto, indicando maior probabilidade de tolerância a inseticidas e evolução de resistência. 


\subsection{APLICAÇÃO DA ESTRUTURA CUTICULAR NO MONITORAMENTO DE RESISTÊNCIA DE TRIATOMÍNEOS}

O tegumento dos insetos serve como barreira de proteção e evita a perda de água prevenindo contra a dissecação. JUÁREZ e FERNÁNDEZ (2007) estudando a cutícula de Triatoma infestans encontraram diferentes zonas: a primeira camada a epicutícula ( $2 \mu \mathrm{m}$ de largura) é responsável pela impermeabilidade da membrana. A segunda camada a procutícula $(\sim 200 \mu \mathrm{m})$ é a faixa mais profunda que dependendo do grau de esclerotinização pode ser dividida em duas camadas: exo e endocutícula.

Por fim, a epiderme é constituída pelas células epidermais, cuja função é a síntese e secreção dos componentes do tegumento. Além disso, entre as células epidermais e a membrana basal, há presença de células modificadas: oenocitos, células formadoras de cerdas e glândulas dermais. Essa última se comunica com o meio externo por meio de poros (Fig 43). 


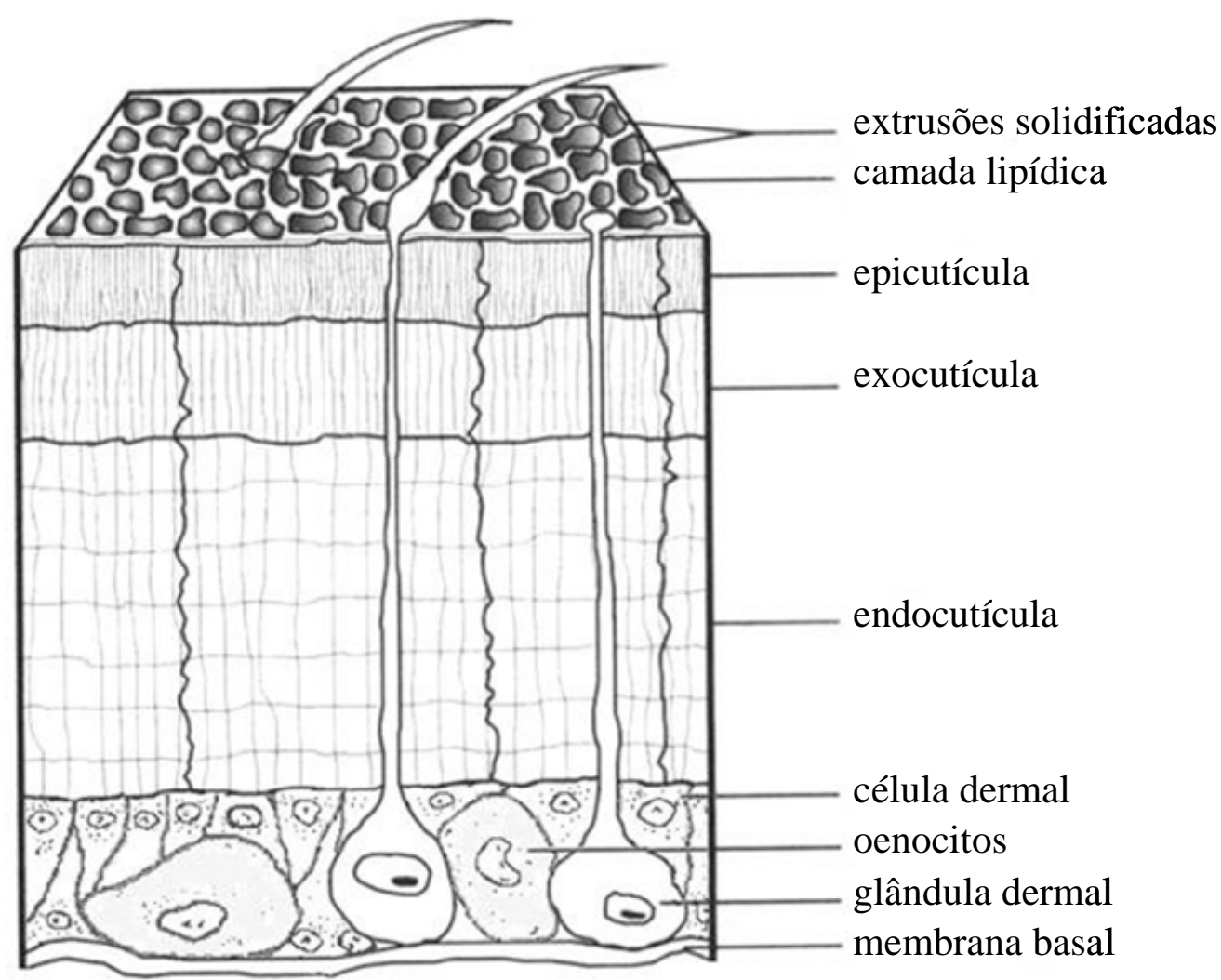

Figura 43 - Diagrama esquemático do corte microtômico do tegumento dos insetos ilustrando as principais camadas da cutícula, segundo JUÁREZ e FERNÁNDEZ (2007). Modificado por OBARA (2010).

A superfície cuticular dos triatomíneos é formada por uma fina camada de lipídeos alcalinos, hidrocarbonetos saturados, ácidos graxos livres saturados, álcoois primários e glicerídeos (JUÁREZ e FERNÁNDEZ, 2007).

O aumento da produção de algumas dessas substâncias pode provocar uma redução na taxa de penetração dos inseticidas. A cutícula de moscas resistentes revelou maior quantidade de lipídeos, mono e di-glicerídeos, esteróis e fosfolipídeos que favoreceram a retenção de inseticidas. 
Recentemente, foi exposto por JUÁREZ e FERNÁNDEZ (2007) que as populações resistentes de triatomíneos apresentam maior quantidade de hidrocarbonetos na cutícula, quando comparadas com as populações suscetíveis.

Sem dúvida, o papel da cutícula é de extrema importância na dinâmica e no modo de ação dos inseticidas, uma vez que, os efeitos toxicológicos das diferentes classes de inseticidas dependem da penetração por meio do tegumento para atingir o sítio alvo (JUÁREZ, 1994).

FONTÁN e ZERBA (1987), utilizando formulações de malathion e parathion marcados com compostos radioativos $\left[{ }^{14} \mathrm{C}\right]$, verificaram as taxas de penetração desses compostos no tegumento de adultos e ninfas de $5^{\circ}$ estádio de $T$. infestans. Nos adultos, a penetração ocorre preferencialmente nas membranas intersegmentares que fazem a união entre o dorso e o ventre, assim como nas que dividem as partes toráxicas. Ao passo que, nas ninfas a penetração do inseticida ocorre por toda a superfície cuticular que é formada quase que totalmente pela endocutícula.

A natureza do solvente também pode influenciar na taxa de penetração (ZERBA, 1988). Os resultados obtidos nesse trabalho demonstram que a acetona foi um solvente que apresentou boa capacidade de evaporação, induzindo a rápida penetração do inseticida na cutícula dos insetos. No entanto, não foi esclarecido se a elevada volatilização da acetona favoreceu a rápida difusão do inseticida através do tegumento das ninfas estudadas.

Aparentemente, as sensilas não influenciaram na taxa de penetração, ao longo da cutícula, mas podem ter alguma importância como porta de entrada, uma vez que possuem poros e canais que se comunicam com a parte interna (Fig. 43). 
SCHOUEST et al. (1983) utilizando MEV para estudar a absorção de inseticidas carbamatos conduzidos em diferentes tipos de solventes, na Musca domestica, evidenciaram claramente padrões de cristalização, deposição de compostos na superfície da cutícula e embaraçamento de sensilas, após aplicação tópica de variadas concentrações de $\mathrm{DL}_{50}$.

Neste trabalho foi possível observar, na cutícula de $P$. megistus (Fig. 37), a deposição de pequenas esferas arredondadas na superfície das suturas intersegmentares, as quais se presumem que sejam as extrusões solidificadas, descritas por JUÁREZ e FERNÁNDEZ (2007).

Ainda, nos resultados não se observou alteração na aparência física, após tratamento com deltametrina, porém, as observações em MEV detectaram importantes diferenças no tegumento das três espécies analisadas; principalmente em relação às características externas que constituem a cutícula e ao padrão morfológico de inserção e tipo de sensilas.

Em resumo, a estrutura cuticular do tórax de ninfas de $1^{\circ}$ estádio de $P$. megistus, $T$. brasiliensis e $T$. sordida pode ser descrita por um conjunto de desenhos formados de linhas sinuosas que constituem um sistema de canais intercomunicantes. Nessas cavidades ocorrem rápidos processos de penetração e distribuição de inseticidas.

Recentemente, estudo realizado por PEDRINI et al. (2009) demonstraram por meio de MEV, a relação entre a largura do tegumento e a resistência à deltametrina em populações de $T$. infestans da Argentina e Bolívia. A cutícula de ninfas de $4^{\circ}$ estádio de populações resistentes $(32,1 \mu \mathrm{m})$ apresenta maior espessura quando comparadas com populações suscetíveis $(17,8 \mu \mathrm{m})$. 
Seguramente, esses resultados abrem novas expectativas para o estudo de resistência de triatomíneos. Por fim, a MEV pode ser considerada uma importante ferramenta que poderá contribuir na elucidação de algumas questões, como por exemplo: Se o mecanismo que confere resistência aos vetores da DC é por redução na penetração? Onde e como são depositados e/ou expressos os compostos que retém as moléculas de inseticida? Existe outro mecanismo associado?

\subsection{EFEITO DOS BIOENSAIOS DE CAMPO EM POPULAÇÕES DE}

\section{T. brasiliensis}

A aplicação residual de inseticidas piretróides se apresenta como uma ferramenta valiosa que foi adotada como procedimento de rotina, na luta contra os triatomíneos e outros vetores, principalmente em situações de emergência.

O desempenho dos programas de controle de vetores deve ser periodicamente avaliado por meio dos bioensaios de campo. Na área dos vetores da DC, esses testes biológicos têm sido realizados há vários anos, pois oferecem condições para: comparar diferentes tipos de substratos (PENA et al., 1984); avaliar a persistência ou efeito residual dos inseticidas (OLIVEIRA FILHO et al., 1986; MAZARIEGOARANA et al., 2002); comparar diferentes concentrações e produtos (MARCONDES e PINTO, 1989; ZERBA et al., 1987); avaliar a taxa de reinfestações (GÜRTLER et al., 1994); estudar a influência sazonal nas ações de campo (GORLA, 1991); testar novos produtos (OLIVEIRA FILHO, 1997); avaliar os efeitos toxicológicos dos inseticidas (GENTILE et al., 2004a); determinar a concentração do princípio ativo dos inseticidas (ROJAS de ARIAS et al., 2004) e 
estudar novos protocolos de controle (GENTILE et al., 2004b; AMELOTTI et al., 2009).

Neste trabalho, os bioensaios de campo revelaram que a aplicação da dose de campo, em diferentes superfícies, elimina de modo uniforme (100\%), mesmo as populações que apresentaram as maiores frequências de resistência. Considera-se essa informação extremamente importante, já que os níveis de controle atingidos, atualmente, apontam para a incontestável efetividade do tratamento químico, originalmente com inseticidas organoclorados, e hoje com piretróides.

Os inseticidas da classe dos piretróides, tal como a deltametrina têm sido bastante efetivos no controle de triatomíneos, em vários países do Cone Sul. FERRO et al. (1995) expondo 10 ninfas de $1^{\circ}$ de $T$. infestans obtiveram uma taxa de mortalidade de $80 \%$, após 72 horas de exposição em paredes de barro tratadas com deltametrina, a 25 mg i.a. $/ \mathrm{m}^{2}$; no distrito de Ybytymí, região leste do Paraguai. Essa taxa de mortalidade aumentou para $100 \%$ no décimo dia de observação, em laboratório.

No Chaco Paraguaio, os bioensaios de campo com deltametrina $(25 \mathrm{mg}$ i.a. $/ \mathrm{m}^{2}$ ) demonstraram que esse composto persiste em quantidade suficiente por até três meses, após o tratamento. Ninfas de $3^{\circ}$ estádio de $T$. infestans apresentaram $100 \%$ de mortalidade em substratos de barro, depois de 72 horas de exposição (ROJAS de ARIAS et al., 2003; 2004).

Nas zonas rurais argentinas de Santiago Del Estero, onde se registrava os mais altos índices de prevalência da DC, a utilização da deltametrina, a $25 \mathrm{mg}$ i.a. $/ \mathrm{m}^{2}$, permitiu a redução significativa do índice de infestação de $88 \%$ para $5 \%$, seis meses após o tratamento. Os resultados entomológicos indicaram que depois de mais 
de um ano após o tratamento, praticamente não foi observada reinfestação intradomiciliar por T. infestans (GÜRTLER et al., 1994; ZERBA et al., 1987).

No Brasil, MARCONDES e PINTO (1989) utilizaram deltametrina para pulverizar 402 UDs no município de São Sebastião do Umbuzeiro, extremo sul da Paraíba. Os resultados das primeiras avaliações comprovaram grande mortalidade de triatomíneos e persistência prolongada dos efeitos.

DIOTAIUTI e PINTO (1991) em localidades do município de Posse, Estado do Goiás avaliaram a ação residual de deltametrina 5\% - $25 \mathrm{mg}$ i.a. $/ \mathrm{m}^{2}$ utilizando ninfas de $3^{\circ}$ estádio de $T$. sordida e $T$. infestans. A persistência da ação inseticida permaneceu por até 360 dias e as duas espécies apresentaram suscetibilidade semelhante.

A ação triatomicida dos piretróides foi observada no início dos anos 80. Esse grupo de inseticidas, assim como os organoclorados apresenta como sítio de ação as proteínas do canal de sódio. Após poucos minutos de contato, o piretróide é absorvido provocando convulsões, seguida de paralisia (efeito "Knockdown") e, finalmente a morte.

Nas populações de insetos que apresentam resistência ocorre uma paralisia momentânea, seguida de total recuperação locomotora. Esse fenótipo ficou conhecido como resistência kdr (do inglês, "Knockdown resistance").

Neste trabalho não foi observado a recuperação das ninfas, após a exposição à deltametrina, tanto nos bioensaios de laboratórios quanto nos bioensaios de campo, corroborando os resultados de ALZOGARAY et al. (1997) e ALZOGARAY e ZERBA (2001) para ninfas de $3^{\circ}$ estádio de $T$. infestans e $R$. prolixus. 
Finalmente, quanto às dificuldades do monitoramento de resistência de triatomíneos à deltametrina podemos destacar situações que prejudicaram o número de amostras analisadas. Os problemas estavam diretamente relacionados às condições das amostras enviadas pelos Núcleos de Entomologia do país (Anexo 8), dentre o quais podemos citar:

i) insuficiente número de exemplares fêmea. As amostras recebidas dos municípios de Aurilândia/GO, Caconde/SP, Cafelância/PR, Divinolândia/SP, Flores de Goiás/GO, Iaciara/GO, Miranda/MS, Paranaíba/MS e Vicente Pires/DF; devido à pouca quantidade de representantes não permitiram a geração de ninfas F1 suficientes para o monitoramento.

ii) amostras com insetos mortos. Outro fator que contribuiu para o processamento das amostras foi às condições de chegada do material. Durante a triagem observamos que parte das amostras estavam mortas, provavelmente devido à longa duração no transporte ou danos durante a captura. Nessa situação estavam os municípios de Itaipoca/MS, Canindé do São Francisco/SE, Castro Alves/BA, Conceição das Alagoas/MG, Corinto/MG, Cuiabá/MT e Sertaneja/PR.

Neste trabalho recebemos 55 amostras, das quais foi possível monitorar 38 populações procedentes de 35 municípios do Brasil. Apesar dos problemas mencionados acima, considera-se que o número de amostras estudadas foi suficiente para se ter uma visão total e não parcial dos níveis de resistência das principais espécies transmissoras de T. cruzi, no Brasil.

Contudo, sugere-se que sejam realizadas novas capturas, não só para ampliar o número de amostras de municípios, como também para estabelecer um perfil geográfico de resistência a inseticidas utilizados no controle dos vetores da DC. 


\section{CONCLUSÕES}

As conclusões deste trabalho foram agrupadas em três itens:

\section{a) Monitoramento de resistência}

1) A avaliação de resistência de populações nativas de $P$. megistus, T. brasiliensis e $T$. sordida ao inseticida deltametrina foi capaz de detectar pequenas alterações de resposta na taxa de suscetibilidade das espécies estudadas;

2) Os níveis de resistência a deltametrina encontrados para P. megistus, T. brasiliensis e $T$. sordida foram baixos $\left(\mathrm{RR}_{50}<3\right)$ nos 35 municípios de 11 Estados avaliados, seguindo um padrão comparável aos das populações de referência, em termos de suscetibilidade;

3) A Dose Diagnóstica (DD) recomendada para triagem de resistência em populações de campo de $P$. megistus, $T$. brasiliensis e $T$. sordida equivalem a 4,36 $\mu \mathrm{g}$ /inseto, 2,24 $\mu \mathrm{g}$ /inseto e 1,91 $\mu \mathrm{g}$ /inseto, respectivamente. Essas doses correspondem a 1xDL 99 das populações de referência;

4) Houve diferença significativa para as estimativas de $\mathrm{DL}_{50}$ e DL 95 , principalmente para as populações de $P$. megistus de Serranópolis do Iguaçu/PR, T. brasiliensis de Oeiras/PI e T. sordida de Malhada e Mucugê/BA, quando comparadas com as populações de referência;

5) Foi possível identificar populações com elevada variabilidade genética nas três populações estudadas; 
6) Os resultados dos bioensaios de laboratório e campo não indicam, neste momento, a necessidade de substituição do inseticida atualmente utilizado. O uso de piretróides pode continuar nas áreas estudadas, contudo é necessário acompanhar as alterações temporais de suscetibilidade para orientar o planejamento das estratégias de controle a serem aplicadas.

\section{b) Microscopia Eletrônica de Varredura}

1) A estrutura cuticular do tórax de ninfas de $1^{\circ}$ estádio de $P$. megistus, T. brasiliensis e T. sordida é formada por um conjunto de cavidades intercomunicantes com estruturas formadas por linhas sinuosas que favorecem a penetração e distribuição de inseticidas;

2) No aumento de $1500 \mathrm{X}$ foi possível descrever a deposição de extrusões solidificadas aderidas à superfície da sutura intersegmentar de P. megistus;

3) As superfícies cuticulares das áreas estudadas apresentam diferenças morfológicas significativas, revelando-se de grande importância para futuros estudos taxonômicos de triatomíneos.

\section{c) Bioensaios de Campo}

1) Não houve diferença significativa na taxa de mortalidade entre os substratos de barro, tijolo e madeira tratados com deltametrina, portanto, os baixos níveis de resistência detectados no laboratório puderam ser confirmados pelos bioensaios de campo; 
2) Os resultados dos testes de suscetibilidade de parede indicam que os inseticidas piretróides (DeltaGard ${ }^{\circledR}$ WG 250, da Bayer ${ }^{\circledR}$ ) utilizados pelas campanhas de controle de vetores da DC mostrou ser uma alternativa promissora, no Brasil.

\section{CONSIDERAÇÕES FINAIS}

Atualmente, pretende-se instituir a Rede Nacional de Monitoramento de Resistência de Triatomíneos a Inseticidas, sob a coordenação da Secretaria de Vigilância em Saúde, do Ministério da Saúde, com a proposta de agregar cinco laboratórios para a realização das provas biológicas e bioquímicas.

O Centro de Pesquisas René Rachou, da Fundação do Instituto Oswaldo Cruz, em Belo Horizonte/MG atuaria como laboratório de referência nacional para a realização dos ensaios bioquímicos.

Durante o ano de 2010, com a colaboração do laboratório de referência pretende-se capacitar técnicos da SUCEN/Mogi-Guaçu/SP, Laboratório de Entomologia de Pernambuco, Laboratório de Entomologia do Ceará e Laboratório de Entomologia/CGLAB/SVS/MS para a realização das provas biológicas.

Nesse contexto, visando a padronização dos ensaios biológicos para o monitoramento de resistência de triatomíneos a inseticidas, recomenda-se a definição de uma única população de referência de suscetibilidade para $T$. sordida, $T$. brasiliensis, P. megistus e outras espécies a serem estudadas, a fim de melhorar a qualidade do diagnóstico de resistência que serão realizados por esses laboratórios. 
Hoje, a Rede Nacional de Monitoramento de Resistência de Aedes aegypti a Inseticidas (MoReNAa) utiliza uma população de referência a inseticidas, conhecida como população Rockefeller. O emprego dessa cepa permite determinar, com alta precisão, a suscetibilidade de adultos e larvas aos organoclorados, piretróides, análogos de hormônio juvenil e outros inseticidas alternativos (BRAGA e VALLE, 2007b).

Além disso, pouco se sabe sobre a origem genética e bioquímica da resistência à inseticida de espécies triatomínicas com importância na saúde pública. A resistência se processa por diversos mecanismos, podendo ser também de várias modalidades e com diferente grau de resposta. Dessa forma, os ensaios bioquímicos e genéticos devem ser estimulados para detectar os mecanismos de resistência e sua evolução.

Também deve ser encorajada a produção gradual do perfil geográfico de resistência aos inseticidas piretróides utilizados no combate de triatomíneos, não só no Brasil, como também nos diversos países endêmicos para orientar o planejamento adequado das ações de controle dos vetores da DC.

Por fim, a adesão de outros Laboratórios de Entomologia, com infra-estrutura e capacidade técnico-científica adequada seria de extrema importância para o fortalecimento do Programa Nacional de Controle da Doença de Chagas, no Brasil. 


\section{REFERÊNCIAS}

Abad-Franch F, Paucar AC, Carpio C, Cuba Cuba CA, Aguilar M, Miles MA. Biogeograph of triatominae (Hemiptera: Reduviidae) in Equador: implications for the design of control strategies. Mem Inst Oswaldo Cruz 2001; 96 (5): 611 620.

Akhavan D. Análise de custo efetividade do Programa de Controle da Doença de Chagas no Brasil: relatório final. Dariush Akhavan. - Brasília: Programa de desenvolvimento de recursos humanos/OPAS. 1998; 271 p.

Alzogaray RA. Caracterización de la toxicidad de inseticidas piretroides em Triatoma infestans (Klug). [Tese de Doutorado]. Buenos Aires: Facultad de Ciências Exactas y Naturales da Universidad de Buenos Aires; 1996.

Alzogaray RA. Aspectos moleculares de la resistencia a insecticidas. Acta Bioq Clin Latino Am 1998; 32 (3): 387 - 395.

Alzogaray RA, Zerba EN. Incoordination, paralysis and recovery after pyrethroid treatment on nymphs III of Triatoma infestans (Hemipetara: Reduviidae). Mem Inst Oswaldo Cruz 1997; 92 (3): 431 - 435.

Alzogaray RA, Fontán A, Zerba EN. Evaluation of hyperactivity produced by pyrethroid treatment on third instar nymphs of Triatoma infestans (Hemiptera: Reduviidae). Arch Insect Biochem Physiol 1997; 35: 323 - 333.

Alzogaray RA, Zerba EN. Third instar nymphs of Rhodnius prolixus exposed to $\alpha$ - cyanopyrethroids: from hyperactivity to death. Arch Insect Bioq Physiol 2001; 46: 119 - 126. 
Amelotti I, Catalá S, Gorla D. Response of Triatoma infestans to pour-on cypermethrin applied to chickens under laboratory conditions. Mem Inst Oswaldo Cruz 2009; 104 (3): 481 - 485.

Amin AM, Peiris HT. Detection and selection of organophosphate and carbamate resistence in Culex quiquefasciatus from Saudi Arabia. Med Vet Entomol 1980; 4 (3): 269-273.

Anspaugh DD, Rose RL, Koehler PG, Hodgson E, Roe RM. Multiple mechanisms of pyrethroid resitance in the german cockroach, Blattella germanica (L.). Pestic Biochem Physiol 1994; 50: 138 - 148.

Argolo AM, Felix M, Pacheco R, Costa J. Doença de Chagas e seus principais vetores no Brasil. Rio de Janeiro: Imperial Novo Milênio, 2008. Principais vetores de Trypanosoma cruzi no Brasil (com ênfase para o complexo $T$. brasiliensis) (Capítulo VII); p. 41 - 53.

Aufderheid AC, Salo W, Madden M, Streitz J, Buikstra J, Guhl F, Arriaza B, Renier C, Wittmers LE, Fornaciari G, Allison M. A 9,000-year record of Chagas'disease. Proc Nat Acad Science 2004; 101(7): 2034-2039.

Barata JMS. Aspectos morfológicos dos ovos do gênero Rhodnius Stål 1859 (Heteroptera, Reduviidade) e sua importância na identificação específica. [Tese de Doutorado]. São Paulo: Faculdade de Saúde Pública da USP; 1979.

Barbosa da Silva JJr, Siqueira JBJr, Coelho GE, Vilarinhos PT, Pimenta FG Jr. Dengue in Brazil: current situation and control activities. Epidemiol Bull 2002; $23(1): 3-6$

Barbosa SE, Diotaiuti L, Soares RPP, Pereira MH. Differences in saliva composition among three Brasilian populations of Panstrongylus megistus (Hemiptera, Reduviidae). Acta Trop 1999; 72 : 91 - 98. 
Barbosa SE, Soares RPP, Pires HHR, Diotaiuti L. Experimental evidence for a demographic cline in Panstrongylus megistus populations. Mem Inst Oswaldo Cruz 2001; 96 (6): 773 - 775.

Barbosa SE, Dujardin JP, Soares RPP, Pires HHR, Margonari C, Romanha AJ, Panzera F, Linardi PN, Duque-de-melo M, Pimenta P, Pereira M, Dioutaiuti L. Interpopulation variability among Panstrongylus megistus (Hemiptera: Reduviidae) from Brasil. J Med Entomol 2003; 40 (4): 411 - 420.

Barbosa SE, Diotaiuti L, Braga EM, Pereira MH. Variability of the salivary proteins of 20 Brasilian populations of Panstrongylus megistus (Hemiptera: Reduviidae: Triatominae). Acta Trop 2004; 92: 25 - 33.

Barbosa SE, Belisário CJ, Souza RCM, Paula AS, Linardi PM, Romanha AJ, Diotaiuti L. Biogeography of Brasilian populations of Panstrongylus megistus (Hemiptera, Reduviidae, Triatominae) based on molecular marker and pelovegetational data. Acta Trop 2006; 99: 144 - 154.

Barretto MP. Epidemiologia. In: Brener Z, Andrade ZA (eds.) Trypanosoma cruzi e doença de Chagas. Rio de Janeiro: Ed. Guanabara Koogan; 1979. p 89 291.

Barretto MP.Reservatórios del Trypanosoma (Schizotrypanum) cruzi Chagas, 1909. In: Carcavallo RU, Rabinovich JE e Tonn RJ. Factores biológicos y ecológicos en la enfermedad de Chagas: Tomo II - Parasitos - Reservorios Control - Situation Regional. Chagas 1985; 3: 275-288.

Bisset JA, Rodriguez MM, Hemingway J, Diaz C, Small GJ, Ortiz. Malathion and pyrethroid resistance in Culex quinquefasciatus from Cuba: efficacy of pirimiphos-methyl in the presence of at least three resistance mechanisms. Med Vet Entomol 1991; 5: 223 - 228. 
Bloomquist JR. Ion channels as targets of insecticides. Ann Rev Entomol 1996; 41: 163-190.

Borges EC, Dujardin JP, Schofield CJ, Romanha AJ, Diotaiuti L. Genetic variability of Triatoma brasiliensis (Hemiptera: Reduviidae) populations. J Med Entomol 2000a; 37: 872-877.

Borges EC, Romanha AJ, Diotaiuti L. Uso do Random Amplified Polymorphic DNA (RAPD) no estudo populacional do Triatoma brasiliensis Neiva, 1911. Cad Saúde Públ 2000b;16 (Suppl 2): 97 - 100.

Borges EC, Dujardin JP, Schofield CJ, Romanha AJ, Diotaiuti L. Dynamics between sylvatic, peridomestic and domestic populations of Triatoma brasiliensis (Hemiptera: Reduviidae) in Ceará State, northeastern Brazil. Acta Trop 2005; 93 : $119-126$.

Bracco JE, Barata JMS, Marinotti O. Evaluation of insecticide resistance and biochemical mechanisms in a population of Culex quinquefasciatus (Diptera: Culicidae) from São Paulo, Brazil. Mem Inst Oswaldo Cruz 1999; 94 (1): 115 120.

Braga IA, Lima JBP, Soares SS, Valle D. Aedes aegypti resistance to temephos during 2001 in several municipalities in the state of Rio de Janeiro, Sergipe and Alagoas, Brazil. Mem Inst Oswaldo Cruz 2004; 99 (2): 199 - 203.

Braga IA, Valle D. Aedes aegypti: inseticidas, mecanismso de ação e resistência Epidemiol Serv Saúde 2007a; 16 (4): 279 - 293.

Braga IA, Valle D. Aedes aegypti: vigilância, monitoramento da resistência e alternativas de controle no Brasil. Epidemiol Serv Saúde 2007b; 16 (4): 295 302. 
Brattsten LB. Insecticide resistance: research and management. Pestic Sci 1989; 26: $329-332$.

Brodie BB, Maickel RP. Comparative biochemistry of drug metabolism. Proc First Internat Pharmacol Meet 1962. vol. 6, pp. 229 - 324. Pergamon Press, New York, USA.

Brogdon WG, Mcallister JC. Inseticide resistente and vector control. Emerg Infec Diseases 1998; 4 (4): 605-613.

Brooke BD, Hunt RH, Matambo TS, Koekemoer LL, Wyk PV, Coetzee M. Dieldrin resistance in the malaria vector Anopheles gambie in Ghana. Med Vet Entomol 2006; 20: 294 - 299.

Bustamante FM, Gusmão JB. Sobre a possibilidade de erradicação do Triatoma infestans com duas ou três aplicações domiciliárias de BHC. Resultado de uma prova de campo. Rev Bras Malariol 1954; 6: 101 - 113.

Bustamante FM, Carvalho AG. Observações sobre a ação dos inseticidas Dieldrin e BHC contra Triatoma infestans no interior das habitações. Rev Bras Malariol 1957; 9: 305 - 311.

Busvine JR, Barnes S. Observations on mortality among insects exposed to dry insecticidal films. Bull Ent Res 1947; 38: 81-90.

Campos J, Andrade CFS. Susceptibilidade larval de duas populações de Aedes aegypti a inseticidas químicos. Rev Saúde Pública 2001; 35 (3): 323 - 236.

Carbajal de la Fuente AL, Catalá S. Relationship between antennal sensilla pattern and habitat in six species of Triatominae. Mem Inst Oswaldo Cruz 2002; 97: 1121-1125. 
Carbajal de la Fuente AL, Minoli AS, Lopes CM, Noireau F, Lazzari CR, Lorenzo MG. Flight dispersal of the Chagas disease vectors Triatoma brasiliensis and Triatoma pseudomaculata in northeastern Brazil. Acta Trop 2007; 101: 115 -119 .

Carcavallo RU. Sinopsis epidemiológica de la enfermedad de Chagas. In: Carcavallo, RU, Rabinovich JE, Tonn, RJ. Factores biológicos y ecológicos en la enfermedad de Chagas: Tomo I - Epidemiología - Vectores. Chagas 1985; 2: 1920.

Carcavallo, RU, Galindez- Girón, I. Systematic value of the scutellum in Triatominae (Hemiptera, Reduviidae). Entomol Vect 1995; 2 (1): 23-29.

Carcavallo RU, Zeledón R, Jurberg J, Galíndez-Girón I. Morfologia externa de Triatoma ryckmani Zeledón e Ponce, 1972 vista através da Microscopia Eletrônica de Varredura. Mem Inst Oswaldo Cruz 1996; 91 (6): 727-731.

Casida JE. Pyrethrum flowers and pyrethroid insecticides. Environ Health Perspect 1980; 34: $189-202$.

Catalá S. The cave organ of Triatominae (Hemiptera, Reduviidae) under scanning electron microscopy. Mem Inst Oswaldo Cruz 1994; 89 (2): 275-277.

Catalá S, Schofield CJ. Antennal sensilla of Rhodnius. J Morphol 1994; 219: 193-203.

Catalá S. Sensilla associated with the rostrum of eight species of Triatominae. J Morphol 1996; 228: 195-201.

Catalá S. Antennal sensilla of Triatominae (Hemiptera, Reduviidae): a comparative study of five genera. Int J Insect Morphol Embriol 1997; 26(2): 6773. 
Catalá S, Dujardin JP. Antennal sensilla patterns indicate geographic and ecotopic variability among Triatoma infestans (Hemiptera, Reduviidae). J Med Entomol 2001; 38(3): 423-428.

Catalá S, Maida DM, Caro-Riano H, Jaramillo N, Moreno J. Changes associated with laboratory rearing in antennal sensilla patterns of Triatoma infestans, Rhodnius prolixus, and Rhodnius pallescens (Hemiptera, Reduviidae, Triatominae). Mem Instituto Oswaldo Cruz 2004; 99: 25-30.

Ceretti Jr. W. Estudos sobre domiciliação espontânea em galinheiros experimentais por população silvestre de triatomíneos no município de Araraquara, São Paulo, no período de XI/1998 a III/2002. [Dissertação de Mestrado]. São Paulo: Faculdade de Saúde Pública da USP; 2003.

Chagas C. Nova tripanozomiase humana. Mem Inst Oswaldo Cruz 1909; (Tomo I): $159-218$.

Chandre F, Darriet F, Doannio JM, Rivière F, Pasteur N, Guillet P. Distribution of organophosphate and carbamate resistance in Culex pipiens quinquefaciatus (Diptera: Culicidae) in West Africa. J Med Entomol 1997; 34 (6): 664 - 671.

Chandre F, Darriet F, Darder M, Cuany A, Doannio JM, Pasteur N, Guillet P. Pyrethroid resistance in Culex quinquefaciatus form West Africa. Med Vet Entomol 1998; 12: 359 - 366.

Chang CP, Plapp FWJr. DDT and pyrethroids: receptor biding in relation to knockdown resistance $(k d r)$ in the house fly. Pestic Biochem Physio 1983; 20: 86 $-91$.

Cheikh HB, Ali-Haouas BA, Marquine M, Pasteur N. Resistance to organophosphorus and pyretrhoid inseticides in Culex pipiens (Diptera: Culicidae) from Tunisia. J Med Entomol 1998; 35 (3): 251 - 260. 
Chilcutt CF, Tabashnik BE. Evolution of pesticide resistance and coeficiente angular of the concentration-motality line: are they related? J Econ Entomol 1995; 88 (1): $11-20$.

Consenso Brasileiro em Doença de Chagas. Secretaria de Vigilância em Saúde do Ministério da Saúde. Rev Bras Med Trop 2005; 38 Suppl 3: 1-29.

Consoli RAGB, Lourenço de Oliveira R. Técnicas. In: Principais mosquitos de importância sanitária no Brasil. Rio de Janeiro: Editora Fiocruz; 1994. p. 161196.

Correia-Lima FG. Doença de Chagas no município de Oeiras, Piauí - estudo seccional nas localidades de Colônia e Oitis. [Dissertação de Mestrado]. Rio de Janeiro: Faculdade de Medicina da Universidade Federal do Rio de Janeiro; 1976.

Costa J, Jurberg J, Barth OM. Estudos morfológicos de Cavernicola lenti Barreto \& Arias, 1985 (Hemiptera, Reduviidae, Triatominae). Mem Inst Oswaldo Cruz 1991; 86 (2): 247-263.

Costa J, Barth OM, Marchon-Silva V, Almeida CE, Freitas-Sibajev MGR, Panzera F. Morphological studies on the Triatoma brasiliensis Neiva, 1911 (Hemiptera, Reduviidae, Triatominae) genital structures and eggs of different chromatic forms. Mem Inst Oswaldo Cruz 1997a; 92 (4): 493 - 498.

Costa J, Freitas-Sibajev MGR, Marchon-Silva V, Pires MQ, Pacheco RS. Isoenzymes detect variation in population of Triatoma brasiliensis (Hemiptera, reduviidae, Triatominae). Mem Inst Oswaldo Cruz 1997b; 92 (4): 459 - 464.

Costa J, Almeida JR, Britto C, Duarte R, Marchon-Silva V, Pacheco RS. Ecotopes, natural infection and trophic resources of Triatoma brasiliensis 
(Hemiptera, Reduviidae, Triatominae). Mem Inst Oswaldo Cruz 1998; 93 (1): 7 13.

Costa J, Peterson AT, Beard CB. Ecologic niche modeling and differentiation of populations of Triatoma brasiliensis Neiva, 1911 the most important Chagas' disease vector in northeastern Brazil (Hemiptera, Reduviidae, Triatominae). Am J Trop Med Hyg 2002; 67 (5): 516 - 520.

Costa J, Almeida CE, Dujardin JP, Beard CB. Crossing experiments detect genetic incompatibility among populations of Triatoma brasiliensis Neiva, 1911 (Heteroptera, Reduviidae, Triatominae). Mem Inst Oswaldo Cruz 2003a; 98 (5): $637-639$.

Costa J, Almeida CE, Dotson EM, Lins A, Vinhaes M, Silveira AC, Beard CB. The epidemiologic importance os Triatoma brasiliensis as a Chagas disease vector in Brasil: a revision of domiciliary captures during 1993 - 1999. Mem Inst Oswaldo Cruz 2003b; 98 (4): 443 - 449.

Costa J, Argolo AM, Felix M. Redescription of Triatoma melanica Neiva \& Lent, 1941, new status (Hemiptera: Reduviidae: Triatominae). Zootaxa 2006; 1385: 47-52.

Costa J, Felix M. Triatoma juazeirensis sp. nov. from the state of Bahia, Northeastern Brazil (Hemiptera: Reduviidae: Triatominae). Mem Inst Oswaldo Cruz 2007; 102 (1): 87-90.

Costa J, Peterson AT, Dujardin JP. Morphological evidence suggests homoploid hybridization as a possible mode of speciation in the Triatominae (Hemiptera, Heteroptera, Reduviidae). Inf Gen Evol 2009; 9: 263 - 270.

Costa Neto PLO. Estatística. 2002. São Paulo, Editora Edgard Blucher. 
Coura JR, Barret TV, Arboleda-Naranjo M. Ataque de populações humanas por triatomíneos silvestres no Amazonas: uma nova forma de transmissão da infecção chagásica? Rev Soc Bras Med Trop 1994; 27: 251 - 253.

Coura JR, Borges-Pereira J, Alves Filho FI, Castro JAF, Cunha RV, Costa W, Junqueira ACV. Morbidade da doença de Chagas em áreas do sertão da Paraíba e da caatinga do Piauí. Rev Soc Bras Med Trop 1996; 29 (2): 197 - 205.

Coura JR, Junqueira ACV, Fernandes O, Valente SAS, Miles MA. Emerging Chagas disease in Amazonian Brazil. Trends in Parasitol 2002; 18 (4): 171-176.

Coura JR, Dias JCP. Epidemiology, control and surveillance of Chagas disease 100 years after its discovery. Mem Inst Oswaldo Cruz 2009; 104 Suppl. 1: 31-40.

Crocco L, Catalá S. Host preferences of Triatoma sordida. Ann Trop Med Parasitol 1997; 91 (8): 927 - 930.

Di Luciano VS. Morphology of the stridulatory groove of Triatoma infestans (Hemiptera, Reduviidae). J Med Entomol 1981; 18 (1): 24-32.

Dias E, Libânio S, Lisboa M. Lucta contra os escorpiões. Mem Inst Oswaldo Cruz 1924; 17: 5-25.

Dias E, Pellegrino J. Alguns ensaios com o "Gamexanne" no combate aos transmissores da doença de Chagas. Brasil Médico 1948; 62: 185-190.

Dias E, Pinto OS. Combate aos triatomas com B.H.C. na cidade de Bambuí, Minas Gerais. Rev Bras Malar Doen Trop 1952; 4 (1): 62-64.

Dias E, Pinto OS, Pellegrino J, Castro JA. Ensaio experimental de luta contra triatomíneos por meio de inseticidas de ação residual. Rev Bras Malar Doen Trop 1952; 4 (1): 22-46. 
Dias JPC. Control of Chagas Disease in Brazil. Parasitol Today 1987; 3 (11): 336 $-341$.

Dias JPC. Doença de Chagas no Brasil - situação atual e perspectivas. Inf Epidemiol SUS 1992; 1: 17-32.

Dias JCP. Controle da Doença de Chagas. In: Dias JCP, Coura JR, organizadores. Clínica e terapêutica da Doença de Chagas. Uma abordagem para o clínico geral. Rio de Janeiro: Fiocruz; 1997. p. 453-467.

Dias JCP. Problemas e possibilidades de participação comunitária no controle das grandes endemias no Brasil. Cad Saúde Públ 1998; 14 Suppl 2: 19-37.

Dias JCP. Epidemiologia. In: Brener Z, Andrade ZA, Barral- Netto M. Trypanosoma cruzi e Doença de Chagas. Rio de Janeiro: Guanabara Koogan S.

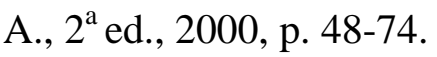

Dias JCP. Doença de Chagas, ambiente, participação e Estado. Cad Saúde Públ 2001; 17 (Suppl): 165-169.

Dias JCP, Silveira AC, Schofield CJ. The impact of Chagas Disease Control in Latin América - A review. Mem Inst Oswaldo Cruz 2002; 97 (5): 603-612.

Dias JCP, Macedo VO. Doença de Chagas. In: Coura JR, editor. Dinâmica das doenças infecciosas e parasitárias. Rio de Janeiro: Guanabara Koogan; 2005. v. 1, p.557-593.

Dias JCP. Doença de Chagas: suscessos e dasafios. Cad Saúde Públ 2006; 22 (10): 2020-2021.

Dias JCP. Elimination of Chagas disease transmission: perspectives. Mem Inst Oswaldo Cruz 2009; 104 Suppl. 1: 41-45. 
Dias JP, Bastos C, Araújo E, Mascarenhas AV, Netto EM, Grassi F, Silva, M, Tatto E, Mendonça J, Araújo RF, Shikanai-Yasuda MA, Aras R. Acute Chagas disease associated with oral transmission. Rev Soc Bras Med Trop 2008; 41 (3): $296-300$.

Diotaiuti L, Pinto CT. Suscetibilidade biológica do Triatoma sordida e Triatoma infestans a deltametrina e lambdacyalotrina em condições de campo. Rev Soc Bras Med Trop 1991; 24 (3): 151 - 155.

Diotaiuti L, Loiola CF, Dias JCP. The ecology of Triatoma sordida in natural environments in two different regions of the state of Minas Gerais, Brasil. Rev Inst Med Trop São Paulo 1993; 35 (3): 237 - 245.

Diotaiuti L, Paula OR, Falcão PL, Dias JCP. Evaluation of the Chagas disease vector control program in Minas Gerais, Brasil, with special reference to Triatoma sordida. Bull Pan Americ Health Organization 1994; 28: 211-219.

Diotaiuti L, de Paula OR, Falcão PL, Dias JCP. Avaliação do programa de controle vetorial da doença de Chagas em Minas Gerais, Brasil, com referência especial a Triatoma sordida. Bol Oficina Sanit Panam 1995; 118 (3): 211 - 219.

Diotaiuti L, Azeredo BVM, Busek SCU, Fernandes AJ. Controle do Triatoma sordida no peridomicílio rural do município de Porteirinha, Minas Gerais, Brasil. Rev Panam Salud Publ 1998; 3 (1): 21 - 25.

Diotaiuti L, Filho OFF, Carneiro FCF, Dias JCP, Pires HHR, Schofield CJ. Aspectos operacionais do controle do T. brasiliensis. Cad Saúde Públ 2000; 16 (Suppl 2): $61-67$.

Elliot M, Farnham AC, Janes NF, Needham PH, Pearson BC. 5-Benzyl-3furylmethyl chrysanthemate: a new potent insecticide. Nature 1967; 213: 493 494. 
ESRI 2004. Arcview GIS. Environmental Systems Research Institute, Redlands.

Farnham AW, Murray AWA, Sawicki RM, Denholm I, White JC. Characterization of the structure activity relationship of kdr and two variants of super $k d r$ to pyrethroids in the housefly (Musca domestica). Pestic Sci 1987; 19: $209-220$.

Ferreira ILM, Silva TPT. Eliminação da transmisão da doneça de Chagas pelo Triatoma infestans no Brasil: um fato histórico. Rev Soc Bras Med Trop 2006; 39 (5): 507-509.

Ferro EA, Rojas de Arias A, Ferreira ME, Simancas LC, Rios LS, Rosner JM. Residual effect of lambdacyalothrin on Triatoma infestans. Mem Inst Oswaldo Cruz 1995; 90 (3): $415-419$.

Forattini OP, Rocha e Silva EO, Ferreira OA, Rabello EX, Pattoli D. Aspectos ecológicos da Tripanossomíase Americana: III - Dispersão local de triatomíneos, com especial referência a Triatoma sordida. Rev Saúde Públ 1971; 5: 193 - 205.

Forattini OP. Entomogeografia médica no Brasil. In: Lacaz CS, coordenador. Introdução a geografia médica no Brasil. São Paulo: Blucher; 1972. p. 191-212.

Forattini OP, Ferreira OA, Rocha e Silva EO, Rabello EX. Aspectos ecológicos da Tripanossomíase Americana: VIII - Domiciliação de Panstrongylus megistus e sua presença extradomiciliar. Rev Saúde Públ 1977a; 11: 73-86.

Forattini OP, Ferreira OA, Rocha e Silva EO, Rabello EX. Aspectos ecológicos da Tripanossomíase Americana: IX - Variação e mobilidade de Panstrongylus megistus em ecótopos artificiais. Rev Saúde Públ 1977b; 11: 119-213.

Forattini OP, Rocha e Silva EO, Ferreira OA, Rabello EX, Santos JLF, Lima AR. Aspectos ecológicos da Tripanossomíase Americana: XI - Domiciliação de 
Panstrongylus megistus e potencial enzoótico. Rev Saúde Públ 1977c; 11: 52750.

Forattini OP, Rocha e Silva EO, Rabello EX, Andrade JCR, Rodrigues VLCC. Aspectos ecológicos da Tripanossomíase Americana: XIII - Potencial enzoótico doméstico em área de ocorrência de Panstrongylus megistus, sob vigilância epidemiológica. Rev Saúde Públ 1978a; 12: 417-24.

Forattini OP, Ferreira OA, Rocha e Silva EO, Rabello EX. Aspectos ecológicos da Tripanossomíase Americana: XII - Variação regional da tendência de Panstrongylus megistus à domiciliação. Rev Saúde Públ 1978b; 12: 209-33.

Forattini OP, Ferreira OA, Rocha e Silva EO, Rabello EX. Aspectos ecológicos da Tripanossomíase Americana: XV - Desenvolvimento, variação e permanência de Triatoma sordida, Panstrongylus megistus e Rhodnius neglectus em ecótopos artificiais. Rev Saúde Públ 1979; 13: 220-34.

Forattini OP. Biogeografia, origem e distribuição da domiciliação de triatomíneos no Brasil. Rev Saúde Públ 1980; 14: 265-99.

Forattini OP, Barata JMS, Dellatorre CC, Buralli GM. Nota sobre domiciliação de Panstrongylus megistus no litoral do Estado de São Paulo, Brasil. Rev Saúde Públ 1982a; 16: 127 - 131.

Forattini OP, Barata JMS, Santos JLF, Silveira AC. Hábitos alimentares, infecção natural e distribuição de triatomíneos domiciliados na Região Central do Brasil. Rev Saúde Públ 1982b; 16: 171 - 204.

Forattini OP, Ferreira OA, Rabello EX, Barata JMS, Santos JLF. Aspectos ecológicos da Tripanossomíase Americana: XIX - Desenvolvimento da domiciliaçao triatomínea regional, em centro de endemismo de Panstrongylus megistus. Rev Saúde Públ 1983; 17: 436-60. 
Fontán A, Zerba EN. Mode of entry insecticides in Triatoma infestans. Arch Insect Biochem Physiol 1987; 4: 313 - 323.

Fournier D, Mutero A. Mini Review: Modification of acetylcholinesterase as a mechanism of resistance to inseticides. Comp Biochem Physiol 1994; 108C (1): $19-31$.

Galvão C, Jurberg J, Carcavallo RU, Segura CAM, Girón IG, Curto de Casas SI. Distribuição geográfica e dispersão alti-latitudinal de alguns gêneros e espécies da Tribo Triatomini Jeannel, 1919 (Hemiptera, Reduviidae, Triatominae). Mem Inst Oswaldo Cruz 1998; 93 (1): 33 - 37.

Gammon DW, Brown MA, Casida JE. Two classes of pyrethroid action in the cockroach. Pestic Biochem Physiol 1981; 15: 181 - 191.

Gaunt M, Miles M. The ecotopes and evolution of Triatomine bugs (Triatominae) and their associated trypanosomes. Mem Inst Oswaldo Cruz 2000; 95 (4): 557 565.

Gentile AG, Sartini JL, Campo MC, Sánchez JF. Eficacia del fipronil en el control del ciclo peridomiciliario de Triatoma infestans en un área con resistencia a la deltametrina. Cad Saúde Públ 2004a; 20 (5): 1240 - 1248.

Gentile AG, Sartini JL, Campo MC, Sánchez JF. La aerotermia como alternativa para el control de Triatoma infestans (Hemiptera, Reduviidae) resistentes a deltametrina. Cad Saúde Públ 2004b; 20 (4): 1014 - 1019.

Georghiou GP, Wirth M, Tran H, Saume F, Knudsen AB. Potential for organophosphate resistance in Aedes aegypti (Diptera: Culicidae) in the Caribbean area and neighboring countries. J Med Entomol 1987; 24: 290 - 294.

Gerolt P. The fate of diedrin in insects. J Econ Entomol 1965; 58: 850 - 857. 
Gerolt P. Mode of entry of contact insecticides. J Insect Physiol 1969; 15: 563 580.

Ghiasuddin SM, Soderlund DM. Pyrethroid insecticides: Potent, Stereospecific enhancers of mouse brain sodium channel activation. Pestic Biochem Physiol 1985; 24: 200 - 206.

Gonçalves TCM, Jurberg J, Costa JM, Souza W. Estudo morfológico comparativo de ovos e ninfas de Triatoma maculata (Erichson, 1848) e Triatoma pseudomaculata Corrêa \& Spínola, 1964 (Hemiptera, Reduviidae, Triatominae). Mem Inst Oswaldo Cruz 1985; (80): 263-276.

González-Audino P, Vassena C, Barrios S, Zerba E, Picollo MI. Role of enhance detoxication in a deltamethrin-resistant population of Triatoma infestans (Hemiptera, Reduviidae) from Argentina. Mem Inst Oswaldo Cruz 2004; 99 (3): 335-339.

González-Audino P, Barrios S, Vassena C, cueto GM, Zerba E, Picollo MI. Increase monooxygenase activity associated with resistance to permethrin in Pediculus humanus capitis (Anoplura: Pediculidae) from Argentina. J Med Entomol 2005; 42 (3): 342 - 345.

González T, Bisset JA, Días C, Rodríguez MM, Brandolini MB. Insecticide resistance in a Culex quinquefaciatus strain from Rio de Janeiro, Brasil. Mem Inst Oswaldo Cruz 1999; 94 (1): 121 - 122.

Gorla DE. Recovery of Triatoma infestans populations after insecticide application: an experimental field study. Med Vet Entomol 1991; 5: 311 - 324.

Gracco M, Catalá S. Inter-specific and development differences on the array of antennal chemoreceptors in four species of Triatominae (Hemiptera: Reduviidae). Mem Inst Oswaldo Cruz 2000; 95 (1): 67-74. 
Grant IH, Gold JW, Winter M. Transfusion associated acute Chagas'disease acquired in the United States. Ann Inter Med 1987; 111: 849-851.

Grisson RE, Konno TJr, Motoyama N, Dauterman WC. Comparision between in vivo and in vitro cutaneous penetration of fenvalerate in tabacco budworm (Lepdoptera: Noctuidae). J Econ Entomol 1989; (82): 41 - 44.

Guglielmone AA, Castelli ME, Volpogni MM, Anziani OS, Mangold AJ. Dymanics of cypermethrin resistance in the Field in the horn fly, Haematobia irritans. Med Vet Entomol 2002; 16: 310 - 315.

Guhl F, Jaramillo N, Vallejo GA, Yockteng R, Cardenas-Arroyo F, Fornaciari G, Arriza B, Aufderheide C. Isolation of Trypanosoma cruzi DNA in 4,000-year old mummified human tissue from Northern Chile. Am J Phys Antrop 1999; 108: 401-407.

Guhl F, Jaramillo N, Carranza JC, Vallejo GA. Molecular characterization and diagnosis of Trypanosoma cruzi and T. rangeli. Arch Med Res 2002; 33: 362370.

Gürtler RE, Petersen RM, Cecere MC, Schweigmann NJ, Chuit R, Gualtieri JM, Wisnivesky-Colli C. Chagas disease in north-west Argentina: risk of domestic reinfestation by Triatoma infestans after a single community-wide application of deltametrina. Trans R Soc Med Trop Hyg 1994; 88: 27 - 30.

Halliday WR, Burnham KP. Chossing the optimal diagnostic dose for monitoring insecticide resistance. J Econ Entomol 1990; 83 (4): 1151 - 1159.

Hargreaves K, Koekemoer LL, Brooke BD, Hunt RH, Mthembu J, Coetzee M. Anopheles funestus resistant to pyretrhoid insecticides in South Africa. Med Vet Entomol 2000; 14: 181 - 189. 
Haridass ET, Ananthakrishnan TN. Functional morphology of the fossula spongiosa in some Reduviids (Insecta, Heteroptera, Reduviidae). Proc Indian Acad Sci 1980; 89 (5): 457-466.

Hemingway J. Genetics of organophosphate and carbamate resistance in Anopheles atroparvus (Diptera: Culicidae). J Econ Entomol 1982; 75: 1055 1058.

Hemingway J, Myamoto J, Herath PRJ. A possible novel link between organophosphorus and DDT insecticide resistance genes in Anopheles: Supporting evidence from fenitrothion metabolism studies. Pestic Biochem Physiol 1990; 39: 49-56.

Hemingway J, Small GJ, Monro A, Sawyer BV. Insecticide resitance gene frequencies in Anopheles sacharovi poulations of the Çukurova plain, Andana Province, Turquia. Med Vet Entomol 1992; 6: 342 - 348.

Hemingway J, Karunaratne SH. Mosquito carboxylesterases: a review of the molecular biology and biochemistry of a major insecticide resistence mechanism. Med Vet Entomol 1998; 12 (1): 1-12.

Hemingway J, Miller J, Mumcuoglu KY. Pyrethroid resitance mechanisms in the head louse Pediculus capitis from Israel: implications for control 1999; 13: 89 96.

Hemingway J, Ranson $\mathrm{H}$. Insecticide resistance in insect vectors of human disease. Ann Rev Entomol 2000; 45: 371 - 391.

Hodgson E. The significance of cytochrome P450 in insects. Insect Biochem 1983; 13 (3): $237-246$. 
Hoffmann RC. Situação atual da vigilância entomológica do Programa de Controle da Doença de Chagas na região de Campinas, São Paulo, Brasil. [Dissertação de Mestrado]. São Paulo: Faculdade de Saúde Pública da USP; 2007.

Juárez MP. Hydrocarbon biosynthesis in Triatoma infestans eggs. Arch Insect Biochem Physiol 1994; 25: 193 - 206.

Juarez MP, Fernández GC. Cuticular hydrocarbons of triatomines. Comp Biochem Physiol 2007; Part A 147: 711 - 730.

Jurberg J, Galvão C, Barth OM. Estudo morfológico de ovos e ninfas de Triatoma nitida Usinger 1839 (Hemiptera, Reduviidae, Triatominae). Rev Bras Biol 1991; 51 (2): 365-372.

Jurberg J, Fagundes LM de, Barth OM. Estudo morfológico de ovos e ninfas de Dipetalogaster maxima (Uhler 1894) (Hemiptera, Reduviidae, Triatominae). Mem Inst Oswaldo Cruz 1993; 86 (2): 269- 283.

Jurberg J, Vogel M. Morfologia de huevos y ninfas de Triatoma matogrossensis Leite e Barbosa, 1953 (Hemiptera, Reduviidae). Entomol Vectores 1994; 1 (6): $167-177$.

Jurberg J, Campos P. Morfologia de huevos y ninfas de Triatoma vitticeps (Stål, 1859) (Hemiptera, Reduviidae). Entomol Vectores 1995; 2 (1): 9-22.

Jurberg J, Silva MBA, Galvão C, Silva- Rocha D da, Barbosa HS, Carcavallo RU. Descrição dos ovos e dos estádios ninfais de Triatoma jurbergi Carcavallo, Galvão \& Lent, 1998 vistos através de microscopia óptica e eletrônica de varredura (Hemiptera, Reduviidae). Mem Inst Oswaldo Cruz 2002; 97 (2): 209216. 
Jurberg J, Galvão C, Noireau F, Carcavallo RU, Rocha DS, Lent H. Uma iconografia dos triatomíneos (Hemiptera: Reduviidae). Entomol Vect 2004; 11 (3): 457-494.

Karunaratne SHPP, Hemingway J. Insecticide resistance spectra and resistance mechanisms in populations of Japanese encephalitis vector mosquitoes, Culex tritaeniorhynchus and Cx gelidus, in Sri Lanka. Med Vet Entomol 2000; 14: 430 $-436$.

Kirchhoff LV, Gam AA, Gillam F. American trypanosomiasis (Chagas disease) in Central American immigrants. Amer J Trop Med Hyg 1987; 82: 915-920.

Lainson R, Shaw JJ, Frahia H, Miles MA, Draper CC. Chaga's disease in Amazon Basin I. Trypanosoma cruzi infections in silvatic mammals, triatomine bugs and man in the State of Pará, north Brazil. Trans Royal Soc Med Trop Hyg 1979; 73(2): 193-204.

Lee CY, Hemingway J, Yap HH, Chong NL. Biochemical characterization of insecticide resistance in the german cockroach, Blattella germanica, from Malaysia. Med Vet Entomol 2000; 14: 11 - 18.

Lee SH, Gao JR, Yoon KS, Mumcuoglu KY, Taplin D, Edman JD, Takano-Lee M, Clark M. Sodium channel mutations associated with knockdown resistance in the human head louse, Pediculus capitis (De Geer). Pestic Biochem Physiol 2003; 75: $79-91$.

Lent H, Oliveira SJ. Nota preliminar sobre a ação do DDT (dicloro-difeniltricloetana) em insetos transmissores da doença de Chagas. Rev Bras Biol 1944; 4: 329-331. 
Lent H, Wygodzinsky P. Revision on the Triatominae (Hemiptera,Reduviidae) and their significance as vectors of Chagas'disease. Bull. of the American Mus. of Nat. Hist. 1979; 163(3) : 123-520.

LeOra Software. POLO - PC: a user's guide to probit or logic analysis. LeOra Software, Berkeley, CA.

Lima JBP, Pereira da Cunha M, Silva Jr RC, Galardo AKR, Soares SS, Braga IA, Ramos RP, Valle D. Resistance of Aedes aegypti to organophosphate in several municipalities in the State of Rio de Janeiro and Espírito Santo, Brazil. Am J Trop Med Hyg 2003; 68 (3): 329 - 333.

Lima JTF. Incremento do programa de controle da doença de Chagas no Brasil. Rev Soc Bras Med Trop 1983; 16: 128 - 129.

Lichfield J, Wilcoxon F. A simplified method of evaluation dose-effect experiments. J Pharmacol Exp Ther 1949; 96: 99 - 113.

Lofgren CS, Keller JC, Burden GS. Resistance tests with the bed bugs and evaluation of insecticides for its control. J Econ Entomol 1958; 51 (8): 241 - 244.

Macoris MLG, Andrighetti MT, Takaku L, Carmen MG, Garbeloto VC, Cirino VCB. Alteração de resposta de suscetibilidade de Aedes aegypti a inseticidas organofosforados em municípios do Estado de São Paulo, Brasil. Rev Saúde Públ 1999; 33 (5): $521-522$.

Magnin M, Marboutin E, Pasteur N. Insecticide resistance in Culex quinquefasciatus (Diptera: Culicidae) in West Africa. J Med Entomol 1988; 25 (2): 99 - 104. 
Marcondes CB, Pinto CT. Avaliação da eficiência de deltametrina (K-othrine 50FW), em doses baixas, no controle de triatomíneos em São Sebastião do Umbuzeiro, Paraíba. Rev Soc Bras Med Trop 1989; 22 (2): 85 - 90.

Matambo TS, Abdalla H, Brooke BD, Koekemoer LL, Mnzava A, Hunt RH, Coetzee M. Insecticide resistance in the malarial mosquito Anopheles arabiensis and association with the $k d r$ mutation. Med Vet Entomol 2007; 21: 97 - 102.

Matsumura F. The permeability of the cuticle of Periplaneta americana (L.) to malathion. J Insect Physiol 1963; 9: 207 - 221.

Mazariego-Arana MA, San-Juan ER, Alejandre-Aguilar R, Nogueda-Torres B. Activity and residual effect of two formulations of lambdacyhalothrin sprayed on palm leaves to Rhodnius prolixus. Mem Inst Oswaldo Cruz 2002; 97 (3): 353 357 ,

Mclaughlin GA. History of pyrethrum. In: Casida JE, editor. Pyrethrum. New York: Academic Press; 1973. p. 3 - 15.

Metcalf RL. Insect resistance to insecticides. Pestic Sci 1989; 26: 333 - 358.

Ministério da Saúde. Superintendência de Campanhas de Saúde Pública. O controle das endemias no Brasil de 1979 a 1984. Brasília, DF; 1985.

Ministério da Saúde. Portaria no 1.399, de 15 dezembro de 1999. Regulamenta a NOB SUS 01/96 no que se refere às competências da União, estados, municípios e Distrito Federal, na área de epidemiologia e controle de doenças, define a sistemática de financiamento e dá outras providências. Diário Oficial da União. 16 dez. 1999; Seção 1:4.

Ministério da Saúde. Portaria $\mathrm{n}^{\circ} 1.172$, de 15 junho de 2004. Regulamenta a NOB SUS 01/96 no que se refere às competências da União, Estados, Municípios 
e Distrito Federal, na área de Vigilância em Saúde, define a sistemática de financiamento e dá outras providências. Diário Oficial da União. 15 jun. 2004.

Ministério da Saúde. Secretaria de Vigilância em Saúde. Nota técnica de 04 de abril de 2005: Doença de Chagas relacionada à ingestão de caldo de cana em Santa Catarina. Brasília, DF; 2005.

Moncayo A. Chagas Disease: Current epidemiological trends after the interruption of vectorial and transfusional in the Southern Cone Countries. Mem Inst Oswaldo Cruz 2003; 98 (5): 577-591.

Moncayo A, Silveira AC. Current epidemiological trends for Chagas disease in Latin America and future challenges in epidemiology, surveillance and health policy. Mem Inst Oswaldo Cruz 2009; 104 (Suppl. I): 17 - 30.

Montalvan CJA. Ensayos de profilaxia de enfermedad de Chagas en Guayaquil. Rev Equ Hig 1952; 8: 23-28.

Monteiro FA, Perez R, Panzera F, Dujardin JP, Galvão C, Rocha D, Noireau F, Schofield C, Beard CB. Mitochondrial DNA variation of Triatoma infestans populations and its implication on the specific status of T. melanosoma. Mem Inst Oswaldo Cruz 1999; 94: 229 - 238.

Monteiro FA, Donnelly MJ, Beard CB and Costa J. Nested clade and phylogeographic analyses of the Chagas disease vector Triatoma brasiliensis in Northeast Brazil. Mol Phylogenet Evol 2004; 32: 46-56.

Monteiro FA, Jurberg J, Lasoki C. Very low levels of genetic variation in natural peridomestic populations of the Chagas disease vector Triatoma sordida (Hemiptera: Reduviidae) in Southeastern Brazil. Am J Trop Med Hyg 2009; 81 (2): $223-227$. 
Moreno AR, Carcavallo RU. Enfoque ecológico para epidemiologia da doença de Chagas. In: Atlas of Chagas Disease Vectors on the Americas. Ed. R.U. Carcavallo, I.G. Girón, J. Jurberg \& H. Lent, Vol. III. Editora Fiocruz, Rio de Janeiro; 1999.

Moreno ML, Gorla D, Catalá S. Association between antennal phenotype, wing polymorphism and sex in the genus Mepraia (Reduviidae: Triatominae). Infect Genet Evol 2006; 6:228-234.

Myamba J, Maxwell CA, Asidi A, Curtis CF. Pyrethroid resistance in tropical bedbugs, Cimex hemipterus, associated with use of treated bednets. Med Vet Entomol 2002; 16: 448 - 451.

Nauen R. Perspective insecticide resistance in disease vectors of public health importance. Pest Manag Sci 2007; 63: 628 - 633.

Neghme A. Alguns dados sobre profilaxia de la enfermedad de Chagas em Chile. I Reunion Panamericana sobre Enfermedad de Chagas, Tucuman, 1949. Fasc 1 1950; 65-66.

Neiva VL, Gumiel M, Oliveira MGG, Dotson E, Lima MM, Dujardin JP, Almeida CE, Costa J. High phenotypic variability was detected in a possible hybrid zone of the Triatoma brasiliensis species complex, in the state of Pernambuco, Brazil (Hemiptera, Heteroptera, Reduviidae). In: XXXV Annual meeting on basic research in Chagas'disease; 2008, out 27-29; Águas de Lindóia, Brasil.

Nelson MJ, Colmenares P. Topical application of insecticides to $R$. prolixus (Reduviidae: Triatominae) a Chagas disease vector. Document WHO/BVC/79.737. Geneva, WHO. 1979. 
N'Guessan R, Darriet F, Guillet P, Carnevale P, Traore-lamizana M, Corborel V, Koffi AA, Chandre F. Resistance to carbosulfan in Anopheles gambie from Ivory Coast, based on reduced sensivity of acetylcholinesterase. Med Vet Entomol $2003 ; 17: 19-25$.

Nielsen-Leroux C, Pasquier F, Charles JF, Sinègre G, Gaven B, Pasteur N. Resistance to Bacillus sphaericus involves different mechanisms in Culex pipiens (Diptera: Culicidae) larvae. J Med Entomol 1997; 34 (3) 321 - 327.

Nieto-Caicedo M. Primeros resultados en la campaña anti-triatoma com el gamexano en Venezuela. I Reunion Panamericana sobre Enfermedad de Chagas, Tucuman, 1949. Fasc 1 1950; 63-64.

Nóbrega AA, Garcia MH, Tatto E, Obara MT, Costa E, Sobel J, Araujo WN. Oral transmission of Chagas Disease by consumption of açaí Palm Fruit, Brasil. Emerging Inf. Diseases 2009; 15 (4): 653 - 655.

Nocerino F, Hernández A. Establishment of baseline data on the insecticide susceptibilities of the Chagas'disease vector Rhodnius prolixus in Venezuela. PAHO Bull 1986; 20 (4): 366 - 369.

Nogueira RMR, Miagostovich MP, Schatzmayr HG, Santos, FB, Araujo ESM, Filippis AMB, Souza RV, Zagne SMO, Nicolai C, Baran M, Teixeira-Filho G. Dengue in the State of Rio de Janeiro, Brazil 1986 - 1998. Mem Inst Oswaldo Cuz 1999; 94 (3): 297 - 304.

Obara MT. Estudo de ovos de dez espécies da subfamília Triatominae (Hemiptera, Reduviidae). [Dissertação de Mestrado]. São Paulo: Faculdade de Saúde Pública da Universidade de São Paulo; 2003.

Obara MT, Rosa JA da, Ceretti Jr W, Urbinatti PR, Osório Quintero L, Barata JMS, Galvão C, Jurberg J.A study of the scutellum in eight Chagas disease vector 
species from genus Triatoma (Hemiptera, Reduviidae) using optical and scanning electron microscopy. Mem Inst Oswaldo Cruz 2007a; 102 (4): 463-468.

Obara MT, Rosa JA da, Silva NN da, Ceretti Jr. W, Urbinatti PR, Barata JMS, Jurberg J, Galvão C. Estudo morfológico e histológico dos ovos de seis espécies do gênero Triatoma (Hemiptera: Reduviidae). Neotrop Entomol 2007b, 36 (5): 798-806.

Obara MT, Barata JMS, Silva NN da, Ceretti Jr. W, Urbinatti PR, Rosa JA, Jurberg J, Galvão C. Estudo de ovos de quatro espécies do gênero Meccus (Hemiptera, Reduviidae, Triatominae), vetores da doença de Chagas. Mem Inst Oswaldo Cruz 2007c; 102 (1): 13-19.

Oliveira AWS, Silva IG. Distribuição geográfica e indicadores entomológicos de triatomíneos sinantrópicos capturados no Estado de Goiás. Rev Soc Bras Med Trop 2007; 40 (2): $204-208$.

Oliveira Filho AM, Pichin R, Melo MTV, Silva WS, Santos CE, Henney MA, Figueredo MJ. Laboratory screening of 23 insecticides for triatomine control deternimation of $\mathrm{LD}_{50}$ and $\mathrm{LD}_{95}$ for Panstrongylus megistus. Ciência e Cult 1981; 33 (Suppl 1): 455.

Oliveira Filho AM, Melo MTV, Santos CE, Silva LB. Insecticide activity of houses walls 13 months post-treatment, measured by biological assay in the Posse - Goiás large scale field trial. Mem Inst Oswaldo Cruz 1986; (Suppl) 81: 171.

Oliveira Filho AM. Uso de nuevas herramientas para el control de triatominos en diferentes situaciones entomlógicas en el continente americano. Rev Soc Bras Med Trop 1997; 30 (1): 41 - 46. 
Oliveira Filho AM. Differences of susceptibility of five triatomine species to pyrethroid insecticides - implications for Chagas disease vector control. Mem Inst Oswaldo Cruz 1999; 94 (Suppl 1): 425 - 428.

Oliveira Filho AM, Melo MTV, Santos C, Filho OFF, Carneiro FCF, Oliveira Lima JW, Vieira JBF, Gadelha FV, Ishihata J. Tratamentos focais e totais com inseticidas de ação residual para o controle de Triatoma brasiliensis e Triatoma pseudomaculata no Nordeste brasileiro. Cad Saúde Públ 2000; 16 (Supl 2): 105 111.

OPAS - Organização Pan Americana de Saúde. Reunião Internacional sobre Vigilância e Prevenção da doença de Chagas na Amazônia. Implementação da Iniciativa Intergovernamental de Vigilância e Prevenção da doença de Chagas na Amazônia. Manaus/Amazonas. Rev Soc Bras Med Trop 2005a; 38 (1): 82-89.

OPAS - Organização Pan Americana de Saúde. II Reunion tecnica latinoamericana de monitoreo de resistencia a insecticidas em triatominos vectores de Chagas. Panamá, 11 a 13 de abril de 2005b.

OPAS - Organização Pan Americana de Saúde. $2^{\circ}$ Reunião da Inicitativa Intergovernamental de Vigilância e Prevenção da doença de Chagas na Amazônia. Caiena/Guiana Francesa. Rev Soc Bras Med Trop 2006; 39 (3): 311317.

OPAS - Organização Pan Americana de Saúde. Guia para vigilância, prevenção, controle e manejo clínico da doença de Chagas aguda transmitida por alimentos. Rio de Janeiro. Série de manuais técnicos. PANAFTOSA/OPAS/OMS, 2009. p. $1-69$.

Orihuela PLS, Vassena CV, Zerba EM, Picollo MI. Relative contribution of monooxygenase and esterase to pyrethroid resistance in Triatoma infestans 
(Hemiptera: Reduviidae) from Argentina and Bolivia. J Med Entomol 2008; 45 (2): $298-306$.

Osimani JJ, Veríssimo S, Carbonelli PB. La profilaxis de La enfermdedad de Chagas en el Uruguay por medio del gamexano. Experiencias realizadas. Plan de luta contra el Triatoma infestans. Bol Ofic Sanit Panamer 1950; 29: 1125 - 1134.

Osório-Quintero L. Avaliação do valor sistemático do Processo do I Urotergito em machos de onze espécies de da subfamília Triatominae (Hemiptera, Reduviidae). [Tese de Doutorado]. São Paulo: Faculdade de Saúde Pública da USP; 2002.

Paster N, Isek A, Georghiou GP. Genetic and biochemical studies of the highly active esterases A and B associated with organophosphate resistance in mosquitos of the Culex pipens complex. Biochem Genet 1981; 10: 909-919.

Patterson JS, Barbosa SE, Feliciangeli MD. On the genus Panstrongylus Berg 1879: Evolution, ecology and epidemiological significance. Acta Trop 2009; 110: $187-199$.

Pedreira de Freitas JL. Resultados da aplicação de "Rhodiatox" e "Gamexane" contra triatomíneos. Observações sobre o poder residual. Rev Paul Med 1950; 36 : $235-244$.

Pedreira de Freitas JL. Importância do expurgo seletivo dos domicílios e anexos para profilaxia da moléstia de chagas pelo combate aos triatomíneos. Arq Hig Saúde Públ 1963; 28 (97): 217- 272.

Pedrini N, Mijailovsky SJ, Girotti JR, Stariolo R, Cardozo RM, Gentile A, Juárez MP. Control of Pyrethroid-Resistant Chagas disease vectors with entomopathogenic fungi. PLOS Negl Trop Disease 2009; 3 (5): 1 - 11. Disponível em www.plosntds.org 
Penna R, Bosworth A, Brasil IA, Marsden PD. Persistência da atividade residual do BHC na superfície de diferentes materiais de construção. Rev Soc Bras Med Trop 1984; 17: 95 - 99.

Pereira da Cunha M, Lima JBP, Brogdon WG, Moya GE, Valle. Monitoring of resistance to the pyretrhoid cypermethrin in Brazilian Aedes aegypti (Diptera: Culicidae) populations collected between 2001 and 2003. Mem Inst Oswaldo Cruz 2005; 100 (4): $441-444$.

Pereira KS, Schmidt FL, Guaraldo AMA, Franco RMB, Dias VL, Passos LAC. Chagas disease as a foodborne illness. J Food Protection 2009; 72 (2): 441 - 446.

Perlowagora-Szumlewicz A. A eficácia do expurgo domiciliário com dieldrin no controle do vetor da doença de Chagas. Rev Bras Malar Doen Trop 1956; 8: 289304.

Pessoa GCA. Monitoramento da suscetibilidade ao piretróide deltametrina em populações de Triatoma sordida Stål, 1859 (Hemiptera: Reduviidae). [Dissertação de Mestrado]. Belo Horizonte: Centro de Pesquisas René Rachou da Fundação Oswaldo Cruz; 2008.

Picollo MI, Vassena CV, Cueto GAM, Vernetti M, Zerba EM. Resistance to insecticides and effect of synergists on permethrin toxicity in Pediculus capitis (Anoplura: Pediculidae) from Buenos Aires. J Med Entomol 2000; 37 (5): 721 725 .

Picollo MI, Vassena C, Orihuela PS, Barrios S, Zaidemberg M, Zerba E. High resistence to pyrrethroid insecticides associated with ineffective field treatments in Triatoma infestans (Hemipetra: Reduviidade from Northern Argentina. J Med Entomol 2005; 42 (4) 637-642. 
Pinto OS, Bicalho JC. Profilaxia da doença de Chagas no Estado de Minas Gerais por meio de inseticidas. Rev Bras Malar Doen Trop 1952; 4 (2): 145-156.

Pires HHR, Borges EC, Andrade RE, Lorosa ES, Diotaiuti L. Peridomiciliary infestation with Triatoma sordida Stal, 1859 in the county of Serra do Ramalho, Bahia, Brasil. Mem Inst Oswaldo Cruz 1999; 94 (2): 147 - 149.

Ramsey JM, Schofield CJ. Control of Chagas disease vectors. Salud Publ México 2003; 45 (2): 123-128.

Rawlins A, Wan JH. Resistance in some Caribbean populations of Aedes aegypti to several insecticides. J Amer Mosq Control Assoc 1995; 11 (1): 59 - 65.

Ray JW. The epoxidation of aldrin by housefly microsomes and its inhibition by carbon monoxide. Biochem Pharmacol 1967; 16: 99 - 107.

Robertson JL, Smith KC, Savin NE, Lavigne RJ. Effects of dose selection and sample size on the precision of lethal dose estimates in dose-motality regression. J Econ Entomol 1984; 77: 833 - 837.

Rocha DS, Jurberg J, Galvão C. Descrição de ovos e ninfas de Triatoma lecticularia (Stål, 1859) (Hemiptera, Reduviidae, Triatominae). Entomol Vectores 1996; 3 (5): 123-135.

Rodcharoen J, Mulla. Resistance development in Culex quinquefasciatus (Diptera: Culicidae) to Bacillus sphaericus. J Med Entomol 1994; 87 (5): 1133 1140 .

Rodrigues VLCC, Ferraz-Filho AN, Ishihata GK, Silva EOR. Triatoma brasiliensis Neiva, 1911 (Hemiptera, Reduviidae): observações sobre seu comportamento em relação à fonte alimentar em galinheiro experimental. Cad Saúde Públ 1995; 11 (2): 266 - 270. 
Rojas de Arias A, Lehane MJ, Schofield CJ, Fournet A. Comparative evaluation of pyrethroid insecticide formulations against Triatoma infestans (Klug): residual efficacy on four substrate. Mem Inst Oswaldo Cruz 2003; 98 (7): 975 - 980.

Rojas de Arias A, Lehane MJ, Schofield CJ, Maldonado M. Pyrethroid insecticide evaluation on different house structure in a Chagas disease endemic area of the Paraguayan Chaco. Mem Inst Oswaldo Cruz 2004; 99 (6): 6657 662.

Romaña C, Abalos JW. Acción de "Gamexanne”sobre los triatomídeos. Control domiciliario. Ann Inst Med Regional Tucuman 1948; 2: 95-106.

Rosa JA da, Barata JMS, Barelli N. Spiracles of $5^{\text {th }}$ instar nymphs in six species of Triatominae (Hemiptera, Reduviidae) using Scanning Electron Microscopy. Mem Inst Oswaldo Cruz 1992; 87 (2): 301-302.

Rosa JA da, Tres DFA, Santos JLF, Barata JMS. Estudo morfométrico dos segmentos antenais de ninfas e adultos de duas colônias de Triatoma rubrovaria (Blanchard, 1843) (Hemiptera, Reduviidae). Entomol Vectores 2000; 7 (3): 255264.

Roush RT, Miller GL. Considerations for design of insecticide resistance monitoring programs. J Econ Entomol 1986; 79: 293 - 298.

Salgado AP, Pinto OS. Levantamento dos triatomíneos domiciliários como trabalho preliminar a um programa profilático contra a doença de Chagas. Normas adotadas pelo Serviço Nacional de Malária. Rev Bras Malariol 1952; 4 48.

Santos CM, Jurberg J, Galvão C, Rosa JA, Ceretti-Jr C, Barata JMS, Obara MT. Comparative description of eggs from three species of Rhodnius (Hemiptera: Reduviidae: Triatominae). Mem Inst Oswaldo Cruz 2009; 104 (7): 1012 - 1018. 
Sarquis O, Borges-Pereira J, Mac Cord JR, Gomes TF, Cabello PH, Lima MM. Epidemiology of Chagas disease in Jaguaruana, Ceará, Brazil. I. Presence of triatomines and index of Trypanosoma cruzi infection in four localities of rural area. Mem Inst Oswaldo Cruz 2004; 99 (3): 263 - 270.

Sarquis O, Sposina R, Oliveira TG, Mac Coard JR, Cabello PH, Borges-Pereira J, Lima MM. Aspects of peridomiciliary ecotopes in rural areas of northeastern Brazil associated to triatomine (Hemiptera, Reduviidae) infestation, vectors of Chagas disease. Mem Inst Oswaldo Cruz 2006; 101 (2): 143 - 147.

Schatzmayr HG. Dengue situation by year 2000. Mem Inst Oswaldo Cruz 2000; 95: $179-181$.

Schenone H, Christensen HA, Vásquez AM de, González C, Méndez E, Rojas A e Villarroel F. Fuentes de alimentación de Triatomas domesticos y su implicancia en relación a la enfermedad de Chagas en areas rurales de siete regiones de Chile. Bol Chil Parasitol 1985; 40: 34-38.

Schmunis GA. La tripanosomiasis Americana como problema de salud pública. En: La enfermedad de Chagas y el sistema nervioso. Org Pan Salud Publ Sci 1994; 547: 3-31.

Schmunis GA, Dias JCP. La reforma del setor salud, descentralización, prevención y control de enfermedades transmitidas por vectores. Cad Saúde Públ 2000; 16 (Sppl 2): 117-123.

Schofield CJ. Triatominae: Biología y Control. 1994; West Sussex: Eurocommunica Publications.

Schofield CJ, Jannin J, Salvatella R. The future of Chagas disease control. Trends Parasitol 2006; 22 (12): 583-588. 
Schouest LPJr, Umetsu N, Miller TA. Solvent-modified deposition of insecticides on house fly (Diptera: Muscidae) cuticle. J Econ Entomol 1983; 76: $973-982$.

Sfara V, Zerba EN, Alzogaray RA. Toxicity of pyrethroids and repellency of diethyltoluamide in two deltamethrin-resistant colonies of Triatoma infestans Klug, 1834 (Hemiptera: Reduviidae). Mem Inst Oswaldo Cruz 2006; 101 (1): 89 $-94$.

Shaw J, Laison R, Fraiha H. Considerações sobre a epidemiologia dos primeiros casos autóctones de doença de Chagas registrados em Belém, Pará, Brasil. Rev Saúde Públ 1969; 3: 153 - 157.

Sherlock I, Muniz TM. Combate ao Panstrongylus megistus com o malathion concentrado. Rev Soc Bras Med Trop 1975; 9 (6): 289-296.

Sherlock I, Muniz TM, Guitton N. A ação do malathion sobre os ovos de triatomíneos vetores de doença de Chagas. Rev Soc Bras Med Trop 1976; 10 (2): 77-84.

Silva MBA, Barbosa HS, Jurberg J, Galvão C, Carcavallo RU. Comparative ultrastructural analysis of the antennae of Triatoma guazu and Triatoma jurbergi (Hemiptera, Reduviidae) during the nymphal stage development. J Med Entomol 2002; 39(5): 705-715.

Silveira AC. Profilaxia Doença de Chagas. In: Brener Z, Andrade Z, Barral-Neto M, editores. Trypanozoma cruzi e Doença de Chagas. 2 ed. Rio de Janeiro: Guanabara Koogan; 2000. p.75-87.

Silveira AC. Enfoque de riesgo em actividades de control de triatominos. Rev Pat Trop 2004; 33 (2): 193-206. 
Silveira AC, Vinhaes MC. Doença de Chagas: aspectos epidemiológicos e de controle. Rev Soc Bras Med Trop 1998; 31 Suppl 2: 50-60.

Smissaert HR. Cholinesterase inhibition in spider mites susceptible and resistant to organophosphate. Science 1964; 143: 129 - 131.

Soares RPP, Evangelista LG, Laranja LS, Diotaiuti L. Population dynamics and feeding behavior os Triatoma brasiliensis and Triatoma pseudomaculata, main vectors of Chagas disease in northeastern Brazil. Mem Inst Oswaldo Cruz 2000; 95 (2): $151-155$.

Soderlund DM, Bloomquist JR. Neurotoxic actions of pyrethroid insecticides. Ann Rev Entomol 1989; 34: 77 - 96.

Soderlund DM. Review: Pyrethroids, knockdown resistance and sodium channels. Pest Manag Sci 2008; 64: 610 - 616.

Sonoda IV. Triatoma infestans e Triatoma brasiliensis: avaliação da resistência ao piretróide deltamentrina e análise intraespecífica da variabilidade genética. [Tese de Doutorado]. Belo Horizonte: Centro de Pesquisas René Rachou da Fundação Oswaldo Cruz; 2009.

Sonoda IV, Pessoa GCA, Cortez MR, Dias JCP, Romanha AJ, Diotaiuti L. Susceptibility of Triatoma infestans to deltamethrin in Rio Grande do Sul, Brazil. Mem Inst Oswaldo Cruz 2009; 104 (4): 668 - 670.

Stark JD, Banks JE. Population level effects of pesticides and other toxicants on arthropods. Annu Rev Entomol 2003; 48: 505 - 519.

Steindel M, Toma HK, Pinto CLC, Grisard EC, Schlemper Jr BR. Colonização de ecótopos artificiais pelo Panstrongylus megistus na Ilha de Santa Catarina, 
Florianópolis, Santa Catarina, Brasil. Rev Inst Med Trop São Paulo 1994; 36 (1): $43-50$.

Sugiura M, Horibe Y, Kawada H, Tabaki M. Insect spiracle as the main penetration route of pyrethroids. Pestic Biochem Physiol 2008; 91: 135 - 140.

Tabashnik BE, Roush RT. Introduction. In: Roush RT, Tabashnik BE, editors. Pesticide resistance in arthropods. New York: Chapman and Hall; 1990. p. 1 - 3.

Takahashi M, Yasutomi K. Insecticidal resistance of Culex tritaeniorhynchus (Diptera: Culicidae) in Japan: genetics and mechanisms of resistance to organophosphorus insecticides. J Med Entomol 1987; 24 (6): 595 - 603.

Teixeira ARL, Nascimento RJ, Sturn N. Evolution and pathology in Chagas disease - A Review. Mem Inst Oswaldo Cruz 2006; 101 (5): 463-491.

Toledo MJO, Kuhl JB, Silva SV, Gasperi MV, Araújo SM. Estudo sobre triatomíneos e reservatórios silvetres de Trypanosoma cruzi no Estado do Paraná, Sul do Brasil. Resultados preliminares. Rev Soc Bras Med Trop 1997; 30 (3): $197-203$.

Toloza AC, Germano M, Cueto GM, Vassena C, Zerba E, Picollo MI. Differencial patterns of insecticide resistance in eggs and first instar of Triatoma infestans (Hemiptera: Reduviidae) from Argentina and Bolivia. J Med Entomol 2008; 45 (3): 421-426.

Valente SAS, Valente VC, Neto HF. Considerations on the epidemiology and transmission of Chagas disease in the Brazilian Amazon. Mem Inst Oswaldo Cruz 1999; 94 Suppl I: 395 - 398.

Vassena CV, Picollo MI, Zerba EN. Insecticida resistance in Brasilian Triatoma infestans and Venezuelan Rhodnius prolixus. Med Vet Entomol 2000; 14: 51-55. 
Vassena CV, Cueto GM, González-Audino P, Alzogaray RA, Zerba EN, Picollo MI. Prevalence and levels of permethrin resistance in Pediculus humanus capitis De Geer (Anoplura: Pediculidae) from Buenos Aires, Argentina. J Med Entomol 2003; 40 (4): 447 - 450.

Vanessa CV, Picollo MI. Monitoreo de resistencia a insecticidas en poblaciones de campo de Triatoma infestans y Rhodnius prolixus, insectos vectores de la efermedad de Chagas. 2003. [on line 12 maio de 2007]. Disponível em: http://www.sertox.com.ar/retel/default.htm

Villate F, Bachmann TT. How many genes encode cholinesterase in artropods? Pestic Biochem Physiol 2002; 73: 122 - 129.

Villela MM, Souza JB, Azeredo BVM, Dias JC. Vigilância entomológica da doença de Chagas na região centro-oeste de Minas Gerais, Brasil, entre os anos de 2000 e 2003. Cad Saúde Públ 2005; 21 (3): 878 - 886.

Villela MM, Souza JB, Melo VP, Dias JCP. Avaliação do programa de Controle da doença de Chagas em relação à presença de Panstrongylus megistus na região centro oeste do Estado de Minas Gerais, Brasil. Cad Saúde Públ 2009; 25 (4): $907-917$.

Walter A, Rego IP, Ferreira AJ, Rogier C. Risk factors for reinvasion of human dwellings by sylvatic triatomines in northern Bahia State, Brasil. Cad Saúde Publ 2005; 21 (3): 974 - 978.

Wanderley DMC, Carvalho ME, Silva RA, Rodrigues VLCC, Barbosa GL, Curado I. Programa de Controle da doença de Chagas. Boletim Epidemiol Paulista 2006; Supl. Especial SUCEN. Disponível em: http://www.cve.saude.sp.gov.br/agencia/bepa37_suple.htm 
Ware GW. Na introduction to inseticides ( $3^{\text {rd }}$ edition) - University of Minnesota 2000 [on line 12 maio de 2007]. Disponível em: http://ipmworld.umn.edu/chaper/ware.htm

Wirth MC, Georghiou GP, Malik JI, Abro GH. Laboratory selection for resistance to Bacillus sphaericus in Culex quinquefasciatus (Diptera: Culicidae) from California, USA. J Med Entomol 2000; 37 (4): 534 - 540.

World Health Organization. $7^{\text {th }}$ report of the World health expert comite on insecticides. (Série de Informes Técnicos, 125). Geneva; 1957.

World Health Organization. Chemical methods for the control of vectors and pests of public health importance. WHO/CDT/WHOPES. Geneva; 1987.

World Health Organization. Control of Chagas disease. WHO Technical Report Series 811, World Health Organization, Geneva; 1991.

World Health Organization. Vector resistence to pesticide. Expert Committee on vector biology and control (Série de Informes Técnicos, 818). Geneva; 1992.

World Health Organization. Protocolo de evaluación de efecto insecticida sobre triatominos. Acta Toxicol. Argentina; 2:29-32; 1994.

World Health Organization. Chagas disease: interruption of transmission in Uruguay. Wkly Epidemiol Rec 73: 1 - 4, 1998.

World Health Organization. Chagas disease: interruption of transmission in Chile. Wkly Epidemiol Rec 2: 10 - 12, 2000.

World Health Organization. Control of Chagas disease. Second Report of the WHO Expert Committee. WHO Technical Report Series 905: 109, 2002. 
World Health Organization. Control of Chagas disease. Second Report of the WHO Expert Committee. WHO Technical Report Series Buenos Aires, p. 7, 2006.

Yuan ZM, Pei GF, Regis L, Nielsen-Leroux C, Cai QX. Cross-resistance between strains of Bacillus sphaericus but not B. thurigiensis israelensis in colonies of the mosquito Culex quinquefasciatus. Med Vet Entomol 2003; 17: $251-256$.

Zhai J, Robinson WH. Measuring cypermethrin resistance in the german cochroach (Orthoptera: Blatteliidae). J Econ Entomol 1992; 85 (2): 348 - 351.

Zerba EN. Insecticidal activity of pyrethroids on insects of medical importance. Parasitol Today 1988; 4 (7): 53 - 57.

Zerba EN, Wallace G, Picollo MI, Casabé N, Licastro S, Wood E, Hurvitz A, Andrés A. Evaluatión de la $\beta$-cipermetrina para el control de Triatoma infestans. Rev Panam Salud Publica 1987; 1 (2): 133 - 137.

Zerba EN. Susceptibility and resistance to insecticide of Chagas disease vectors. Medicina Buenos Aires 1999a; 59: (Suppl II): 41 - 46.

Zerba EN. Past and present of Chagas disease control and futures need. Geneva: WHO/WHOPES 1999b; pp. 1 - 30. 
Anexo 1 - Análise de Probitos da linhagem suscetível de P. megistus.

Name of the file: RGT 13
22/08/2009
deltametrina

Mortality in the control: $0 \%(0 / 100)$

Number of iterations: 3 . Doses in LOG_10 units: Yes

$\begin{array}{ll}\text { CHI2 } & 6.524772 \\ \text { Prob }= & .9113084\end{array} \quad \mathrm{df}=3$

\begin{tabular}{lcll} 
LC & $\begin{array}{l}\text { Level of } \\
\text { Confidence }\end{array}$ \\
\hline $1=0.24298$ & .95 & $0.17900<\mathrm{LC}<$ & 0.30295 \\
$2=0.28777$ & .95 & $0.21910<\mathrm{LC}<$ & 0.35064 \\
$3=0.32039$ & .95 & $0.24904<\mathrm{LC}<$ & 0.38481 \\
$4=0.34734$ & .95 & $0.27419<\mathrm{LC}<$ & 0.41274 \\
$5=0.37093$ & .95 & $0.29648<\mathrm{LC}<$ & 0.43700 \\
$10=0.46481$ & .95 & $0.38740<\mathrm{LC}<$ & 0.53215 \\
$20=0.61089$ & .95 & $0.53381<\mathrm{LC}<$ & 0.67787 \\
$30=0.74393$ & .95 & $0.66945<\mathrm{LC}<$ & 0.81095 \\
$40=0.88025$ & .95 & $0.80721<\mathrm{LC}<$ & 0.95095 \\
$50=1.02988$ & .95 & $0.95338<\mathrm{LC}<$ & 1.11237 \\
$60=1.20495$ & .95 & $1.11551<\mathrm{LC}<$ & 1.31344 \\
$70=1.42574$ & .95 & $1.30837<\mathrm{LC}<$ & 1.58338 \\
$80=1.73626$ & .95 & $1.56545<\mathrm{LC}<$ & 1.98542 \\
$90=2.28190$ & .95 & $1.99429<\mathrm{LC}<$ & 2.73553 \\
$95=2.85942$ & .95 & $2.42864<\mathrm{LC}<$ & 3.57426 \\
$96=3.05363$ & .95 & $2.57139<\mathrm{LC}<$ & 3.86486 \\
$97=3.31052$ & .95 & $2.75806<\mathrm{LC}<$ & 4.25519 \\
$98=3.68574$ & .95 & $3.02680<\mathrm{LC}<$ & 4.83654 \\
$99=4.36523$ & .95 & $3.50333<\mathrm{LC}<$ & 5.91997 \\
\hline
\end{tabular}

$\mathrm{A}=5.003804+/-6.238931 \mathrm{E}-02$ (probit unit)

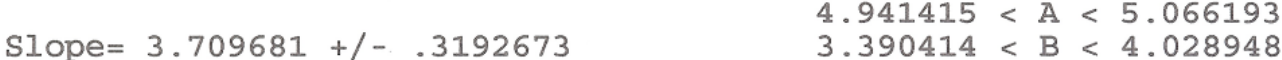

$M=1.381251 \mathrm{E}-02$ in LOG_10 (dose) unit, and 1.0323 in dose unit

Variance of the $\mathrm{LC} 50=2.82852 \mathrm{E}-04$

heterogeneity $=1$

Name of the file: RGT 13

$22 / 08 / 2009$

deltametrina 
Anexo 2 - Análise de Probitos da linhagem suscetível de T. brasiliensis.

\begin{tabular}{|c|c|c|c|c|c|c|c|}
\hline $\mathrm{n}$ & Dose & $\begin{array}{l}\text { Mort. } \\
\operatorname{corr}\left(\frac{\circ}{\circ}\right)\end{array}$ & probit & $\begin{array}{l}\text { Total } \\
\text { treated }\end{array}$ & Killed & $\begin{array}{l}\text { Killed } \\
\text { expected }\end{array}$ & $\begin{array}{l}\text { CHI2 } \\
\text { contribution }\end{array}$ \\
\hline 1 & 0.3000 & 3.8 & 3.23078 & 130 & 5 & 6.87 & 0.5360 \\
\hline 2 & 0.5000 & 29.2 & 4.453731 & 130 & 38 & 34.95 & 0.3652 \\
\hline 3 & 0.7500 & 59.2 & 5.233084 & 130 & 77 & 74.21 & 0.2439 \\
\hline 4 & 1.0000 & 74.6 & 5.662126 & 130 & 97 & 100.25 & 0.4602 \\
\hline
\end{tabular}

Mortality in the control: $0 \%(0 / 130)$

Number of iterations: 3 . Doses in LOG_10 units: Yes

$\begin{array}{ll}\text { CHI2 } & 1.605173 \\ \text { Prolo } & .5518296\end{array} \quad \mathrm{df}=2$

\begin{tabular}{lcll} 
LC & $\begin{array}{l}\text { Level of } \\
\text { Confidence }\end{array}$ \\
\hline $1=0.20900$ & .95 & $0.16570<\mathrm{LC}<$ & 0.24765 \\
$2=0.24018$ & .95 & $0.19541<\mathrm{LC}<$ & 0.27944 \\
$3=0.26233$ & .95 & $0.21693<\mathrm{LC}<$ & 0.30177 \\
$4=0.28033$ & .95 & $0.23464<\mathrm{LC}<$ & 0.31977 \\
$5=0.29588$ & .95 & $0.25008<\mathrm{LC}<$ & 0.33524 \\
$10=0.35614$ & .95 & $0.31095<\mathrm{LC}<$ & 0.39465 \\
$20=0.44580$ & .95 & $0.40343<\mathrm{LC}<$ & 0.48258 \\
$30=0.52414$ & .95 & $0.48437<\mathrm{LC}<$ & 0.56063 \\
$40=0.60185$ & .95 & $0.56280<\mathrm{LC}<$ & 0.64107 \\
$50=0.68472$ & .95 & $0.64283<\mathrm{LC}<$ & 0.73166 \\
$60=0.77899$ & .95 & $0.72913<\mathrm{LC}<$ & 0.84091 \\
$70=0.89448$ & .95 & $0.82964<\mathrm{LC}<$ & 0.98190 \\
$80=1.05168$ & .95 & $0.96056<\mathrm{LC}<$ & 1.18290 \\
$90=1.31643$ & .95 & $1.17191<\mathrm{LC}<$ & 1.53820 \\
$95=1.58455$ & .95 & $1.37835<\mathrm{LC}<$ & 1.91434 \\
$96=1.67246$ & .95 & $1.44477<\mathrm{LC}<$ & 2.04068 \\
$97=1.78722$ & .95 & $1.53068<\mathrm{LC}<$ & 2.20767 \\
$98=1.95205$ & .95 & $1.65262<\mathrm{LC}<$ & 2.45128 \\
$99=2.24320$ & .95 & $1.86436<\mathrm{LC}<$ & 2.89157 \\
\hline
\end{tabular}

Regression line: $Y=A+$ Slope $*(X-M)$

$\mathrm{A}=4.887002+/-.0630574$ (probit unit)

$4.137304<B<4.892474$

$\mathrm{M}=-.1895179$ in LOG_10(dose) unit, and 0.6464 in dose unit

Variance of the LC50= $1.994455 \mathrm{E}-04$

heterogeneity $=1$

Name of the file: RGT 39

$08 / 08 / 2009$

deltametrina 


\section{Anexo 3 - Análise de Probitos da linhagem suscetível de T. sordida.}

\begin{tabular}{|c|c|c|c|c|c|c|c|}
\hline $\mathrm{n}$ & Dose & $\begin{array}{l}\text { Mort. } \\
\text { corr (\%) }\end{array}$ & probit & $\begin{array}{c}\text { Total } \\
\text { treated }\end{array}$ & Killed & $\begin{array}{c}\text { Killed } \\
\text { expected }\end{array}$ & $\begin{array}{l}\text { CHI2 } \\
\text { contribution }\end{array}$ \\
\hline 1 & 0.3000 & 12.0 & 3.824909 & 100 & 12 & 9.49 & 0.7324 \\
\hline 2 & 0.5000 & 33.0 & 4.56052 & 100 & 33 & 37.83 & 0.9922 \\
\hline 3 & 0.7500 & 70.0 & 5.524002 & 100 & 70 & 68.60 & 0.0906 \\
\hline 4 & 1.0000 & 84.0 & 5.994422 & 100 & 84 & 85.28 & 0.1304 \\
\hline 5 & 1.5000 & 98.0 & 7.054189 & 100 & 98 & $96.73 *$ & 0.5077 \\
\hline
\end{tabular}

Mortality in the control: $0 \div(0 / 100)$

Number of iterations: 3 . Doses in LOG_10 units: Yes

CHI2 $=2.453262 \quad \mathrm{df}=3$

Prob $=.5162011$

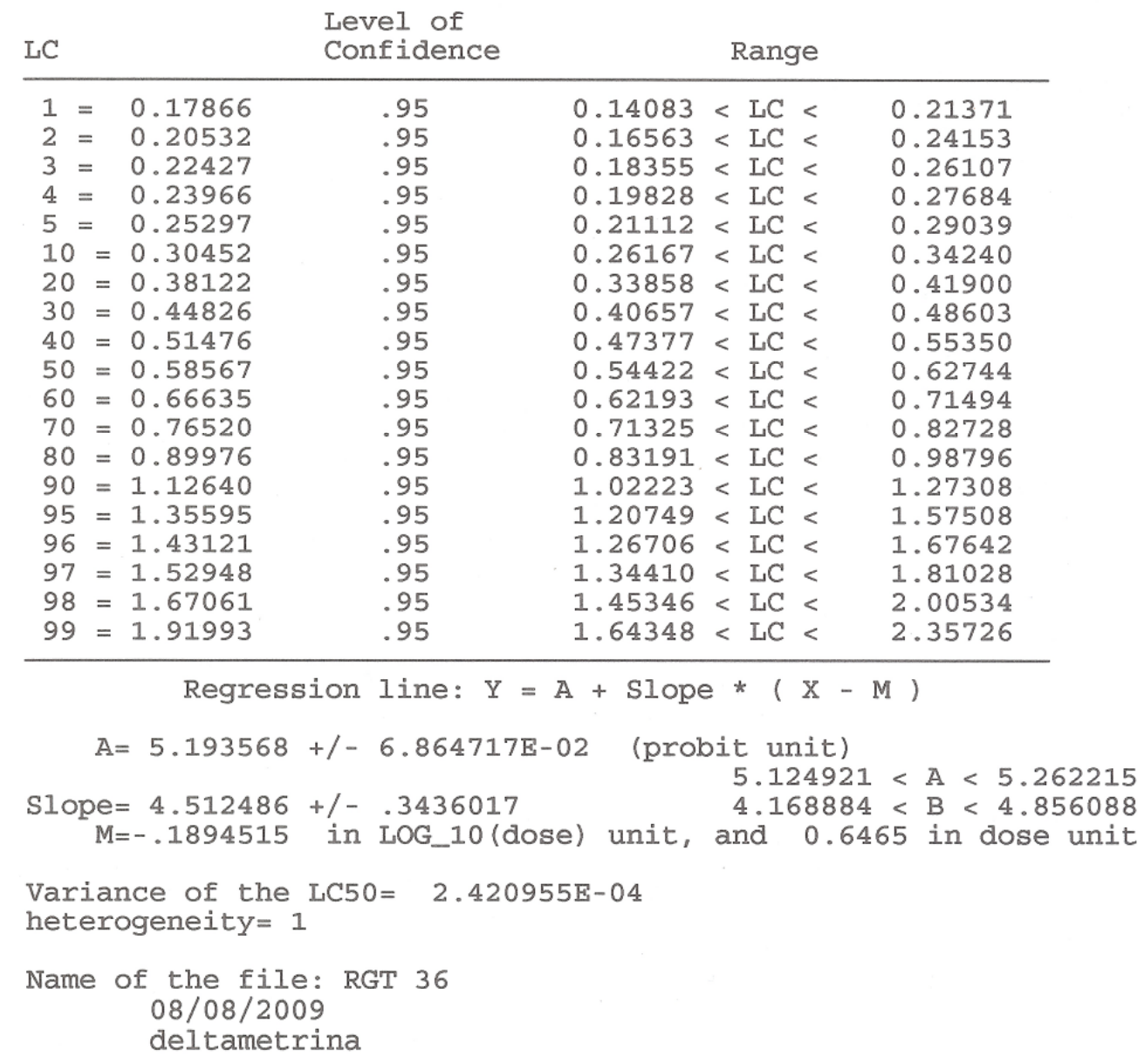




\title{
Anexo 4 - Modelo de Ofício enviado para 19 Secretarias Estaduais de Saúde do país solicitando envio de material entomológico
}

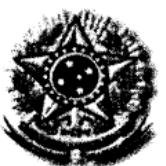 \\ MINISTÉRIO DA SAÚDE \\ SECRETARIA DE VIGILÂNCIA EM SAÚDE \\ Esplanada dos Ministérios, Edifício Sede, $1^{\circ}$ andar, Ala Norte \\ CEP 70058-900 - Brasília/DF \\ Tel. (61) 3213-8272 \\ SIPAR N ${ }^{\circ} 25000.033 .239 / 08-52$ \\ Ofício-Circular n ${ }^{\circ}$ 38/2009/GAB/SVS/MS
}

Brasília, 10 de março de 2008.

\author{
A Sua Excelência o(a) Senhor(a) \\ EUGENNIO PACCELI DE FREITAS COELHO \\ Secretário (a) de Estado da Saúde \\ Av. NS 01, QI AANO, Praça dos Girassóis \\ 77015-007 - Palmas/TO
}

Assunto: Solicitação de Captura de Triatomíneos - Vetores da Doença de Chagas

\author{
Senhor(a) Secretário(a),
}

1. Ao tempo em que cumprimento cordialmente Vossa Excelência ressalto que existem poucas informações sobre o "status de resistência" de populações triatomínicas, em relação aos inseticidas utilizados no seu controle. A resistência a inseticidas é definida pela Organização Mundial de Saúde (OMS) como sendo uma característica herdável, portanto, genética, ao qual confere um aumento na tolerância a um pesticida ou grupo de pesticidas, de modo que os indivíduos resistentes sobrevivem à concentração do(s) componente(s) que seriam normalmente letais para a maioria dos indivíduos de uma população da mesma espécie (suscetível).

2. A Coordenação-Geral de Laboratórios de Saúde Pública-CGLAB, desta Secretaria, com o intuito de coordenar, promover, apoiar e fomentar a melhoria contínua dos serviços prestados pela Rede de Nacional de Laboratórios de Entomologia tem como uma de suas estratégias a implantação de programas de monitoramento de resistência de vetores aos inseticidas utilizados no controle, principalmente, em triatomíneos.

3. $\quad \mathrm{O}$ monitoramento de resistência de triatomíneos fornecerá parâmetros para selecionar a melhor opção de inseticidas que sejam mais efetivos, seguros e de baixo custo, reduzindo o número de aplicações. Ainda, o encontro de indícios de resistência permitirá um melhor entendimento dos elementos que favorecem, não só a reemergência de populações exposta ao tratamento, como também a recolonização por meio de migrações de uma espécie ou de outras espécies, provenientes de ambientes peridomiciliares ou silvestres. 
4. Dentre os objetivos do monitoramento de resistência de triatomíneos destacam-

se:
a) avaliar a ação letal ou toxicidade de diferentes produtos comerciais utilizados no controle de triatomíneos;
b) fornecer um parâmetro de mortalidade estimulado pela aplicação tópica de um inseticida em determinada dose;
c) comparar o efeito de cada produto testado em diferentes populações de triatomíneos;
d) determinar a proporção de indivíduos resistentes; e
e) determinar os mecanismos primários de resistência.

5. De um modo geral, o monitoramento consiste em:

a) envio de material entomológico para o Laboratório de Entomologia Médica da CGLAB, que realizará a aplicação tópica de $0,2 \mu l$ de solução na superfície dorsal de ninfas de I estádio por meio de microseringa Halmilton de $10 \mu \mathrm{lcom}$ dispenser;

b) os inseticidas testados pertencem à classe dos piretróides. Um total de 50 ninfas de campo e 15 ninfas controle (suscetível) serão expostos, a pelo menos cinco diluições. Cada prova biológica terá três replicações, em diferentes momentos;

c) a intensidade da resistência será avaliada por meio do quociente da $\mathrm{DL}_{50}$ da população de campo pela $\mathrm{DL}_{50}$ da linhagem suscetível. Quanto maior o nível de resistência, maior será a magnitude da resistência;

d) a CGLAB compara os resultados e comunica ao laboratório, quanto a possível existência de focos de populações triatomínicas resistentes.

6. O início do programa de monitoramento está previsto para o mês de maio deste ano, a princípio para as seguintes espécies: Triatoma sordida, Triatoma brasiliensis, Triatoma pseudomaculata, Triatoma rubrovaria e Panstrongylus megistus.

7. Diante do exposto, esta Secretaria, por meio do Departamento de Vigilância Epidemiológica (DEVEP), estará implantando o monitoramento de resistência de triatomíneos. Para tanto, solicito o apoio de Vossa Excelência para a realização de captura das espécies acima citadas. Cada amostra entomológica deverá contar com no mínimo dez insetos. As amostras deverão ser enviadas para o Laboratório de Entomologia Médica/CGLAB, Caixa Postal 4524, CEP: 70.904-970 - Brasília/DF, até a última semana do próximo mês de abril, de acordo com a metodologia, que ora anexamos.

8. Para informações e orientações adicionais, seu corpo técnico poderá entrar em contato CGLAB, pelo telefone (61) 3213-8272 ou pelo e-mail: marcos.obara@saude.gov.br.

Atenciosamente,

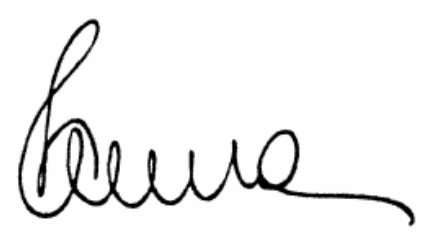

Gerson Penna

Secretário 


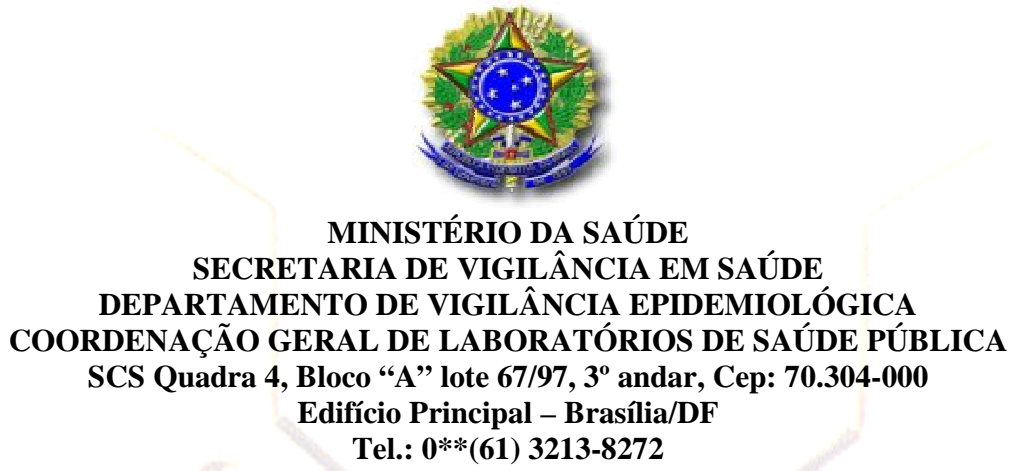

\section{PROTOCOLO DE ENVIO}

- Os triatomíneos provenientes do campo devem ser manipulados com auxílio de pinça entomológica e luva para que não haja contato direto do triatomíneo com a pele. Recomenda-se que os insetos sejam colocados em recipiente (bacia ou pote) para triagem. Serão priorizados os triatomíneos oriundos do ambientes intra e peridomiciliar de regiões que sofreram altas pressões de inseticidas ao longo do tempo.

- Após isso, os insetos devem ser colocados dentro de recipientes com tampa de rosca, por exemplo, tubo Falcon $50 \mathrm{ml}$. A tampa deverá possuir pequenos furos para entrada e circulação de ar. ATENTAR aos tamanhos dos furos para que as ninfas não ultrapassem e fujam. No interior do recipiente deverá haver um papel vertical em forma de sanfona (andador);

- Os recipientes deverão ser acondicionados em caixas de madeira ou isopor envolvidos em papel para evitar a fuga dos triatomíneos e impactos que prejudiquem as estruturas. Recomenda-se que se façam "bolas de jornal" que complementem os espaços vazios da caixa de transporte.

- Cada caixa de madeira ou isopor deverão ter no máximo 3 a 4 recipientes. Cada recipiente no máximo 10 exemplares;

- Todas as amostras enviadas devem apresentar fichas de registros padronizados, contendo os seguintes dados: local de coleta (município, região, Estado, País); data da coleta, nome do coletor e tipo de hábitat. Também, os dados de georreferenciamento e os antecedentes de controle do local deverão estar anexados. 
Anexo 5 - Lista de amostras de triatomíneos de campo capturadas, no Brasil. As três primeiras espécies foram utilizadas como população de referência.

\begin{tabular}{|c|c|c|c|}
\hline Data captura & Espécie & Localidade/Município/Estado & Ecótopo \\
\hline $8 / 3 / 1982$ & T. sordida & Cordeiros/BA & Não informado \\
\hline $21 / 2 / 1984$ & T. brasiliensis & Umari/CE & Não informado \\
\hline $27 / 7 / 1987$ & P. megistus & $\begin{array}{l}\text { Povoado de Quixadá/Sento } \\
\text { Sé/BA }\end{array}$ & Não informado \\
\hline 18/11/2007 & T. sordida & Miranda/MS & Peridomicílio \\
\hline $6 / 2 / 2008$ & T. brasiliensis & Canindé do São Francisco/SE & Peridomicílio \\
\hline $13 / 3 / 2008$ & T. sordida & $\begin{array}{l}\text { Faz. Modelo e Sítio Santa } \\
\text { Fé/Poxoréu/MT }\end{array}$ & Não informado \\
\hline $13 / 3 / 2008$ & T. sordida & Cinturão Verde/Cuiabá/MT & Não informado \\
\hline $17 / 3 / 2008$ & T. sordida & $\begin{array}{l}\text { Faz. Veneranda e } \\
\text { Mucambo/Aurora do } \\
\text { Tocantins/TO }\end{array}$ & $\begin{array}{l}\text { Galinheiro e } \\
\text { Chiqueiro }\end{array}$ \\
\hline $8 / 4 / 2008$ & T. sordida & Morrinhos/Flores de Goiás/GO & Peridomicílio \\
\hline $8 / 4 / 2008$ & T. sordida & Itaipoca/MS & Galinheiro \\
\hline 9/4/2008 & T. sordida & Extrema/Iaciara/GO & Peridomicílio \\
\hline $11 / 4 / 2008$ & T. sordida & $\begin{array}{l}\text { Povoado de Aguão/Campo } \\
\text { Grande/MS }\end{array}$ & Galinheiro \\
\hline
\end{tabular}




\begin{tabular}{|c|c|c|c|}
\hline $15 / 4 / 2008$ & T. sordida & $\begin{array}{l}\text { Povoado Colônia } \\
\text { Velha/Terenos/MS }\end{array}$ & Galinheiro \\
\hline $15 / 4 / 2008$ & T. sordida & $\begin{array}{l}\text { Faz. Empedrado I/São Luiz dos } \\
\text { Montes Belos/GO }\end{array}$ & Peridomicílio \\
\hline $15 / 4 / 2008$ & T. brasiliensis & $\begin{array}{l}\text { Faz. Vaca } \\
\text { Morta/Itaporanga/PB }\end{array}$ & Intra \\
\hline $16 / 4 / 2008$ & T. sordida & $\begin{array}{l}\text { Sítio Maria } \\
\text { Curadeira/Douradina/MS }\end{array}$ & Galinheiro \\
\hline $16 / 4 / 2008$ & T. sordida & $\begin{array}{l}\text { Povoado Córrego Seco e } \\
\text { Diamantina/Firminópolis/GO }\end{array}$ & Peridomicílio \\
\hline $16 / 4 / 2008$ & T. sordida & $\begin{array}{l}\text { Faz. Estância } \\
\text { Ermelinda/Rochedo/MS }\end{array}$ & Galinheiro \\
\hline $16 / 4 / 2008$ & T. brasiliensis & Sítio Junco de Cima/Piancó/PB & Intra e Peri \\
\hline $17 / 4 / 2008$ & T. sordida & Serra do Capim/Aurilândia/GO & Peridomicílio \\
\hline $18 / 4 / 2008$ & T. brasiliensis & Sítio Tabocas/Oeiras/PI & Intra \\
\hline $20 / 4 / 2008$ & T. brasiliensis & Sítio Sapé/Oeiras/PI & Intra \\
\hline $21 / 4 / 2008$ & T. brasiliensis & Sítio Formosa II/Oeiras/PI & Intra \\
\hline $22 / 4 / 2008$ & T. sordida & $\begin{array}{l}\text { Faz. Samambaia e } \\
\text { Barreirão/Guarani de } \\
\text { Goiás/GO }\end{array}$ & Peridomicílio \\
\hline $24 / 4 / 2008$ & T. brasiliensis & $\begin{array}{l}\text { Faz. Olho d' Água das } \\
\text { Dores/Monteiro/PB }\end{array}$ & Peridomicílio \\
\hline $25 / 4 / 2008$ & T. brasiliensis & $\begin{array}{l}\text { Sítio Santana e } \\
\text { Quixabeiras/Salgueiro/PE }\end{array}$ & Peridomicílio \\
\hline $0 / 4 / 2008$ & P. megistus & Serranópolis do Igaçu/PR & Intra \\
\hline
\end{tabular}




\begin{tabular}{|c|c|c|c|}
\hline $3 / 5 / 2008$ & T. sordida & $\begin{array}{l}\text { Sítio Serrinha e Cascata/São } \\
\text { José do Povo/MT }\end{array}$ & Não informado \\
\hline $16 / 5 / 2008$ & T. brasiliensis & $\begin{array}{l}\text { Sítio Pedra do Sino e Faz. } \\
\text { Lajinha/Caicó/RN }\end{array}$ & Peridomicílio \\
\hline $19 / 5 / 2008$ & T. brasiliensis & $\begin{array}{l}\text { Faz. Lagoas e Povoado } \\
\text { Capim/Petrolina/PE }\end{array}$ & Peridomicílio \\
\hline $19 / 5 / 2008$ & T. brasiliensis & $\begin{array}{l}\text { Faz. Morada Nova/Lagoa } \\
\text { Grande/PE }\end{array}$ & Peridomicílio \\
\hline $26 / 5 / 2008$ & T. sordida & $\begin{array}{l}\text { Faz. Santa Helena, Corredor e } \\
\text { Foquilha/Corinto/MG }\end{array}$ & Curral e Galinheiro \\
\hline $28 / 5 / 2008$ & T. brasiliensis & $\begin{array}{l}\text { Faz. Jardim e Nova/Serra } \\
\text { Talhada/PE }\end{array}$ & Peridomicílio \\
\hline $7 / 6 / 2008$ & T. sordida & Povoado Rodeador/Lontra/MG & Peridomicílio \\
\hline $10 / 6 / 2008$ & T. sordida & $\begin{array}{l}\text { Sítio Nossa S. da } \\
\text { Aparecida/Sertaneja/PR }\end{array}$ & Galinheiro \\
\hline $17 / 6 / 2008$ & T. sordida & $\begin{array}{l}\text { Faz. José Rodrigues/Aparecida } \\
\text { do Taboado/MS }\end{array}$ & $\begin{array}{l}\text { Galinheiro e } \\
\text { Chiqueiro }\end{array}$ \\
\hline $19 / 6 / 2008$ & T. sordida & Sítio Serra/Paranaíba/MS & Galinheiro e Paiol \\
\hline $24 / 6 / 2008$ & T. sordida & Conceição das Alagoas/MG & Galinheiro \\
\hline $8 / 7 / 2008$ & T. brasiliensis & Sítio Pau de Chapada/Oeiras/PI & Intradomicílio \\
\hline $15 / 7 / 2008$ & T. brasiliensis & $\begin{array}{l}\text { Faz. Laranjeiras/São José de } \\
\text { Espinharas/PB }\end{array}$ & Peridomicílio \\
\hline $16 / 7 / 2008$ & T. brasiliensis & $\begin{array}{l}\text { Faz. Cacimba de Pedra/Mãe d' } \\
\text { água/PB }\end{array}$ & Peridomicílio \\
\hline $23 / 7 / 2008$ & T. brasiliensis & $\begin{array}{l}\text { Sítio São Luiz/São } \\
\text { Francisco/PB }\end{array}$ & Peridomicílio \\
\hline
\end{tabular}


Peridomicílio

$22 / 9 / 2008$

P. megistus

Cafelândia/PR

Peridomicílio

$15 / 10 / 2008$

T. sordida

Faz. Rio Preto e

Povoado/Palmeiras/BA

Galinheiro

$16 / 10 / 2008$

T. sordida

Faz. Emburana/Posse/GO

Peridomicílio

$11 / 11 / 2008$

P. megistus

Caconde/SP

Não informado

$29 / 11 / 2008$

P. megistus

Divinolândia/SP

Não informado

$7 / 5 / 2009$

P. megistus

Castro Alves/BA

Galinheiro

$12 / 5 / 2009$

T. sordida

Pov. Boa Vista do

Galinheiro

Canal/Cafarnaum/BA

$19 / 5 / 2009$

T. sordida

Faz. Bonfim e

Galinheiro

Lage/Mucugê/BA

$20 / 5 / 2009$

T. sordida

Faz. Boa Vista/Rio de Contas/BA

$20 / 5 / 2009$

T. sordida

Faz. Serra do João

Alves/Malhada/BA

20/5/2009

T. sordida

Faz. Micaela/Carinhanha/BA

Galinheiro

$22 / 5 / 2009$

T. sordida

Assentamento Roçado I e Gado Bravo/Xique Xique

Peridomicílio

$26 / 5 / 2009$

T. sordida

Faz. Alto Verde/Nova

Galinheiro

Redenção/BA

$17 / 9 / 2009$

P. megistus

Vicente Pires/DF

Galinheiro 
Anexo 6 - Ficha para bioensaios por aplicação tópica sobre ninfas $1^{\circ}$

\section{BIOENSAIOS POR APLICAÇÃO TÓPICA SOBRE NINFAS $1^{\circ}$}

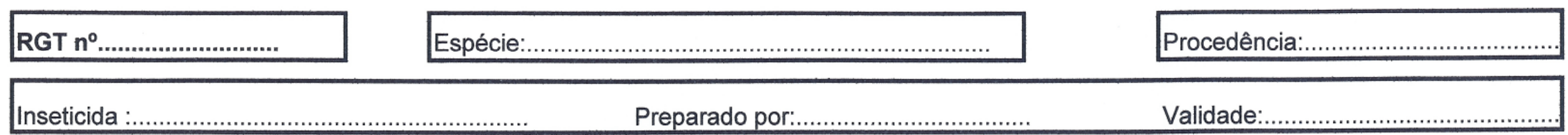

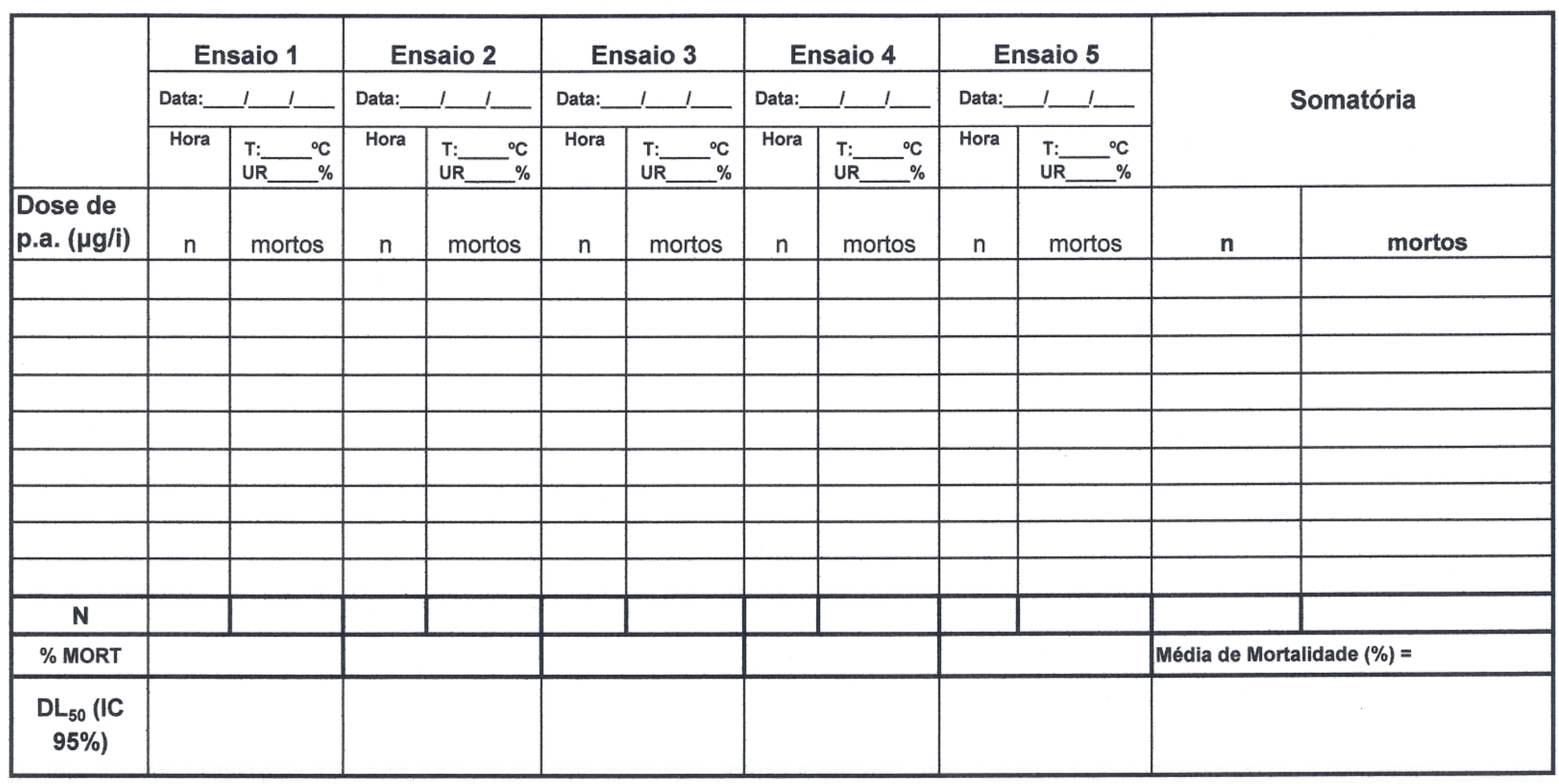


Anexo 7 - Ficha para bioensaios de campo com ninfas $1^{\circ}$

\section{BIOENSAIOS DE CAMPO COM NINFAS $1^{\circ}$}

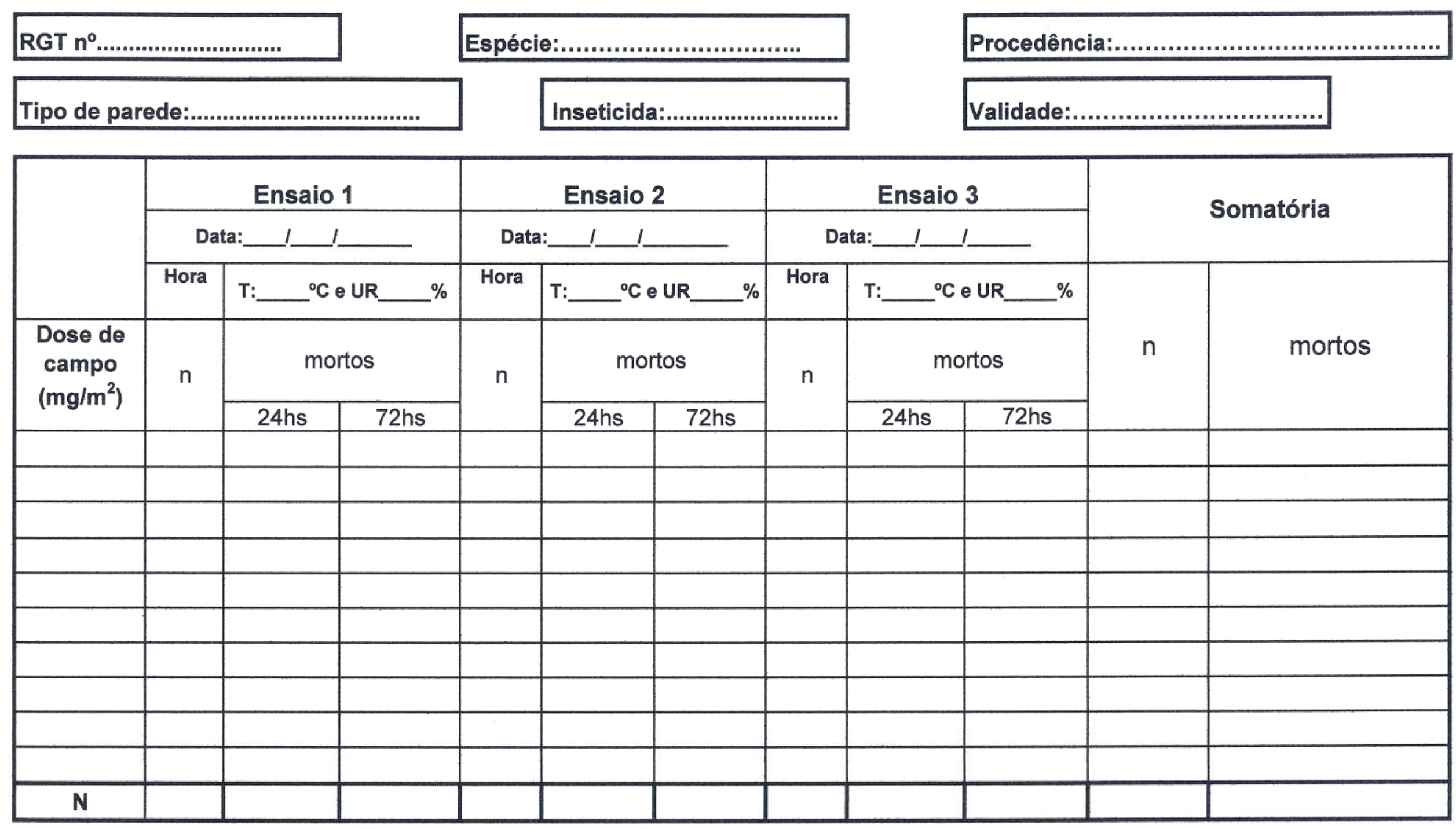


Anexo 8 - Lista dos Núcleos de Entomologia Médica do Brasil, em ordem alfabética.

\section{$A C R E$}

Responsável: Cláudio Rodrigues de

Souza

Endereço: Av. Antônio da Rocha

Viana

$\mathrm{N}^{\circ} 1584$ - Vila Ivonete

CEP: 69.980-560 / Rio Branco - AC

Tel.: (68) 3223-1170/1172 Ramal 250

E-mail:

claudinho.entomologia@yahoo.com.br

\section{ALAGOAS}

Responsável: Edson Duarte Pacheco Endereço: Lab. Central Dr. Aristeu Lopes

Av. Marechal Castelo Branco, 1773 Jatuíca

CEP: 57.036-340 / Maceió - AL

Tel.: (82) 3315-2712 / 3315-2722

E-mail: duarte.pacheco@bol.com.br

\section{AMAPÁ}

Responsável: Volmir Miguel Zanini Endereço: Rua Tancredo Neves $n^{\circ}$ 1118 - São Lázaro - LACEN CEP: 68.908-530 / Macapá - AP Tel.: (96) 3212-6115 / 6169/6165 Fax: (96) 3212-6115

E-mail: vmzanini@hotmail.com

\section{AMAZONAS}

Responsável: Erica Cristina da Silva Chagas

Endereço: Rod. Deputado Vital de Mendonça

$\mathrm{Km}$ 9, s/n ${ }^{\circ}$ - Flores

CEP: 69.048-660 / Manaus - AM

Tel.: (92) 3654-5786

Fax: (92) 3643-6314

E-mail: ericachagas@gmal.com

\section{BAHIA}

Responsável: Renato Freitas Araújo
Endereço: LACEN. Rua Waldemar

Falcão, 123 - Bairro Brotas

CEP: 40.295-001 / Salvador - BA

Tel.: (71) 3356-2299 - 8846-2541

Fax: (71) 356-0139

E-mail: birdeagle01@yahoo.com.br

\section{CEARÁ}

Responsável: Lindemberg Caranha de Sousa

Endereço: Núcleo de Controle de Endemias (NUVET/SESA-CE)

Rua dos Tabajaras, 268, Praia de Iracema

CEP: 60.060-510 / Fortaleza - CE

Tel.: (85) 3101-5445

E-mail: insect.berg@gmail.com

\section{DISTRITO FEDERAL}

Responsável: Rodrigo Menna Barreto Rodrigues

Endereço: Estrada Contorno do

Bosque Lote 4, Setor de Áreas

Isoladas Norte - SAIN

CEP: 70.620.000/Brasília - DF

Tel.: (61) 3344-3475

Fax: (61) 3341-1682

E-mail: romebaro@saude.df.gov.br

\section{ESPÍRITO SANTO}

Responsável: Helder Ricas Rezende Endereço: Av. Maruípe, 1469, $3^{\circ}$ andar, UFES, Parasitologia , Bairro Maruípe CEP: 29.040-090 / Vitória - ES

Tel.: (27) 3335-7292

Fax: (27) 3324-2038

E-mail: hedericas@hotmail.com

\section{GOIÁS}

Responsável: Marcelo SantaLucia Endereço: LACEN - Av. Contorno, 3556 - Bairro Jardim Bela Vista 
CEP: 74.853-120 / Goiânia - GO

Tel.: (62) 3201-3888 ramal 210

Fax: (62) 3201-3884

E-mail:

lacen.dirgeral@saude.go.gov.br

\section{MARANHÃO}

Responsável: Lucy Eugênia Mendes

Borges Câmara

Endereço: LACEN - Rua dos

Quilombos, 35 Prédio da FUNASA -

Bairro Jordoa

CEP: 65.040-055 / São Luís - MA

Tel.: (98) 3243-6215

Fax: (98) 243-2445

E-mail: lacen@lacen.ma.gov.br

\section{MATO GROSSO}

Responsável: Giovana Belém

Endereço: SES. Av.Adauto Botelho,

S/N, Parque da Saúde - Bairro Coxipó

CEP: 78.085-200 / Cuiabá - MT

Tel.: (65) 3661-2494 / 3613-5372

Fax: (65) 3613-5377 / 3613-5369

E-mail: giovanabio@terra.com.br

\section{MATO GROSSO DO SUL}

Responsável: Paulo Silva de Almeida

Endereço: Júlio de Castilho -1120

Vila Sobrinho

CEP: 79112-000/ Campo Grande - MS

Tel.: (67) 3361-9801

Fax: (67) 3361-9801

E-mail:

psilvadealmeida@yahoo.com.br

\section{MINAS GERAIS}

Responsável: Mauro Lúcio Lima

Endereço: Núcleo de Entomologia da SES/MG

Rua Rio de Janeiro, 1200 - Bairro

Centro

CEP: 30.160-041 / Belo Horizonte MG

Tel.: (31) 3273-6171 ou 9282-4125
E-mail: mauroluciolima@hotmail.com

\section{PARÁ}

Responsável: Arnaldo Fayal

Endereço: Cidade Nova VI, WE - 65

$\mathrm{n}^{\circ}$ 972, Prédio da FUNASA - Bairro

Coqueiro

CEP: 67.140-000 - Ananindeua - PA

Tel.: (91) 4006-4267 / 9117-8675

E-mail: fayal@canal13.com.br

\section{PARAÍBA}

Responsável: Laura Ney Marcelino

Passerat de Silans

Endereço: Núcleo de Entomologia da SES/PB.

Rua Professor Geraldo Von Shosten, 258 Prédio da FUNASA - Bairro

Jaguaribe

CEP: 58.015-190 / João Pessoa - PB

Tel.: (83) 32222192

Fax: (83) 32222192

E-mail: lauraney@jpa.neoline.com.br

\section{PARANÁ}

Responsável: Allan Martins da Silva Endereço: SES. Coordenadoria de Pesquisa em Entomologia Médica,19

Regional de saúde

Rua Doutor Heráclio, 90, Bairro

Centro

CEP: 86.400-000 / Jacarezinho - PR

Tel.: (43) 3330-4466 ou 9940-1274

E-mail: allanms@ibest.com.br

\section{PERNAMBUCO}

Responsável: Andréia da Silva

Endereço: LABEND. Av. Conde da

Boa Vista 1570 - Bairro Boa Vista

CEP: 50.060-040 / Recife - PE

Tel.: (81) 34234845

Fax: (81) 34234845

E-mail: andreiasilv1@ig.com.br 


\section{PIAUÍ}

Responsável: Reginaldo Rorís

Cavalcante

Endereço: Universidade Federal do

Piauí, Campus Ministro Petrônio

Portela - Bairro Ininga, Anexo do SG

16

CEP: 64.049-550 / Teresina / PI

Tel.: (86) 3237-1010

Fax: (86) 3232-6927

E-mail: roris@ufpi.br

\section{RIO DE JANEIRO}

Responsável: Cristina Giordano

Endereço: Avenida Brasil, 4.036 -

Sala 109. Prédio de Expansão da

Fiocruz

CEP: 21.040-361 / Rio de Janeiro - RJ

Tel.: (21) 3882-9012

Fax: (21) 2260-1069

E-mail:

cristina.giordano@saude.rj.gov.br

\section{RIO GRANDE DO NORTE}

Responsável: Arlinete Souza de

Medeiros

Endereço: SES. SEVEP/CORE. Av.

Alexandrino de Alencar, 1402 -

Prédio da FUNASA - Bairro Tirol

CEP: 59.015-450 / Natal - RN

Tel.: (84) 3232-2623

Fax: (84) 3232-2623

E-mail: arlinetek@yahoo.com.br

\section{RIO GRANDE DO SUL}

Responsável: Getúlio Dornelles Souza Endereço: LACEN / FEPPS, Seção de

Reservatórios e Vetores/IPB.

Av. Ipiranga, 5400 - Bairro Jardim

Botânico

CEP 90.610-000 / Porto Alegre - RS

Tel.: (51) 3288-4024

Fax: (51) 3288-4015

E-mail: getuliods@pop.com.br

\section{RONDÔNIA}

Responsável: Alda Lobato

Endereço: LACEN. Rua Anita

Garibaldi, 4130 - Bairro Costa e Silva

CEP: 78.903-770 / Porto Velho - RO

Tel.: (69) 3216-5300 / 9258-4247

E-mail: fatsantosro@hotmail.com

\section{RORAIMA}

Responsável: Ducinéia de Aguiar Barros

Endereço: Rua Major Carlos Mardel, $\mathrm{n}^{\circ} 213$

Bairro 31 de março

CEP: 69.300-300 / Boa Vista - RR

Tel.: (95) 3626 - 9801

E-mail: ducibio10@yahoo.com.br

\section{SANTA CATARINA}

Responsável: João Cezar do

Nascimento

Endereço: Rua Felipe Schmidt, 800

Centro

CEP: 88.010-002 / Florianópolis - SC

Tel.: (48) 32381137

E-mail: jcimento@hotmail.com.br

\section{SÃO PAULO}

Responsável: Dr. Mikio Moriwaki Endereço: Rua Paula Souza, 166 Bairro Luz

CEP: 01027-000 / São Paulo - SP

Tel.: (11) 3311-1100

Fax: (11) 3229-8292

\section{SERGIPE}

Responsável: Catarina Zita Dantas de Araújo

Endereço: Rua Campo do Brito, 551

CEP: 49.028-380 / Aracaju - SE

Tel.: (79) 3234-6043/6022

E-mail:

catarina.araujo@hemolacen.se.gov.br 


\section{TOCANTINS}

Responsável: Aline Ayres

Endereço: Av. LO - 2-Quadra 104

norte - lote 30 Edf.Lauro Knop

CEP: 77.006-022 / Palmas -TO

Tel.: (63) 3218-3297

Fax: (63) 3218-3293

E-mail: entomologia@saude.to.gov.br 
